

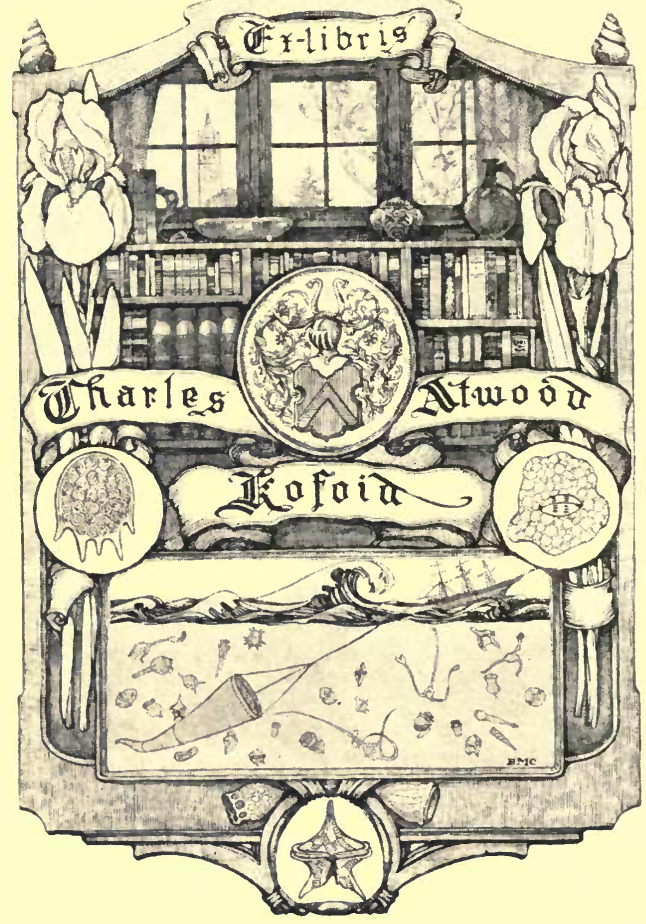




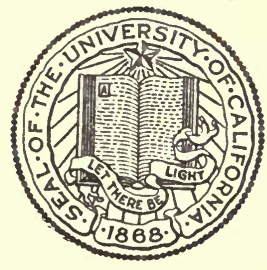

THE LIBRARY

OF

THE UNIVERSITY

OF CALIFORNIA

PRESENTED BY

PROF. CHARLES A. KOFOID AND

MRS. PRUDENCE W. KOFOID 
3r 3/6
eolpi 


\section{BRITISH BIRDS}

\section{FOR CAGES AND AVIARIES.}






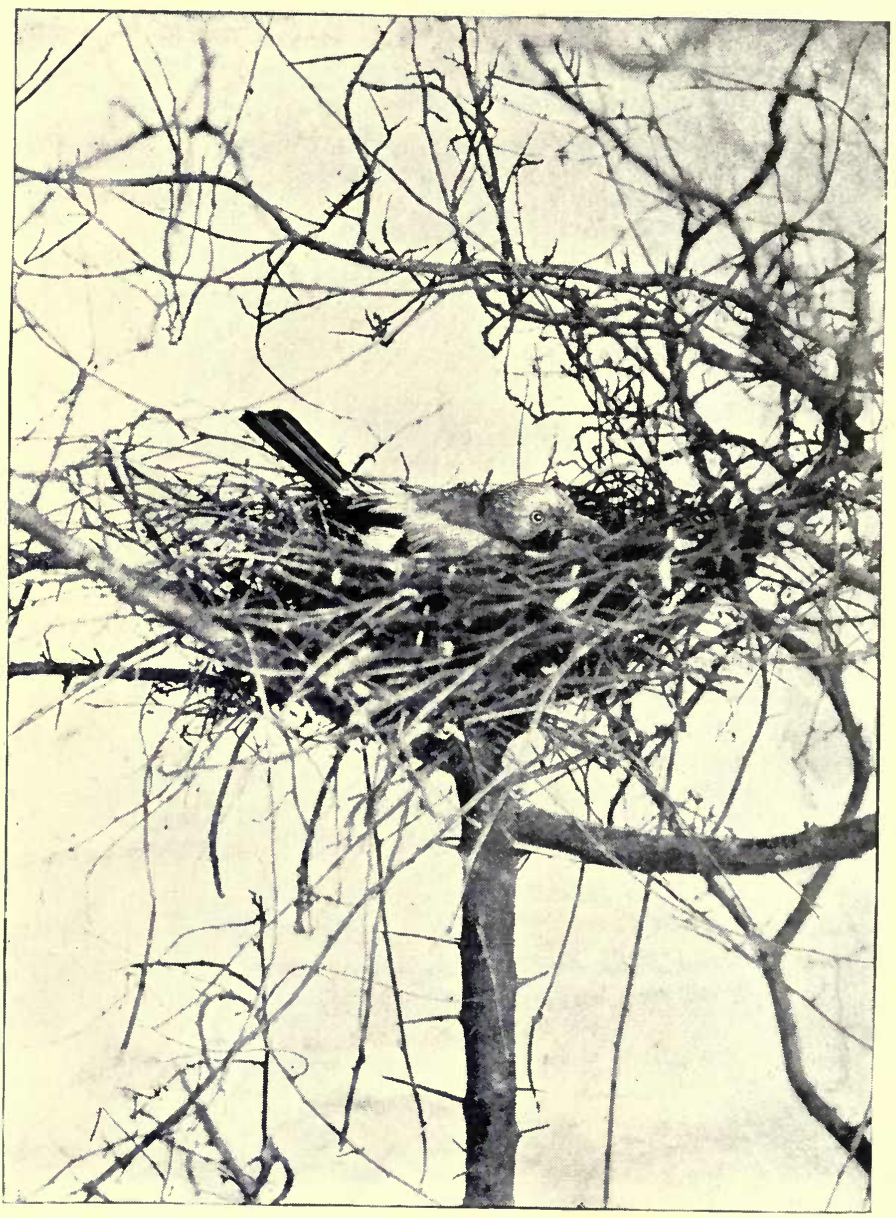

JAI SITTING ON NEST IN AVIARY. 


\section{BRITISH BIRDS}

FOR

\section{CAGES AND AVIARIES.}

A

HandBook Relating to all British Birds WHICH MAY BE KEPT IN CONFINEMENT.

BY

W. T. GREENE, M.A., M.D., F.Z.S., eTC., Author of "The Grey Parrot", "Popular Parrakeets", "Notes on Cage Birds",

"Diseases of Cage Birds", etc., and Editor of the Aviary Department of The Bazaar

ILLUSTRATED

LONDON :

L. UPCOTT GILL, I70, STRAND, W.C. 1899 . 



\section{S'F461 G69}

\section{PREFACE.}

"What, another bird-book!" someone may feel tempted to exclaim, on reading the title of the present volume; "surely there are enough of them and to spare."

But is that so?

When a subject is practically inexhaustible and as yet only its merest outside fringe has been touched upon, it is obvious that there is still something to be said about it, especially as new facts are being noted every day, and discoveries made that were undreamt of even a short time before. Further, there is as much to unlearn as to learn. If history has been built up out of fable, as some assert is the case, much more is this true of Natural History, which is founded, not only on fable, but on ignorance and prejudice as well.

Error is tenacious of existence-as hard to kill, indeed, as the proverbial cat-and one reason for this is that when the average person has accepted or imagined a mistake, cuddled, petted, and made much of it for years and years, not to speak of pledging his credit on its behalf, it takes a good deal of persuading to induce him to cast it adrift and transfer his affections to the truth.

The feat, however; though difficult, is not impossible of accomplishment, providing the said average person's opponent only goes the right way to work and, while steadily upholding his own protégé, treads upon as few 
corns as possible and ruffles as few susceptibilities as may be, bearing in mind the fact that there are victories that are worse than a defeat, and that nothing is ever gained by losing temper.

Such being the case, another bird-book is not only admissible, but imperatively called for, if for no other reason than to chronicle the latest discoveries made in Natural History by the many earnest thinkers who devote more or less of their time and energy to the better understanding of the subject, and particularly that branch of it that treats of the management of the feathered tribes in a state of domesticity or of absolute captivity.

There are probably not many people who, admitting the initial right of man to confine birds of various kinds for his pleasure or advantage, would deny the fact that if birds are kept it is desirable that their habits and inclinations should be studied, conformed to and gratified as far as practicable, in order to make them as happy and comfortable as possible in their new surroundings.

Of course, there are a few well-intentioned people who hold that we have no right to make "winged prisoners" under any combination of circumstances whatever, but such amiable enthusiasts need not detain us long, for if their contention were pushed to its legitimate conclusion, it would be equally unlawful for a man to keep a horse, a cow, or even a few head of domestic poultry.

The object, then, of this book, which by no means professes to be infallible, is to facilitate the keeping in cage and aviary of every kind of British Bird that is really suitable for the purpose. The rules laid down and the directions given are all the outcome of much practical experience in a study that has been dear to the writer from early pinafore days, and is still as full of interest and attraction as ever. 
As the book is intended for the benefit of budding aviarists as well as for those who can boast of more experience, it is hoped that the latter will not take exception to anything that may savour to them of mere trivial detail, but which nevertheless is indispensable to the former. There is much common ground upon which they can walk together, and it is trusted that upon these points they will agree, for no interests have been ignored, nor, it is believed, have any been thrust into undue prominence, while a few original notes and recommendations will, it is hoped, be found to be trustworthy and acceptable to all.

For convenience of reference the book has been arranged on the alphabetical or dictionary plan.

W T. G.

Iveagh Lodge,

Belvedere, Kent.

March, I899. 



\section{BRITISH BIRDS}

\section{FOR CAGES AND AVIARIES.}

\section{INTRODUCTION.}

Totwithstanding the outcry that is being raised in certain quarters against the practice of keeping birds in confinement, whether in cage or aviary, it is quite certain that some have always been so kept, and in all probability will continue to be; therefore it is surely better that they should be treated correctly and with due regard to their natural requirements, than otherwise.

It is not civilized nations only who have kept birds: there is scarcely a tribe of painted savages among the palm-trees of the Islands in the Pacific, that does not tame and train Cockatoos and other Parrots, and keep them fastened to perches and stands, for their own amusement. The writer, however, is not concerned to defend the practice of keeping birds, for he is convinced that it is not only lawful but laudable, and as he has done it in the past, he sees no reason why he should forbear doing it in the future; but there is keeping and keeping, and it will not be his fault if the readers of these pages are not properly instructed in the art of managing tame birds correctly, as well as made acquainted with the species best adapted for domestication. 
A very high authority might be quoted in support of the contention that "every kind (nature) of birds is tamed and hath been tamed of mankind"-but it is unnecessary to pursue that part of the subject any further, though the temptation to do so is undoubtedly very great. It must, however, be mentioned that the very persons who cry out the loudest about what they are pleased to term the "iniquity of making winged prisoners," are themselves densely ignorant upon the subject concerning which they would presume to dictate to others. For example, in a recent pamphlet issued by one of the most noisy of the clique, it is asserted that the Bullfinch lives almost entirely, if not quite, upon insects and is consequently the friend and not the foe of the horticulturist, who is undoubtedly persecuting the poor bird to the verge of extermination.

Every tyro in Natural History is perfectly aware that the Bullfinch does not eat insects and does eat the buds of trees (though his doing so by no means inflicts the harm imagined); but he also eats a vast quantity of seeds of many kinds of noxious weeds, and on that account alone is of benefit to the farmer and gardener. The writer has gone pretty deeply into this matter of the Bullfinch and buds, and can say this, that so far from doing harm to the trees he honours by his attentions, the bird does good. Say he consumes r 20 buds a day,-and repeated observations of tame birds show that is about the average,-what would that amount to in the year? 43,800 .

The total may startle at first sight. But the gardener prunes his trees! The writer knows one large orchard from which no less than three thousand cartloads of branches were removed by the owner in one year! There were a few buds destroyed there, were there not? With between 200 and 300 branches to a load, say 250 as an average, and a thousand buds on each branch (for the writer counted those on a medium-sized bough, and found that they numbered exactly IOO3), we at once get the surprising total of seven hundred and fifty million buds $(750,000,000)$ removed voluntarily by the proprietor of the orchard for the good of his trees. 
The Bullfinch is one of Nature's pruners, be it remembered; nor does he live on buds alone, he also consumes a variety of pernicious seeds. Now let us inquire, who knows most about birds and their ways, the person who keeps and studies them, in confinement if you will, or the persons who consider them such sacred beings that they must only be looked at from a distance?

Then again, how many people-men and women whose lives are one unceasing round of miserable drudgery, or whose health debars them from participating in the amusements and outdoor recreations of the leisured and healthy favourites of fortune-derive the utmost gratification and pleasure from the society of a pet bird or two? It is to be feared that the advocates of "freedom for all birds" wilfully shut their eyes to these facts, or imagine the convenience of a bird to be a superior consideration to that of one of their own species; but again we have the very highest authority that one man is of more value than many sparrows.

It is impossible to know birds without keeping them, and even if they are caged merely for the benefit of the owner, they are fulfilling a part that is certainly worthy of attention.

However, we have no sort of hope that any amount of argument in favour of keeping birds in cages and aviaries will have any weight with the objectors, and so we leave them, to turn our attention to those who, like the writer, are never happier than when surrounded by birds of all kinds.

Some species, certainly, are more fitted for domesticity than others, and a great deal will depend upon the season of the year when they are taken, on the food offered to them, on the situation and nature of their lodging, if their keeping is to mean pleasure to the owner.

It is not attempted to furnish an exhaustive history of British Birds in the following pages, but to mention such facts connected with those that are suitable for caging as will enable a tyro in the art to keep them with the minimum of inconvenience to the birds themselves, as well as the maximum of pleasure to himself, or herself, for it is pleasant to think that so many women now 
devote themselves to the congenial and absorbing pursuit of keeping and breeding various kinds of birds.

Some prefer seed-eaters to soft-billed birds, and others give the preference to the latter, which are popularly, but erroneously, believed to be more difficult to preserve in confinement than the former. But it only requires a little knowledge of their natural habits to enable one sort to succeed in a state of domestication as well as the other: indeed, of the two, insectivorous birds are less trouble to cater for than the seed-eaters; but both have their drawbacks, as well as their advantages, which will all be duly considered in turn.

Some like to bring up their birds by hand from the nest, and where this is practicable, it is much the better way; but it means a certain amount, or rather a great deal of trouble, and where that is an object, it is advised that the attempt be not made. Others again prefer to get their birds full-grown, either by buying them from the dealers, or catching them for themselves; but we must confess to not having much partiality for the latter plan, and cannot recommend its adoption, notwithstanding the encomiums passed on the pursuit by some of its votaries, who wax eloquent over the pleasure to be derived from the contemplation of rural scenery and novel surroundings, not to speak of the exercise of patience in waiting and watching for the advent of the quarry, and

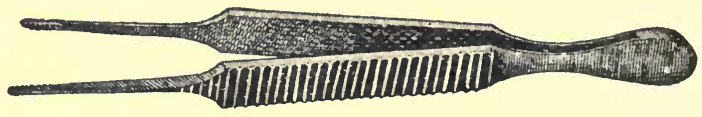

Forceps for Feeding Soft-Billed Birds.

the excitement attending upon its capture. This excitement is just what we object to, as lending a fictitious attraction to the pursuit, which, if followed at all, should be practised on its own merits and not from any adventitious motive.

Personally, we prefer hand-reared birds, and in the 
case of the soft-billed species there is no question that it is the best way to secure a reliable pet. Provided with a little pair of forceps (see illustration), there is not, or need not be, the slightest difficulty in rearing any of the warblers, from the Nightingale down to the Goldencrested Wren: the last, by the bye, has not been included in the present work for several reasons, one of which is the difficulty in procuring it, and another the amount of care requisite for its preservation, for although it remains with us all the year round, it is almost impossible to preserve it through the winter in confinement, on account of its impatience of cold.

As each species is passed in review the food most suitable for it will be mentioned, also whether it is or is not a suitable subject for being kept in an aviary out of doors; and as the novice might like to try rearing one or more by hand, the site and appearance of the nest will be indicated, as well as the season of the year when it is most likely to be met with. The difference between the sexes, and between the adult and young birds, where such exists, will be pointed out, and directions given for distinguishing the one from the other.

As many people lay much stress upon the song, as much information as possible will be afforded on that point, and in each case it will be said whether the bird has any, or what, pretension to be classed among the musical members of the great family of birds; while the migratory species will be differentiated from those that remain with us throughout the year.

Then some birds are more suited for cage-life, and others do better in an outdoor aviary, or flying about at liberty in a bird-room indoors, and these will also be distinguished from each other; a few species being indicated which can only be acceptably kept in the latter situation.

The shape and size of the cage suitable for each species are points that need very carefully attending to, if complete success is to be attained; and as nothing enhances the pleasure of keeping birds so much as the rearing of a brood or broods of young, every possible 
instruction will be given on the subject of the feeding and breeding in confinement of the different kinds of birds passed in review, premising that if suitably lodged, and intelligently fed and attended to, there is no bird that will not successfully nest and rear its young in confinement-a practical proof, if such were needed, that captivity is not so distasteful to birds as some of their self-styled friends would like it to be imagined.

To this end the material and construction of the several kinds of nests will be indicated, as well as the positions for their domicile affected by each. The number of eggs to a brood must also be known, or rather the average number, otherwise mistakes would be made, and incubation perhaps be thought at an end before it really was.

Patience, however, it must be remembered, is of all things most necessary in matters ornithological. A slight precipitancy on the part of the owner may easily mar the labour of weeks in a moment, as when, thinking the young birds ought to be out, he breaks the shells (to help them) a day before they are due, and so destroys them all: therefore, it becomes essential to mention not only the average number of eggs laid, but the period at which their incubation commences and the length of time this takes.

Some birds only have one brood in the season, while others have two, or more; where such is the case, the fact will be stated, as well as the precise time for taking the young, in order to bring them up by hand; for if too old, they may refuse to feed, or to be fed, and if too young they may not be able to keep themselves warm enough without being brooded by the mother, especially at night.

If it be noticed how, and how often, birds feed their nestlings, it will be seen that the length of time usually mentioned in books that is to elapse between what one may call each meal, is inaccurately given at half an hour, or even an hour, for, as a matter of fact, every little bird (we are not now speaking of the predaceous species) is fed every eight or ten minutes from daylight to dusk, one mouthful at a time.

Forty-seven times in an hour have two Nightingales 
been observed to visit their nest, in which were five young, and assuming that one of the little ones only received an insect on each occasion, that would give a fraction over nine minutes between each morsel, which is about the usual method practised by soft-billed birds. Surely we cannot do better than imitate Nature as closely as we can, especially as long intervals between heavy meals are apt to produce indigestion with its accompaniments of flatulence and diarrhøa, and too often premature death.

In taking young birds from the parents, many wellmeaning people contend that one or two only should be removed from the nest, as the old birds fret and mourn, or even die from a broken heart from their loss! It is an amiable idea, but none the less a fallacy. Birds very quickly reconcile themselves to the inevitable, and although they undoubtedly make a noise and evince other signs of distress, when the nest is taken, or is robbed, to use a favourite expression of the lookers at, as opposed to the keepers of birds, their grief, if they are capable of such a feeling, is very short-lived; for, if carefully watched, they will be found starting to repair their loss the very next day, seemingly quite oblivious of the past. But the readiness with which many birds forsake their eggs, and even their callow young, is proof positive that the good people who attribute their own feelings and sentiments to the birds in parallel circumstances, fall into no inconsiderable error.

Many fanciers treat their birds incorrectly; but that is an error that knowledge will rectify, and this can be obtained in two ways-by sad experience, or from books, written expressly for them by those who have previously gone over the same ground and proved every step of the way.

The following work has been written for the welfare of the birds kept and the advantage of their keepers, and is now presented with every confidence, both by writer and publisher, that it will answer that purpose.

It may be as well to say, that other British birds exist over and above those mentioned in the following pages, but although we have high authority for the statement that "every kind of bird is tamed and hath been tamed 
of mankind," it has been thought advisable to omit them, either on account of the inherent difficulties of the task, or because of the insignificance of the best result that could be obtained after efforts of no small account, or simply because the creatures themselves, though once numerous in, have now practically ceased to be inhabitants of, our islands.

In the first category may be placed the birds known as Golden-crested Wrens, Long-tailed Tits, Dartford Warblers and possibly a few more; while in the second we have Swallows and Martins and their relations the Swifts, which, no doubt, might be preserved, at least for a time, but at what a cost of time and attention! And in the third there are the Bustards, the Bitterns, and others, which are, as far as Britain is concerned, to all intents and purposes as extinct as the Dodo.

Then there are a variety of birds claimed to be British by Morris and some other writers on the strength of a few specimens, or even a solitary one, seen or shot in the country, but which in all probability had escaped from confinement, as the Passenger Pigeon of North America, for instance, the Belted Kingfisher, or the Spine-tailed Swallow, or the Guira or Yellow-billed Cuckoo, the Greater Nightingale and some more, while the Roller, the Beeeater and the Hoopoe have scarcely any more reason to be counted British.

Some Hawks and Eagles also are very doubtful inhabitants, while the climax of absurdity is reached when the Griffon and Egyptian Vultures are actually included in a work that purports to be a history of native birds. A similar objection may be made to the list of Owls included in the same work, most of which occurred singly and as the result of accident, and by no extension of reasoning can justly be claimed as British.

If the domestication of the many charming and indisputably native birds which are passed in review in the following pages is made easier for the amateur, the object, or at least one of the chief objects, held in view by the writer, will have been attained. 


\section{A DICTIONARY OF BRITISH CAGE BIRDS.}

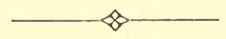

THE HEDGE ACCENTOR. See Hedge Sparrow.

\section{AQUATIC FOWL.}

Of these many species are susceptible of domestication, or semi-domestication, and form very attractive additions to a collection, but as they are mostly of large size they require ample accommodation and strict attention to keep them in presentable form. For information see under specific heads.

\section{THE ARCTIC TERN. See under Terns.}

\section{THE AVOCET.}

A bird seldom met with nowadays in this country, where once it was fairly common. It is a migratory species, arriving in spring and departing again in the early autumn. During its stay here it frequents the coast, preferring those parts that are muddy. It swims, walks and flies very gracefully and has full use of its curiously curved bill, for the possession of which it was the fashion among naturalists of a by-gone generation to bestow upon it a vast and most unnecessary amount of pity.

Like the coast Plovẹrs it fẹeds on marine insects, crus- 
tacea, molluscs, etc., but never ventures into deep water in pursuit of them. It deposits its eggs, two to four in number, among the short grass that grows near its haunts, and the young are able to run about almost directly after being hatched.

The up-curved bill is about 3 inches long, black in colour and flexible to a certain extent. In this connection Morris has penned a sentence the meaning of which is not quite apparent. It reads as follows: "The bill of the Avocet may therefore be regarded as the extreme model which Nature could trace, or at least preserve. The modern doctrine of 'types' seems to be a legitimate descendant of this nonsense."

Like the Plovers, the female Avocet will feign lameness in order to draw off an intruder from the vicinity of the nest, which is not very easy to discover on the flat surface of the ground where it is made, for it only consists of a few blades of grass and the colour of the eggs is in harmony with that of their surroundings. In colour, the Avocet is merely black and white, with a small understudy of grey.

THE BARN OWL. See under Owls.

THE BAR.TAILED GODWIT. See under Godwits.

THE BEAN GOOSE. See under Geese.

THE BEARDED TIT. See under Tits. 
THE BERNACLE GOOSE. See under Geese.

THE BLACK-BACKED GULLS. See under Gulls.

\section{THE BLACKBIRD.}

This bird is larger than the Thrush, measuring from $9 \frac{1}{2}$ to $10 \frac{1}{4}$ inches in length, of which the tail takes up about 4 inches. Except when quite young, the sexes are easily distinguished from each other, for the male is jet black all over, except his bill and his eyelids, which are bright yellow-orange, and his legs, which are dark slate colour with a brownish tinge.

The female is rusty-brown and more or less indistinctly spotted on the breast, and but for her size bears a considerable likeness to a Melanoid Thrush, for which she is occasionally mistaken, by people whose theoretical is greater than their practical knowledge of the birds.

While in their nest-plumage the young are much more like their mother than their father, and are even more spotted on the breast than she is. Not long since one was exhibited as a living proof of the cross-pairing of Thrush and Blackbird, as well as of the production of hybrids in a state of nature. The naturalist to whom the supposed prodigy was shown advised patience, and in due course the bird moulted into a very ordinary cock Blackbird.

The young male Blackbird is decidedly darker than the sisters, but at the same time it is by no means easy to determine which is which, and the selector is quite as liable as not to make a mistake, unless he can boast of a good deal of experience of a practical kind, when it is easy enough.

Albino Blackbirds are sufficiently common, and would no doubt be still more so, were it not for the cruel and absurd passion for shooting them that possesses so many people. Pied and parti-coloured specimens are also mett 
with, but the cinnamon variety is rare, and is not so handsome as the purely white, which is among the most elegant of birds, when seen in perfect condition.

The Blackbird is naturally shy and unobtrusive in its habits, frequenting woods and copses for the most part; but where he is conscious that he is protected and welcome, he will become very tame and even bold. In the latter case, he is often found in gardens, especially in such as are old-fashioned and of large extent, but it is a question whether he is not there rather for the purpose of seeking

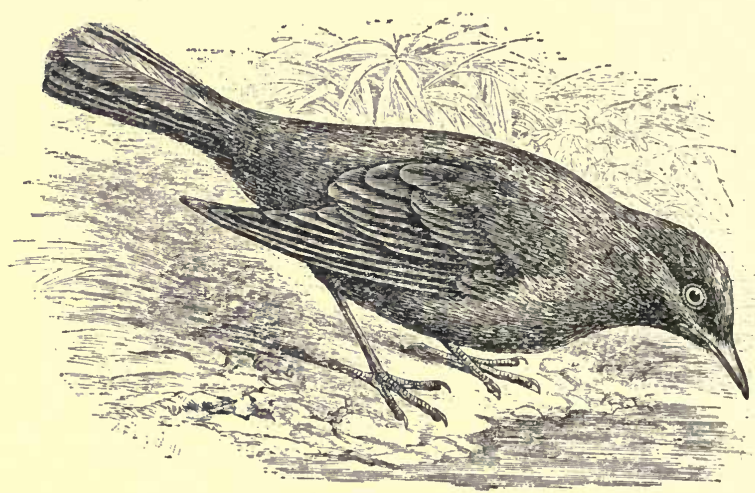

THE BLACKBIRD.

after the natural enemies of the gardener than in search of the products of the enclosure itself.

Like the Song Thrush, he is resident in our midst throughout the year, and is generally to be met with in company of his mate, the male and female keeping pretty closely together at all seasons.

In the house, a cage like either of those recommended for the Thrush will be found suitable for the Blackbird, or he may be kept in a garden aviary, where he and his mate should be alone, for they are somewhat interfering with other birds, even larger ones than themselves, and there they will show to greater advantage than in the house, 
providing there is not too much cover, in which case they would never be seen at all; but there must be some, or the birds would not feel safe, and might hurt themselves and spoil their appearance by dashing about in a panic at the sight of a cat or a stranger.

Insects, snails, worms and fruit form the diet of the Blackbird in its native haunts; in the house it should be dieted like the Thrush, and will then live for a long time, even twenty years, in health and beauty. There is an absurd notion that hemp-seed is a suitable food for Blackbirds in confinement, and sometimes it is given whole and sometimes crushed; but the practice only needs mentioning to stand condemned.

The nest has been found in December with eggs in it, and the question arises, was it an unusually late or a very early brood? In all probability it was the latter, for January, February and March, according to the mildness of the season, are the months commonly selected by these hardy birds for setting up housekeeping.

The second brood is produced in May, as a rule, and there is occasionally a third in June, or even in July. The eggs vary in number from three to six, but more commonly four; the ground colour is pale greenishblue, thickly marked, especially at the larger end, with lines and small spots of reddish-brown.

The nest is placed in a variety of situations, sometimes in a bush, or on a bank, in a hole in a wall, and even on such an unlikely place as a shelf in a tool house. It is constructed on the same principle as that of the Thrush, but has a certain amount of lining, of which the other is destitute. Incubation lasts about fifteen days, and is performed by the female alone; both birds, however, attend to the young, and are most energetic in their defence of them, attacking without hesitation, and often successfully beating off, such formidable foes as a cat or a bird of prey, which they intimidate as much by their loud and angry vociferations as by their direct assault with pointed beak and powerful wing.

If wanted for training, the young should be taken when the wing and tail quills begin to sprout. They are no more 
difficult to rear than those of the Song Thrush when treated as advised for the latter.

In confinement the Blackbird will sometimes breed and even successfully rear a brood of young ones, especially in a good-sized garden aviary, but it is not unusual for the eggs to be barren, the male not being nearly as ardent as the Thrush.

Alliances with the latter are mentioned, among others by Morris, but from hearsay only, and must be accepted with reserve.

The diseases of the Blackbird are much the same as those of the Song Thrush, and are to be treated as advised in the case of that bird. Bechstein mentions, in addition, an obstruction of the rump-gland, which he considers, no doubt correctly, to be due to insufficient bathing.

The handsome plumage and rich mellow tones of the male have made the Blackbird a great favourite with persons who like to have tame birds about them, and with justice, for his imitative powers are such, that he will not only pick up and render correctly a tune, or tunes, that may be played or whistled to him, but he will also learn to repeat words and short sentences with extraordinary accuracy. His natural note, however, is broken with a variety of noisy tones, and is more agreeable when heard in the open country from a low bush, or now and then from amid the branches of a moderately high tree, than when uttered in the house.

In a state of nature, the song of this species is heard in the spring chiefly, the season of courtship among birds; it is prolonged during the period of incubation, and ceases as soon as the young are hatched, to be renewed again in the autumn; but in the house a Blackbird will sing pretty well all the year round, sometimes not even resting during the period of moult.

Many people prefer the song of the Blackbird to that of the Bullfinch, whose voice, as the venerable father of cage-bird lore remarks, is softer and more flute-like, but also more melancholy. The price of the two birds, continues Bechstein, is about the same, when well taught. 
THE RING BLACKBIRD. See Ring Ouzel (under Thrushes).

THE BLACK-CAP. See Tit (Great).

\section{THE BLACKCAP WARBLER.}

In the estimation of many people the Blackcap Warbler is, scarcely, if at all, inferior to the Nightingale as a songster. Like the latter, it is a bird of passage, arriving in April and taking its departure in September. During its sojourn with us it lives on a mixed diet of berries and insects, but the young are fed entirely with the latter, chiefly small caterpillars, which do a great deal of harm to vegetation. It is rather smaller than the Nightingale, and is of a general grey colour, darker above than on the under surface of the body. The top of the head is black in the male and chestnut-brown in the female and the young of both sexes.

It frequents woods and gardens, often breeding in the latter. The nest, which is compactly built of grass and lined with hair, is usually placed in a low bush, with very little attempt at concealment: the eggs, four or five in number, are creamy-white in colour, spotted and streaked with yellow and brown. There are generally two, but sometimes three nests in the season, the young of the first being, as a rule, males, and those of the later nests females.

In the house, this bird must be provided with a large cage, for its plumage is very soft and frays readily, which of course spoils its appearance. It is fond of bathing, and should have full opportunity afforded it for doing so every day. It is not nearly so delicate as the Nightingale with regard to cold, for it has been known to pass the winter in an outdoor aviary in this country without suffering any apparent inconvenience from the exposure.

It is extremely fond of bread and milk as well as of fruit of all kinds, but more especially of a ripe pear. 
Instances are on record of its having bred not only in a large aviary out of doors but in a cage; the birds that did so, however, had been brought up by hand from the nest, a feat that is by no means difficult of accomplishment on bread and milk and ants' eggs.

The Blackcap is apt to suffer from sore feet unless the perches are well and frequently attended to; but if the precaution of washing and scraping them every two or three days is taken, there will be nothing to fear in this respect.

In addition to its own song, which is a very charming

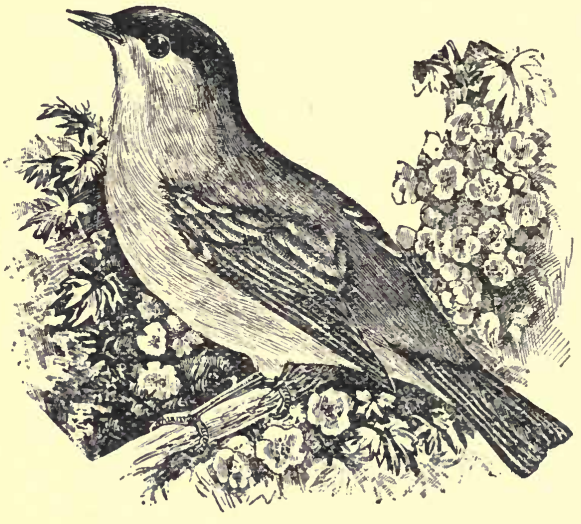

THE BLACKCAP WARBLEP. one, and would no doubt be thought more of than it is if it were uttered in the stillness of the night, instead of in broad daylight and amid a babel of sounds, the Blackcap will pick up a tune that is whistled or played to it on a flute and render the same with amazing correctness. It

will also learn to say a few words, and will live from ten to fourteen years in the house.

The concluding remarks relating to the Nightingale are equally applicable in the present instance, and it may be added that hand-reared specimens of this species will breed in a cage or aviary as freely as Canaries, making their compact, but not heavy, nest of hay in a bush if there is one at their disposal, or lacking that, in an ordinary nestbasket similar to those made of wicker for the use of Canaries on the Continent. The lining of the nest merely consists of the finer portions of the hay, but the different 
pieces are very firmly interwoven, so that it really requires an effort to separate them afterwards. The nest differs much in this respect from that of the Nightingale or Robin, both of which are rather loosely put together and will not stand a great amount of handling; indeed they sometimes collapse altogether before the young Robins or Nightingales are ready to fly; but the elastic nest of the Blackcap may often be found in the spring as firm and compact as it was when the little builders first put it together, nearly twelve months before.

The Blackcap, like the Nightingale, is an amiable little creature, and never interferes with any other bird. It is amazingly fond of the berries of the ivy, which are usually just ripe when it arrives, and it is curious to see the bird gulp them down whole, apparently without any effort, though in proportion to the size of the swallower they are certainly as large as a good-sized orange would be for us.

The young, like those of all the soft-billed species, gape very widely, and the morsel given to them requires to be literally thrust down the throat or they would be unable to swallow it, a fact that must be borne in mind when feeding them; it is manifest therefore that some finer instrument than even the most taper fingers must be used for the purpose, and the forceps (p. 4) will be found invaluable for the purpose. Young Canaries and other Finches close their short bills on the food presented to them, but young soft-billed birds cannot do this, and must have the food pushed far down, otherwise it will be rejected and the poor birdling be in danger of being starved.

THE BLACK GROUSE. See under Grouse.

THE BLACK TERN. See under Terns. 
THE BLACK-HEADED BUNTING. See Bunting (Reed).

THE BLACK-HEADED GULL. See under Gulls.

THE BLACK-TAILED GODWIT. See under Godwits.

THE BLACK.THROATED DIVER. See under Divers.

THE BLUE TIT. See under Tits.

THE BOHEMIAN CHATTERER. See Waxwing.

THE BONXIE. See Skua.

THE BRAMBLING or BRAMBLE FINCH. See under Finches.

THE BRENT GOOSE. See under Geese. 
THE BROWN GULL. See Skua.

THE BROWN LINNET. See Linnet (Common).

THE BROWN PARTRIDGE. See under Partridges.

THE BROWN SNIPE. See Snipe (Common).

THE BULLFINCH. See under Finches.

\section{THE BUNTINGS.}

The Black-headed Bunting. See Reed Bunting.

\section{The Cirl Bunting.}

Not unlike the Yellow-hammer, but rather smaller, and may be readily distinguished from it by a triangular dark patch under the chin. It arrives in summer and occasionally breeds here, but is a native of the shores of the Mediterranean and of Asia Minor.

\section{The Common or Corn Bunting.}

Though a resident of this country, this bird is so unpretending in appearance, as well as unobtrusive in habit, that although fairly common everywhere it is very 
apt to be overlooked by the casual observer, or confounded with one of the Larks or Pipits: it is dark brownish-grey in colour, about the size of a Skylark, and the male and female are alike. The nest is placed among grass but not on the ground, and the eggs, four or five in number, are greyish-white, spotted and streaked with black and reddish-brown. It has no song to speak of, only a few harsh notes.

\section{The Ortolan.}

Beloved of epicures, to gratify whose taste it is imported in large numbers from the sunny south and fattened, the Ortolan is a very rare visitor to our shores on its own account. It is about the same size and shape as the Yellowhammer, and may be distinguished by the greenish shade of its plumage, which presents none of the rich yellow markings that distinguish the latter.

\section{The Reed Bunting.}

This bird, also called Black-headed Bunting, is common in the vicinity of water, arriving in April to breed and taking its departure in September. It has a whitish-grey breast, with a black head and chin, the rest of the plumage being brown. The female has no black marks and is not at all unlike a very clean hen Sparrow. The nest is securely fixed among reeds overhanging the water, and there the males sit and sing nearly all night long, while the building of the nest and the process of incubation are going on. The eggs, four to six in number, vary a good deal in appearance in the same nest, and are greyishwhite with indistinct markings of a darker colour.

\section{The Snow Bunting.}

This bird is a winter visitor from the Arctic Circle, where it breeds. It is brown and white in colour, rather pretty, prefers a stone to a perch for sitting on, and rarely survives one of our summers, the heat quickly upsetting its liver and killing it. 


\section{The Yellow.Hammer.}

This handsome bird is a resident about 6 inches in length, chestnut brown and bright yellow in colour; the female has much less of the latter on her head and neck. Its song is pretty and is commonly represented by the words "a little bit o' bread and no che-ee-se." The nest, very compactly built of grass and roots and lined with hair, is placed in a low bush, and there are three, sometimes four, broods of five or six each in the year. The eggs are grey, streaked with zig-zag lines of purplish brown, and studded with small dark spots. The young are easily reared on ants' eggs and bread and

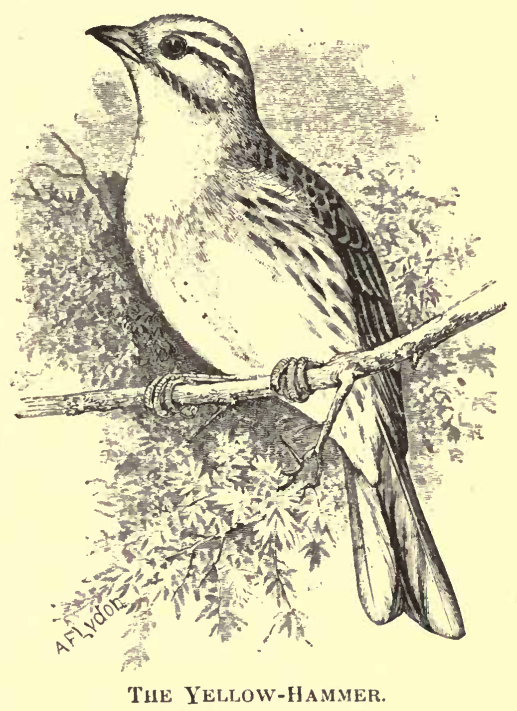
milk, as also are those of all the Buntings.

THE BUTCHER BIRD. See Shrike (Great).

THE BUZZARD. See under Hawks.

THE MOOR BUZZARD. See Harrier (Marsh). 


\section{THE CALANDRA LARK. See under Larks.}

\section{THE CARRION CROW. See under Crows.}

\section{THE CHAFFINCH.}

This bird is not a Finch at all, but a species intermediate between the Finches and the Buntings, for, unlike the Finches, it does not disgorge its food, and, like the Buntings, it consumes as much insect as it does vegetable food, and feeds its young exclusively upon the former. These statements may be denied, but can easily be verified by observation, and are commended to the notice of the unprejudiced reader as the result of close personal observation extending over not a few years.

The male Chaffinch is a very handsome bird, and when in good feather and health, about one of the most showy that we possess: he is about the same size as a well-grown Canary, but will not produce mules with the latter, or, as far as we are aware, with any other bird, unless it be its very near relation the Brambling, or possibly the American bird known by the name of Nonpareil, which appears to bear considerable likeness to it.

It is superfluous to describe in detail the appearance of such a well-known songster as the cock Chaffinch, but it may be briefly stated, that while he is resplendent with pretty well all the colours of the rainbow, his little hen is an unpretending quakerish-looking person in grey attire, relieved by bands of white upon the sleeves, that is to say, upon the wings, and both sexes are distinguished by the adornment of a crest, which they raise or depress at pleasure, though that of the male is more conspicuous than the one that is sported by the female.

The nest of the Chaffinch is the ne plus ultra of avine architecture, and is pointed to by most writers on the attractive subject of ornithology as the exact model of what a nest should be. It is often placed in an apple or 
other fruit tree, and is made to assimilate with its surroundings so closely as to render it rather difficult to discover; but the vociferations of the owner often give the clue to its whereabouts.

The eggs are four or five in number, of a pale bluishgrey colour, spotted and streaked with purplish-brown. The young of the first nest are for the most part males, and those of the second or subsequent brood, females. The little ones resemble their mother very closely, but the young males have a sub-ruddy tinge on the breast, that is discernible in contrast to the dingier hue of the females.

If required for teaching, they must be removed from the nest when the tail feathers appear, for if left longer, they would acquire

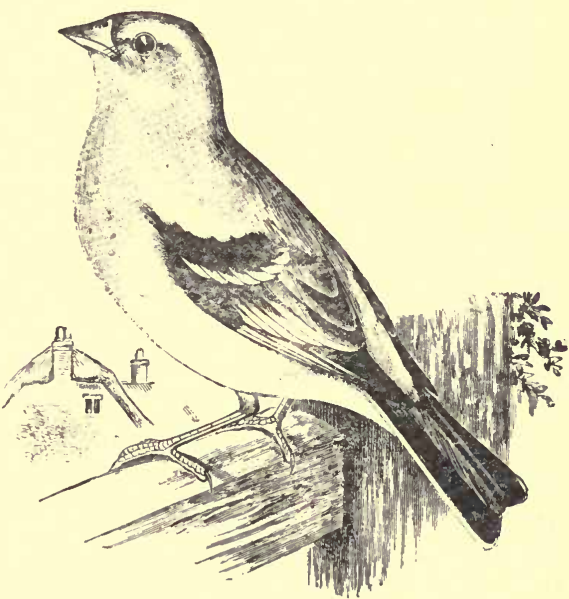

The Chaffinch. at least part of the paternal song. Although their natural diet consists of small caterpillars, which both parents unite in carrying to them every few minutes, from dawn to dusk, they can be reared readily enough on ants' eggs and bread and milk, if a little pair of forceps be used for conveying the food into their widely gaping mouths; or if the young are put in a cage and hung up near the place where they were hatched, the parents will feed and attend to them, until they are able to provide for themselves.

The song of the Chaffinch is pleasing enough, but varies 
a good deal, some being much better performers in this respect than others; but they have no great variety of note, and until within comparatively late years were seldom kept in this country, although long the rage in Germany, where they are scarcely held inferior to the Nightingale.

Blindness is not uncommon among them in confinement, and is due to the too generous use of hempseed: it is of course incurable. A good deal of nonsense has been uttered and written on the subject of mules between this bird and the Canary, or some one of the other Finches proper, but when a moment's reflection is bestowed upon the widely divergent habits of the two species, especially in the matter of food, and manner in which they nourish their young, it will be seen, or should be seen, that a fruitful alliance between them is out of the question, for to breed mules, there must be a certain amount of analogy between the parents, while between the Canary and the Chaffinch there is absolutely none, except that they are both small birds, which is not by any means sufficient. Therefore the gentleman who offered $£$ io for a cross between a Chaffinch and a Canary would have been perfectly safe in increasing his offer to a thousand or even to a million pounds; but apparently he was of opinion that the smallest premium was enough to stimulate amateurs of mule breeding, and it is certain that although nearly twenty years have elapsed, the reward has never been claimed.

Before attaching any importance to the assertion of the recent occurrence of Canary-Chaffinch hybrids, it would be requisite to ascertain whether the person making it knew a Chaffinch when he saw one, for a good deal of confusion exists in the minds of many people with regard to the proper names for different birds; thus in some parts the Goldfinch is known as the Red Linnet, and in other quarters he is called a Robin! Therefore until we know who the supposed possessor of the marvel is, judgment must be suspended. 


\section{THE BOHEMIAN CHATTERER. See Waxwing.}

\section{THE CHIFF.CHAFF.}

This is the smallest of the summer birds that enliven our woods and gardens by their welcome presence; it is also the first to arrive, having been met with in February, but more generally in March, and departs in October. It is to be feared, however, that these very early visitors often come to an untimely end, not from the cold, but from inability to find any food.

It measures about 4 inches in length, nearly half of which belongs to the tail. The upper surface of the body is yellowish-green with a brown tinge, and the under parts are yellowish-white gradually turning to white towards the vent.

The Chiff-chaff is an extremely active little creature, and is always on the move; but it is astonishing how a frail creature, that a puff of wind blows out of its course, can traverse vast tracts of sea, as it does, and one wonders how the feat is accomplished.

The nest is oval in shape, with a small hole near the top; it is placed on the ground under cover of some small clump of brushwood, or even a tuft of fern or long grass, and is built outwardly of leaves and stalks of grass, the interior being lined with the finer portions of the same and a little hair. The eggs are six or seven in number, and are white, marked with red spots on the larger end.

The Chiff-chaff can be readily reared from the nest on ants' eggs and bread and milk, and will live for seven or eight years in the house. Being so small it requires a closely wired cage or aviary, and as it is of an extremely inquisitive nature, it often effects its escape from confinement, availing itself of the tiniest opening through which it can manage to squeeze itself. In autumn it visits gardens, but is more usually found in woods and copses.

The song of this species is a pretty little warbling, not sustained, but rather of an intermittent character; the bird is, 
however, capable to a great extent of imitating the notes of other birds, and one, hand-reared, that was in the writer's possession for a considerable time had learned of its own accord to imitate the song of a Canary in quite a wonderful manner, considering the relative sizes of the two performers.

There is one drawback to keeping this pretty little bird in the house: its natural food consists of insects of the smallest size, such as gnats, aphides, and tiny beetles, so that if it is given mealworms or blackbeetles it will be absolutely necessary to cut them up, or the bird will have not only great difficulty in disposing of them, but they will give rise to indigestion, which of course is much to be deprecated. As the cutting up of live insects with penknife or scissors is objectionable, it is a good plan to kill them by either pouring boiling water on them, or dropping them into it, which at once destroys them, and in the most painless manner possible, as they appear to die instantly without the slightest struggle.

\section{THE CHOUGH.}

At one time the Chough was a sufficiently common bird on the southern and eastern coasts of Great Britain, but his beautiful glossy black plumage, long red bill and orange-coloured legs, marked him out for notice, and he has been in such request not only by aviarists, but by taxidermists and "collectors," that he is now pretty well exterminated.

Like the other members of the Crow family, the Cornish Chough will become very tame and as full of quips and cranks as a country circus clown, but his scarcity has made him valuable, and at shows he generally commands a prize.

The natural diet of the species consists of insects of all kinds, land and water molluscs, and an occasional bit of carrion for a change: in the house he may be fed like the other members of the family with which he is connected.

The female Chough can be distinguished from her mate by her slightly smaller size, her shorter and 
straighter bill, and by the less intensely red colour of the latter, as well as of her legs.

It may not be generally known that a pair of these birds nest in confinement if they are provided with a suitable lodging, that is, if they are placed in an enclosure of sufficient size to enable them to freely exercise their handsome. wings, with some handy ledge of artificial rockwork, on which to construct their inartificial nest of sticks: but they will breed under such circumstances freely and successfully, too; and now that they are so expensive, rearing a few of them would be well worth the attention of an amateur who has, or could have made, a suitable place for their simple requirements.

In the matter of food, there need not be much difficulty, for if a full supply of their natural diet, as indicated above, cannot be obtained, they are not particular, and will do well on all kinds of table scraps and in addition a few insects of some kind.

The thievish propensities of the Chough fully equal those of the Raven, the Magpie and the Jackdaw, and the same care must be taken in his case not to leave any glittering objects of small size anywhere, where he would be likely to see them, and be tempted to bear them off.

The colour of the plumage is black, with steel-blue reflections on the head and neck, and green on the tail and wings. The young have little of this metallic gloss, and the female is less conspicuous in this respect than her mate.

A full-grown Chough weighs fourteen or fifteen ounces.

THE CIRL BUNTING. See under Buntings.

THE CITRIL FINCH. See Finch (Serin). 
THE COAL or COLE TIT. See Tit (Great).

\section{THE COOT.}

A rather large bird, measuring I foot 6 inches in length and weighing from $1 \frac{1}{4}$ pounds to 2 pounds. The general colour is black, the bill and a bare patch above it yellowishwhite; the secondaries have white tips which make a white line across the middle of the wing. The sexes are alike in colour but the female is rather smaller than the male.

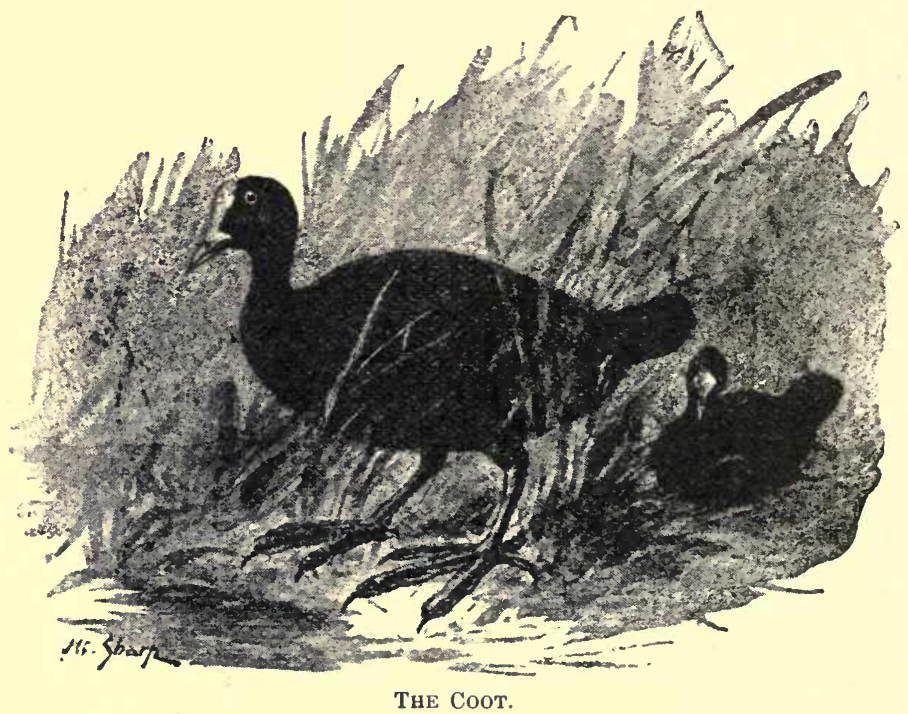

The eggs vary a good deal in appearance, some being dull yellow, others pale brown with a greenish tinge, and yet others stone colour with brown spots; they are six or seven in number, but occasionally as many as fourteen have been found in one nest. When such is the case, 
no doubt they were the produce of two hens nesting together.

The Coot feeds on grass when other food is scarce, but its usual diet consists of small fish, aquatic insects and various kinds of water plants. They swim and dive well although the feet are only semi-palmated, or webbed.

\section{THE CORMORANT.}

Somewhat smaller than the Gannet and of a jet black colour with metallic reflections on the breast; the back and wings have a brownish shade and the neck is grey; a patch of white indicates the insertion of the thighs; the bill is yellowish greenish-grey and there is a bare space round the lower mandible; the eye is yellowish-green.

The eggs, which are small for the size of the bird, are pale bluish-green, two in number, as a rule, and are deposited in a nest of large size generally made on a rock. The parents take the bill of the young into their own crop, after the manner of Pigeons and Parrots.

This bird has on several occasions nested and reared its young in the London Zoological Gardens.

THE CORN BUNTING. See under Buntings.

THE CORN CRAKE. See Landrail (under Rails).

THE CRESTED TIT. See under Tits. 
THE CROSSBILL. See Grosbeak (under Finches).

\section{THE CROWS.}

These form a well known group, adequately represented in this country by the Chough, Carrion Crow, Jackdaw, Jay, Magpie, Nutcracker, Raven, and Rook ; each of which is treated under its own heading.

\section{The Carrion Crow.}

A bird which is sometimes confounded with the Raven, but is a perfectly distinct species, with several peculiar characteristics. It is, however, a miniature Raven, and chiefly differs from its congener in size. It measures about I 8 inches in length, and is of much rarer occurrence than was the case a few years since. It is of rather solitary habits, living in pairs, which build a big nest of sticks in the top of the highest tree they can find. The young are as easy to rear as those of the Raven, and the bird itself is quite as amusing and interesting as the latter.

It is now generally conceded that the Hooded Crow is merely a variety of the one under consideration, for the two birds occasionally interbreed, and the young resemble one or other of the parents and are never blotched or variegated. The fact that the two sorts are rarely found together confirms the belief that the Carrion Crow is dimorphous.

\section{The Hooded Crow. See Carrion Crow.}

The Water Crow. See Dipper.

\section{THE CUCKOO.}

This is not a desirable bird to cage, though it can be preserved for a year or two in confinement with great care 
and with judicious management; but it seldom survives a second winter in captivity, and as it is of great use as a destroyer of may-bugs and other pernicious insects, it seems a pity to interfere with it.

Every one is acquainted with its peculiar habit of laying its eggs among those of other birds, the old Cuckoo seldom making a mistake in the selection of a nurse for her offspring; the Yellow-hammer, the Hedge Sparrow, the Pipits and the Wagtails, being those usually selected, though young Cuckoos have been found in the nests of Wrens, Chiff-chaffs and even, it is said, in that of one of the Finches, which so far departed from the habits of their race as to feed their foster-child with caterpillars! But such tales lack confirmation, and should be received with caution, being on a par with the well-known fable of his nephew's invention, related to the Royal Society by the elder Jenner, of the murderous habits and extraordinary instinct of the little blind and naked Cuckoo directly on its emerging from the shell: a tale, by the way, that seems to be but slowly dying in spite of the ample, if tardy, confession of the practical joker himself.

The Cuckoo is about the size of a Barbary Dove, and has very short legs, with zygodactylous toes. 'The head, neck, and upper surface of the body are dark ashen-grey, with iridescent hues on the back and wing-coverts; the lower parts are grey with darker spots. The female is smaller than her mate, and greyer in colour, with transverse spots on the lower surface.

The Cuckoo is a bird of passage, arriving in April and departing about the end of August, before which time its peculiar cry has ceased. Although it will eat some fruit, the bulk of its diet consists of insects. It is very impatient of cold.

THE CUCKOO'S MATE. See Wryneck. 


\section{THE CURLEWS. \\ The Common Curlew.}

This bird is much larger than any other member of the group, or family, in which it has been placed, attaining to a weight of 22 ounces or more, and a length of $\mathrm{r}$ foot 9 or 10 inches.

The call or note is well known and is loud and clear, uttered when the bird is on the wing, and has a whistling sound. It flies strongly and is of a wandering disposition, usually travelling at a great height in the air.

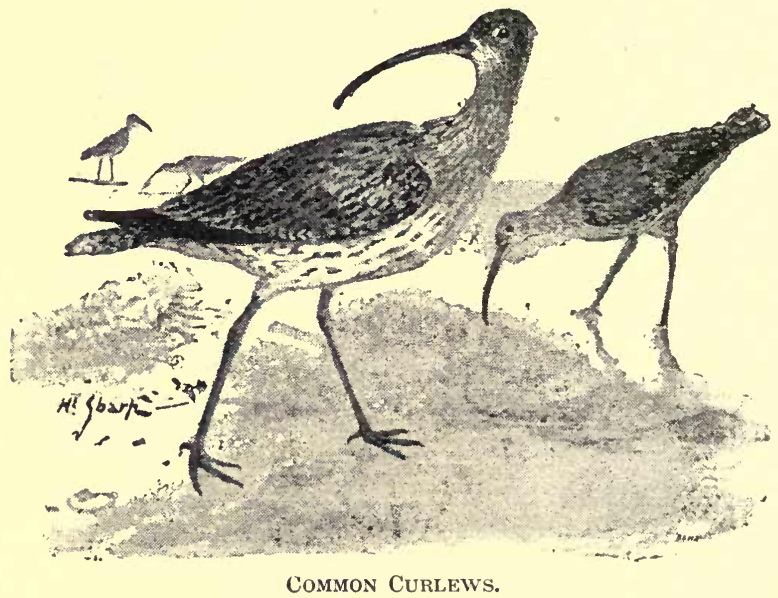

The eggs are laid on the ground among grass or rushes and are four in number, differing so much in appearance that scarcely two are found at all alike; they are wonderfully large for the size of the bird. The young can run about almost as soon as they are hatched; the parents attend them carefully until they are able to fly, which does not take place for some time. They are easily tamed.

The Little Curlew. See Whimbrel. 


\section{The Stone Curlew. See Thick-Knee.}

\section{The Whimbrel.}

Very much like the Curlew, but is not much more than half its size, for which reason its popular name of Little Curlew is not at all inappropriate. It breeds in the north, but spends the winter here. It is a noisy and restless bird, nesting among ling and heather on moors. The eggs are four in number, of a dark greenish-brown colour spotted with still darker brown. The young run about almost directly upon making their appearance from the shell. The legs and feet are of a darker colour than those of the Curlews, but the plumage of both species is very similar.

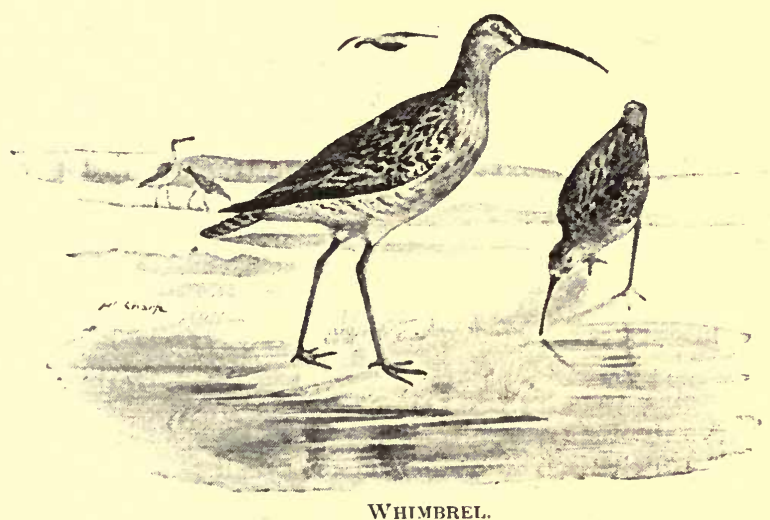

The Whimbrel feeds on aquatic insects, worms and small molluscs, which it probes for in the sand and mud with its long bill: in the young this organ is at first extremely short, and it does not attain its adult length of $3 \frac{1}{2}$ inches for more than a year. 
THE CURWILlET. See Sanderling.

THE CUSHAT. See Ringdove (under Doves).

THE DABCHICK. See Grebe (Little).

THE DARTFORD WARBLER. See Introduction, page 8 .

\section{THE DIPPER.}

This bird, which is also sometimes called the Water Thrush and Water Crow, is not a very commonly occurring bird in this country, no doubt for the reason that not every district furnishes the conditions necessary to its mode of existence, which is curious, not to say unique. It is about the size of the Song Thrush, and as it flits along the bank of a stream with its back towards the spectator, might be easily mistaken for one. It is, however, not speckled, but of uniform colour, dark rusty-brown above, inclining to black on the tail and wing feathers; the throat and breast are white, gradually passing into maroon and that into blackish slate on the under tailcoverts. In length the tail measures $I_{2} \frac{1}{2}$ inches, and the tips of the folded wings only reach as far as its middle.

The plumage of the female is lighter, particularly on the head and nape, and the white of her throat is tinged with grey.

It is usually found in more or less hilly or mountainous districts, along the banks of streams towards their source, where the water is not so liable to be frozen in severe weather, but in the summer time it ventures much lower down. If kept in confinement, it is best placed in 
a garden aviary where the conditions under which it exists in a state of nature are imitated as closely as may be, and a miniature stream is caused to trickle over a pebbly bed by the side of an artificially formed bank, studded with stones and planted with ferns and the shrubs usually found growing in the situation imitated.

The natural food of the Dipper consists of aquatic insects of various kinds, molluscs, worms, and, it is said, small fish: it is also reported to be peculiarly destructive to spawn, and is credited with destroying that of the trout and even of the salmon, for which reason it finds but scant favour in the eyes of the disciples of Izaak Walton, that "quaint old cruel coxcomb," as Byron called him, who love to do their own killing.

It is doubtful, however, if the accusation can be substantiated, at least to any extent, and yet in one locality in Scotland upwards of five hundred of these curious birds,- "Kingfishers" they call them there,-are reported to have been killed in three years.

It is with difficulty accustomed to the use of artificial food, but will after a time take crushed dog-biscuit and crissel, and thrive, more or less, upon the unusual diet, but does better if allowed plenty of ants' eggs, mealworms, and other insects in addition.

The nest is large, built mostly under an overhanging ledge of stone, or some other projection, the entrance to it being through a comparatively small hole; but where it is placed in a more open situation it is domed.

The eggs, four or five in number, are white, and the mother is so devoted to her charge, that she has sometimes suffered herself to be taken with them, and has finished incubating them in captivity, rearing the brood single-handed, so to speak. As the young soon quit the nest they should, if wanted for the aviary, be taken early, when it is not difficult to rear them on ants' eggs, mealworms and other insects, with the addition of a little raw meat.

The song of the Dipper has some resemblance to that of the Thrush, and his sonorous strains are heard at a great distance, especially as he sings during the night. 
One curious circumstance connected with this bird is the power it possesses of walking at the bottom of the water; true, this has been denied, but as the reason given was, that in the opinion of the person who made it such a feat was impossible, the objection can only be taken for what it is worth.

\section{THE DIVERS.}

\section{The Black-Throated Diver.}

This is not unlike the Great Northern Diver, but is smaller, and has a grey head and neck; the chin and throat, however, are black, with a grey patch between. As in the case of the Great Northern Diver, the legs are placed very far back, and when the bird is seen sitting on the shore it has very much the attitude and appearance of a Penguin.

\section{The Great Northern Diver.}

This bird is also called the Imber, Great Doucker, and Ring-necked Diver. It is a northern species and is practically extinct in Britain, though in Orkney it is still occasionally seen, and is believed to breed there, or to have done so within the last few years.

It is a shy bird, but nevertheless quite capable of being preserved in captivity if supplied with suitable food, that is to say fish, of which it consumes an immense quantity, being a large bird: it attains to a weight of from 12 to 14 pounds, and measures about $2 \frac{1}{2}$ feet or a little more in length. The beak is about 3 inches long and of a dark horn colour. The head and neck are black, but the latter part is marked with black and white spots, one at the top in front, and two lower down, one on each side; the back of the neck, back, wings and rump are thickly spotted with round white spots on a black ground; the under parts are white. The eggs, two or three in number, are brownish green with a few spots of reddish purple; both sexes share the task of incubation, which lasts for 8 days, the young taking to the water soon after being hatched. 
The female is not as large as the male, and the black on her head and face has little or none of the green shade visible on him in certain lights.

The Ring-Necked Diver. See Great Northern Diver.

THE DOTTEREL. See under Plovers.

THE RINGED DOTTEREL. See Plover (Ringed).

\section{THE GREAT DOUCKER. See Diver (Great Nor. thern).}

\section{THE DOVES AND PIGEONS.}

\section{The Ringdove.}

This bird is also known by the names of Wood Pigeon, Wood Quest, Cushat, Queest, and probably by other local names: it is also asserted, on the authority of Morris, to be the Ysguthan of the Ancient British. It may be that the name by which it is most generally known, namely that of Ringdove, is not particularly applicable to it, but there it is, and it only leads to confusion to give the same designation to a foreign species, that is, to the Barbary Turtle (Turtur risorius), a practice that cannot be too strongly condemned.

Not only is the Ringdove a British species, but it occurs all over Europe, and, it is said, in Northern Asia and Northern Africa. It has considerably increased in numbers in this country of late years, and is almost the only bird that has done so, the other possible exceptions being the Starling and the common House Sparrow. 
In the winter the resident population of Ringdoves is augmented by numerous arrivals from the Continent, to which the strangers, or as many of them as are then surviving, return when the more genial weather of springtime has set in.

It is a large bird, measuring 18 inches in length, and, when in good condition weighs from i 8 to 20 ounces, the female being a trifle smaller and, of course, not so heavy. She can only be distinguished from her mate by her more

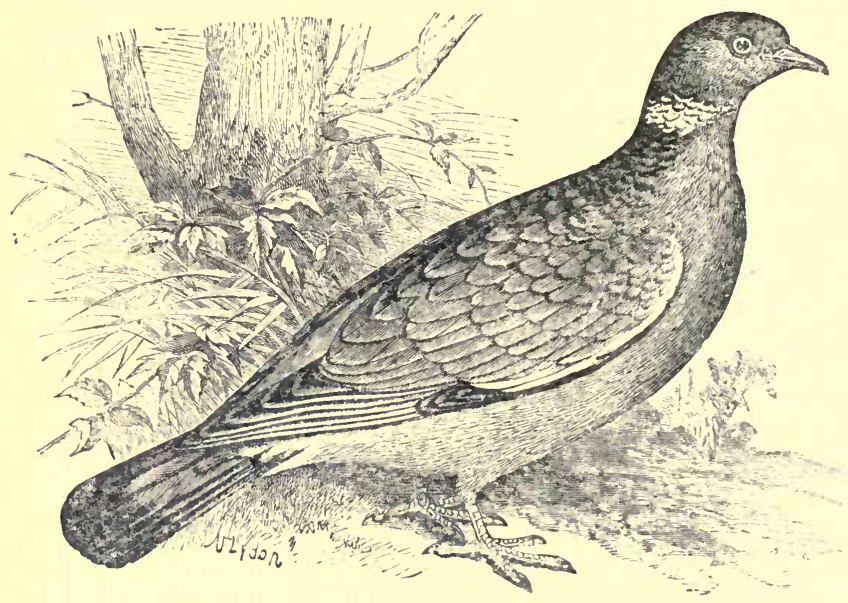

THE RINGDONE.

feminine appearance, except during the breeding season, when he develops two protuberances, or knobs, of a reddish-yellow colour on the upper mandible, which are totally lacking in the female.

The general colour of this species is a fine slaty-blue with metallic reflections on the neck and breast; on each side of the neck is a small patch of glossy white (the ring to which the bird owes its name); the tail is long and broad, and consists of twelve feathers, with a dark band across the lower third, 
It is a wood-loving species and formerly seldom came near human habitations; cases, however, are on record in which it has been so well disposed towards man as to establish itself in gardens, and become so tame as to accept food from the hand of its protector. Whether that be the case or not, it has of late years taken up its abode in considerable numbers in several of the London Parks, where it breeds and is quite as tame and fearless as the Sparrows. The writer counted thirty-six one afternoon in St. James's Park, and saw two in Leicester Square, as well as several others in the open space around Westminster Abbey.

This is a curious exemplification of the changes that take place spontaneously in the habits of wild animals, and the explanation probably is that the birds were so persecuted in their native haunts as to seek protection from their enemies amid the smoke and bustle of towns; and having found the security they were in search of, settled themselves finally in the most unlikely places.

Like most of the Pigeons, the Ringdove lays two eggs, white in colour, on an inartistic platform of sticks very variously situated according to circumstances, sometimes on a tall tree forty, fifty, or more feet from the ground, and sometimes in a shrub or even a hedge of very moderate height only. The nest, so-called, is such a very flimsy construction that a high wind often scatters it in every direction, and the eggs are discernible through it to any person standing below. About twenty feet above the soil is, however, an average distance, and firs and pines are very frequently selected, but more especially the larch, the horizontally projecting branches of which afford a convenient foundation for the nest.

The young grow rapidly, and are easily enough reared on soaked peas and other seeds, but the precaution of mixing a little clean grit with the food now and then should on no account be neglected, as it helps the little Doves to digest their meals more perfectly. Thus reared, the Wood Pigeons will generally get to be very tame. Their eggs may be put under a domestic Pigeon, but sometimes the latter will refuse to feed the little strangers, which are covered first with yellow down and then with bluish prickles 
that make them look more like young hedgehogs than birds. Notwithstanding assertions to the contrary, it is certain that a cross between this bird and the domestic Pigeon has never been obtained, for although pairing may occur the eggs are always barren, or at least have been so hitherto.

Unless kept in an aviary the size of a small field and planted with trees, Columba palumbus will not breed in confinement, and it certainly is not worth the trouble and expense to accommodate them to their liking in order that they may reproduce their species in captivity.

The food of the wild Cushat is very varied, and consists of seeds of all kinds, from chestnuts and acorns down to the black shining triangular seeds of Polygonum repens and other weeds (of which they consume immense quantities) all more or less injurious to the agriculturist. In confinement they will eat every kind of corn that may be going, as well as lawn clippings, waste cabbage-leaves and turniptops, of which last they devour a good deal during the winter, particularly when there is snow upon the ground, and they also at the same time will peck holes in the tops of the turnips themselves, which makes the farmer, forgetful of the good they do in other respects, hate them with bitter hatred, and compass their destruction whenever and wherever he can.

The Ringdove, however, is prolific, and usually has three broods in the season, that is six young Pigeons added to the columbine population by each pair of breeders in one year. Swift of wing, and vigilant even when feeding on the ground, the Wood Quest can give a good account of all its enemies save man, who thins its ranks, either for the purposes of the table or from sheer spleen arising from the bird's supposed ravages among his crops, more than all the rest of its foes put together.

The Ringdove when sitting on her eggs will desert them on the smallest provocation, even though they may be on the point of hatching; but once the young ones are out of the shell the parents are very bold in their defence, and will even carry them away (how, is not precisely known) to a place of greater security. 


\section{The Rock Pigeon (Columba livia, Linn.).}

This Pigeon is the real origin of all our domestic breeds, at least in this country, and not (as asserted by a writer who also thought the dormouse was the progenitor of all the rats and mice) the Stock Dove, which owes its English name to quite another reason as already mentioned.

The Rock Pigeon, like its domesticated descendants, never perches in trees, at least among the small boughs, for it has no grasping power in its toes, but sometimes it will settle on a broad flat horizontal branch on which it can obtain sure foothold. Nor does it nest in them, or on the ground, but on ledges of rock, or in caves, and very generally on the coast, showing that the tame breeds have not deviated in this respect from their original; they resemble it, too, in form, unless they are artificially bred out of all resemblance to their ancestor, as, for example the Fantails, Owls, Nuns, \&c., of the fancier. They all have a white patch over the tail, a black bar across the wing, and a black ending to each of the tail feathers, exactly after the manner of the wild Rock Pigeon, as can be seen by watching the flocks of ownerless Pigeons that frequent St. - Paul's Cathedral, the British Museum, the Custom House, and other public buildings in London.

Everybody knows or has heard of the late Mr. Charles Darwin's experiments with Pigeons, which he crossed and re-crossed until at last he obtained birds that were indistinguishable from their wild progenitors. This he considered was a proof of the correctness of his theories respecting the origin of species, although it really only demonstrated that artificial selection created varieties, which is quite a different thing, and was already well known to systematic breeders.

The Rock Pigeon is not as widely spread in this country as the Ringdove, but it is more numerous than the Stock Dove, no doubt on account of the inaccessible nature of many of the places it frequents. Morris says it occasionally breeds in old trees, quite twenty miles inland, but this is entirely contrary to the experience of the present writer. 
The Rock Pigeon is supposed to pair for life, and as a rule probably does so; but as conjugal infidelity and divorce, or at least separation, are by no means unknown among its domesticated descendants, it may be that the union is not always as permanent a one as has been imagined.

A good deal of romance has grown up round the fidelity, constancy, or what not of Doves in general, but it has not nearly such a foundation in fact as some persons think. Macgillivray, for instance, waxes most poetical over the untimely fate of one of these birds which he had brought up, but the fact remains that they are exceedingly pugnacious, and will fight among themselves even to the bitter end.

The flight of the Rock Pigeon resembles that of the domestic breeds, even to an occasional "tumble" when on the wing, and differs greatly from that of the Ringdove and Stock Dove, which is much more direct. Where they exist in large numbers they are certainly capable of devouring a large quantity of grain, for the crop of a fullgrown bird will contain half a pint of seed: but where are they so numerous? They also eat a good deal of green vegetable food, are particularly fond of charlock seed, and pick up quantities of small snails, as their domesticated descendants are in the habit of doing.

While the Ringdove is about 18 inches in length and averages about 20 ounces in weight, and the Stock Dove measures I 4 inches, the Rock Pigeon is only $\mathrm{I}_{2}$ or I 3 inches in length and weighs but I I ounces or thereabouts.

The female differs very little from the male, but the metallic tinting of her neck and breast feathers is less brilliant than in the case of her mate; her neck is also thinner, and the terminal spot in the tail feathers has a brownish tinge.

The feathers of all Pigeons come off very easily, but those of the present species are even more readily detached than any of the others, and will fall out in handfuls, so to speak, at the slightest touch; but the loss is quickly made good, for they grow again with marvellous rapidity at any season of the year. 
As might be supposed, it is not at all difficult to tame the Rock Pigeon, and instances are on record where it has voluntarily availed itself of the accommodation of the Dovecote, to which it will become as attached as its proper inmates if it has been brought up there in consequence of the eggs having been hatched by a domesticated foster-mother. It is curious, however, that although young Ring and Stock Doves may be reared in the same manner, they will, with scarce an exception, betake them to their native haunts and the more congenial companionship of their respective races, proving that their relationship to their nurse is much more remote, if indeed it exist at all, than that of the Rock Pigeon, or Rock Dove as it is also not infrequently called, the terms Pigeon and Dove appearing to be interchangeable.

Morris says that these birds roll in dust, but the present writer has not chanced to come across any that did so, all appearing to bathe, after the manner of their descendants, in water. He also says they sometimes sleep on the ground, but this is very doubtful, and where they appeared to do so they were in all probability confounded with the Stock Dove, which certainly does, at least sometimes, act in the manner described.

The young are able to shift for themselves in about a month or five weeks from their birth, and the parents have three, sometimes four, broods in the season, which extends from April to the end of September.

These birds are free drinkers, and take up the water by a sucking movement in the mandibles and throat in a continuous draught. The young are fed on seed macerated for a time in the crop and then regurgitated into the mouth of the young one, which is thrust far down into the parental throat. At first, however, they receive a milky secretion from a set of peculiar glands situated in the crop.

\section{The Stock Dove (Columba crnas, Linn.).}

This is a smaller bird than the Ringdove and differs from it in several essential points, although the two species have occasionally been confounded one with the other. In the 
first place the nesting arrangements of the two species are totally different, as the Stock Dove for the most part collects a few bits of stick at the bottom of a hole in a tree trunk (stock, whence the name), or failing such will deposit them on the bare ground under the shelter of a clump of gorse or some more or less efficient cover.

The eggs are also smaller and rounder than those of the Ringdove, but they are hatched in about the same time, that is to say between seventeen and eighteen days, after the manner of all the members of the Dove family, with one or two possible exceptions. The young squabs are indistinguishable from their congeners, but the plumage of the parent birds offers some marked contrasts. Thus, the plumage of the Stock Dove is of a darker blue than that of the Wood Pigeon and it has no white on the neck, while the breast is of a ruddy vinous tint, whence the specific name anas, from the Greek "oivo;"-wine, which it is supposed to resemble in colour. The quills of the wings and tail are black, or nearly so, and the latter are marked by a light coloured patch about the centre, except the centre pair, which are of a uniform dark colour throughout; the bill and the legs and feet are orange-red, and the iris is of almost the same shade.

The female scarcely differs from the male in appearance, but her breast is not quite so ruddy as his. White, mottled, and liver-coloured specimens of the Stock Dove as well as of the Wood Quest have now and then been seen and, as a matier of course, shot. Toussenel, the author of a very curious book called l'Ornithologie passionnelle, once saw a white one paired with a male of the ordinary colour, and at once jumped to the conclusion that she was "a Dovecote Pigeon," and that the two species interbred, which they never do, all tales to the contrary having no better foundation.

The Stock Dove is very careful of its eggs, and instances are recorded where it has suffered itself to be captured rather than desert its charge. The male sits in the daytime and the female at night, after the manner of all the members of the Dove-pigeon family. There are usually only two broods in one year, and the second is never 
reared in the same hole in which the first were hatched, although that may be resorted to in the following season.

Dry leaves are occasionally used to line the nesting cavity, which may extend down into the hole of a tree to a depth of a foot or more.

The food is the same as that of the Ringdove.

\section{The Turtle Dove (Turtur communis, Slb.).}

This is the smallest of our native Pigeons, only measuring from I I to I 2 inches from point of beak to end of tail; it is also of more slender form than the others, and rarely attains to a greater weight than 6 ounces, while the female is somewhat less.

It is a very handsome bird, with a good deal of bronzed metallic tinting on the back and wings; the top of the head, sides, and lower abdomen are greyish-blue, and the breast has a subdued reddish-fawn tint; the tail is black except the tips of the inner feathers, which are white.

On each side of the neck is a round patch of black feathers tipped with white, which forms a conspicuous feature, almost as noticeable as the "ring" of the Wood Quest or the "collar" of the Barbary Turtle.

It is a bird of passage, arriving here in April, or if the season is a backward one, not till May, and departing in August or September. As the males precede the females by a week or more, it is presumable that they only pair for the season, and all the romantic superstructure built by the poets on their supposed unswerving fidelity to each other falls to the ground.

The nest is not built with any more skill than that of the other Pigeons, but is well concealed among leaves and young growth. The eggs are considerably elongated, and are white, hatching in about seventeen days. The young are not difficult to rear by hand on soaked seeds of different kinds, but seldom become thoroughly tame. There is usually only one brood, but sometimes two occur in the season, and if the second nest is disturbed the birds do not, as a rule, attempt a third. 
The Turtle Dove breeds freely in confinement, not only with a mate of its own kind, but with members of allied species, especially the Barbary Turtle, hybrids with which are not uncommon: Bechstein believed, or said, that these cross-bred Doves were fertile, but the experience of subsequent observers has not borne out the assertion.

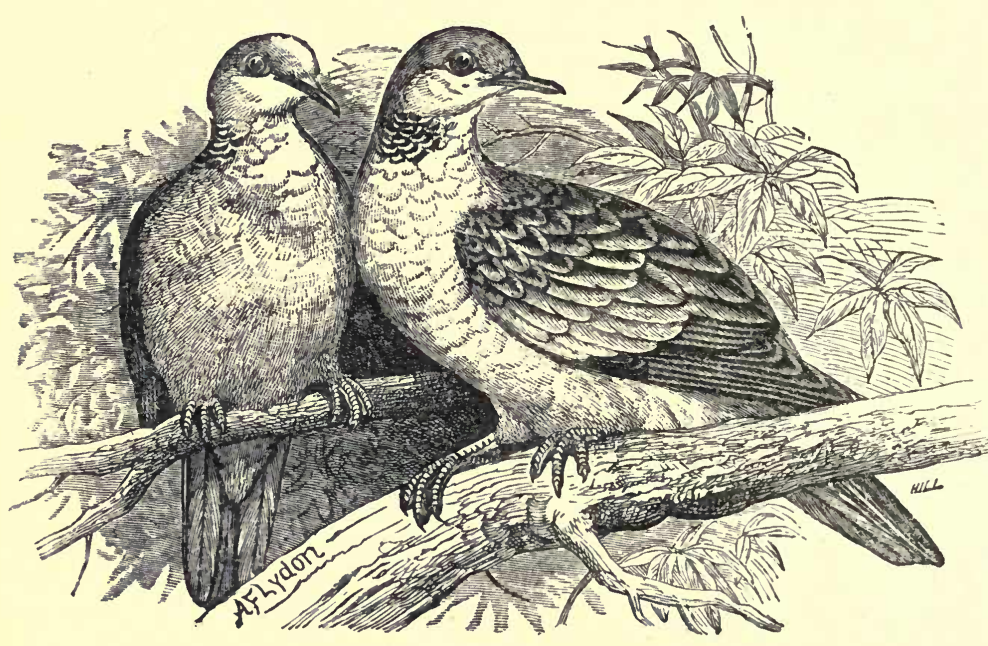

TURTLE DONES.

- The food of the Turtle Dove is the same as that of the Ringdove and Stock Dove, and like them it seeks for it on the ground. It is a thirsty creature and is always found near water, whether in pond, lake, or running stream. In confinement they will eat any kind of grain, and should have an adequate supply of green food, while to replace the small snails on which they feed freely, a handful of ants' eggs should be supplied to them now and then, and these they will greedily devour; they will also eat small worms and any kind of little beetles and other insects of a suitable size. 
The Wood Pigeon or Wood Quest. See Ringdove.

\section{THE DUCKS.}

\section{The Eider Duck.}

Every one knows this Duck, at least by repute. It is a large handsome species, entirely a bird of the ocean, of wandering rather than migratory habits, and occurs principally in the outlying Scottish Islands, where it is protected on account of the valuable down plucked from its own body for covering the eggs: these are of a light green colour and are four or five in number.

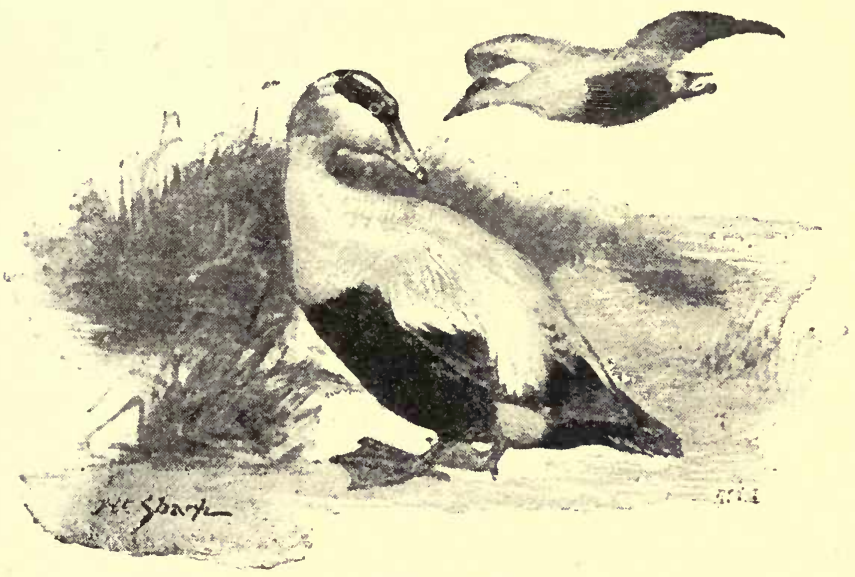

Eider Ducks.

The male weighs between 6 and 8 pounds, and the female a few ounces less. The top of his head is jet black, which is also the colour of the lower half of the breast, the belly, under tail-coverts and rump; the shoulders are slate-colour and so is the nape of the neck; the wings and tail are greyish-brown, and the remainder white, 
including the long scapularies, but excepting the neck and breast, which are ruddy buff. The legs and feet are dusky green. The female is much duller in all her colouring, as well as somewhat smaller than the male.

\section{The Gadwall.}

This Duck has bred in the Gardens of the Zoological Society; it is closely connected with the famous Canvasbacked Duck of America, and is a handsome bird, very susceptible of domestication. It is of rare occurrence in

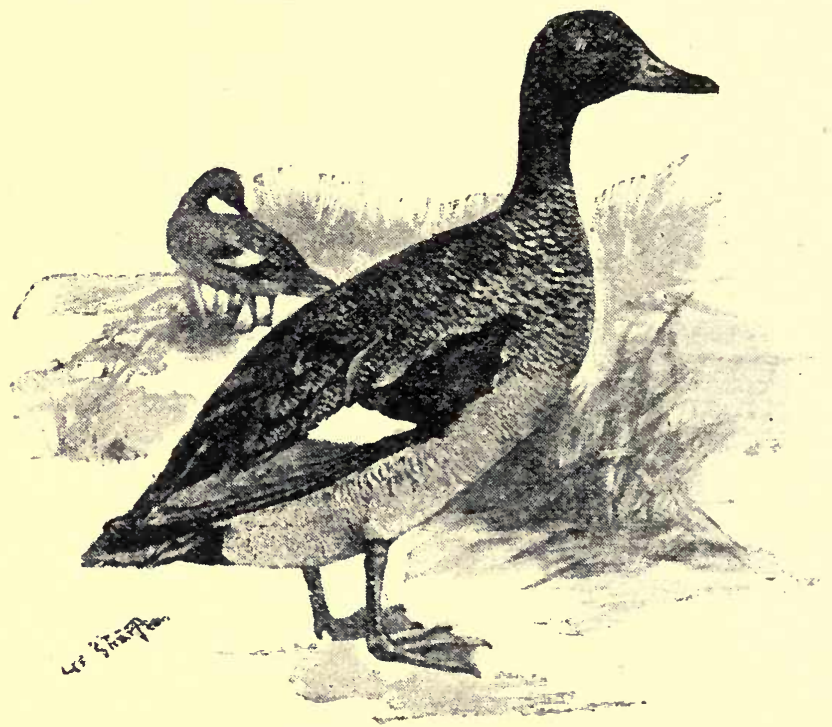

The Gadwali.

this country. The Gadwall feeds on water insects, small fish, frogs, aquatic plants and seeds. The nest is placed among reeds. Its eggs are five or six in number, whitishbuff in colour. 


\section{The Garganey.}

Rather larger than the Teal and distinguished by a number of elongated narrow feathers springing from the scapulars. These are of a deep black colour shading into

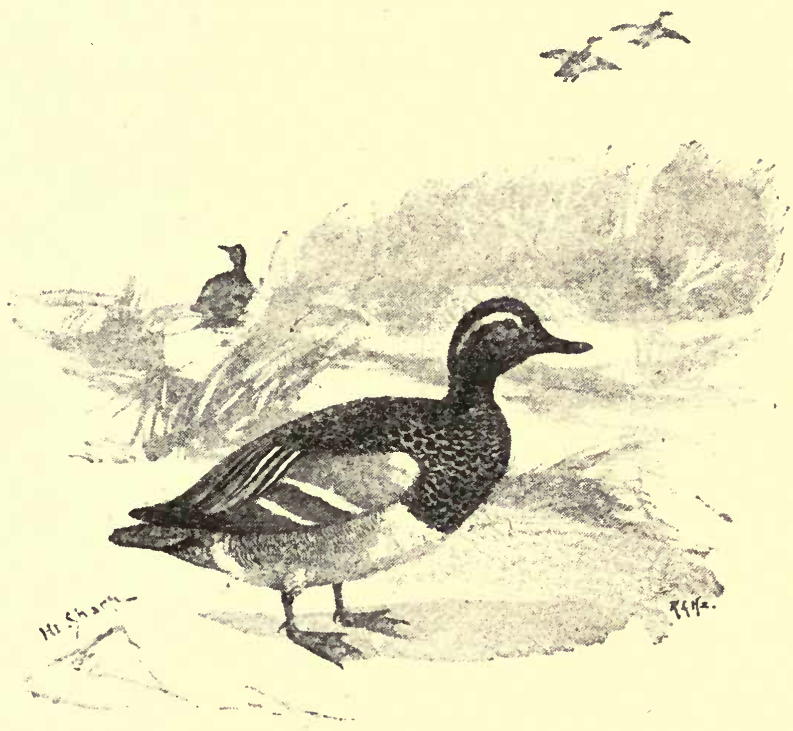

The Garganey.

grey at their free extremities; they are wanting in the female and in the young males of the year, which resemble their mother. It is of rare occurrence in Great Britain and unknown in Ireland. 


\section{The Golden-eyed Duck.}

This is a larger bird than the Pochard, weighing about 2 pounds. It is black and white in colour, the former washed with metallic tints; the iris is bright yellow, whence its English name. It does not breed in this country, though occurring here in considerable numbers during the late

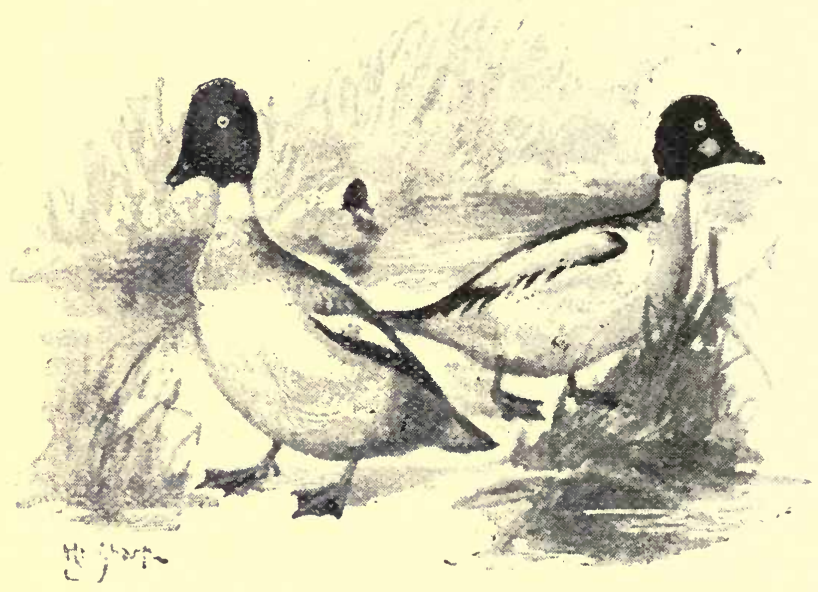

GuLden-EYED DUCKS.

autumn and winter-"where peaceful rivers, soft and slow, amid the verdant landscape flow"-according to Mr. Morris, quoting from an old metrical version of the Psalms. The female is rusty-brown in those parts where the male is black, namely, the head, back, and rump. 


\section{The Pintail.}

Very like the Garganey, but distinguished from that by the extreme length of the two middle feathers of the tail, which are glossy black, by a white breast, a Mallard-

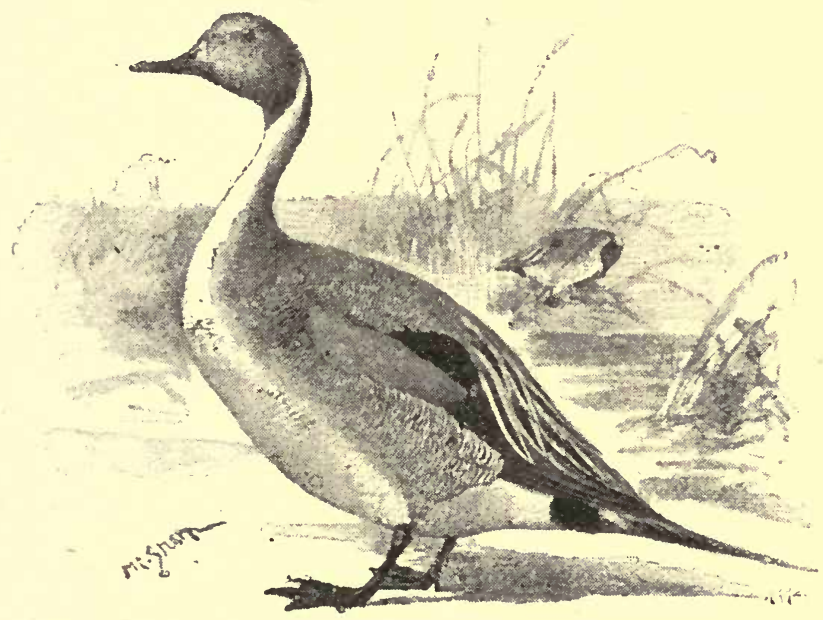

THE PINTAIL.

like patch of metallic colouring on the wings, and longer and broader scapular feathers. It breeds freely in confinement and has produced hybrids with the Common Duck.

\section{The Pochard.}

This Duck was formerly much more abundant in England than it has been since the reclamation of the fens; still it is frequently met with, and breeds freely in several localities; it also occurs in Ireland and Scotland, and is found inland as well as on the coast. It is about I foot 6 inches in length, weighs nearly 2 pounds, and flies and swims well.

The eggs resemble those of the other species of Ducks 
and are ten or twelve in number. It will breed in captivity and become quite tame and confident, if well treated. The bill is black at the base and tip, but lead colour in the middle; the head and the upper part of the neck are rusty brown; the lower part of the neck

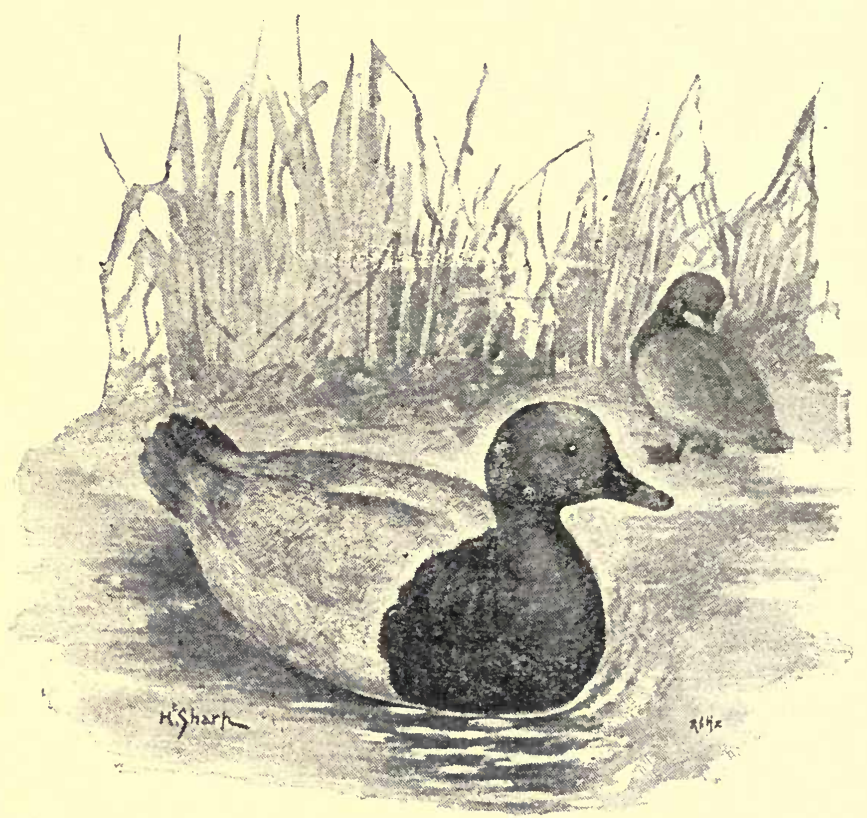

POCHARDS.

and upper portion of the breast, black, which also is the colour of the rump, tail and under tail coverts; the wings, back and sides are canvas marked and the remaining under parts, white. Its food consists partly of vegetable and partly of animal matters. 


\section{The Scaup.}

This Duck has a leaden blue bill, black head, neck and breast, canvas-marked back, brown tail, greyish wings, and white under parts. It is a regular winter visitor in suitable localities. They have a habit of turning up the

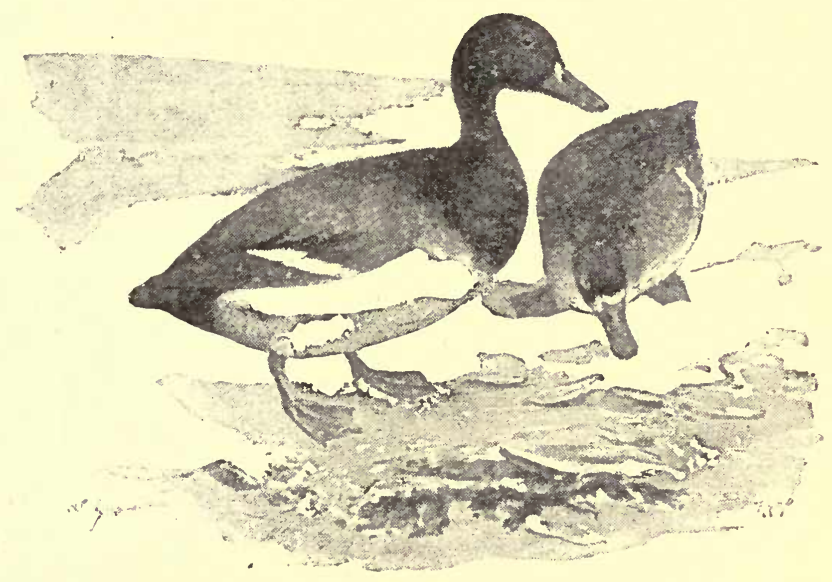

Scaup Ducks.

mud with the beak in search of food, whence their name (scoop), according to Morris. This species will breed freely in confinement.

\section{The Sheldrakes.}

The Common Sheldrake is strictly maritime in its habits and is rarely seen far from the coast; its nest has been found in Norfolk and other parts of England, as well as in Ireland and Scotland, although rarely. The eggs are ten or twelve in number, white with a very faint tinge of green; the young take to the water directly they are hatched, and may be reared in captivity if the eggs are set under a common Duck, a hen, or even in an incubator. The natural food consists of marine vegetables, worms, 
crustacea, insects and fish, but they also eat grain and seeds when other food is not to be had. In confinement they will thrive on a judicious mixture of both kinds of diet.

The weight of an adult specimen is close on 3 pounds, and the length about 2 feet $I$ inch, or 2 feet 2 inches. The beak is orange, the head and upper neck glossy black, the lower neck white, and the breast and back of the neck at its lower part rufous brown; the wings are

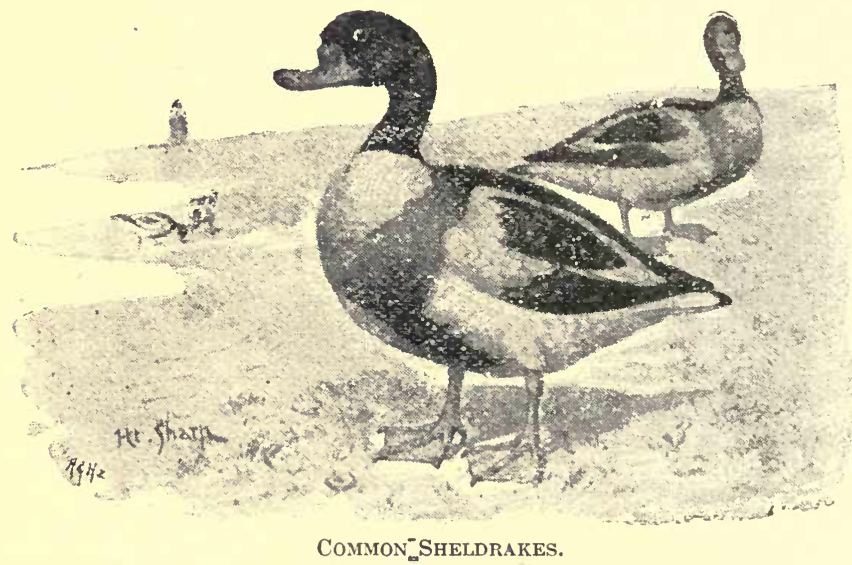

black, white and green, and the rest of the body is white, except the tip of the tail, which is black. The female resembles her mate generally, but is smaller and her colours are less brilliant.

The Ruddy Sheldrake has the bill a dark slate grey; the head and neck are yellowish brown. A narrow black ring surrounds the junction of the neck and body, the lesser wing-coverts are pale buff, the greater green with a metallic lustre; the primaries, rump and tail, are black, and the rest of the body ruddy brown; the legs and feet are blackish-grey. 
It is about the same size as the last. It builds in holes in the banks of rivers, lining the cavity with its own down and feathers; the eggs are white, and from nine to eleven or twelve in number. It is only an occasional visitor to this country.

\section{The Shoveller.}

A very handsome Duck. The bill is black; head and neck glossy black with steel-blue reflections; breast and lesser wing-coverts white with a slight buff tinge; brown

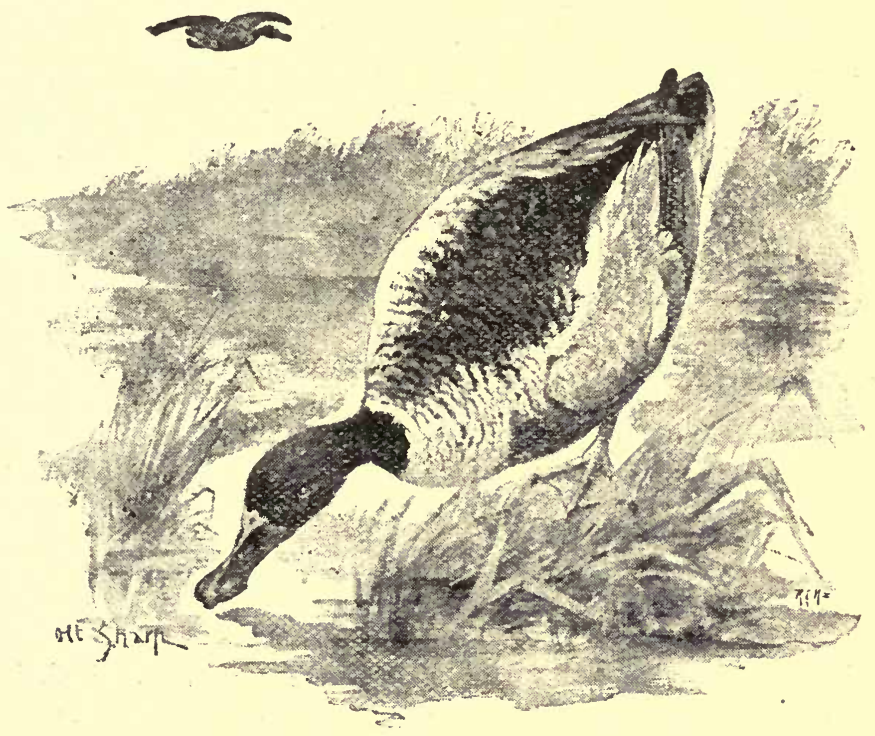

THE SHoveller.

scapulars with white margins; back brown with lighter margins; tail white all but two centre feathers which are. brown; breast and belly deep chestnut-brown; wing-coverts glossy green; under tail-coverts black. 
It is an uncommon winter visitor but a few remain to breed in secluded localities. It is considered to be very good eating, and breeds freely in confinement. A free supply of ants' eggs is conducive to a successful rear of the young brood, and this remark applies equally to all the other members of the Duck sub-family here considered.

\section{The Smew.}

This Duck, whose name is probably a corruption of Sea-mew, is black and white in colour, with light slate blue primaries and sides; the tail is greyish blue, which is also the colour of the bill. It is a winter visitor, but is supposed to breed sometimes in the north of Scotland.

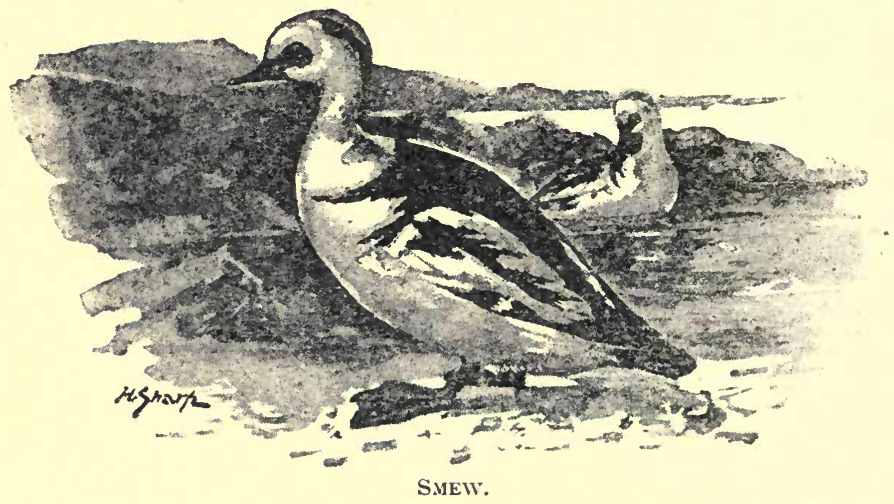

Like all the other members of the family to which it belongs, it is readily tamed, and will breed in confinement if judiciously fed on a due admixture of animal and vegetable food. 


\section{The Teal.}

This is the smallest member of the Duck family found in this country; it is a pretty bird, with a good deal of the canvas-backed mottling about its shoulders and sides, and

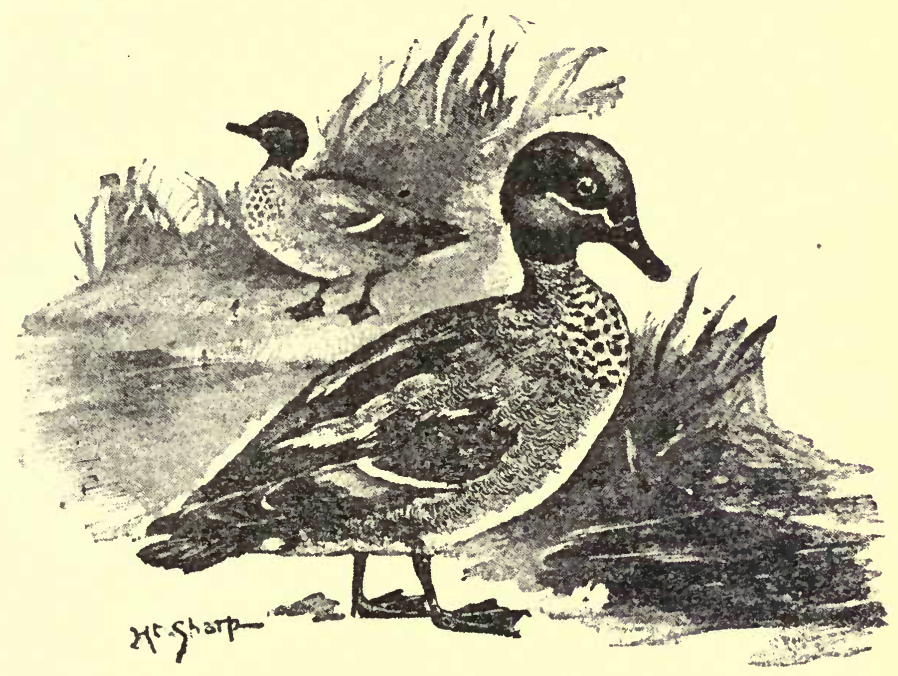

TEAL.

metallic green on the face and wings: in winter he puts on the same greyish brown dress always worn by the female.

This species is common in the country, and is considered very good eating. It frequents moorland and marshy districts, but breeds freely in confinement. 


\section{The Tufted Duck.}

This Duck is most frequently met with here in winter, though it sometimes breeds in sequestered spots. It is a stoutly built bird, and about I foot 5 inches in length. It wears a crest of long narrow black feathers with greenish reflections, which make its head look rather out of proportion with the rest of the body; the general colour is blackish

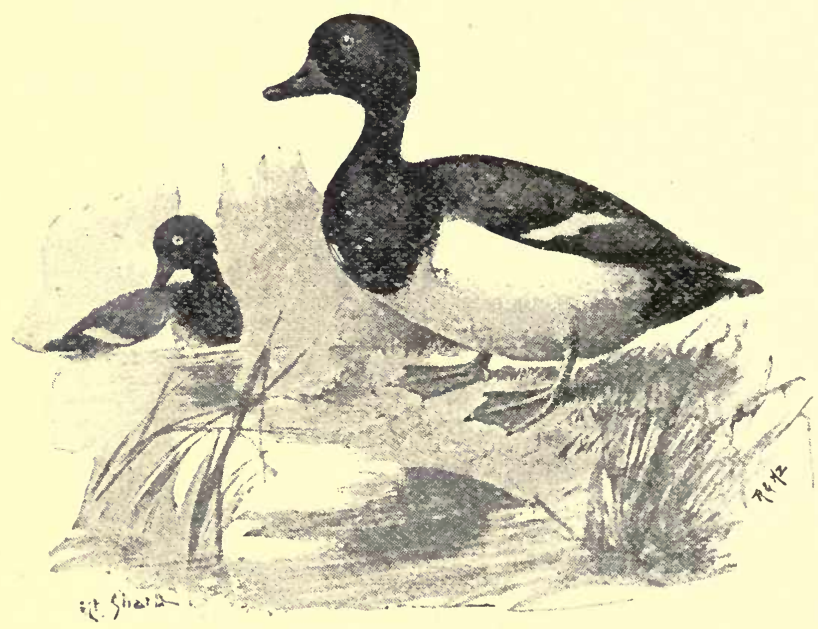

TuFted Ducks.

brown with a metallic lustre, a white bar crosses the wing, and the belly and under parts are white. In the summer the plumage assumes a generally browner shade, which is always the colour of the female.

\section{The Wigeon.}

This is a handsome Duck with a pale buff head, brown face, light rufous brown breast, canvas back and sides, white lesser wing-coverts, glittering green greater wingcoverts, and blackish-grey primaries. The under parts 
are white, and the tail black; the bill is greenish slate colour. It is not uncommon in many parts of the British Isles, though less frequently encountered than formerly,

$$
+4
$$

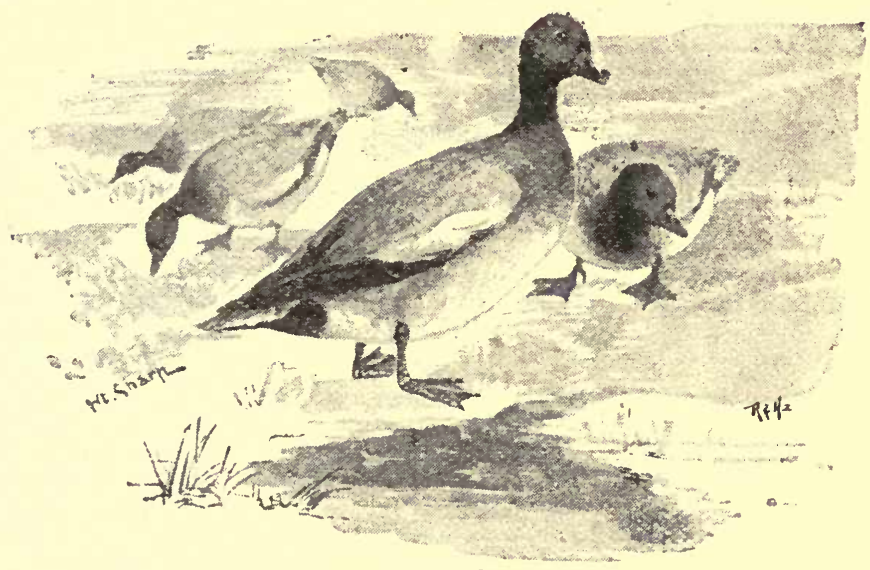

WIGEON.

and retires north to breed. It is very easily tamed, has frequently nested in confinement, and, no doubt, could be easily domesticated.

\section{The Wild Duck.}

Too well known to need description. Suffice it to say that except in point of size it closely resembles the domestic variety known by the name of Rouen Duck. It exists in a semi-domesticated state in several of the London parks and other places, and if reared among tame Ducks will not fly away but stay contentedly in their society. 
THE DUCK HAWK. See Harrier (Marsh).

THE DULL WILLY. See Plover (Ringed).

THE DUNLIN. See under Sandpipers.

THE DUNNOCK. See Hedge Sparrow.

\section{THE GOLDEN EAGLE}

Derives its name from the reddish-golden colour of its neck feathers. It has a powerful curved beak of a horngrey colour and a yellow cere; the naked parts of the toes are of the same colour, but the legs are covered with feathers. The rounded tail is crossed by alternate bands of blue-grey and black; the general colour of the plumage is brown with a yellowish shade, and the iris is reddish-brown.

The Golden Eagle is practically extinct in this country; for though we occasionally hear of one or two being shot here and there, they are evidently adventurous explorers from the Continent, paying for their temerity with their lives very soon after venturing on our inhospitable shores, their large size and distinguished appearance affording an easy aim and an irresistible temptation to the shooter.

At no very remote period they were common in the north of England and in Scotland, and built their nests in inaccessible mountain fastnesses; but the lover of nature is no longer to be gratified by the sight of their buoyant flight over hill and vale, or their majestic figure perched "like Patience on a monument" upon some towering altitude overlooking hill and dale: but what cares the sports- 
man as long as he can gratify his passion for the destruction of life and the spilling of inoffensive blood: for the Golden Eagle is harmless and even useful. True he will prey on rabbits and hares and will perhaps attack a sickly lamb, but that is the extent of his ill-doing, and on the other hand he keeps down the too prolific rodents which without his aid and that of his compeers would multiply exceedingly, to the great detriment of the farmer, already so heavily handicapped.

\section{THE EIDER DUCK. See under Ducks.}

\section{THE FALCONS. See under Hawks.}

\section{THE FIELDFARE.}

This bird is a winter visitor, arriving about the beginning of October. It is about the size of the Blackbird, namely from 10 to $1 \circ \frac{1}{2}$ or $1 \circ \frac{3}{4}$ inches in total length; it resembles its sable-coated relation in its gait and especially in its habit of flirting up the tail and clapping the wings against the sides, when hopping about in search of food. The birds travel in considerable flocks, and are usually met with in companies of at least a score while they remain with us.

The male is more like the Missel Thrush than the Song Thrush and has been not unfrequently mistaken for the former.

The bill, which is about an inch in length, is yellow with a dark point; the legs and feet are brown; the eyes, dark brown; the head, neck, cheeks and rump, ashen grey; eyebrows, white; back, rusty brown; throat and upper breast, buffish yellow with heart-shaped black spots; the remaining under parts are white with heart-shaped dark spots on the sides, and longer ones towards the vent and tail. 
The female is browner and generally duller in appearance, also a trifle smaller, than the male, and the young of both sexes resemble her until after their first moult.

White, pied and cinnamon Fieldfares have now and then been seen, and, as a matter of course, shot.

The Fieldfare is a native of the northern parts of

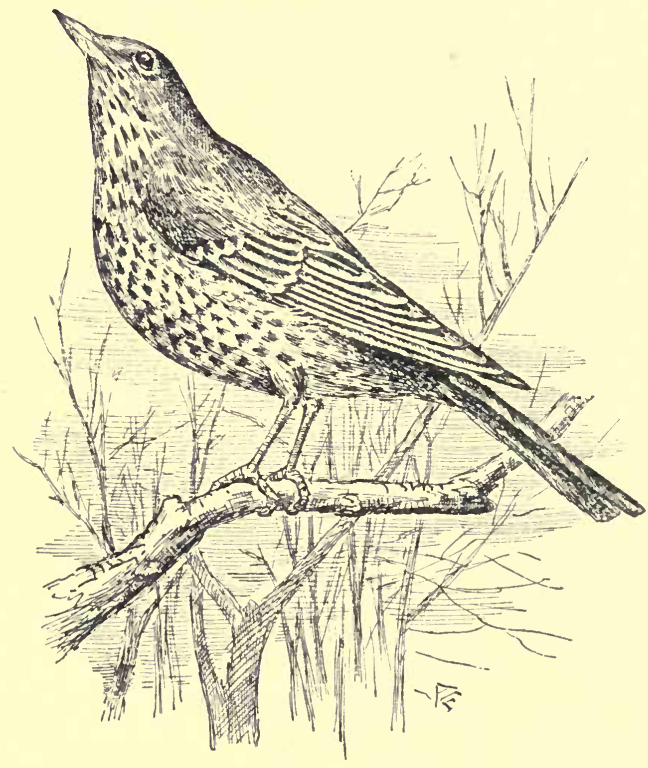

THE FIELDFARE.

Europe and of Siberia, but as it visits us regularly every winter in considerable numbers, and instances are on record where it has even bred with us, it may be reasonably described as a British bird. The nest is said to be built in pine woods, at a varying height from the ground, and is nearly always situated against

the trunk. Many pairs resort to the same locality and construct their dwellings in close proximity to each other. The nests are made of leaves, moss, and grass slightly cemented together with mud, and are lined with the finer portions of the materials used in the construction. The eggs, which are four or five in number, are pale bluishgreen, spotted with dark brown.

If kept in the house, the Fieldfare should have a large 
cage and is then an attractive-looking bird, which is generally noticed at shows, but it is seen to greater advantage in a large garden aviary. Heat is injurious to it, as well as to the snow-bunting and the Bullfinch, and it should never be exposed to this unnecessarily, but be kept in a room without fire; or if out of doors, be provided with plenty of shelter. This is readily obtained by planting the open part of the aviary with elder bushes, which are rarely damaged by the inmates; and if the common, golden, silver and parsley-leaved varieties are judiciously mixed, a very pretty effect will be produced.

Insects and berries are the ordinary food of the Fieldfare, but in hard winters it will eat anything it can find. In confinement, it should be fed as recommended for the Thrush; it is partial to breadcrumbs mixed with an equal quantity of freshly-grated carrot, a dish that is readily partaken of by all the other members of the Thrush family.

As already stated, there is no reliable instance on record of its nesting in a state of captivity, and the few cases in which it is reported to have done so in a wild state in this country, would be all the better for modern confirmation.

The plumage of the Fieldfare is decidedly handsome, and its figure graceful. Morris and other writers praise its song, which the former describes as "soft and melodious," but Bechstein calls it "a mere disagreeable warble"; it may therefore be fairly described as something intermediate between these extremes, or, in other words, as nothing out of the common. The ancient Romans looked upon the Fieldfare as a great delicacy, and the bird was accordingly fattened systematically in large numbers for the table; modern epicures, especially on the Continent, seem to be of the same opinion in this respect, so that out of the myriads of these birds which abandon their arctic homes for our comparatively milder climate every autumn, hundreds only survive to return to their native haunts in the spring, the rest having either succumbed to starvation or been devoured; of the remainder many perish on the return journey, yet the race seems to be in no danger of dying out. 


\section{THE FINCHES.}

The Brambling, Bramble Finch, or Mountain Finch.

This bird is very like the Chaffinch in size, shape and habits, but is a much less conspicuous creature, the prevailing tints of whose plumage are black and brown, variously intermixed and producing a by no means unpleasing result. The female is a trifle smaller than the male, has a less distinct crest, and is paler in colour. It is a migratory species, arriving in winter and departing in

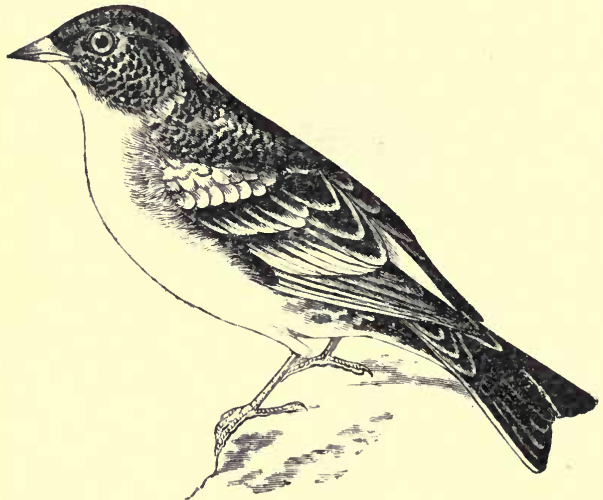

The Brambling or Mountain Finch.

spring, though a few pairs sometimes remain in the north to breed, and in an aviary they will also nest occasionally.

Chaffinches separate during the winter, the males going one way and the females and unmoulted young of both sexes another ; but it is uncertain whether the Brambling acts in the same way or not. The latter bird is fond of beech-mast, and gets very fat upon it. If kept in an aviary it may take what is going, but will also require ants' eggs or insect food in some form or other.

Instances are recorded by different writers where the Brambling has nested in this country, or rather in Scotland, as well as in garden aviaries; but although we have kept a number of them for years, we have never found that any of them evinced the slightest desire to continue the species, while Chaffinches kept under precisely similar circumstances, built and laid freely though, owing to a 
variety of vexatious accidents, they never succeeded in rearing any young.

The writer has also been assured by a gentleman, who is certainly an authority on matters ornithological, that the Brambling and Chaffinch had on one occasion to his knowledge paired, and produced young in an aviary, and that the young birds in question paired among themselves in the following summer, built nests, laid eggs, and actually became parents in their turn! But, while fully recognising the knowledge and the absolute truthfulness of the gentleman in question, the writer cannot but think that a mistake has crept in somewhere, or that the observer's memory is at fault, for if his contention were quite accurate, how is it that the phenomenon has never been repeated?

\section{The Bullfinch.}

When all has been said and done, the Bullfinch is the very nicest of birds, whether you watch him and his sombre but neat-looking mate threading their way, at no great distance from each other, through the leafless boughs of the trees in mid-winter, in search of food, or flitting from spray to spray among the hedgerows when the days are broadening out and warming into spring, or in a cage bowing and calling to the well-beloved one who provides for all his little wants, and whom he rewards for all attentions by the sweetest and most melodious of notes.

There are more brilliantly attired birds on the list of the aviarist, of course, but is there a more harmoniously vested one than he is? Tender rosy-red, jet black, delicate lavender grey, purest white and brilliant metallic blue, are the colours in which he has been dressed by the hand of Mother Nature herself, and difficult it would be to match for simplicity and harmonious blending this combination of opposite hues.

The hen Bullfinch is smaller than her mate, but is fashioned on the same lines, though her colouring is more modest, as becomes her sex (among birds), and she is readily to be distinguished from him at a glance. 
The children take after her, but the young males, even in the nest, have a ruddy tinge upon the breast, and a deeper and more velvety shade of black upon the head.

The natural note of the Bullfinch is not much to boast about, for it is almost as harsh and unmusical as that of the Greenfinch, while his call is long-drawn-out and most melancholy, if unmelodious; but he has the most wonderful imitative faculty and will acquire and pipe an air or the song of another bird, improving upon his original until every ear that hears him is ravished by the harmony he

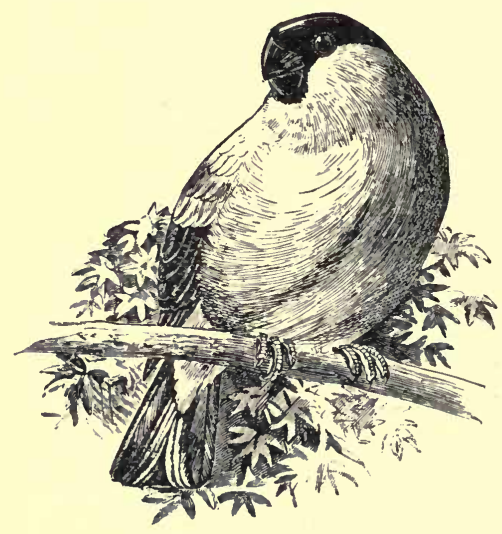

The Bullfinch. pours forth in such delicious floods from his tiny throat, and when it is added that he can imitate the sound of human speech, enough will surely have been said to endear him to every one.

Strange to say, and sad too, the Bullfinch has his enemies; not cats, Hawks and Owls only-that is no more than is to be expected and was arranged for by the Great Father to keep his numbers within bounds-but

rational human beings, or at least beings supposed to be superior to prejudice and malice; yet the amount of the latter that we have seen infused into the heel of a farmer who had just shot one of these charming birds as he trampled the yet palpitating carcase under foot, could scarcely have been surpassed had the poor little bird been the arch enemy of mankind himself.

"Why this rancour, friend?" we asked.

"Why!" was the reply, "the vermin!"-(fancy calling a rosy-breasted Bullfinch vermin!) - "Look at the buds he eats, curse him!" and again the heavy iron-shod heel was 
brought down on the poor mangled remains in a manner that was dreadful to behold.

Foolish agriculturist! do you never prune your trees? Of course you do, and cut away more buds with one sweep of your knife than a Bullfinch would consume in a month. Then look at the economic waste. You don't know, or you would not do it, that one of these little despised birds might, if properly educated, find a purchaser at the fabulous price of $£$ ro. Ten pounds sterling! think of that in these days of agricultural depression! and, in any case, it would be worth Ios. if it only piped a note or two.

A new light? Let us hope so. But how is the Bullinch to be trained?

Take the young ones from the nest (the ruddier breasted if you only want the cocks), and bring them up by hand, which you, friend farmer, or your wife or daughter can quite readily do, on bread and milk and boiled rape-seed, crushed and freed as much as may be from the husk; and while they are being so fed, play or whistle to them the air you wish them to acquire. By the time they are able to feed themselves they will have learned it fairly well, though it will be as well to continue the lessons until after the first moult. -Or, instead of whistling or playing an air to them on the melodeon, flute, or birdorgan, you can talk to the little things and teach them to say "God save the Queen," or "Hip, hip, hurrah for the-" for anybody you like; and you may ask pretty well any sum you like for the little creatures once they are perfect in their task.

Better than shooting them, that, and trampling under heavy heels, eh?

The Bullfinch is the most constant of birds. Talk about Turtledoves! they are not in the same boat with him-he pairs for life, and if he attaches himself to a person when he is kept in captivity, his grief at parting from the loved one is so great that he will often die. Nor is it cupboard love, for he will get fond of even those he sees about, although they may have nothing to do with feeding and attending to him; therefore, if you are intending to sell him, do not make any effort to win his affection, but 
treat all his little advances with indifference or rather coldness, for he quickly responds to any manifestation of regard, though he does not seem to pine for what he has never had.

The nest of the Bullfinch is very often, but not always, built in fruit trees, of roots, the coarser portions of which form the foundation and the finer the lining of the structure. The eggs are usually five in number, of a pale blue colour, thickly spotted with reddish-purple at the larger end. The young are hatched in about fourteen days and if wanted for training must be taken early, before they have had time to hear much of the paternal song, say when the quills of the tail begin to sprout; they should be kept in their own nest as long as possible, fed as already advised, and kept scrupulously clean and dry, or their feet will be deformed.

When they get restless, they may be transferred to a cage, provided with several perches of different size, and well strewn with grit, or dry garden mould. As soon as they can feed themselves, they should have soaked canary seed, boiled rape and a little coarsely-crushed hemp, but too much of the last seed has a tendency to turn the plumage black. Or the little birds can be left with the parents until just ready to fly, when they may be put, nest and all, in a cage that should be hung up near the spot where they were hatched, and the old birds will finish bringing them up; but in this case they will not be such apt pupils (though they may be stronger), as if they had been artificially reared: in the latter case they should be given a mouthful or two (using a small pair of forceps for the purpose) every twelve minutes or so from dawn to dusk.

There are usually two broods in the season, sometimes three, and there are nearly always more cocks in the first nest than in the later ones, which often contain females only; these, however, sometimes pipe very well, and are quite as tame and affectionate as their brothers.

Now and then a pair of tame Bullfinches will breed in a bird-room or aviary, if supplied with something to build in, in the shape of a branch of a tree, and a handful or 
two of dry roots to make their nest with. Mules with the Goldfinch are pretty common, and are the progeny of a male of the latter and a female Bullfinch; a cross with the Canary and other Finches is also to be had occasionally, but in any case the eggs are incubated and the young reared by Canaries.

There is a large variety, it can scarcely be called a species, of the Bullinch that is pretty frequently imported, and is known by the names of Russian, or Siberian Bullfinch. It is not, of course, a British bird, because it is not found wild in this country, and should not, by right, be mentioned here, but seeing the numbers that are brought over and how many people there are who do not know the difference between it and our English birds, it may just be mentioned that it is almost as large again as the latter, and its colours are, as a rule, much more brilliant. It should be fed and treated in every respect like our own Bullfinch, but is even more impatient of artificial heat, which soon weakens and quickly kills it; it should therefore never be kept in a room with a fire, but at the same time it cannot stand a draught any better than any other bird. These large Bullfinches, as a rule, are not such clever performers as the ordinary sort.

\section{The Chaffinch.}

This not being a true Finch, is dealt with under its own heading.

\section{The Citril Finch. See Serin Finch.}

\section{The Goldfinch.}

This Finch runs the Chaffinch very closely for the award for personal beauty and general attractiveness, and were the prize given for song alone would carry it off, without doubt or fear of rivalry. It is a thousand pities that the Goldfinch should be getting so scarce, but it is in great request for the cage, and trappers follow it in season and out of season, with the inevitable result that in many 
localities it is as completely extinct as the Great Auk or the Dodo, a fowl which it is imperative to name in such a connection.

One circumstance that contributes not a little to the increasing scarcity of the Goldfinch is that it is a late breeder, and the young are often taken, indeed nearly always, before they are quite independent of their parents, the consequence being that thousands upon thousands of them die miserably every year from indigestion at a longer or shorter (but never long) interval, after passing from the custody of the dealers, some of whom have written to various papers denying the deplorable mortality: nevertheless, it is unhappily only too certain.

The sexes of the Goldfinch can be distinguished, as a rule, by the darker colour of the small

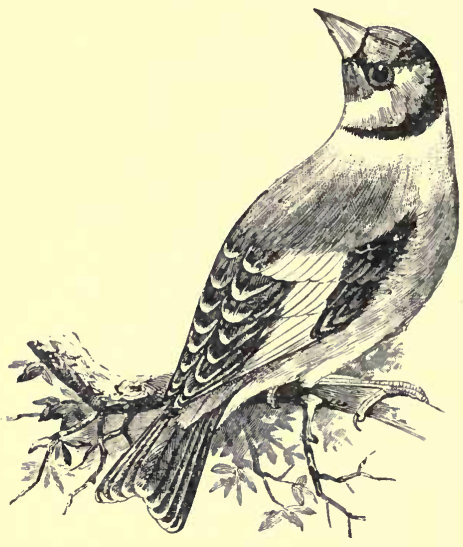

The Goldfinch. wing-coverts, which are browner in the female than in the male; in a full-grown adult of the latter sex they are jet black, but in the females are fringed with brown. In the case of young birds, even when they have put off the immature or nestling "Greypate" attire, the distinction is not so marked, but the cocks are always darker than the hens: the yellow tinge of the breast and the extent and depth of the colour of the "blaze" are often pointed to as differentiating signs of sex, but are not more infallible than that of the shoulder feathers.

The nest of the Goldfinch is often built in an orchard, usually among the terminal twigs of an apple- or cherry- 
tree, and is very neatly and compactly put together: they are suspicious, however, and often begin a number of nests, before finally deciding on a site; but once they have settled down, they are extremely attentive to their domestic duties. They have been bred in cage and aviary with increasing frequency of late, and if their pursuit is carried out as it has been in the past, it is much to be feared that in no other way can the extermination of the race, at least in this country, be prevented, or rather postponed.

The Goldfinch breeds freely in confinement with other birds, the most popular cross being with the Canary, and the next with the Bullfinch: other crosses have been tried, as with the Linnet, Redpoll, Siskin, Greenfinch and Twite; but the reported cross with the Chaffinch and Brambling is either the result of mistaken identity or of pure imagination on the part of the person making the assertion.

In confinement, the Goldfinch does best on a diet consisting for the most part of hemp, on which individuals have been known to survive for as long a period as twenty-four years. The young birds should have canary seed soaked for them, and their hemp should be slightly crushed; they also should have plenty of green food and an unfailing supply of grit, remembering that fine sand is of no use as a substitute, and that the grit is employed in the gizzard in lieu of teeth, for triturating (masticating) the food and so preparing it for assimilation.

Never put a Goldfinch in a round cage, but use a square or an oblong one, and if the bird exhibits a tendency to look up and so make itself giddy, cover it over on top.

A Goldfinch that is well cared for will not ail, but if it is improperly fed, or otherwise ill-treated, it will soon develop a variety of complaints for the most part incurable.

The eggs, four or five in number, are not unlike those of the Canary, but are smaller: the young of the first nest are mostly males, and those of the second, mostly females, In their wild state the favourite food of 
he Goldfinch is thistle-seed, which it seeks far and wide, clinging to the prickly stems of the plants as tenaciously as a Titmouse and extracting the objects of its desire with its long and pointed ivory bill.

At one time the thistle was a dreadful pest in New Zealand (may be so still), and Goldfinches were imported in some numbers for the purpose of keeping it in check. which they are certainly well calculated to do, though, whether they fulfilled the wish of their importers is uncertain; however, they have thriven there and are now spoken of as being very abundant in the "Britain of the Southern Hemisphere." Whence it is quite on the cards that we may in the near future have to import them, if prompt steps are not in the meantime taken to insure their protection over here.

The Goldfinch is a very teachable little bird, but is not endowed with any great capacity for expressing what he learns; he does his best, however, and it is unreasonable to ask or expect more; but, as a musician, he will never rival the Canary, the Bullfinch, or the Nightingale.

Occasionally, these birds are harnessed and trained to draw up miniature buckets out of artificial wells, to open seed-boxes, pretend to be dead, and perform other tricks of the like kind, which are much better done by the Redpoll; however, some folk are fond of these performances, and who are we that we should find fault with them?

\section{The Greenfinch.}

This bird, sometimes called the Green Linnet, is a "common object" in most parts of the country, and the adult male in full plumage a sufficiently handsome one. The form may be a trifle clumsy, and the plumage be somewhat suggestive of boiled spinach and egg, but the dark green and the golden yellow on the wings have their attraction for some eyes, while the harsh rasping note of the bird passes for an agreeable song in certain quarters. Truly there is no accounting for taste, and we are not going to quarrel with anybody about such trivial matters. 
It must be admitted, however, that the female Greenfinch is a dingy-looking little grey thing with a suspicion of green and yellow here and there, while the young are curiously speckled, so that some inexperienced persons have imagined them to be hybrids between the ordinary brown Linnet and the Greenfinch, and the fable that the two species interbreed promiscuously in a state of freedom passes current for truth in certain quarters, where one might naturally have looked for more enlightenment.

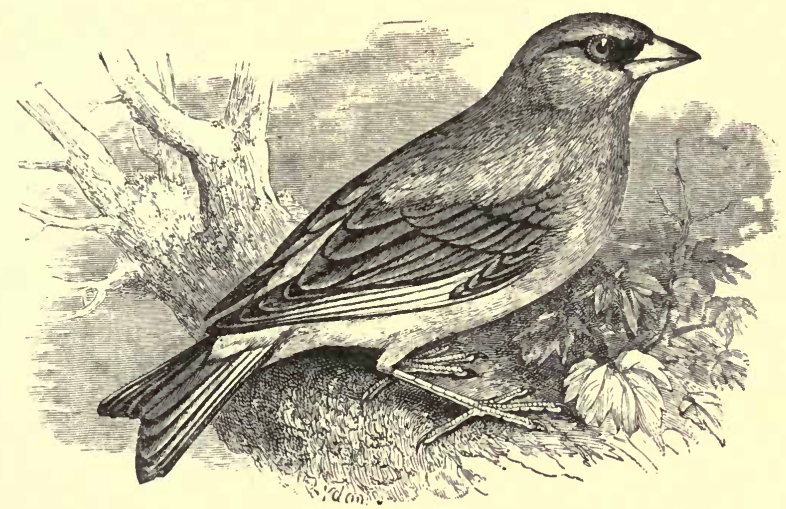

The Greenfinch.

The call-note of this species is singularly loud and clear, and reminds the auditor of that of the Canary; the eggs of the two species are also very much alike, and the notion suggested itself to a well-known ornithologist, a few years ago, that there might be some "common ancestor" connection between them: so the two birds were paired together, and produced a series of mules, for mules the young ones all were and nothing more, and the evolutionary theory, at least as far as the Greenfinch and the Canary were concerned, broke down.

The food of the Greenfinch consists of seeds and buds, and it does a good deal of mischief in gardens and 
orchards that is laid to the account of the Bullfinch and the Sparrow, nor has it the redeeming traits that distinguish those birds, which suffer for misdoings not their own; it never touches an insect, and prefers the seeds of cultivation to those that are produced in a state of nature.

The nest of the Greenfinch is very neatly and compactly built of grass and roots, and is usually well concealed in a thick growth of leaves: as a rule there are two, but sometimes three, broods of four or five each in the season. The eggs, as we have said, bear a general resemblance to those of the Canary, but they are a little larger than those of the latter, which, given comparative freedom in a garden aviary, will build a nest very closely resembling that of the Greenfinch.

The latter bird is not at all backward about nesting in confinement, and will do so in an inverted birch-broom as freely as it will in its native haunts. The young are fed entirely on green food for the first three weeks of their existence, and will scarcely be reared without a sufficient supply of the same, which is, of course, first swallowed by the parents, macerated for a time in the crop, and then regurgitated for the benefit of their offspring, as can readily be verified by watching a pair of tame Greenfinches in an aviary.

In winter these birds are gregarious, and the flocks, often consisting of a hundred or more individuals, keep so closely together, that, with a little patience, they may all be trapped; the birds, with inconceivable fatuity, returning again and again to the nets, attracted no doubt by the cries of their imprisoned companions.

The Greenfinch is an excellent subject for the budding aviarist to try his 'prentice hand on, for it is, as we have said, sufficiently handsome, and also very hardy and accommodating.

The best food for it, in confinement, is hemp and canary seed, to which such green food should be added as happens to be in season, and an abundance of suitable grit: without the assistance of the last-named the bird is apt to fall into a decline, the only disease to which the captive Green Linnet would appear to be liable. 
If a pair are breeding, they should have plenty of green stuff-cabbage, lettuce, groundsel and all manner of garden produce, as without it they will scarcely be able to rear their young. Sometimes the progeny of this bird and a Canary are prettily variegated, and some have been met with that are wholly yellow (a form of albinism probably).

The so-called wild mules are simply females that have been turned adrift by a breeder.

\section{The Pine Grosbeak.}

This bird and the Crossbill may be bracketed together as presenting many points of resemblance: thus, they are both denizens of the far north, irregular in their visits to this country, which they pay during the winter only, and irregular in their manner of life. Their favourite foods are the seeds of the various coniferæ, but failing these they will eat any others they can find. Very rarely indeed have their nests been reported in our islands, and notwithstanding the handsome, almost brilliant colouration of the males, they are not very desirable as inmates of the aviary, from their Parrot-like habit of clinging to the wires, which exposes them to the attacks of marauding cats. They are apt to be quarrelsome, too, and are decidedly impatient of heat. The male Grosbeak is a trifle bigger than the Siberian Bullfinch, and the Crossbill about the same size. There are supposed to be several other varieties of the latter bird besides the one usually seen, but they are of extremely rare occurrence.

One peculiarity common to both the Pine Grosbeak and the Crossbill is that the males lose the beautiful red colour of the breast after moulting in confinement and remain of a dull yellowish brown appearance that is far from attractive. Why they should do so is as impossible of explanation in their case as it is in that of the Linnet and Redpoll. It has been stated that the ruddy tint is a nuptial adornment, and that it is lost in confinement because the reproductive instinct is then in abeyance. A moment's reflection, however, should have told the propounder of the 
above theory,-a noted collector of dried skins and empty egg-shells, but possessing only a very limited knowledge of live birds and their ways, - that his plausible theory was untenable, for the Linnet breeds quite freely in the house, with a mate of his own or of some kindred

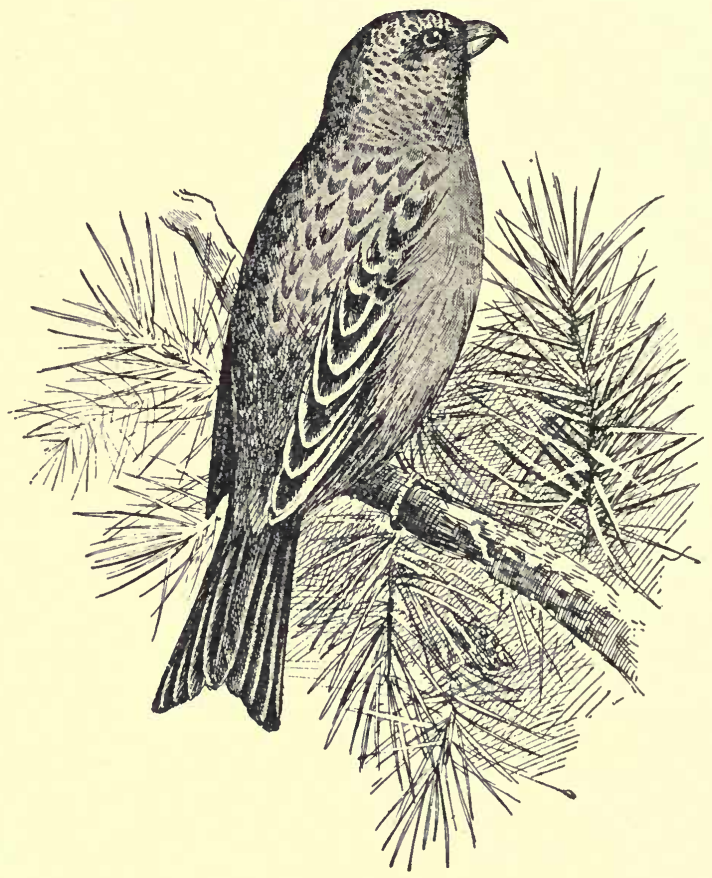

The Pine Grosbeak.

species, but does not, for all that, resume his rosy vest in confinement.

No, the breeding instinct has nothing to do with the phenomenon, though change of food, want of fresh air and exercise and of light may have: but even in a large garden aviary where the bird would be supposed to have 
everything of the kind indicated that he required, he will lose his red when moulting and remain brown to the end of his days.

The Redpoll, however, when placed out of doors will, to a certain extent, regain his full colours, that is, his poll will turn red, but his breast only resumes the merest shade of the becoming colour with which Nature had at first so liberally endowed him. Evidently the cause of the loss of colour in confinement, common to all these birds, and to some foreign species,- - the Pürple Finch of America for example,-is more recondite than any that has yet occurred to the mind of the ornithologist.

\section{The Hawfinch.}

This is a large bird and a handsome one, but Bechstein was of opinion that one must be a great lover of birds indeed to wish to have it in the house. It is 7 inches long, of which $2 \frac{1}{2}$ inches belong to the tail. The beak is very stout and thick, blue in summer, and flesh-coloured with a black tip in winter.

The head, face, shoulders and back, are brown; the throat, black; the nape, blue; the wing-coverts, white; the primaries, steel black; the secondaries, of the same colour, have square ends; the under parts are pale buff, and the tail greyish-white, except at the base, where the feathers are black; the legs and feet are greyish flesh-colour. The female is rather smaller and paler in colour than the male, whom she otherwise resembles.

These birds feed on seeds and berries, and will live for a number of years in the house.

The nest is a compact structure of grass-stems and moss, placed on the branch of a tree, generally in a cleft between two boughs; and the eggs are four or five in number, of a greenish-grey colour, streaked and speckled with brown and bluish-black. The young are easily reared on bread and milk and soaked seed, crushed to free it from the husk, and will then become very tame.

The Hawfinch has not much natural song, but when 
reared from the nest, will learn the notes of other birds to a certain extent, though never as perfectly as a Bullfinch, if better than a Greenfinch. It may also be

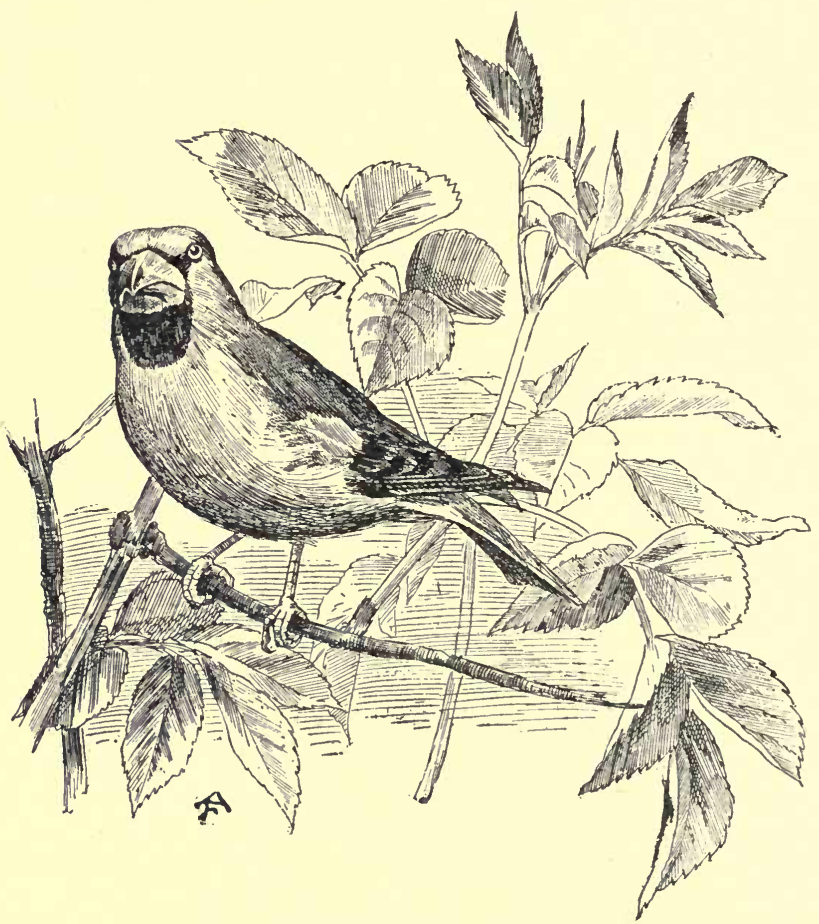

THE HAWFinch.

trained to come and go, and rarely abandons its home and the comforts connected therewith.

It is a winter visitor, but some couples remain to breed during the summer, and more would, no doubt, do so, if they were not so systematically persecuted as they are. 


\section{The Linnets. See under Linnets.}

\section{The Mountain Finch. See Brambling.}

The Pine Grosbeak. See pag. 75.

The Redpolls. See under Linnets.

\section{The Serin Finch.}

This is a rare winter visitor, coming to us now and then in twos and threes from the same quarters as the Siskin, the female of which it greatly resembles, but is more mottled on the breast.

A few are taken every season, but the bird is little known, except to the initiated. It must be fed and treated like the Siskin, and will breed with it, producing a mule that is larger than either of its parents (probably owing to the abundant supply of nourishing food on which it has been reared) and bearing a general likeness to an ordinary green Canary.

The male of this species is very like the female, and except that the latter is a little greyer on the back could scarcely be distinguished from it; but small as the difference is, it has been seized upon by some particularising naturalists to constitute her into a distinct species with the name of Citril Finch.

\section{The Siskin.}

This favourite Finch is, with the exception of the Redpoll, the smallest member of the group, measuring barely $4 \frac{1}{2}$ inches in total length, $I_{\frac{3}{4}}$ inches of which are included in the tail. The general colour of the plumage is green, but the male has the top of the head and the throat black; the rump, breast and under parts are greenish-yellow; the secondaries and wing-coverts are also edged with the same colour. The varieties recorded are the white or buff and black, or a mixture of the above colours. The female has no black on the head or throat.

When wild, this bird frequents the northern parts of Europe, where pine and fir forests abound, and in them it 
breeds, rarely doing so in southern latitudes. In the house it may be kept in any ordinary cage, providing it is large enough to give the bird room to hop about freely. It soon becomes familiar, and may be allowed out in the room: a few grains of hemp, placed on the floor of the cage, will always get it back again, without fuss or trouble.

Its natural food consists of the seeds of the coniferæ, and failing these it will eat those of the thistle and other plants, and in the house may have summer-rape and canary

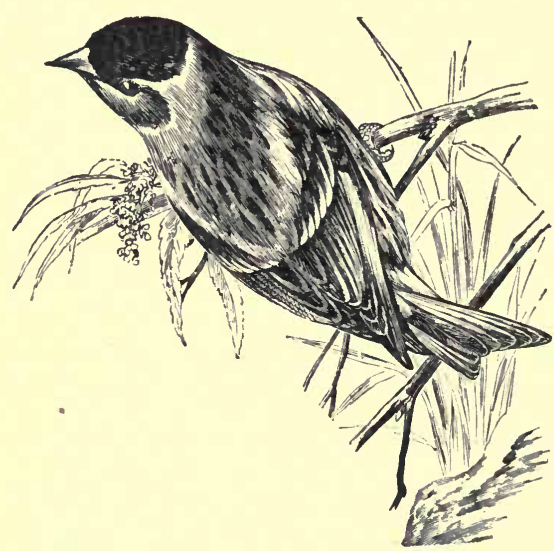

THE Siskin. seed, but not too much hemp, which would fatten it so much that the bird would soon die of apoplexy; inga, otherwise niger, has a similar effect, as also have maw and linseed, none of which should be allowed except in very small quantities now and then for a change.

The nest is often placed among the terminal branches of the trees it frequents, and is

built of roots and small twigs, secured by cobwebs and fibre. The eggs, which are of a light greyish colour, are thickly spotted with purplish-brown; they are usually five in number. There are two broods in the year. In the house, the male will pair and produce mules with a Canary, or other Finch, or he will mate with a female Siskin which, as a rule, is quite ready to nest in a cage, sitting on her own eggs and even occasionally fully rearing her young.

Siskin mules are not remarkable for elegance of form, beauty of colouring or for size; sometimes, when the mother is a Canary, they are mottled, but, as often as 
not, they are the exact counterpart of their father as regards plumage, but approach the mother in the matter of size. They are but poor songsters and not in much request.

Some of the South African Finches are now and then exhibited at bird shows and labelled as mules between the Siskin and some other bird, but no one but an utter novice could be gulled by such a transparent device. And yet the Yellow Thickbilled Finch of the Cape got a prize at a show (nameless) some years ago as a Siskin-Bullfinch mule!

The Siskin is a hardy bird, when treated correctly, and it is surprising what it will endure in the way of illtreatment without succumbing to the effects of the mistaken kindness of its thoughtless guardian. Thus, although a native of the far north, it is often kept in an apartment with a stove temperature, and fed on oily seeds; and yet it is the exception for it to die from a stroke of apoplexy or from fatty degeneration of the liver. It is subject to epilepsy, the venerable Bechstein declares, but that was a pious opinion merely of the Father of Cage-bird Lorenot a necessary consequence of the bird's existence in a cage, but the result of some error in the management. The same authority is correct in stating that it may be kept for eight to twelve years.

Sometimes it is trained like the Redpoll, but it is better not to force its nature and make it perform tricks foreign to its habits.

The great ease with which it is tamed is the chief attraction of the Siskin, and the process is a simple one. Let the owner offer the bird a grain of hemp through the bars of the cage. At first it will be alarmed and possibly flutter about a little; then, finding that no harm is intended, it will rest, and noticing the seed, look at it attentively for a minute or two; then it will approach cautiously and with every symptom of mingled fear and daring snatch the coveted morsel from between the tips of the fingers; but the next time it will take it more readily, and in a few days without any hesitation whatever, calling for the tit-bit as soon as it sees its guardian. Then the door of the cage may be opened, and it will presently fly on to 
the hand that holds the hemp, and then will follow its owner all about the room and even out of doors in pursuit of the dainty it covets, but of which, for the reason already given, it must not have too much.

\section{THE FLUSHER. See Shrike (Red-backed).}

\section{THE FLYCATCHERS.}

The food of all the Flycatchers consists of small insects, and they must do a great deal of good, seeing the enormous numbers of these that they destroy.

There is no song, only a little chirp, but the young ones are noisy in their small way. The nest is frequently resorted to for several years in succession.

\section{The Pied Flycatcher.}

A pretty little bird of common enough occurrence, but owing to its shy and retiring habits not very often seen in this country.

Its unostentatious colouring is simply black and white, the latter on the forehead, breast and other under parts, the greater wing-coverts and secondaries and the outer tail feathers, but on the abdomen the white is tinged with grey; the remainder of the plumage is black.

It is a very active bird, and its tail is in almost perpetual motion. The sexes resemble each other, but the young are spotted and speckled with black on the white, and with white on the black parts.

The nest is made in some convenient hole or crevice of a tree or building; the eggs are white, and seven or even nine in number. The young can be reared on ants' eggs and small insects, but they seldom live long in confinement.

When searching for food, it is very active, moving rapidly about, jerking and fanning its tail and flapping its wings every second or two, according to the manner of its kind. 


\section{The Red-breasted Flycatcher.}

This visits us occasionally and might easily be mistaken for a small Robin, except that it has no red on the head and some white on the tail.

\section{The Spotted Flycatcher.}

This is not unlike a miniature Thrush in shape and colouring, but it has not the manners of the latter bird, or its song.

\section{THE GADWALL. See under Ducks.}

\section{THE GANNET.}

A handsome bird of the size of a small Goose, which some observant writer has declared wears a perpetual smile; it is the head of the Cormorant family, and lives, practically, on a diet composed exclusively of fish, for which no adequate substitute can be provided in captivity. For this reason the fancier who wishes to keep either the Gannet or Common Cormorant should reside within a convenient distance from the sea, or have a tolerably long purse at his disposal: granted, however, one or both of these conditions, he will find a pair of Gannets (pinioned when young) a pleasing and interesting object of study.

When mature the birds are white with a buff tinge on the head, crown and upper part of the neck: the chin and the primaries are dusky black, and the skin round the eyes is bare and of a blue shade; the bill is pale blue, whiter towards the tip. The female does not differ from the male in appearance, but the young are much darker than their parents.

The full adult plumage is not acquired until the fourth year. Morris says one egg only is laid, but as a rule 
there are two, and the young sit on their natal rock for some weeks before they descend to the water, which they generally do not approach until able to fly.

A full grown Gannet (otherwise Solan Goose) weighs between 6 and 7 pounds and measures from $2 \frac{3}{4}$ feet to 3 feet in length.

THE GARGANEY. See under Ducks.

\section{THE GEESE.}

Of these there are several genera and species amiong our native birds. The Grey Lag Goose, the Pinkfooted Goose, the Bean Goose, the Bernacle Goose,

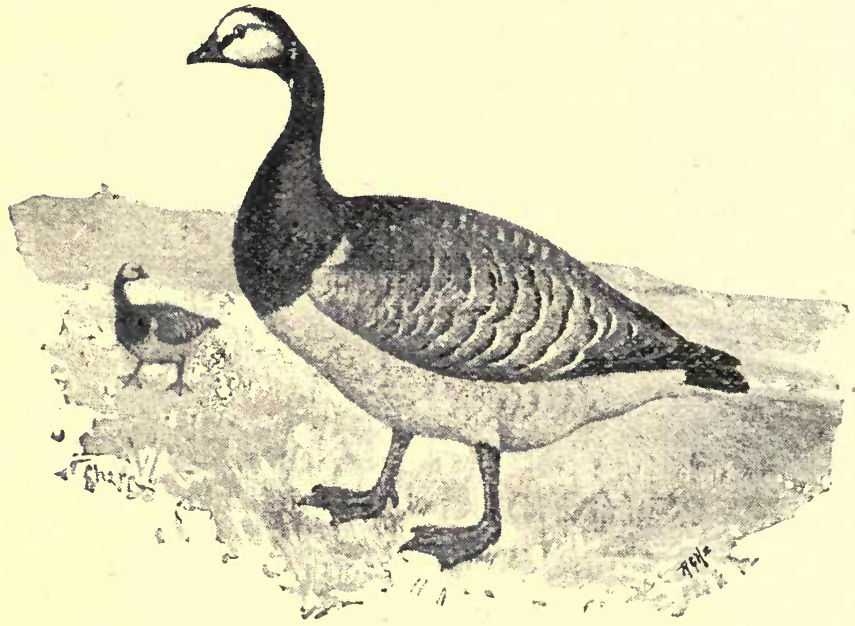

The Bernacle Goose.

and the Brent Goose, have all been kept at the "Zoo" as well as in many private collections, where most of them 


\section{FOR CAGES AND AVIARIES.}

have bred and interbred. There is no difficulty in rearing and keeping them where ample space is available and

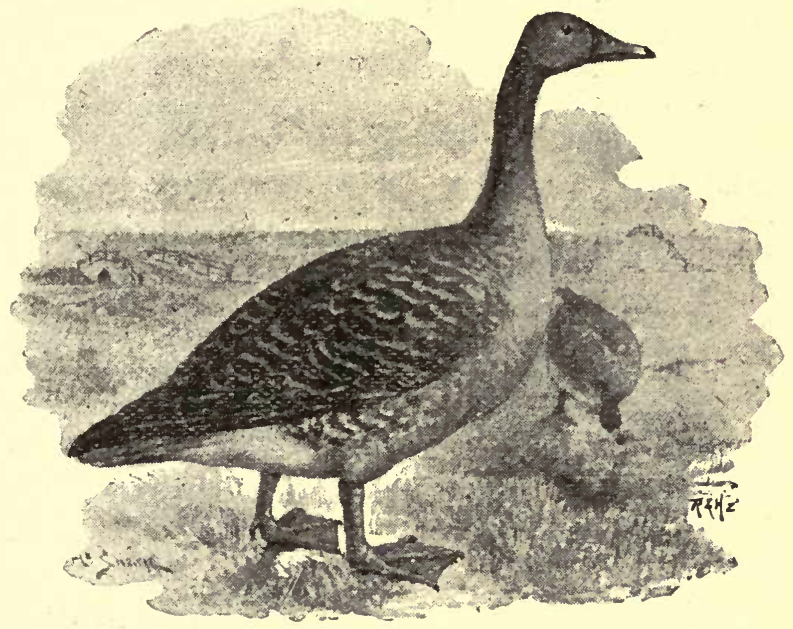

THe Bean Goose.

they can be treated in accordance with their natural habits, which are mainly herbivorous. Unless pinioned, they are apt to fly away at the period of their annual migrations.

THE GLAUCOUS GULL. See under Gulls.

THE GOAT.SUCKER. See Nightjar. 


\section{THE GODWITS.}

\section{The Bar-Tailed Godwit.}

Also called the Red-breasted Snipe, from the bright chestnut red, deepening to orange-brown on the vent, of the whole under surface of the body; the upper parts are brown, spotted with black, except the rump which is white, a bar of a greenish colour across the middle of the wing, and a yellowish-brown tail crossed by four bars of a greyish black colour: the bill is orange with a black tip, and the long legs and toes are greenish grey.

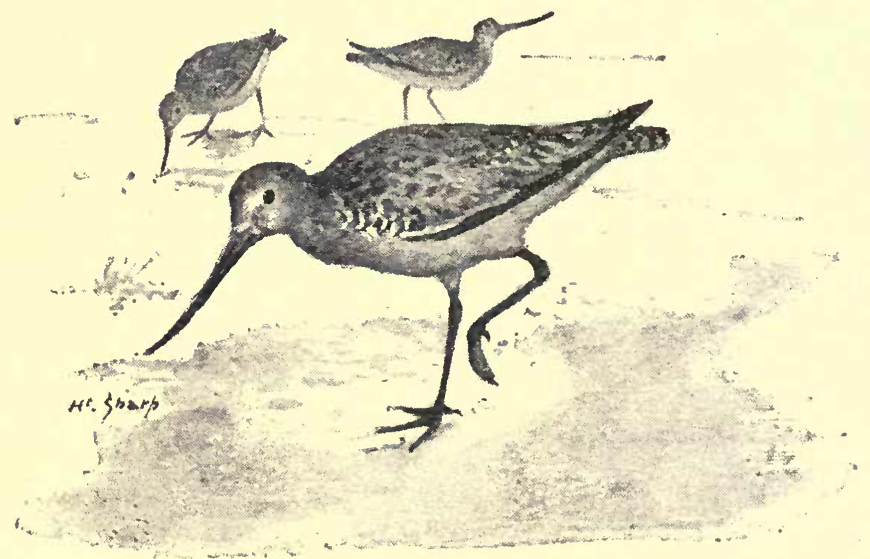

BAR-TAILED GodWits.

The Godwits visit us in winter and breed in the north. They are considered to be very good eating, but have a decidedly fishy taste, as might be expected from their diet: this they extract from the mud at the mouths of rivers which they frequent. They are nearly the size of a Woodcock, the female being, as is usual in this and some allied families, a little bigger than the male. 


$$
\text { FOR CAGES AND AVIARIES. }
$$

\section{The Black-Tailed Godwit.}

Also called the Lesser Godwit, though about the same size as the Bar-tailed Godwit, and the Shrieker. It is generally distributed throughout England, and breeds regularly in several localities; it feeds on insects, worms, etc., is more spotted than the Bar-Tailed Godwit and has a black tail.

The Lesser Godwit. See Black-Tailed Godwit.

THE GOLDEN-CRESTED WREN. See Introduction, page 8 .

THE GOLDEN EAGLE. See Eagle.

THE GOLDEN.EYED DUCK. See under Ducks.

THE GOLDEN PLOVER. See under Plovers.

THE GOLDFINCH. See under Finches.

\section{THE GOOSANDER.}

This is a very widely dispersed species, occurring in Europe, Asia and America; at one time it was very numerous in this country, but it is much less so at the present day. It frequents the coast and the mouths of rivers, swimming 
and diving well. The eggs, elongated in form, are from four to eight in number, of a creamy colour when newly laid.

The male is about 4 pounds in weight, and over 2 feet in length. It is black on the head, throat, back and primaries; grey on the lesser and greater wing-coverts, rump and tail; the rest of the body is pale buff; the bill and iris, dull orange. The female is brown where her mate is black.

GOOSE. See Gannet and Geese.

THE GOSHAWK. See under Hawks.

THE GREAT DOUCKER. See Diver (Great Northern).

THE GREAT NORTHERN DIVER. See under Divers.

THE GREAT PLOVER. See Thick-knee.

THE GREAT SHRIKE. See under Shrikes.

THE GREAT SNIPE. See Snipe (Common). 
THE GREAT TIT. See under Tits.

THE GREATER BLACK-BACKED GULL. See under Gulls.

THE GREATER REDPOLL. See Linnet (Common).

THE GREATER SPOTTED WOODPECKER. See under Woodpeckers.

THE GREATER WHITETHROAT. See under Whitethroats.

\section{THE GREBES.}

\section{The Dabchick, or Little Grebe.}

This is a pretty little creature of rather wide distribution, although not numerous anywhere. Very often it lives in a state of semi-domestication on ornamental waters, and comes to be fed along with the Ducks and other feathered inhabitants of the locality.

It nests near the water, making a considerable erection for its eggs which are 5 or 6 in number, of a dirty white colour; the mother covers them with weeds when she gets off to feed and they soon get very dirty. The young take to the water directly they are freed from the shell. The length of the Dabchick is 9 or 10 inches; as it is stoutly built its weight is more than might be expected, reaching to 6 or 7 or more ounces. The plumage varies according to the season, brown in winter, of a darker shade above than below, and lighter in summer, when the face 
and neck are reddish-brown, the back dark brown, waved with grey, and the under parts grey with lighter markings.

\section{The Red.necked Grebe.}

A rare winter visitor. It is a handsome bird about 18 inches in length and 19 or 20 ounces in weight. It is more a marine than an inland species. The head, which is ornamented with a flattish crest, is black, but the face is bluish grey, the back dark brown with a light edging to each feather, the breast rufous brown, the belly and a patch on the wing white, the beak yellow at the base and black at the end.

The wings are very short, yet the Red-necked Grebe flies well and executes long journeys by sea and land. It is fairly common in Scotland during the winter. The food consists of fish and marine insects which they obtain by diving and swimming under water. The colours of the female are duller than those of the male. The young have the throat a dirty white, and the back is lighter coloured than that of the adult.

THE GREENFINCH. See under Finches.

\section{THE GREEN LINNET. See Greenfinch (under Finches).}

THE GREEN PLOVER. See Plover (Golden).

THE GREEN WOODPECKER. See under Wood. peckers. 
THE GREY HEN. See Grouse (Black).

THE GREY LAG GOOSE. See under Geese.

THE GREY PLOVER. See under Plovers.

THE GREY SHRIKE. See under Shrikes.

THE GREY WAGTAIL. See under Wagtails.

\section{THE GROUSE.}

\section{The Black Grouse.}

This is the largest of our indigenous game birds, and is found in suitable localities in the northern counties of England, but more so in Scotland, though it is doubtful if they could hold their own without the strict "protection" that is awarded to them.

The male is a handsome bird, and the unassuming female is not without a certain quiet charm of her own. His general colour is black; the vent, the tips and centre of the greater wing-coverts, as well as a small spot on the shoulder and a narrow line under the eye, are white, while above the eye is an inverted crescent of a bright colour. The tail is curved outwardly at the extremity in the form of an ancient lyre, the outer feathers being the longest: he weighs about 4 pounds.

The female, known as the Grey Hen, is only about half as heavy as her mate, and is brown and yellowish- 
buff, every feather barred with a dark and a light mark that gives her a mottled, greyish appearance; she also has the white shoulder spot and the red eye streak like her mate. The legs of both sexes are covered in front with hair-like feathers, but the toes are bare.

The species is polygamous, and the females are said not to breed before they are three years old. The eggs are six to eight or nine in number, yellowish-white spotted with brown. Black Grouse incubate for 21 days.

\section{The Red Grouse.}

This bird has the distinction of occurring in Great Britain only, and there mainly in the northern Kingdom, attempts to introduce it elsewhere having practically been a failure. It is found on moors and heaths, but also on lower ground if there is any heather there, upon the tops of which it principally feeds. It is too well known to need description. It has occasionally bred in confinement. The eggs vary from eight to twelve in number, and are very different in appearance, even in the same batch, but the most usual colour is greyish-white thickly marked with black and brown spots. In point of size and weight these birds are somewhat variable, some weighing as much as 30 ounces, while others only scale 19 ounces. The Red Grouse pairs probably for life, and both parents attend to the young: these are able to run soon after being hatched, at which time they feed principally on insects.

\section{THE GUILLEMOT.}

This is one of the commonest of our seaside birds, and exists in great numbers in many suitable localities. They only lay one egg, and those of individual birds are very variable in appearance, some being green, others light brown, and others cream colour, spotted with black and brown; they are extraordinarily large for the size of the bird, and are round at one end and very tapering at the 
other: this causes them to resist the action of the wind, which merely turns them round and round without blowing them from the slight depressions where they have been laid. The general colour of the Guillemot is dull black above and snowy white on the under surface, with a broad white curved line across the wing. The bill is dark grey.

\section{THE GULLS.}

There is no difficulty in keeping these birds in confinement, pinioned (which must be done before the bones of the wings have become ossified) and running about either in a garden or an enclosure in a garden, or they may be kept in an aviary of large size furnished with a pond and suitable rocks of artificial construction, in which case they will appear to much greater advantage than in a place of smaller dimensions, or with their natural movements hampered.

The Gullery, however, must not be overcrowded, and it will be as well not to trust the smaller with the larger species, for these birds are pugnacious and tyrannical and the weaker would be sure to suffer. The enciosure must be of considerable size if it is to contain many birds, for owing to their food and the large quantity of it they consume, the copious white excretions would speedily make it objectionable to sight and smell: therefore the hose must be freely used, and the pond must have a cemented bottom so that it may be readily emptied and cleansed from time to time.

Many of the Gulls will breed in confinement and hybrids are not unfrequently produced between different but allied species; however these are only noticeable as curiosities for they are barren and the cross cannot be perpetuated, as it can when occurring between varieties of the same species.

In the matter of feeding the Gulls are accommodating, all being fish that comes to their net. 
The Black-backed Gulls. See Greater and Lesser Black·backed Gulls.

\section{The Black-Headed Gull and the Laughing Gull.}

These birds are so very much alike that many naturalists consider them to be one and the same, but Morris differentiates them; one or two, it is one of the "common objects" of the sea-shore, and an occasional one on

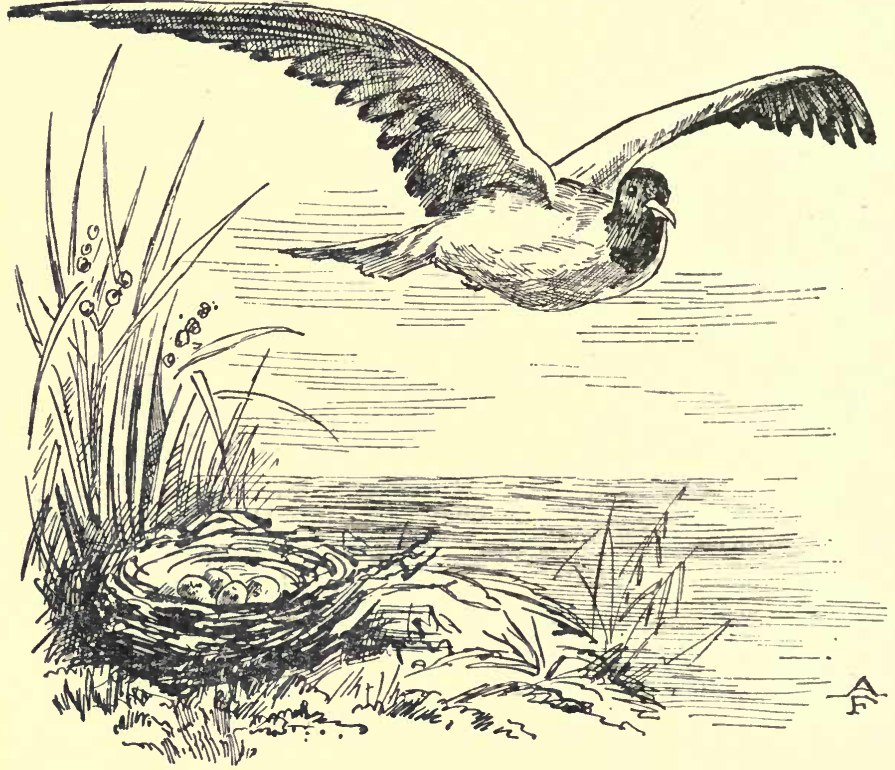

The Biack-headed Gull.

inland lakes and ponds. It has bred in confinement, but only comes to see us of its own accord during the winter. It is a small species, under a foot in length and about Io or I 2 ounces in weight. It is sometimes called the Hooded Mew, on account of its black head; the second- 
aries are black with white tips and the rest of the plumage is grey, much darker on the upper than the lower surface, which is nearly white.

The young, two or three in number, are said to betake themselves to the water as soon as hatched, which, if correct, is contrary to the usual habit of the family.

\section{The Brown Gull. See Skua.}

\section{The Common Gull.}

Also known as the Sea-mew. In spite of its name it is not of such frequent occurrence as some of the other

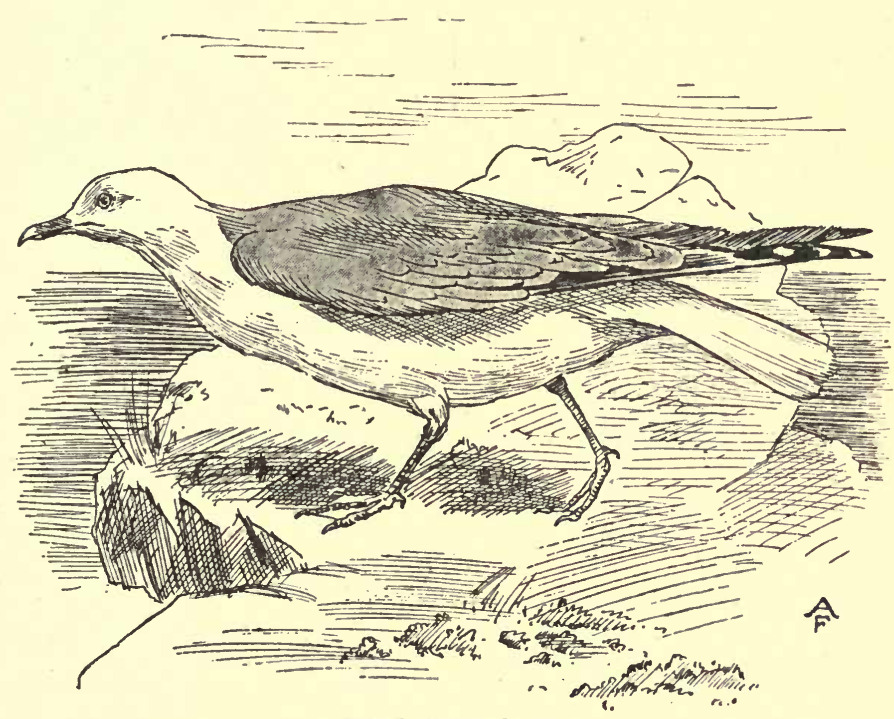

The Common Gull.

species of Gulls, partly on account of the persecution it receives at the hands of gunners who shoot for the 
pleasure of destroying life: it is a small bird, weighing about a pound and from 15 to 18 inches in length, the width of the outspread wings being about three feet. The nest is placed on the turf or on a rock, and in the latter situation consists of a large amount of grass and seaweed. The bird is grey above and white below with black primaries, the bill is grey with a yellow tip, and the legs and feet are grey slate. The young are spotted with grey and black.

\section{The Glaucous Gull.}

Not unlike the Kittiwake but much larger, weighing between 3 and 4 pounds. It is light bluish-grey on the upper and white on the lower surface of the body, but whereas the primaries of the Kittiwake are black with white tips, those of the Glaucous Gull are pure white.

The eggs are deposited on the ground among stones, as well as on ledges of rocks above high water mark, and incubation lasts four weeks.

The young are a pale fawn or buff tinged with grey, and the points of their folded wings barely reach to the end of the tail, while in the adult they rather project beyond.

They are not nearly of as common occurrence here as other species, only appearing during very severe weather which has driven them south from their natural habitat on the shores of the Polar seas.

\section{The Greater Black·backed Gull.}

A very fine bird that breeds abundantly on the Scottish islands and in other places in the north of Scotland, but it is much less frequent in England. Except in regard to size it exactly resembles the Lesser Black-backed Gull, but it measures rather more than $2 \frac{1}{2}$ feet, with a wing expanse of over 5 feet, and weighs about 5 pounds. The female is somewhat less than the male. The young are mottled with greyish brown, and have light coloured legs and feet. 


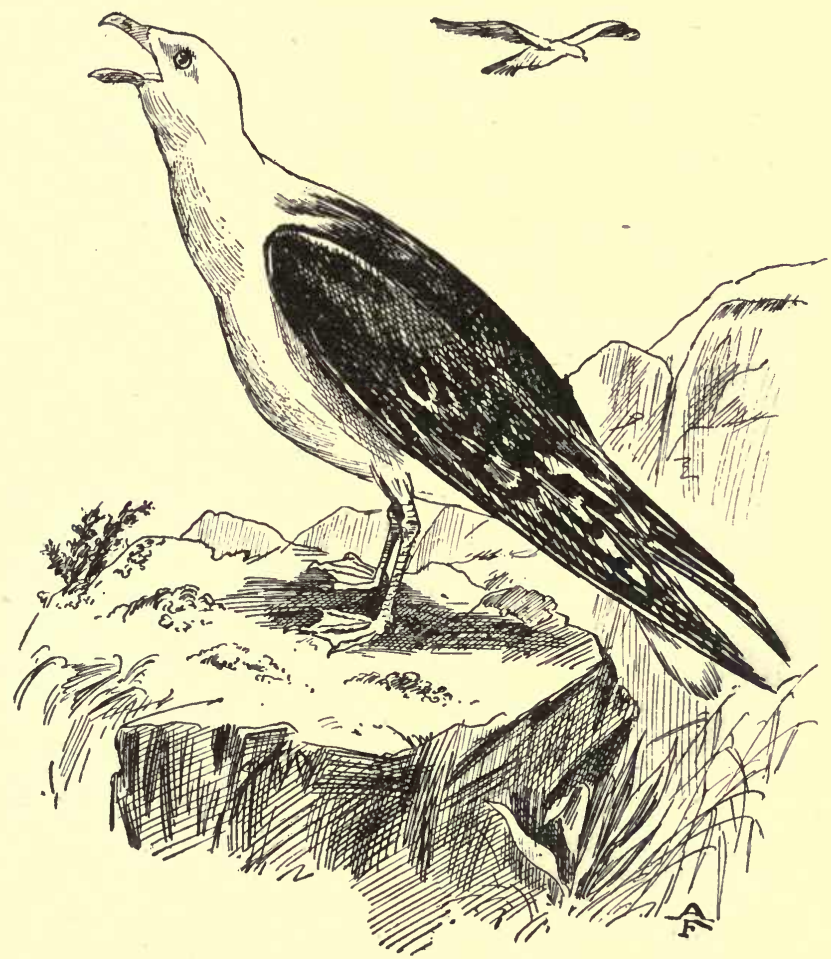

The Greater Black-BaCked Gull.

\section{The Herring Gull.}

One of the commonest of the British representatives of its family. It breeds abundantly in the north of England, Ireland and Scotland, on cliffs, numbers of them congregating together for the purpose of rearing their young. The eggs are two or three in number, of a light greenish-brown spotted with darker brown of several shades. The length of this bird is about 2 feet, and its weight from 
30 ounces to 3 pounds. The upper parts are bluish-grey, except the primaries, which are black with white tips, and the lower surface is white with a greyish tinge towards the vent. The legs and feet are grey, and the bill is pale yellow.

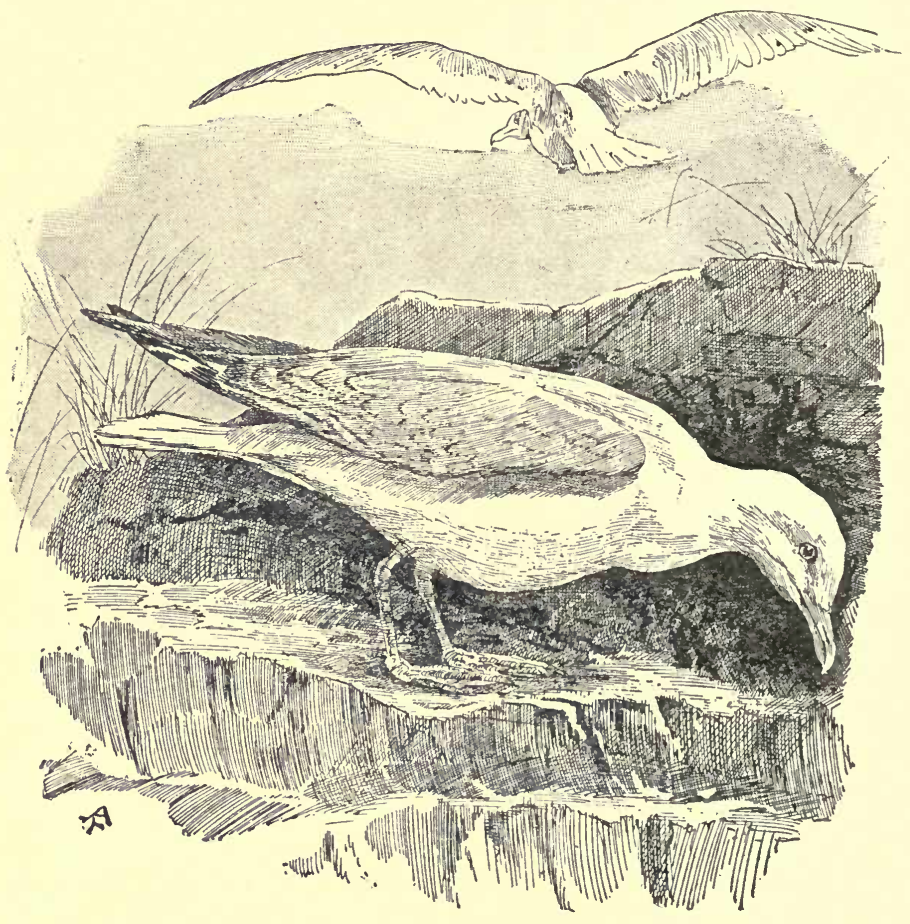

HerRing Gulls.

Like the other Gulls this species is susceptible of being tamed, and may often be seen following the plough with the Rooks. The young are mottled with brown and do not reach maturity for two years. 


\section{The Kittiwake.}

So called from the fancied resemblance of its cry to those syllables. It occurs in considerable numbers in Scotland and the north of England, but has been much persecuted by cockney sportsmen.

Many instances are on record of the Kittiwake becoming voluntarily semi-domesticated, going and returning from

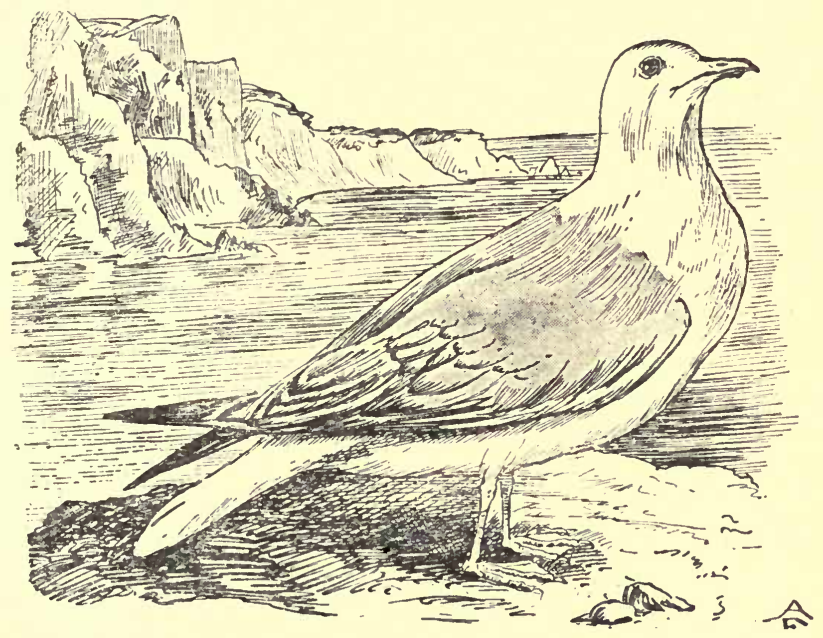

The KitTiWaKe.

its retreat at its own free will, in one case for a period of more than twenty-seven years! It nests in May or June and lays two eggs, those in different nests varying greatly in colour and markings. The length of the Kittiwake is a little over I foot, and its general colour is slate grey on the back and white on the under parts of the body.

The Laughing Gull. See Black·headed Gull. 


\section{The Lesser Black-backed Gull.}

This Gull is found on the west coasts of England and Scotland and is of much less frequent occurrence in the south and east, although occasionally seen there in the winter. It is about the same size as the Black-headed Gull.

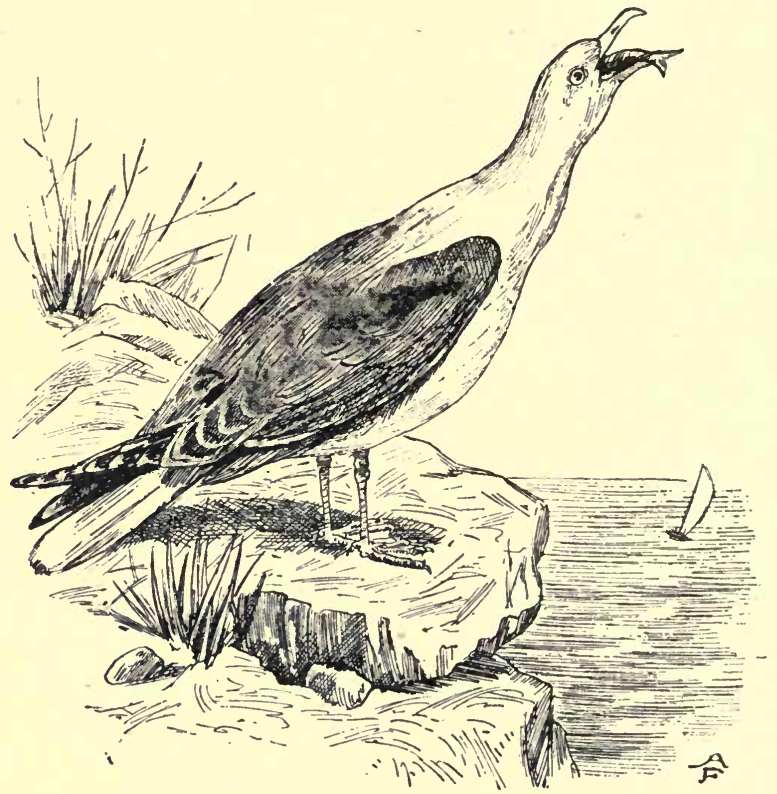

The Lesser Black-Backed Gull.

The nest is placed in all kinds of places and contains, as a rule, three eggs, which vary a good deal in appearance: they are usually laid in June. Wings dark slate-grey with white tips to primaries and secondaries, the rest of the body pale greyish white, beak and legs yellow. 


\section{THE WHITE.HEADED HARPY. See Harrier (Marsh).}

\section{THE HARRIERS.}

\section{The Hen.Harrier.}

The male Hen-Harrier (which reads somewhat like a contradiction in terms) is by no means "a common object" in this country, and does not appear ever to have been of frequent occurrence, at least of late years; it is one of our smaller Hawks, measuring something over 18 inches, and weighing about a pound (the female is decidedly larger). His general colour is bluish-grey, darker on the upper than on the lower surface; the feathers of the neck have a dark edging, and those of the tail, except the central pair, are crossed by fine narrow bands of a blackish-grey. The head is grey, and the cere yellow; the legs and feet are yellowish-grey, darker behind than in front. The female is much browner, especially on the back, and she is less spotted than her partner; even in the nest the distinctions of size and colour are apparent, the females being always darker and bigger than the males.

The nest, placed near or even on the ground under furze or other dense cover, is composed of sticks, grass, and other similar material; it is loose!y put together, and displays little architectural skill on the part of the builder. The eggs are four or five in number, and are of a light greenish-blue ground colour sparsely spotted with yellowish brown, but they vary a great deal in appearance. Bewick described some as of a reddish ground colour with white spots.

This species flies low, but strongly, and is said to be destructive to young game, furred and feathered, for which reason it has incurred the enmity of the gamekeepers and their masters, and is rarely met with now-a-days in a stạte of freedom in England, 


\section{The Marsh Harrier.}

This bird is also called Moor Buzzard, Puttock, Duck Hawk, and White-headed Harpy, which last was surely a stretch of imagination on the part of the inventor, for the bird has a light fawn-coloured head thickly marked with narrow black lines; the back is dark brown; the tail and wing-coverts, light lavender blue; the breast, grey-white; the abdomen and thigh feathers, dark fawn, marked with black lines. But the birds vary considerably in appearance. The Marsh Harrier is rather larger than the Hen-Harrier, weighing about 2 I ounces and measuring from 19 to $2 \mathrm{I}$ inches in length. The female is considerably larger than her mate, from which she does not greatly differ in appearance. The young until after the first moult are brown, and have the cere, which is yellow in the adult, of a greenish colour.

The nest is usually placed among reeds or bulrushes at the margin of a pond or lake, but occasionally among furze, or on the branches of a tree overhanging the water. The eggs are four or five in number, and are white as a rule, though sometimes they present a bluish tinge.

The food of the Marsh Harrier consists of small animals and birds, whether captured alive or found dead, eggs, fish and even large insects. It is said to attack Gulls and other sea-birds on their return to their nests from their fishing haunts, and to force them to disgorge their prey, which it catches adroitly before the latter reaches the ground.

\section{Monțagu's Harrier.}

This is a conspicuously handsome Hawk, of lamentably rare occurrence now, and readily distinguishable from the Marsh Harrier by a narrow white gorget that reaches nearly to the back of the neck. The bill is dark bluish-grey, but the cere is yellow, as are also the long shanks and the feet. The general colour is slate-blue, with dark centres to the feathers, but the flights are brown, and the belly and vent greyish-white with reddish-brown marks; the outer tail feathers are white with broad fawn-coloured spots, and the central pairs blue with very narrow dark edgings. The iris is yellow, 
Montagu's Harrier is one of the smallest of our British Hawks, measuring only 17 or 18 inches in length and weighing under a pound. The female is altogether the larger of the two. The nest is placed on the ground amid furze or other cover, and contains four or five white eggs with a blue shade and occasionally brown spots.

The food of this species consists of small birds, their young and eggs, of reptiles, and insects, among the last grasshoppers and large beetles.

\section{THE HAWFINCH. See under Finches.}

\section{THE HAWKS.}

\section{The Buzzard.}

This Hawk is still sufficiently abundant in many parts of the United Kingdom, though from some localities it has been entirely banished by the vigilant guardians of game-preserves, where it certainly commits some havoc. It is thought to be migratory, at least in part, but as it has been met with at all seasons, it is more likely that it merely wanders about the country in search of food, without entirely quitting it for any other land across the sea.

It is one of the easiest to tame and train of all the Hawks, and is frequently taken captive for that purpose and used in the partially revived "sport" of Hawking, into the mysteries and technicalities of which we will not enter.

The rabbit is the natural prey of this bird, and it is probable that had our relations at the Antipodes introduced it instead of going to considerable trouble aud expense to import such uncanny brutes as stoats and weasels, it would have rendered better service than the latter and been open to far less objection in many ways.

The Buzzard pairs early in March, and builds on trees as well as on ledges of rock and among precipitous cliffs; it will also reproduce its species freely in captivity, and a 
solitary female will even hatch and carefully bring up young ducks and chicken.

\section{The Duck Hawk. See Harrier (Marsh).}

\section{The Peregrine Falcon.}

This is a bold and handsome bird, as courageous as docile, and as fearless as beautiful. It was formerly in much request and used to be trained to attack Bustards (now, alas I extinct in Britain), "Herons and Bitterns," and other large birds, and a well-taught "cast" or pair fetched a high price.

The habitat of this species is a very wide one, including America, Asia and Africa, "from Greenland's icy mountains to India's coral strand" and all intervening places, which, considering the great endurance of the bird and its wonderful capacity for flight, no less than its extreme hardihood, is not to be wondered at. It is now rare in Britain, and will probably soon be extinct, for it is a poacher and offends against the sacred game-laws.

The Peregrine feeds principally upon other birds, attacking, killing and bearing off in its talons some as large as itself, or even larger; but it also preys on small quadrupeds, having been known to master even a hedgehog in spite of that animal's formidable panoply of spines. Cats have occasionally been attacked, and sometimes have turned the tables on the aggressor, while others have succumbed to the Peregrine's ferocious and determined assault.

It pairs in the spring, the female as usual being the larger of the two. The nest is built on a ledge of rock in an inaccessible position, and is resorted to year after year, by a new couple of tenants if the old ones have been destroyed; or if one of the pair is killed the survivor promptly finds a partner, and the process of incubation, or of feeding the young, goes on as before. The eggs are generally four in number, of globular form, light red in colour dotted over with patches of a darker shade. Incubation last for about three weeks, and both parents take part in nourishing and defending the young. 


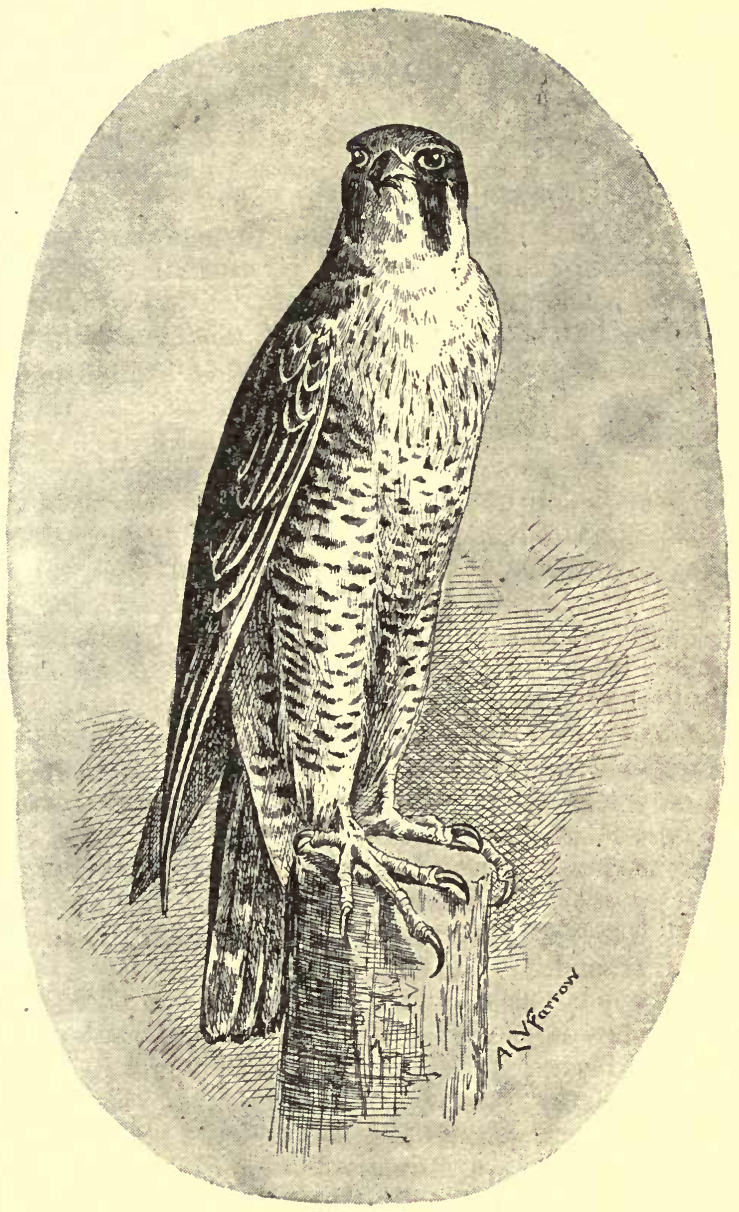

THE PEREGRINTE FALCON, 
The male measures about 20 inches in length, and the female as much as 25 or 26 inches, and her weight is proportionately greater than that of her mate, who weighs about two pounds.

The upper surface is brown with a black centre to each feather, and the under parts whitish-grey on the neck, brownish on the breast and belly with crescentic dark brown markings, and blue-grey on the vent and under surface of the tail, which is crossed by a number of narrow black bars; the tips of the tail feathers are white. The bill is slate colour and the cere yellow; the legs and feet are yellowish-grey; and the talons, horn-colour.

\section{The Goshawk.}

The thick head of the Goshawk gives it somewhat of an owlish appearance, which is belied by its audacity and courage. The female is much bigger than the male, but in this instance, at all events, "the best goods are made into the smallest parcels," for he far excels her in prowess, and at one time was valued, notwithstanding his comparatively limited powers of flight, for flying at ground game such as hares and rabbits, as well as at pheasants and partridges, which indeed form the bird's natural prey, and it will only take them if alive, utterly disdaining carrion.

The nest is made of sticks, and is placed close to the trunk of fir and other tall trees. The eggs vary from two to five in number, the average being three; they are bluishwhite with a few reddish-yellow spots upon them, especially at the larger end.

All the upper parts of the Goshawk are dark brown, and the under parts grey with a bluish tint, especially on the sides and vent, thickly dotted with arrow-headed spots of a blackish-grey colour. The cere, the iris, the legs, and strong feet are yellow; the bill and the powerful talons are horn grey. It is a strongly built bird about I 8 or 20 inches in length, but the female measures two or three inches more.

Macgillivray, after comparing Continental and American Goshawks with some obtained in Britain, found that there 
was no practical difference between them, whether in the adult or immature state.

Morris thought that the name Goshawk, variously rendered Goss-hawk, or Gose-hawk, was a corruption of Goose-hawk, so named from the robust shape and size of the bird.

\section{The Harriers. See under Harriers.}

\section{The Hobby.}

This bird is described as "a spirited and daring Hawk" by Morris, but in confinement, at any rate, is very quiet and inoffensive, permitting itself to be bullied to any extent by an impudent Magpie and even by a Jay, but possibly in that case the-bird's spirit may have been broken and it may have acquired a timidity that is foreign to its nature.

As a British species the Hobby is pretty well extinct, which is to be regretted, for it is not only a handsome but an eminently useful bird, as it feeds largely on the large beetles and moths, the larvæ of which are so destructive to growing timber. It also preys on small birds and quadrupeds, and on frogs and other reptiles.

The Hobby is a wood-loving species, and makes its nest of sticks among the topmost boughs of tall trees, very often selecting the abandoned abode of some other bird, or, failing that, driving away the rightful owners. The eggs, usually deposited in June, vary from two to four in number; they are white, sometimes with a blue tinge, and are spotted with yellowish-brown.

The Hobby has a general air of resemblance to the Peregrine, but its breast is streaked instead of being barred; it is also of more slender build and has larger wings. A white curved streak surmounts the eye, below which is a black mark, divided at its lower end into a fork. The legs and feet are very dusky yellow, and the iris is about the same colour, the under surface of the wings being light grey.

It is very easily domesticated, and will live on the offal procurable from a poulterer, with an occasional change in the shape of a mouse or a Sparrow. Mealworms, too, are favourite morsels, nor will it even disdain the humble blackbeetle, 


\section{The Kestrel.}

This is one of the least of our native Hawks, and a very pretty and interesting bird. It is often named the Windhover, from its habit of soaring in a motionless way in the teeth of the wind; in some places it is known as the Stonegall, and in others as the Stannel Hawk.

The male is I 3 inches long, or thereabouts, and the female a little more. The colouring of both sexes is rich chestnut-brown above and grey to white below, streaked and spotted regularly with black. The tail is

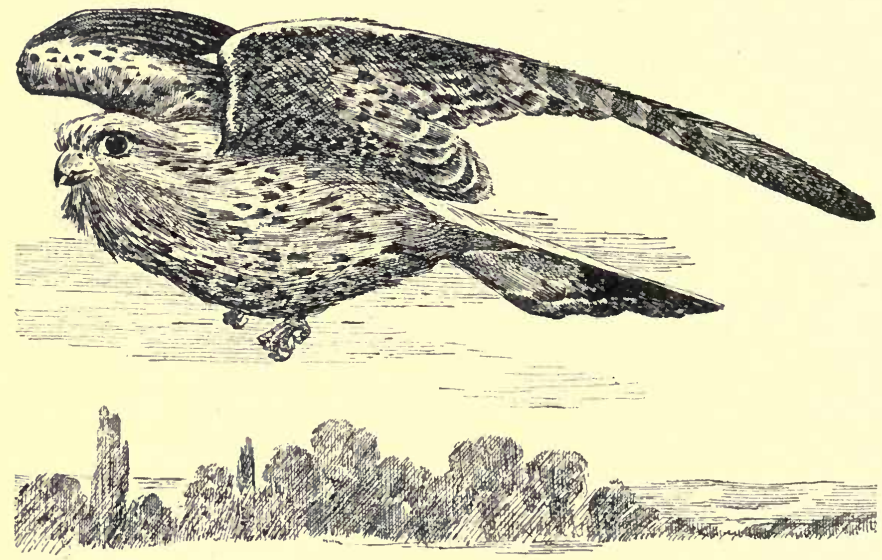

THE Kestrel.

lead-colour with white tips, above which is a broad band of black. The primaries are dark greyish-brown with round black spots on the inner webs. The feet are yellowish-grey.

It is very easily tamed and will breed in confinement, nesting on the ground under some slight cover In its wild state, the nest is often found near the sea shore, but sometimes it is placed in a tree, or in a hole in a bank, or on a ruined building or wall; in fact, in any place where the bird fancies it will be safe. 
The eggs, which are four or five in number, vary a good deal; one before the author as he writes, is very like that of the Merlin, but is slightly larger and has larger spots not so closely placed together as in the case of the latter.

The Kestrel feeds principally on large insects, but it will also catch and kill small birds and mice.

If not well supplied with food these birds will soon attack each other in confinement, and the vanquished will be incontinently devoured by the victor.

Like all the Hawks and other birds of prey, even the Nightingale, the Kestrel ejects the indigestible portions of its food in little masses of an oblong form technically known as "pellets."

\section{The Kite.}

This bird is the head of the Milvine Family and the last of the Hawks, properly so called. Its name is synonymous with that of thief, robber, bandit and coward, though why it should have been so degraded is not very clear, for in disposition and prowess it does not differ in any material respect from its congeners.

It is a powerful bird on the wing, measuring 5 feet from tip to tip of the outstretched pinions, and yet it only weighs a little over a couple of pounds; the female, however, is larger.

The Kite may be distinguished from the other Hawks by its forked tail. In colour it is reddish-brown, darker on the upper than the under surface, and the top of the head has a bluish tinge. It builds its nest in trees, and lays three or four round eggs of a bluish-white ground colour, spotted somewhat sparsely with yellowish-brown, and in some cases not at all.

The food is much the same as that of the other Hawks, but it also hunts for and eats earthworms, and will not disdain to make a meal of any dead carcase it may come across, for which reason in the old hawking times it was considered "ignoble," and on the principle "give a dog a bad name and hang him," it came to be connected with everything that was reprehensible and vile. 
Practically, the Kite is extinct in this country, where there is but very slender chance of its ever being domesticated again, for when one visits these inhospitable shores during the annual migration it is immediately "potted."

\section{The Merlin.}

A bird which is pretty well universally dispersed, and occurs in this country for the most part as an occasional winter visitor. It feeds almost entirely on birds, and will kill those that are double its own size as quickly as it will the smaller ones.

In length the male Merlin measures about 12 inches and it weighs 5 or 6 ounces, while the female turns the scale at 9 ounces and is 13 or 14 inches long.

It is dark grey above, and reddish-fawn on the under surface with dark streaks on the breast, belly and thighs; the tail is dark blue-grey, with black tips and three bands or bars of black across it.

The nest is made on the ground, as a rule, under some slight cover, and consists merely of a shallow depression in the soil, into which a few straws or heather sprays are scratched. The eggs are three or four in number, but sometimes only two; they are very round in form, of a reddish-brown, thickly marked with many small and a few larger spots of a darker shade of the same colour.

\section{The Peregrine Falcon. See page 104.}

\section{The Sparrow.Hawk.}

This bird furnishes a notable proof of the mischievous consequences of interfering to destroy the balance of nature, for he too has been pretty well exterminated from our midst, and the Sparrows have multiplied in many places to such an extent as to have become a veritable nuisance.

The Sparrow-Hawk is pretty and bold-looking, with an upright carriage and fearless, dauntless expression that commends it at once to notice, notwithstanding its small size and slender form; the male only weighing 5 or 6 ounces, and the female about 9 ounces; she measures 
I 5 inches in length, and he only I I or 12 inches. In appearance, too, they are different, the female being brown and lacking to a great extent the "bloom" that adds so much to the attractiveness of the male.

The nest is built in high trees, and advantage is often taken of the deserted abode of a Carrion Crow or a Magpie; the same place is resorted to season after season, the necessary repairs being made before the eggs are laid. These are bluish-white in colour and are much marked with reddishbrown.

The young at first are covered with grey down, and the young females are easily differentiated by their, superior size, which is almost invariably the case with all kinds of birds of prey.

Although such deadly enemies to all small

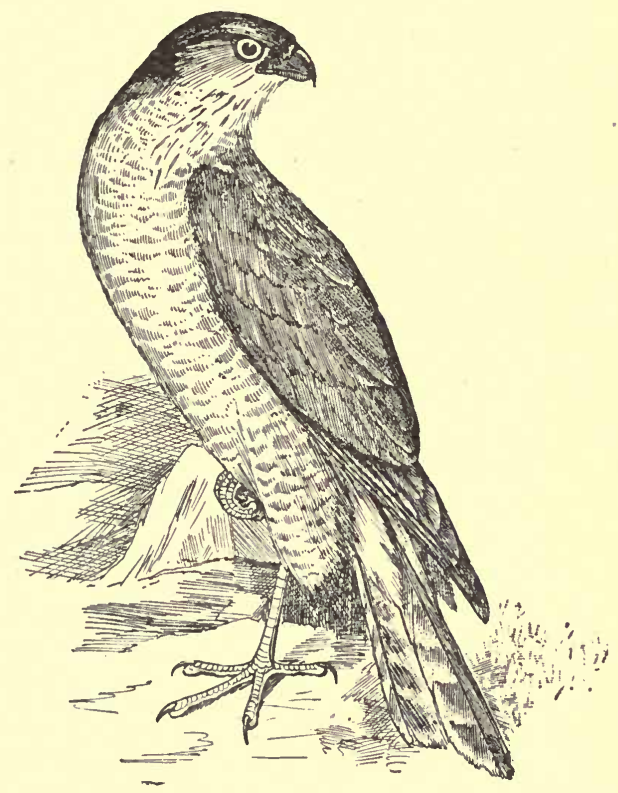

The Sparrow-Hawk.

birds, the latter sometimes combine to chase and heckle one of them; and although at other times active enough on the wing, the Sparrow-Hawk on such occasions contents himself with gliding aimlessly about for a time, and then darts swiftly away in a straight line, soon distancing his small but numerous and most persistent tormentors. 
In addition to little birds, which form its usual and favourite diet, the Sparrow-Hawk will eat mice, beetles and grasshoppers; and occasionally in captivity, if food runs short, they will attack, kill and devour one another, the male, in such cases, usually succumbing to the assault of the female.

This species has bred in confinement, but requires a full supply of its natural food, for which butcher's meat and even the offal from the poulterer's shop form no adequate substitute.

It is rather a shy bird, especially when feeding, and usually retires to some secluded spot in order to devour at leisure the produce of its chase.

\section{The Stannel Hawk. See Kestrel.}

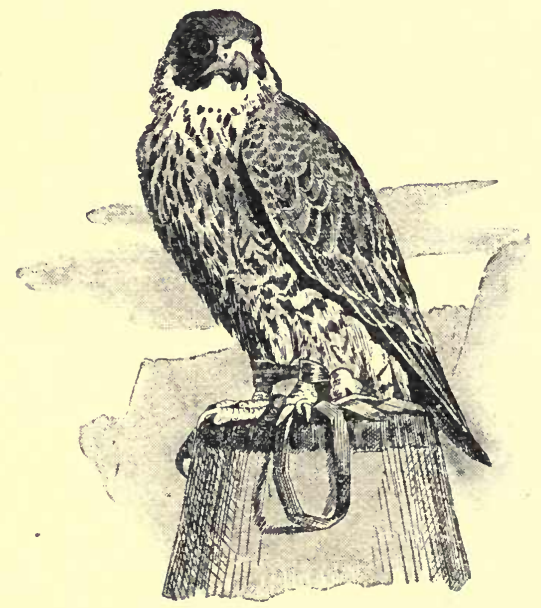

The TIERCEL.

\section{The Tiercel, Tircelet, or Tassel.}

'This is the male Falcon, which is much smaller, weaker, and less daring than the female; it was therefore not so much in request as the latter for purposes of sport. 


\section{THE HEDGE ACCENTOR. See Hedge Sparrow.}

\section{THE HEDGE SPARROW, OR DUNNOCK.}

This bird, commonly but erroneously named Hedge Sparrow, is really the Hedge Accentor. It is soft-billed and has no connection whatever with our familiar friend the House Sparrow, except that it is a permanent resident in Britain. Its length is $5 \frac{1}{4}$ inches, $2 \frac{1}{4}$ inches of which are occupied by the tail. Its general colour is brown, and as every feather on the upper surface of the body has a dark centre, the back and wings have a mottled appearance; the throat and breast are slate grey, but the belly is lighter.

The female is altogether lighter in her colouring as well as somewhat smaller than her mate.

Few people care to keep a bird that has neither beauty of plumage nor agreeable song to recommend it, but notwithstanding these drawbacks Accentors make desirable inmates of the aviary, where they nest and lay freely, if they do not always rear their young.

Bechstein says that the female may be paired with the Redbreast, and that such unions usually succeed very well: if he meant as regards the production of hybrids, that is extremely doubtful.

The nest is strongly and compactly built of moss, lined with hair, and is usually well concealed in a low bush, box and privet being often selected. The eggs are four or five in number, and are of the richest turquoise-blue imaginable. The young can be easily reared on bread and milk and ants' eggs, but individuals taken when full grown quickly reconcile themselves to the loss of their freedom and become very tame.

Bechstein makes the startling announcement that the Accentor is subject to a complaint resembling small-pox, but this, like the Robin hybrids, is more than doubtful; they are, however, liable to a kind of leprosy or skin disease, that begins at the root of the bill and extends over the whole of the head and neck, where the feathers fall out and are replaced by an unsightly scaly scurf, that 
is apparently without effect on the general health. It is certainly not worth while attempting to cure the patient, and any bird so affected had better be chloroformed at once.

When wild this species lives on insects and seeds of all kinds, and in confinement is very partial to crushed hemp, from which it picks out the kernel, leaving the shell; but it will swallow, and appears to digest, the same seed whole.

The song is a trifling warble, but is continued throughout the year, and sounds pleasant enough when that of more pretentious musicians is stilled. The bird is very easily kept, and though somewhat sombre in appearance has a neat figure, and is extremely peaceable in the aviary.

\section{THE HEN.HARRIER. See under Harriers.}

\section{THE HERON.}

Of late years the Heron has become very scarce in Britain. It stands at the head of a numerous series of genera and species, and being a fine upstanding bird, of graceful carriage and handsome plumage, offers too ready a mark for the "sportsman" on murderous thoughts intent.

The wings expand to the width of 5 feet. The general colour is bluish-grey above and whiter underneath. The head is distinguished by a crest of long black feathers with a backward inclination; and brown feathers, which are long and narrow, form a kind of ruff or frill on the breast; the long legs and the feet are of a greenish colour, and the tail and quills of the wings are blackish slate, or almost black in old specimens.

A Heron does not attain its full adult plumage until it is two years old. The female resembles the male, but she is of a rather duller colour. The young have neither crest, nor frill, and are greyer than their parents.

These birds, like the Rooks, nest in companies on the tops of the highest trees they can find, and the nests themselves, which are made of sticks, are of considerable size and visible from a long distance. 
The food of the Heron consists of fish, frogs and molluscs, both aquatic and terrestrial. One of these birds has been known to empty an aquarium stocked with Goldfish, and almost paid for his larceny with his liberty, for the gardener almost caught him before he could fly away, which he could only do after running with flapping wings for a distance of several yards.

When kept in confinement the Heron is usually pinioned, but this should only be done when the birds are quite young and the bone is rather gristle than hardened into true osseous tissue.

\section{THE HERRING GULL See under Gulls.}

\section{THE HOBBY. See under Hawks.}

\section{THE HOODED CROW. See Crow (Carrion).}

\section{THE HOODED MEW. See Gull (Black-headed).}

\section{THE HOOPOE AND THE ROLLER.}

These are two very rare summer visitors from Asia and Northern Africa that would, doubtless, be much oftener seen were it not for the deplorable habit that prevails of shooting every one of them that makes its appearance in our midst, though very often after the murder has been perpetrated the carcass of the victim is thrown away, the shooter recoiling from the expense incidental to its preservation. The Hoopoe is so well depicted in the illustration that a full verbal description becomes unnecessary, and it will be sufficient to say that the prevailing colours of the plumage are fawn and black.

The Roller is not, properly speaking, a British bird at 
all, notwithstanding the fact that Morris and some other writers so count him in consequence of his occasional occurrence in our midst; but be that as it may, he can

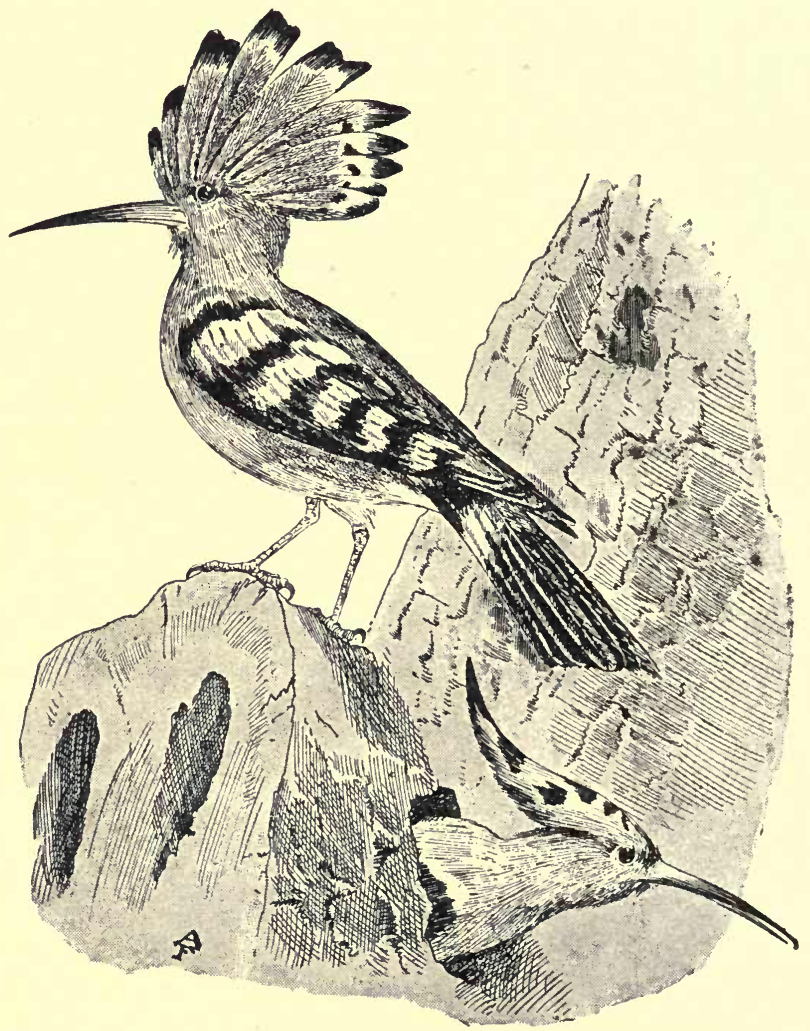

HOOPOES.

scarcely be kept in an ordinary cage for more than a few weeks, or, at most, months.

But he can be kept, and very successfully, too, if he is properly attended to and cared for, remembering that he 
is a native of much warmer climes than ours and that his diet is wholly insectivorous; therefore to keep him, or try to preserve him, at a low temperature on artificial food consisting for the greater part of vegetable matters which he is quite unable to digest, is to condemn him to a speedy but no less painful death, which, we hope, no amateur will in future attempt to do.

The Roller is about 13 inches in length, of slender build, and richly clad in a plumage glittering with metallic tints that fairly dazzle the eye in the sunshine. The top of the head is of that shade of green known as verditer; the neck, breast, belly, and some of the tail feathers are greenish-blue, and a band of the same colour crosses the middle of each wing; the shoulders, the rump, and the primaries are purple; the back and the secondaries and their coverts, rich chestnut-brown; the central pair of tail feathers are dark green, the three next light green, and the outer pair white with black tips; the bill and the feet and legs are orange-brown.

Its beautiful plumage forms the chief attraction of the Roller, for its voice is harsh and it is particularly clamorous, resembling the Jay in this respect, "only more so;" it has no pretension to song.

The female resembles the male so closely that it is almost impossible to tell the difference between them, but perhaps the metallic gloss of her plumage is slightly less brilliant than his; the young are much duHler in colour than their parents and their legs are pale yellow instead of brown.

One drawback to keeping the bird is its quarrelsome habits, for like the Robins it is impatient of other society, except during the breeding season, out of which time the male and female will fight as bitterly as will a couple of males or a couple of females, and both unite in persecuting the young as soon as the latter are able to cater for themselves; and yet, singular to relate, they are partial to building in company.

More adapted for the air than the ground, the Roller is a swift and strong flyer, but progresses awkwardly on the floor, consequently he should be placed in a large aviary, furnished, but not too thickly or so as to impede his flight, 
with boughs, which should always, where practicable, take the place of the abominable regulation straight perch.

The food, which should consist of beetles, cockroaches, mealworms, etc., must not be thrown on the ground, but placed in little cups among the branches, where the birds will take it readily enough, but will starve sooner than descend and pick it off the floor: ants' eggs and wasp-grubs are specially valuable in this case, and beetles, etc., should be killed by dropping into boiling water before being placed at the disposal of the Roller.

As the species is indigenous to the northern parts of Africa and the Mediterranean islands, especially Malta, where it occurs in considerable numbers, it must not be exposed to a lower temperature than 6o degrees Fahr., or it will get congestion of the liver and speedily die.

\section{THE RED.LEGGED HORSEMAN. See Red- shank.}

THE IMBER. See Diver (Great Northern).

\section{THE JACKDAW.}

This bird may be called the Bantam of the Crow family, for he is only I 2 or 13 inches in length. The feathers on his head are of a greyish colour, and he has the power of raising them into a kind of crest. The Jackdaw frequents towns, and often builds his nest on public buildings in company with the semi-wild Pigeons that frequent such places, and to which he is an unfriendly neighbour, for he often robs them of their young. He is not such a good linguist as the Raven, though he is more gifted in that respect than the Rook or the Crow, but he is as mischievous as any of them, and if allowed about at liberty, with or without clipped wings, care should be taken that nothing of glittering appearance be left in his way, for, if it is not too big, he will assuredly carry it off and hide it, and might thus, 
unconsciously, be the means of getting someone into trouble. As everybody knows who has read Cowper, the Jackdaw also frequents church towers, and breeds there as well as among ruins, but he rarely builds a nest in trees, though instances are on record of his having taken possession of the deserted abode of a Rook or of a Carrion Crow.

There is a very stupid notion abroad in some quarters, though happily, one hears much less of it than was the case a few years ago, that the Raven, Crow, Jackdaw, and Starling, as well as the Jay and Magpie, and some other birds, must have the tongue slit in order that they may learn to repeat human speech. It is as astonishing how such an idea can have first arisen, as it is that it should have survived so long. If you ask the person who puts the question: "Why?" you will get no answer, or at least be told that the querist has heard so, or that it is usually done, or some other equally inconsequent

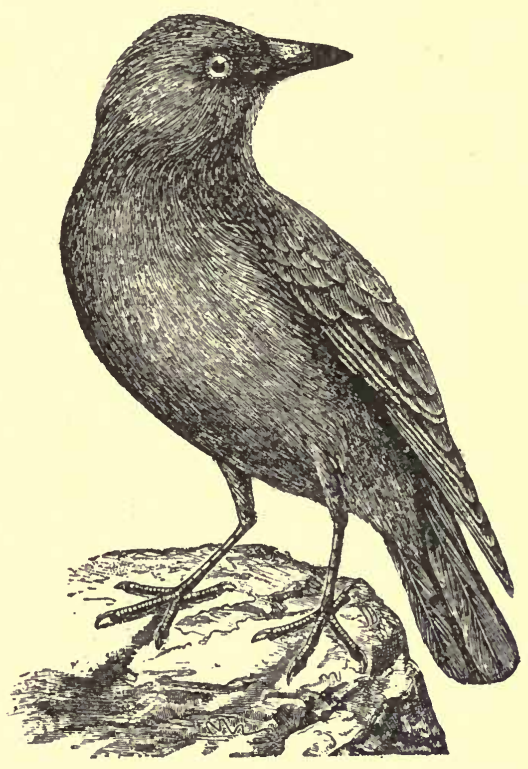

THE JACKDAW. "reason"; but it is a mistake altogether. In the first place, it is horribly cruel to mutilate an unfortunate bird in such a manner, for the tongue is the most sensitive organ it possesses after the eye, and is used not only as one of taste, but as a tactile instrument of extreme sensitiveness and delicacy, and when it is injured, the bird may fairly be said to be deprived of one of the greatest pleasures of its existence. 
Then, again, to cut the tongue actually decreases, instead of increasing, the bird's vocal powers, and the person who cuts it in order to make it talk more freely, positively lessens, if he does not entirely put a stop to, the chance that the bird will ever learn to speak at all. Fortunately, as we have said, the senseless and most cruel practice is dying out, and we hope ere long that it will be utterly forgotten, or only mentioned with a sense of shame and shrinking equal to that with which we hear of the old custom of roasting living Geese in order to improve the flavour, or of pounding Swallows alive in a mortar for the sake of imparting some mysterious vital property to the oil that was obtained from the birds.

\section{THE JACK SNIPE. See Snipe (Common).}

\section{THE JAY.}

If anything, this bird is handsomer than the Magpie; his long silky feathers, crest, sub-ruddy breast and blue wing-patches giving him an air of aristocratic charm that is very attractive; but, even more than the Magpie, he has incurred the displeasure of the "sportsman," and is yearly becoming of rarer and rarer occurrence in our woods and copses, which not long since he adorned by his presence; and the reason is, he disturbs the game by his vociferations and gives them a chance to escape the gun of their would-be destroyer, for the Jay is the sentinel of the woods, and no marauding foe, be it weasel, fox, or "shooter," can escape his vigilance or the expression of his hate.

The female Jay is known by the grey colour of the upper part of the neck, which is vinous red in the male; she also has a less conspicuous crest than he has, and is, perhaps, a trifle smaller: she is also a poor hand at talking, but will become as tame and tricky as her mate.

The Jay is popularly credited with subsisting wholly, or in part, on acorns, and it may be that in time of dearth he will satisfy his hunger on the "fruit" beloved of pigs 
and, it is said, of our Ancient British predecessors; but when more succulent diet is to be had, the Jay turns to it, and devours raspberries, currants, strawberries and other summer fruits, nor does he neglect grapes and peaches or nectarines where he can find them, which is seldom in this land of ours. Of cherries he is fond, and the cherrygrowers have exterminated him from the county of Kent as the sportsmen have in other places, so that before long he will certainly cease to be a British bird; but the average gardener and farmer know no medium, and until the last of

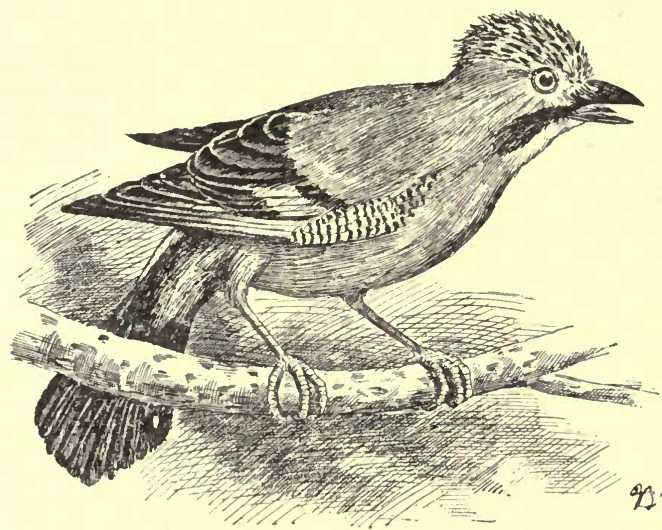

The JAY.

their reputed enemies (but real friends) has bitten the dust, their thirst for vengeance will not be satisfied.

The Jay breeds just when the May-bugs are about, and destroys millions of them; but what does the horticulturist care? He sees the poor Jay taking a few cherries for dessert, and shuts his eyes to the substantial meal of cockchafers which the bird had just previously enjoyed.

The nest of the Jay is placed among thick foliage, and would be difficult to find did not the over anxiety of the parents discover it. The young are easily reared and make delightful pets if fed and treated as advised for the young 
of the Magpie. They require a very roomy cage, on account of the delicate texture of their feathers, which are frayed and destroyed by the slightest friction.

The writer is acquainted with a case in which a pair of tame Jays nested successfully in an aviary (see Frontispiece, from a photograph by Mr. W. Bush, F.C.S.); and that such naturally shy birds should have done so under such circumstances says much for their owner's management and treatment, while it also confirms the contention that every kind of bird can be perfectly tamed by man, and will be as happy (if not happier) in his custody, as in the enjoyment (?) of full liberty out of doors. It is in a great measure a matter of habit, or of use, but there can be no question that a full consciousness of security and peace must add to the happiness of any living creature, more than compensating for the loss of minor privileges, especially when the latter have never been personally known, as in the case of hand-reared birds which have never had the unrestricted freedom that belongs to others in their wild or natural condition. But such trifles as these are entirely overlooked by the benevolent but mistaken people who in the tamest and most confiding of cage birds can see nothing but poor, suffering "winged prisoners."

\section{THE JUDCOCK. See Snipe (Common).}

\section{THE KESTREL. See under Hawks.}

\section{THE KINGFISHER.}

Though not adapted to cage-life, the Kingfisher will live and do well in a garden aviary some 20 feet or so in length through which a little stream can be made to flow; if this expands into a shallow pool at one end of the enclosure, so much the better, and if it is stocked with fish (minnows, etc.) and water-insects, and has a bank on one side, a pair of Kingfishers will do very well in it, and 
need but little attention beyond keeping up their supply of food; but no more than one pair should be kept in the same place, and they will do better without other birdy company. In times of scarcity of fish, a little raw meat cut up small may be tried, and the birds will take to it in default of more suitable diet. As the excrement of the Kingfisher is very copious and white, it will be necessary to have frequent recourse to a garden hose to keep the place in presentable order.

'The female is duller in colour and a little smaller than the male, otherwise the sexes are very much alike. The eggs, five to seven in number, are white, and are laid in a hole, often three feet deep, in a bank; there is no nest properly so called, for the fish-bones found in the burrows of these birds are merely the "pellets" or "castings" that are brought up by every bird of prey, be it terrestrial or aquatic in its habits.

Give the Kingfisher such a habitation as we have just described, and

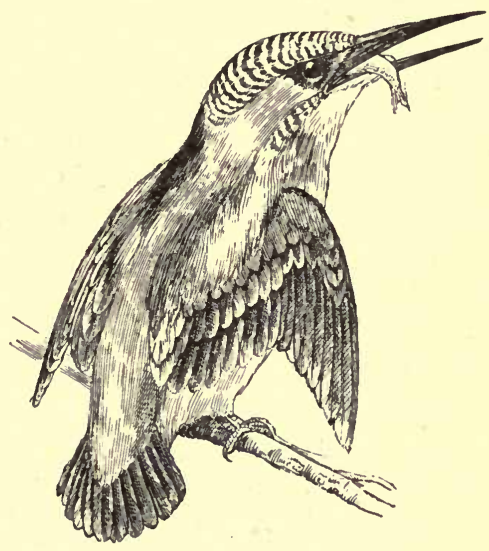

ThE Kingfisher.

he will take a mate and rear a brood, and live happily; but confine him in a small cage where he has no room to fly about and dry himself when he comes out of the water, and he will be miserable and die of inflammation of the lungs, the result of a chill caught from sitting in his "wet clothes," or he will fall into a decline and succumb to consumption brought on by a succession of such chills and colds.

Under such circumstances it is cruelty to keep him, or attempt to keep him rather; but where his habits are understood and catered for, it is not, and may soon be 
the only way to preserve him from extermination in our island, where taxidermists and their minions are ever on the look-out for his beautiful skin.

The young can be reared without much difficulty on fish.

In Scotland the name Kingfisher is applied to the Dipper (which see).

THE KITE. See under Hawks.

THE KITTIWAKE. See under Gulls.

\section{THE KNOT.}

One of our winter visitors, and a handsomer one than the Dunlin, its general colour being bright chestnut-brown,
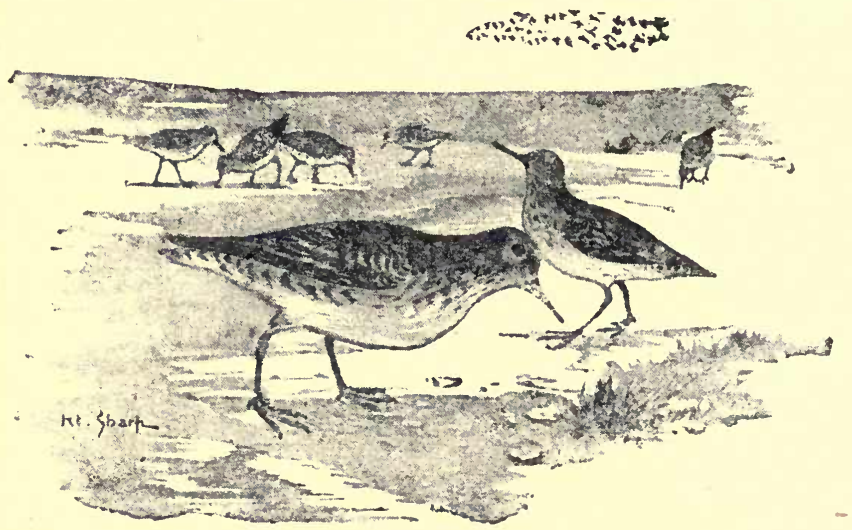

KN()T.

spotted with black and white on the upper surface, but plain on the lower. 
THE LAND.LARK. See Plover (Ringed).

THE LANDRAIL. See under Rails.

THE LAPWING. See under Plovers.

\section{THE LARKS.}

The Calandra Lark.

A very rare visitor to this country, this bird is longer than the Skylark, from which it is distinguished by a dark, almost black, collar round the neck. It should be treated like the Skylark. It is a southern bird and its song is much admired in Italy, where it is of common occurrence.

The Land-Lark, or Sea-Lark. See Plover (Ringed).

\section{The Shore Lark.}

This is an American species that very rarely visits us, via Northern Europe, where it is met with more frequently than in this country. It is intermediate in size between the Skylark and Woodlark. The throat is yellow and there is a black horseshoe-shaped mark on the breast. It is partly arboreal in its habits, and requires to be treated like the other members of the family to which it belongs, as its natural diet consists partly of insects and partly of vegetable matters.

\section{The Skylark.}

This is such a well-known bird (especially during the winter-time in Leadenhall and other markets) that it seems almost superfluous to describe it, but as in at least one instance it has been confounded by a so-called authority 
with the Wood Lark, it may not be quite out of place to say that it is 7 inches in length, of which the tail takes up 3 inches. It has a long, thin bill, that is incapable of shelling seed, which it swallows whole when it partakes of any; but the diet of the Lark in its wild state consists for the most part of insects and the tender blades of growing grass and various sprouting plants.

The female is distinguished by her smaller size, lightercoloured plumage, less conspicuous crest, and more particularly by the absence of the white line round the

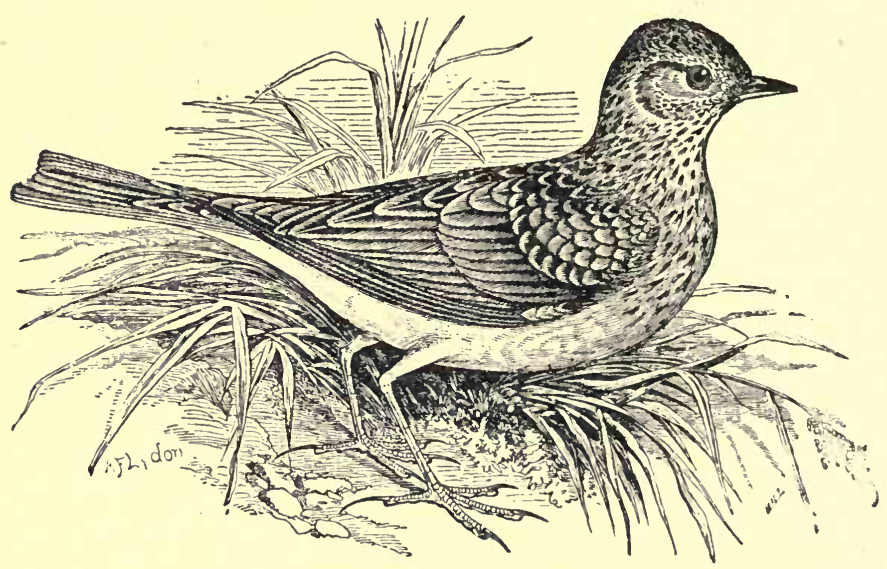

THE SKYLARK.

cheeks; the black spots on the head and breast are more numerous, too, in her case than in that of the male.

These birds do not perch, though they may sometimes be seen sitting on a broad rail, or a gate-post, or even on the flat top of a well-clipped quickset hedge, but their toes have no power to clasp a perch, and the hind one with its extremely long nail (technically "spur") is very inflexible.

The nest is made of grass-stems on the ground among growing grass and corn, so that many of them are destroyed every year by the mowing-machines. The eggs 
are four or five in number, of a whitish-grey colour, spotted and streaked with darker grey; incubation lasts about a fortnight, and the young are easily reared by hand on bread and milk and ants' eggs. When able to feed themselves the same diet may be continued and a little oatmeal be added, together with six or eight mealworms or cockroaches daily, and once or twice a week a little raw beef scraped. Some fanciers recommend egg, but unless perfectly fresh, new-laid in fact, this is apt to induce diarrhœea.

A Lark's cage should be about 2 feet 6 inches or 3 feet long by 2 feet wide and about $I_{5}$ inches high; if higher, the bird would be apt to rise and bump its head, for which reason the top is often made of canvas tightly stretched; but this requires seeing to now and then, as such a construction affords harbour for insect pests.

The Lark does not bathe, but rolls itself in dust, which it should always have an opportunity of doing in the house, and if lice or other insects are suspected to infest the bird, a handful of flowers of sulphur should be mixed in the dust-bath, and that will keep the Lark healthy and clean.

The best green food for one of these birds is a sod of grass, and if this is kept moist by sprinkling it with water every day, the Lark will drink the drops and not require any other moisture, for in its wild state it does not resort to stream or pond for drinking purposes, but slakes its thirst with pearly drops of dew.

A pair of Larks will sometimes breed in a garden aviary, but in such a situation they are apt to hurt themselves by dashing their heads against the roof if suddenly alarmed, say by a cat or passing Crow or Pigeon, and it is well to keep the primaries of one wing clipped; this does not spoil their appearance and keeps them from injuring themselves. The use of the ordinary Lark-cage ought to be made penal.

It is curious that a bird, the rank flesh of which a cat will not usually eat, but which, when pressed by hunger, she forces herself to swallow-to be violently sick a few minutes afterwards-should be esteemed a delicacy for the tables of epicures; but so it is, and the extermination of the species is, in consequence of the depraved taste for 
it, within measurable distance, as may readily be understood when we read that 78,000 were despatched in one month from a single county to Leadenhall Market!

In connection with the foregoing sad fact, it was significant to notice that there were but four entries in the class for Larks at the last Exhibition of Canaries and Cage-birds, held at the Crystal Palace, and a reporter was justified in asking:

"What has become of the Larks? Only four I Have all the rest been eaten?"

Let us hope public opinion will be stirred to move in the matter, and send to Coventry the fashionable devourers of the only bird that "sings at Heaven's gate": the aviarists are guiltless in the matter, for their demands on the species are but as a drop to the ocean in comparison with the demands of the customers of the Leadenhall poultrymen.

\section{The Woodlark.}

About one-third smaller than the Skylark, to which it bears considerable resemblance; but it has a less conspicuous crest, and the hind toe and nail are much shorter, so that it is able to perch, though, as a rule, it prefers not to do so.

The sexes are very much alike in appearance, but the female is lighter in ground colour and more spotted than the male. She sometimes sings a little.

Coarse or sharp sand in the cage makes the feet sore, especially if the evacuations are allowed to accumulate: dry garden mould is better than sand, and care must be taken that it does not get wet.

The Woodlark feeds, like the Skylark, on germinating seeds and on insects, and may be kept for ten or twelve years in the house if treated as recommended for its congener.

\section{THE LAUGHING GULL. See under Gulls.}


THE LESSER BLACK-BACKED GULL. See under Gulls.

THE LESSER GODWIT. See Godwit (Blacktailed).

THE LESSER REDPOLL. See under Linnets.

THE LESSER SPOTTED WOODPECKER. Se under Woodpeckers.

THE LESSER WHITETHROAT. See under Whitethroats.

\section{THE LINNETS AND REDPOLLS.}

The Brown Linnet. See Common Linnet.

\section{The Common Linnet.}

Curiously enough, this bird has been, and still is, the subject of not a little misconception owing to the changes of colour to which the male is subject. In his wild state he has, when adult, a red forehead and a rosy-red breast, when he is termed the Red Linnet and the Greater Redpoll; these characteristics he loses in the house after his first moult there, and is then known as the Brown Linnet; and when he is young, either indoors or out, he resembles his mother, and is consequently called the Grey Linnet, for while the back of the adult male is a fine chestnutbrown colour, that of the female is distinctly grey, and she is also much more spotted on the breast, which is greyish-white, while that of the house-moulted male has a buff or yellowish tinge. 
Wherever there is furze (gorse) there the Linnet is to be found-or should be, for the trappers have exterminated him in some likely localities which he formerly used to frequent in large numbers. The nest is very compactly built of grass and roots, and is sparingly lined with hair; as a rule it is placed in a clump of furze, and the eggs, which are usually five in number, are pale bluish-white, streaked and spotted with reddish-brown.

Grass seeds are the favourite food of the Linnet, but in the autumn it !seems to be as partial to those of the

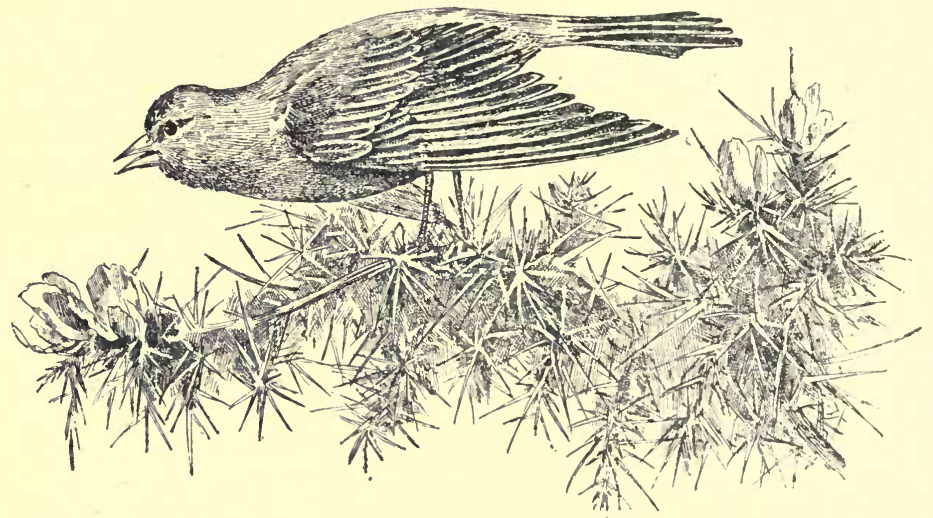

The Common Linnet.

knot-weed (Polygonum repens) as the Sparrow itself; and in the house it is best fed on canary-seed with a little summer rape and some plantain, often called rats' tails in the country.

It will breed freely with the Canary and other Finches, and is in much request for singing-contests, for which it is regularly trained, being kept in a wickedly small cage, covered over with a red handkerchief, as a rule, and accustomed to trill forth its song at the word of command.

A pair of hand-reared Linnets nest freely in a cage, and less so in an outdoor aviary, where some of the males 
will regain their rosy vesture, at least to a certain extent: from this it may be inferred that the loss of it is due less to food than to want of a proper amount of air and exercise, without which the bird soon falls into a decline, and as a correspondent recently complained, "develops excessive corpulency," meaning thereby that the poor creatures puffed their feathers out until they looked like balls of fluff, while in reality they had wasted to mere skin and bone. But we are all so prone to judge by outward appearance only!

A Linnet has an exceedingly sweet natural note, which it trills forth from dawn to dusk pretty well all the year round in the house, where it will live for ten or twelve years, when correctly managed.

\section{The Common or Lesser Redpoll.}

This is a pretty little bird, that is a great favourite, especially with the poorer class of fanciers, who tame it and teach it to play a great many little tricks, among others that of drawing up its drinking-water with a thimble for a bucket from a teacup placed below its stand for a well. Special stands are made for the purpose, sometimes of very elaborate design, and to these the Redpoll is chained, by means of a band of chamois-leather, technically a "brace", that is fastened round its body under the wings, the little chain hanging down between the bird's legs.

It might be thought that such restraint would be very irksome to the Redpoll, but it does not seem to be so after the first day or so, as the little captive makes no attempt to escape even when anyone goes near him, but keeps on drawing water and opening his seed-box when he wants to eat or drink, as if it were the most natural thing in the world to do; singing away in the intervals between his meals as if he had not a care, but was perfectly happy and contented. And when it is added that a Redpoll so chained has been known to pair with a female of his own species that flew freely about the room, it will probably be conceded that he had not much to complain about, as she made her nest close to him and he could hop on to the edge of it and peep at the little light 
blue speckled eggs, when he had a mind to do so, as well as lend a helping hand-that is to say beak-to feed the two little ones that made their appearance in due course.

Other Redpolls have nested and reared young ones in an ordinary Canary breeding-cage, and yet others would have done so in a garden aviary where they were kept with many other birds, had not some mice interfered and sucked the poor little couple's eggs as fast as they were laid in the cosy nest the hen had built in a euonymus bush growing against the wall of the enclosure.

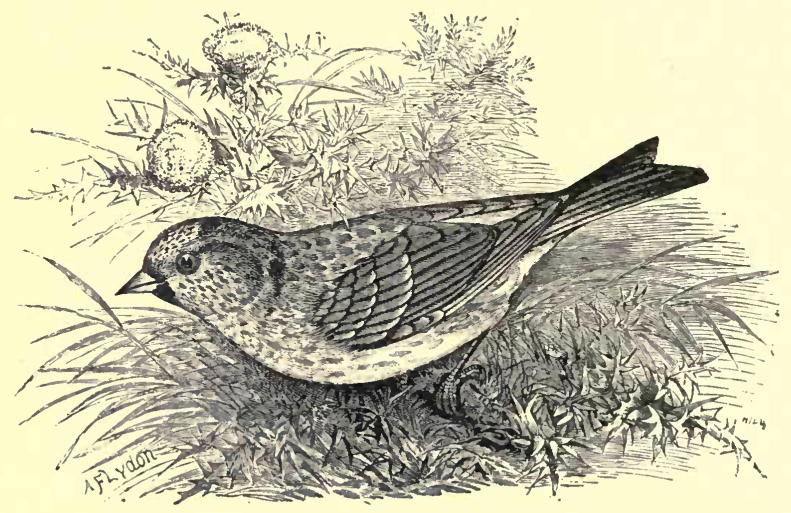

THe Comion or Lesser Redpoll.

Grass and other seeds are the natural food of this species, but it also feeds on aphides and small flies when it can get them; it does not, however, carry them to the young in its bill after the manner of a. Sparrow, but swallows them first to regurgitate them afterwards with the other food when engaged in feeding the little ones. The aphis that infests the rose is an especial delicacy with the Redpoll, but let the aviarist beware of the purplish-black species that is found on the lilac, and more particularly on the laburnum, both of which are poisonous. The aphides, however, that are found in such abundance on the underside of the leaves of the black poplar and the linden or lime 
tree, may be given, as they have no unwholesome property. These birds, however, will do very well without any addition of insects to their diet, eating canary-seed, spray millet, and summer-rape seed, which by the way is a small round reddish-brown seed, only about half the size of the black, acrid winter-rape that is sometimes sold for it by unscrupulous traders, or, possibly, ignorant ones. Green food is desirable, particularly if the little birds are breeding, and then groundsel, plantain, chenopodium and polygonum may be given, as well as grass seed of all kinds and a little middling coarse oatmeal. Needless to say grit is indispensable.

It is curious that there should be any difference of opinion respecting the orthography of the bird's name, which is evidently derived from the colour of the head (old English, poll), but one or two writers spell it as if it had something to do with hops, or perhaps a barber's pole, which is very absurd.

The Redpoll is a late breeder, as the nest has been found towards the end of July with recently-hatched young in it, and in confinement it does not begin to build before the middle of May. Mules have been produced between it and the Linnet, the Canary, Goldfinch and other Finches, but an assertion somewhat recently made, that hybrids had been obtained between it and a Bunting, scarcely needs contradicting, so opposed is the statement to well-ascertained facts.

The nest is not as frequently met with in England as it is in the north of Scotland and in Ireland, but the birds breed here in suitable localities, and would doubtless do so more frequently were they not so often disturbed by the birdcatchers.

It is a miniature Linnet, and like that bird, loses its bright colours in the house, the red cap persisting longer than the rosy vest.

The Greater Redpoll. See Linnet (Common).

The Green Linnet. See Greenfinch (under Finches), 
The Grey Linnet. See Linnet (Common).

\section{The Lesser Redpoll. See Common Redpoll.}

\section{The Mealy Redpoll.}

This is thought to be merely a local variety of the ordinary Redpoll, but it differs from the latter in being less frequently met with on the south side of the Tweed during the summer months, as well as in being somewhat larger.

It is much paler in colour than the ordinary Redpoll and has a lighter coloured bill, while the red of its cap is of even a more fiery shade than that of the latter.

It is a pretty creature and very docile, but not being so common as the other members of the Linnet group it has greater attractions for the "judges" at shows, where it mostly secures a prize when put in competition with them and the Siskin.

It is fed and treated in the same way and is equally hardy when properly managed, but is even more impatient of artificial heat, which quickly destroys, first its liver and then its life.

\section{The Red Linnet. See Linnet (Common).}

\section{The Red-rumped Linnet. See Twite.}

\section{The Twite.}

This bird, sometimes called the Yellow-billed or Redrumped Linnet, differs from the ordinary Linnet in many respects. In the first place it is smaller, being intermediate as regards size between it and the Redpoll; then it has a yellow bill while that of its larger relation is dusky blue in summer and grey in winter; and particularly it has no red on the head and breast, but some on the rump.

The habitat of this species is in the north, and it only comes south in winter. The nest is compactly built and situated in a low bush; the eggs resemble those of the 
Linnet, but are smaller, and like the latter bird, it will breed in confinement, either with a partner of its own kind or with another Finch, including the Canary.

As it has no very distinguishing characteristics to recommend it to the notice of amateurs, this species is not very frequently kept in a cage.

\section{The Yellow-billed Linnet. See Twite.}

\section{THE LITTLE CURLEW. See Whimbrel (under Curlews).}

THE LONG.TAILED TIT. See Introduction, page 8.

\section{THE MAGPIE.}

This is the beau of our woods, and a beauty he is, with his plumage of black and white (but such white and such black!) and his long tapering tail, which he is so fond of flirting up and down, and fanning out to display its indubitable charms.

For all his good looks, he is a bandit and freebooter who lives by his wits, preying for the most part on other birds, especially those that frequent the ground, so that one can scarcely wonder at his gradual extermination: and yet it seems a pity, for he certainly enlivens the landscape and contributes his quota to the concert of the woods.

Solitary in summer, that is going about in single pairs, the Magpies gather themselves into little companies at other times, and are then fairly sociable; but whether they band themselves together for mutual defence or for some other purpose is hard to determine.

The nest, built of sticks, and domed with thorns, is often placed among the terminal branches of a tall slim 
poplar, but occasionally on a flat branch overhanging water or a sudden descent in the ground, and even in a tall hedge when no more suitable position can be found. The eggs are four to six in number, greyishwhite, thickly speckled with small spots of a darker shade

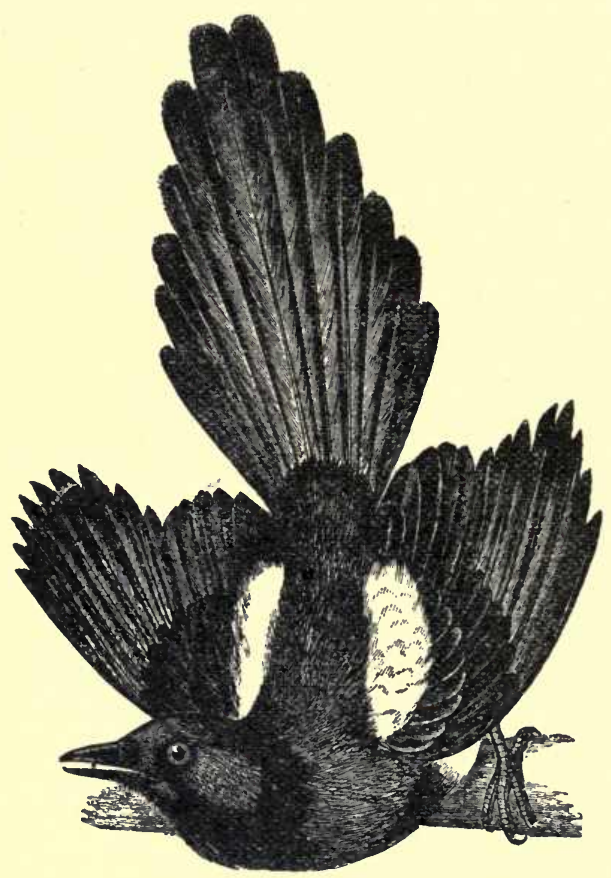

The MagPiE. than the ground colour. The young are fed on insects, young birds, eggs and fruit. Frogs often fall victims to the rapacity of the Magpie, and make a piteous outcry while they are carried aloft to the rob. ber's aerial den, but that does not avail them much for the Magpie has no pity for anything.

$A$ band of these birds once attacked a flock of tame Fantail Pigeons and killed most of them, for no other reason, that could be imagined, than jealousy of the spotless purity of plumage and the innocent (if 'somewhat self-assertive ways of the latter; but sometimes the freebooter meets his match and has the tables turned on him by the domestic cock, especially when the latter happens to belong to one of the game breeds.

Young Magpies are easy to rear on the diet recom- 


$$
\text { FOR CAGES AND AVIARIES. }
$$

mended for the upbringing of youthful Ravens, but will lose the use of their limbs if not kept very dry and clean, and also if they are allowed too much flesh-meat: an insect and fruit diet is better for them, and bread and milk will be found to answer as the staple food.

Hand-reared, the Magpie makes a charming pet, capricious perhaps, but very nice towards those he likes, and as full of fun as of mischief: he will talk, too, and better than many a Parrot.

THE MANX SHEARWATER. See Shearwater.

THE MARSH HARRIER. See under Harriers.

THE MARSH TIT. See under Tits.

THE MARTINS. See Introduction, page 8.

THE MEADOW PIPIT. See under Pipits.

THE MEALY REDPOLL. See under Linnets.

\section{THE RED.BREASTED MERGANSER.}

This is a remarkably handsome bird, somewhere about half the size of the Goosander. The head, which is ornamented with a nuchal crest, is black, as are the back, 
the primaries and the tail; the lesser wing coverts are white deeply edged with black; the remaining wing feathers are white lightly edged with black; the sides and rump are light slate finely spotted with black; the lower half of the neck and the breast are brown with a number of narrow black spots. The eye and the bill are dull orange. It is a winter visitor, occurring rather in the northern than the southern parts of these Islands, but some remain to breed, especially in Scotland and the Scottish islands.

THE MERLIN. See under Hawks.

THE HOODED MEW. See Gull (Black-headed).

THE MISSEL THRUSH. See under Thrushes.

MONTAGU'S HARRIER. See under Harriers.

THE MOOR BUZZARD. See Harrier (Marsh).

\section{THE MOORHEN.}

This is a member of the Rail Family. It is a native bird, generally dispersed in the vicinity of water, on the margins of which it finds its food. It is readily domesticated, and will voluntarily become tame where it is not interfered with, as in St. James's Park, where it breeds freely. The bill and forehead are orange, but the tip of the former is yellow; all the upper parts are black, and the lower grey, 
gradually fading to white on the lower tail coverts: the legs and extremely long toes are green, the eye is orange, and there is a spot of the same colour just at the knee.

\section{THE MOUNTAIN FINCH. See Brambling (under Finches):}

\section{THE NIGHTINGALE.}

Although not so common a bird as the Robin, the Nightingale is probably quite as well known, at least by repute; for a good many people have never seen the bird alive and do not know it by sight, although they may live within the sound of its beautiful song. It is shy, and keeps to retired woods and copses as a rule; but sometimes it is known to frequent gardens, and has been seen in the grounds of the Crystal Palace at Sydenham, and at Peckham Rye.

It is a somewhat larger bird than the Robin, and stands higher on its legs, which are long and slender and of a greyish flesh-colour. The eye is very bright and full, and in its deportment the bird greatly resembles the Robin, hopping quickly forward, jerking up the tail, flapping the wings, and generally behaving much after the same manner. Bechstein, curiously enough, says it is smaller than the Redbreast, but those that come to Britain, and especially those that frequent the county of Kent, are decidedly longer. The colour of the upper surface of the body is brownish-red, deeper on the rump and the tail than on the back and wings, while the under parts are greyish-white.

The female is rather lighter coloured than the male, but the chief point of difference is in the shade of the back and tail, which is a much deeper red in the case of the latter.

The young are very unlike their parents, being brown in colour with small yellowish dots scattered all over the 
body, which give them somewhat the appearance of a Wren, but the tail has a reddish shade, which serves to distinguish them from any other bird. The young females are rather larger in the nest, but there is very little to distinguish the sexes from each other.

The Nightingale is found wild in most parts of Europe, but in England only in the south-eastern counties, while he is quite unknown in Scotland and Ireland. He frequents wooded places, and builds on or near the ground, usually

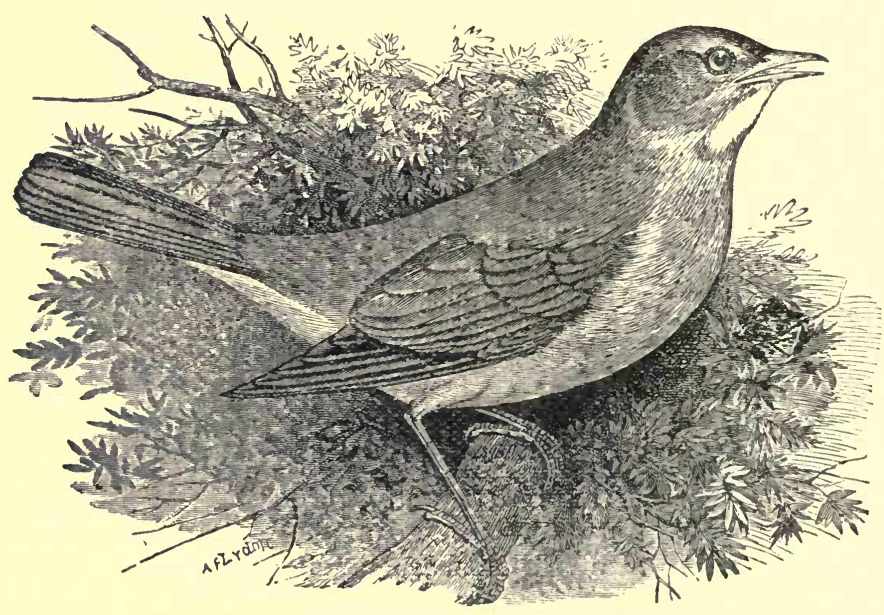

The Nightingale.

amid brambles, and not far from the trunk of a tree. The nest is large, made of leaves outwardly, then grass, and is neatly lined with grass and hair. The eggs are usually five in number and are of an olive-green colour, without spot or marking. As a rule, there is only one brood during the season, but if the birds are disturbed and their eggs or young are taken away before the latter have left the nest, a second brood will generally be produced.

The old birds make a great noise, the female especially scolding vehemently, when the nest is approached, and its 
situation is very often discovered through her over-anxiety to defend it.

The young can be reared without the least difficulty on ants' eggs (Romans' for preference) and small insects of all kinds. A pair of pliers with long narrow blades should be used for dropping the food into their widelygaping, yellow mouths, and they require attending to about every ten minutes from dawn to dusk; a mouthful or two at a time will content them then, but if they are fed at longer intervals and are given more food at a time, they will be very apt to contract indigestion.

The males begin to sing as soon as they can feed themselves, and until they do so, they are better kept in a small basket with a lid. When hand-reared they become exceedingly tame. Many artificial foods are recom mended for the Nightingale, but nothing is so good for them as a diet consisting for the most part of ants' eggs, to which mealworms, blackbeetles, bacon-beetles and other insects are added. Soft food is apt to stick to the corners of the mouth and give rise to troublesome sores.

In the autumn they eat elder-berries and those of the privet and ivy, and a little lettuce or tender cabbage may also then be given. If flying loose in a conservatory, the food should always be placed in a cage, so that the bird can be shut in when required. The floor of the cage may be covered with garden mould, previously dried, or sawdust, and the perches must be kept very clean, or the birds will soon have sore feet.

The Nightingale is very fond of bathing, and should have a shallow pan or saucer of water placed for it on the floor every morning; but it should not be allowed to "tub" in the cage, which would thus be rendered damp and uncomfortable.

A tame Nightingale will never know an hour's uneasiness if fed and treated as advised. But sometimes a fancier may buy one that has not been judiciously treated, and may find that it prefers the unwholesome messes to which it has become used, to the correct diet that he supplies it with. In that case he must not stop the former abruptly, but supply the new along with it, and if a few 
shreds of raw lean meat are placed on top of the ants' eggs, it will not be long before the bird will eat these, too; once he does, it is plain sailing afterwards.

Should there be any sign of constipation, a teaspoonful of Dinneford's fluid magnesia should be given in two tablespoonfuls of water for drinking, and that will quickly relieve the sufferer.

It is comparatively rare for a Nightingale, taken when full-grown, to live long in the house, but those that have been carefully reared from the nest and are properly fed and attended to afterwards, will survive in health and beauty for ten or twelve or even more years in confinement, which is, in all probability, a much longer span of life than they would have enjoyed in a state of freedom.

The exquisite song of the Nightingale forms, no doubt, its chief attraction, but its tameness and familiarity must equally commend it to the notice of bird-lovers. True, it has not the intelligence of the Bullfinch, for instance, and is incapable of developing that affection for its custodian or patron that is such a marked characteristic of the latter bird, but it possesses the inferior quality known as "cupboard love" in a marked degree, and that very often does duty for the nobler sentiment, and affords an equal amount of satisfaction to the recipient.

While it is distinctly understood that the Nightingale is unable to stand the cold of our winters, it would be an error in the opposite extreme to keep it too warm, and especially so in any place where there is not full and free ventilation, without draught. Great heat, particularly when combined with a stagnant atmosphere, will certainly have a most disastrous effect, inducing congestion of the liver, constipation, and fits, as well as premature moult, which has a most debilitating effect.

Extremes of temperature must be avoided, for which reason no worse place could be found for the bird than a kitchen, where the heat is often very great during the day, and is followed by the opposite extreme of cold when the fire has been put out at night. For the same reason it is a very bad plan to cover the cage up closely, for that confines the air, which becomes not only exhausted 
of oxygen, but also vitiated by the emanations drawn up by the heat from the floor of the cage, and the carbonic acid exhaled from the lungs of the bird itself; at the same time, it is very desirable to provide the Nightingale with a curtain or screen over a portion of its dwelling, to the shelter of which it will invariably be found to retire for sleep when evening has set in, as well as when it feels inclined to take a nap during the daytime. This it often does after a full meal, particularly of mealworms-an excellent dish, but one that takes some digesting; for which reason blackbeetles are preferable, or gentles or bacon beetles, when the latter can be obtained, though it would be well worth the amateur's while to cultivate them for the benefit of his pets.

\section{THE NIGHTJAR.}

This is an impossible cage bird, but it has the curious habit of laying its two long narrow eggs on the bare ground, and has occasionally been mistaken for the Cuckoo, a circumstance that has given rise to the fable that the latter bird occasionally incubates her own eggs. This bird is also very commonly called the Goat-sucker, and is much persecuted by rustics, and some folk who ought to know better, under the pretence that it robs the cows of their milk!

\section{THE NORFOLK PLOVER. See Thick-Knee.}

\section{THE NUTCRACKER.}

Properly speaking, this is not a British bird, but a chance visitor to our shores at long intervals; that is sufficient, however, to have secured him a place in Morris's great work. He is a fine bird, over a foot in length and fairly proportioned, of a blackish-brown colour, darker on the lower than on the upper parts of the body, and 
speckled all over with white, like a Starling. His beak is decidedly corvine in shape, and yet he is strictly granivorous, a vegetarian Crow in fact, and lives on seeds of all kinds as well as nuts. The nest is placed in a hollow in a tree (another deviation from corvine habits), and the eggs, four to six in number, are dark greyish-olive with brown streaks. The young are reared on worms and insects as in the case of many other seed-eating birds.

\section{THE NUTHATCH.}

This is not a very common bird in Britain, nor a very suitable one for caging; however, if it can be taken young and brought up by hand from the nest, which is readily done on ants' eggs and small mealworms, it becomes very tame, and is then sufficiently amusing; but it is practically impossible to reconcile to captivity one that has been caught when full grown.

It is about $6 \frac{1}{2}$ inches in length, $1 \frac{1}{2}$ inches of which is included in the tail, while the strong pointed bill is nearly an inch long. The forehead is blue, and the rest of the upper part of the body bluish-grey; the cheeks and throat are white, and a band of black extends from the eye to the back of the head on either side; the breast and belly are orange-brown. The female is greyer.

The Nuthatch is a wood-loving bird, and its nest is placed in a hole in a tree, where four or five white eggs speckled with red are deposited, sometimes on the bare wood and, occasionally, with a little apology for a nest under them. The young are fed on insects, chiefly small caterpillars, which form the greater part of the food of the parents too, although in winter they eat seeds and berries, and evince much cleverness in extracting the kernels of nuts and beech-mast, which they fix securely in a crack of the bark of a branch and then drill with their strong beak, turning round and round as they do so to add additional impetus to the blows they deal.

If kept indoors, they must be fed as recommended for the Tits, but the cage they are put into should be entirely 
of wire, as they would soon bore a wooden one into a congeries of holes and promptly regain their liberty.

We cannot recommend amateurs to attempt the keeping of this bird, which never appears to get reconciled to confinement, but persons living in the country can by judicious management succeed in taming it to a very large extent, by the easy expedient of placing suitable food on

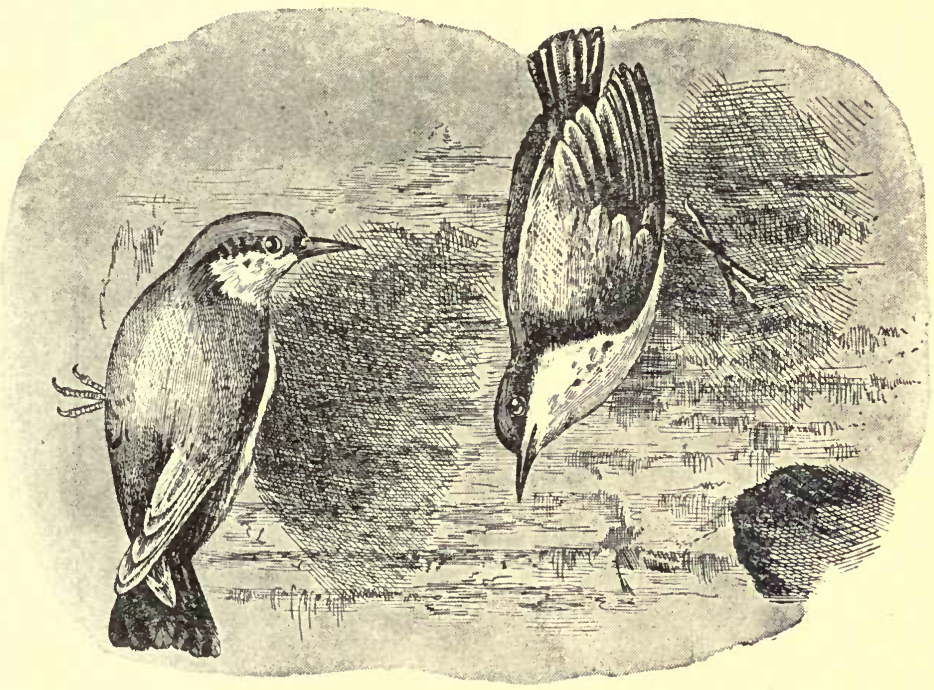

Nuthatches.

a window-sill, or if the latter is too narrow on a tray fixed to it. This should be out of reach of cats, and be plentifully supplied with sunflower- and hemp-seed, suet, ants' eggs, and filberts or walnuts extracted from their shells. The Tits will flock to the seeds, and the Nuthatches, as well as maybe on odd Woodpecker, to the nuts, and after a little while, when they find that no harm is meant to them, all the birds will get very tame and even allow their friend to stand quite close to the shut window, 
without flying away. After a little more time has elapsed, they will not scuttle off when the casement is opened and the purveyor of their good things appears at it and puts a fresh supply of dainties on the board, and then they will venture into the room, and become as tame, confiding, and loving as it is in the nature of these birds to be. This is certainly preferable to putting them into a cage, where they knock themselves about and sadly mar their personal appearance, which is their great and indeed only attraction.

The Nuthatch is one of the birds the present writer has never attempted to bring up by hand, nor can he recall an instance of anyone else having done so; all the examples of the species he has seen in confinement having been captured when full grown in traps, mostly of the primitive brick pattern, baited with nuts. For one Nuthatch that survives when thus caught, at least five die.

\section{THE ORTOLAN. See under Buntings.}

\section{THE RING OUZEL. See under Thrushes.}

\section{THE OWLS.}

\section{The Barn Owl.}

This bird, which Mr. Morris facetiously terms "a High Churchman," in allusion to its habit of frequenting churchtowers, which it often shares with the Jackdaws, is also known as the White Owl from the light colour of its plumage: this is pale buff on the upper and white on the lower surface of the body.

Occasionally it ventures out in the subdued light of a dull day, but is then invariably mobbed by the small birds and has to beat a hasty retreat. Its natural diet consists of 
mice and other small rodents, and the tales circulated by gamekeepers and others that it is destructive to the sacred Partridge and birds of that class, are utterly devoid of foundation, the proof being that in those localities where it has been exterminated field mice have increased to an alarming extent. It also eats the larger beetles, especially

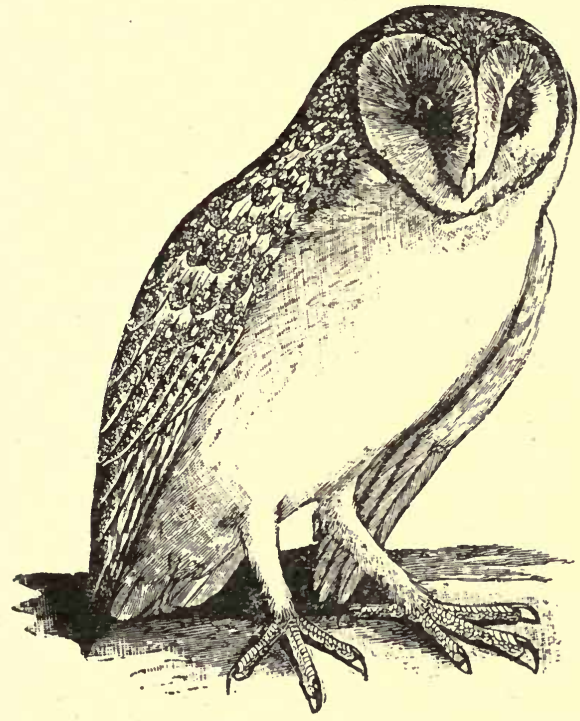

THE BARN OWL. the destructive insect known as the stag beetle: this, or rather its larva, does much harm to trees, in the heart of which it lives, moves and has its being for several years before undergoing its final metamorphosis.

The cry of this Owl is a harsh prolongation of the sounds "teewhit" (the $i$ to be pronounced in the old English fashion and not $e e$, which is the German sound of the third vowel), which is so weird as to cause wholly unnecessary alarm, for the bird is not only quite harmless but extremely useful when confined to its native haunts.

\section{The Tawny Owl.}

This bird differs a good deal from the Barn Owl, not only in appearance but in habits. In feather it is darker, if in size about the same, but it nests on the ground, as often as not in the mouth of a rabbit-burrow, but some- 
times with no better protection for its four white eggs than an overhanging clump of briars or gorse, and occasionally in the hollow trunk of a tree.

The young can be reared on the flesh of small birds and rodents, if desired; but Owls are not nice birds to keep, seeing that they are nocturnal in their habits, sleep when their owners are awake, and wake up when the latter are or should be asleep.

Some time since a correspondent wrote to ask what other food he could give to a tame Owl besides, or except, flesh, suggesting dog-biscuit, various seeds and bread and milk: he was doubtless surprised and probably disgusted when he got the answer that an Owl is carnivorous in its habits and lives entirely on animal matters; if he could not give it suitable food, he had better let it fly away.

Did he? Ah! that is a question that has remained unanswered-probably he preferred the alternative of slowly starving the poor thing on unsuitable diet.

\section{The White Owl. See Barn Owl.}

\section{THE OXEYE. See Tit (Great).}

\section{THE OYSTER.CATCHER. See under Plovers.}

\section{THE PARTRIDGES.}

\section{The Common Brown Partridge.}

This bird is plentiful in most parts of the British Isles, where it is in much request for shooting at the proper season, but it can be readily tamed and makes a very nice pet. It pairs for life and the hen lays from eight to twelve or more eggs, which are of a greenish-brown 
colour, but makes no nest properly so called: incubation lasts for three weeks, and the young run about as soon as they are out of the shell, at which time they feed entirely on insects, principally though on ants and their cocoons or "eggs". When adult they consume a good deal of grain and green food.

It can be reared in confinement if the eggs are placed in charge of a Bantam, which is a better plan than hatching them in an incubator, and the young can be reared on ants' eggs, crissel and hard boiled egg chopped fine, vegetables and seed being gradually added to the dietary.

\section{The Red-legged Partridge.}

This bird is an importation from the continent, and, like a good many other things coming to us from the same quarter, has become a nuisance in the localities where it is established, but it, too, can be tamed and is then very attractive.

It is a decidedly handsome bird, very pugnacious, and poor eating; it has moreover displaced the Common Brown Partridge in some parts, and sportsmen are so irate with the quarrelsome and useless foreigner that many of them denounce it as "vermin" and would exterminate it from its new-found home if they could. But it is prolific, hardy and cunning and defies all efforts that have its extermination from its adopted country for object.

THE PEEWIT. See Lapwing (under Plovers).

THE PEREGRINE FALCON. See under Hawks. 


\section{THE PHEASANT FAMILY}

is a very comprehensive one, numbering among its members such diverse forms as the Quail, Frankolins, Tragopans and the Guinea Fowl, none of which, however, with the exception of the first, are entitled to the distinction of being called British birds. For further information see Grouse (Black).

\section{The Common Pheasant.}

This is an introduced species, but is such an old inhabitant that it is usually reckoned to be one of our British birds. As it is known to every one and pretty well everywhere in this country its consideration need not detain us long. It is reared in great numbers for the pleasure of killing it afterwards, and its association with man has so demoralized the creature that it mates freely (being polygamous) with various more or less nearly related species, the offspring of the ill-assorted unions being barren hybrids. Both sexes err in this respect, though perhaps the male is the more frequent offender of the two.

THE PIED FLYCATCHER. See under Flycatchers.

THE PIED WAGTAIL. See under Wagtails.

THE PIGEONS. See under Doves.

THE PINE GROSBEAK. See under Finches. 
THE PINK-FOOTED GOOSE. See under Geese.

THE PINTAIL. See under Ducks.

\section{THE PIPITS.}

This is a numerous family, that seems to form a connecting link between the Larks and the Wagtails, as they certainly partake of the characteristics of both. In addition to the Meadow and Tree Pipits, Richard's Pipit, the Tawny Pipit, the Water-Pipit, the Red-throated Pipit, and the Rock Pipit, are to be met with more or less frequently in this country.

The first and last named are more Lark-like in appearance than some of the rest, and bear such a strong resemblance to each other, that it requires a somewhat experienced eye to discriminate between them.

Notwithstanding the formation of their feet, all the Pipits are able to perch, and most of them sleep in that position, though the Meadow Pipit not unfrequently passes the night on the ground, on which they all nearly always nest, usually under the cover of a stone or even a clump of coarse grass.

The writer is not acquainted with an instance of any of them having bred in confinement, though if comfortably situated, there seems no reason why they should not do so, as well as their near relations the Wagtails and the Larks; but as the Wagtails succeed better in an outdoor aviary than indoors, in all probability the Pipits would do so too. They have, however, very little to recommend them to the notice of amateurs.

\section{The Red.throated Pipit.}

The Red-throated Pipit has puzzled more than one naturalist to place it, for it resembles the Lark more closely than any of its congeners. As its name indicates, 
the chin, throat and upper breast are tawny-red, and the bill and eye-streak are of the same colour; the lower breast, abdomen and vent are buff; there are but very few spots on the breast, but on the sides of the neck they are more abundant, and are continued on the sides to the insertion of the thighs. The legs and feet are yellowish-brown, and the hind claw is of conspicuous length.

\section{The Rock and Richard's Pipits.}

The Rock Pipit is darker in colour than the one that bears the specific name of Richard: the latter is bluishgrey on the chin, and the thighs and lower abdomen are darker than in the other. The Rock Pipit is a dark greenishbrown shade all over, with a few indistinct spots on the breast, while Richard's breast marks are as conspicuous as those of a Lark. Both of the foregoing have a long hindclaw or nail, which gives them a Lark-like look that is unmistakable.

\section{The Tawny Pipit.}

The Tawny Pipit has more of a yellowy-buff tinge on the breast, belly and edges of the secondaries and greater coverts; it is also distinguished by a yellowish-white throat and eye-streak.

\section{The Water-Pipit.}

The Water-Pipit is more like a Wagtail than the Rock, Richard's, and Tawny Pipits: it is grey on the upper surface, with brown tail and wings, the edges of the feathers on the latter being of a brownish-buff colour; the breast is light buff; the chin, eye-streak, and belly are greyish-white; the thighs and vent light bluish-grey; the legs dark slate colour, and the hinder nail of moderate length only. 


\section{THE PLOVERS.}

\section{The Dotterel.}

This is a much handsomer bird than the Ringed Plover, but is somewhat difficult to describe: the head is dark grey, with a streak of bright yellow running down from the eye to the neck; the throat is white with minute spots of dark grey; the breast is darker grey with a still darker lacing, then succeeds a narrow band of pure white, followed by a broad ruddy patch and that by a black one, while the rest of the lower parts are pale buff; the back is greyish brown, the wings are brown of a darker shade, marbled with lighter shadings of the same colour, and the tail is yellowish grey with lighter margins to each feather.

It is only a passing visitor with us on its way to breed in the far north. Habits and food, same as those of the other Plovers.

\section{The Golden Plover.}

This is a handsome creature, with jet black face, throat, breast, belly and thighs, whitish grey sides marked with dark grey spots; brown back, with black centres to the

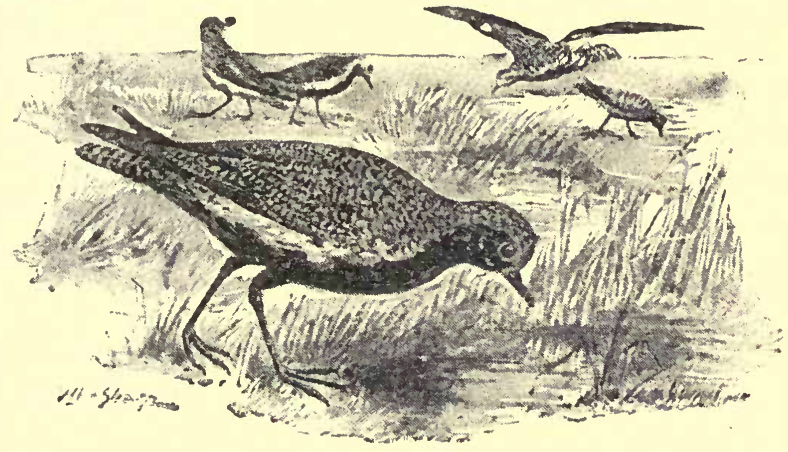

Golden Plovers.

feathers, and greenish yellow wings, also black centred: the bill is dark horn colour, and the legs and feet yellowish- 
grey. Its food consists for the most part of insects, but also of berries and other vegetable matters. Yellow Plover and Green Plover are other names for this species.

The eggs are usually four in number, and large for the bird that lays them; the ground colour is yellowish-grey and they are spotted variously with brown and black. The young run directly they are out of the shell, and when feathered are darker than their parents, their under parts being curiously marbled with yellow, white and black.

\section{The Great Plover. See Thick-Knee.}

\section{The Green Plover. See Golden Plover.}

\section{The Grey Plover.}

This bird is much like the Golden Plover, except that its only colours are black below and light bluish grey above, the latter thickly mottled with black. In its habits and choice of food it resembles the Golden Plover.

\section{The Lapwing.}

This bird is sometimes called the Peewit from its peculiar cry. It is perhaps the best known of all the Plovers and is a conspicuously handsome creature, whose long nuchal crest of dark green feathers adds materially to its attractiveness. A white streak surmounts the eye, the neck is white and so are the under parts, but the rest of the body, including the lower half of the tail, is dark green glittering with metallic lustre: the upper half of the tail is white, and the vent feathers buff; the bill is black, and the iris grey.

The female has a smaller crest, but otherwise resembles the male.

It is well-known by its curious habit (more or less followed by all the Plovers) of feigning lameness in order to draw away intruders from the vicinity of the nest.

The eggs, which are usually four in number, are in great request for the table, and the quest is so keen that 
the numbers of this handsome and eminently useful species, as well as its congeners, have sensibly diminished of late years. The young run about as soon as hatched,

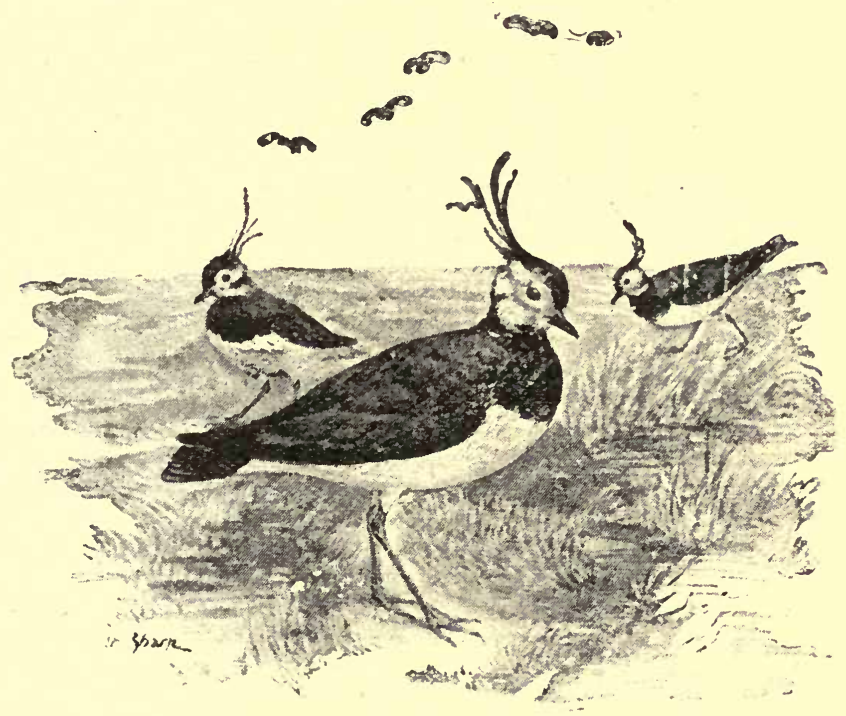

LAPWINGS.

and feed on small worms, snails, slugs and insects of all kinds. They are very easy to rear by feeding them, as nearly as possible, on the diet natural for them, when they become extremely tame and make very interesting pets.

\section{The Norfolk Plover. See Thick-Knee.}

\section{The Oyster.catcher, or Sea.pie.}

This is a black and white bird about $I \frac{1}{2}$ feet in length, with orange-yellow bill and greenish-yellow legs and feet, and weighing 16 or 17 ounces. It is of wandering rather than migratory habits, collecting in small flocks during 
the winter season but nearly always on the coast. The eggs are four in number as is usual with the Plovers, and yellowish or buff-white spotted with black, brown and grey.

The young can run about very actively soon after they are hatched, and can be reared without much difficulty on their natural diet, marine insects, small crustacea,

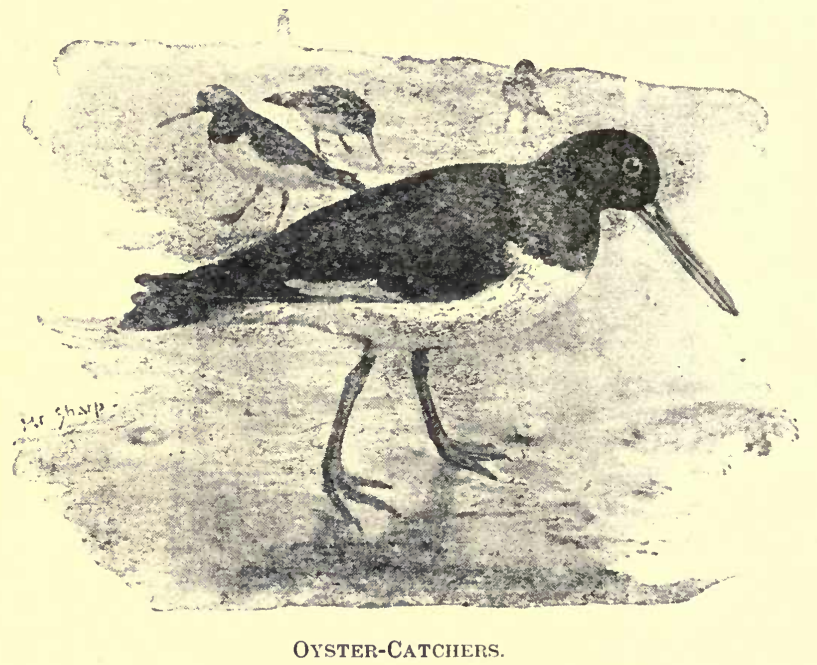

molluscs and fish. If pursued they hide their heads after the manner of the Ostrich. The nest is generally placed among stones above high water mark, but sometimes on grass.

Male and female are alike. They moult twice a year, spring and autumn.

The Plover's Page. See Dunlin (under Sandpipers).

\section{The Ringed Plover, or Ringed Dotterel.}

Also called the Land-Lark, Sea-Lark, Dull Willy and other local names. In the northern parts of the British Isles it is a resident species, but a winter visitor only in the south. 
The eggs, four in number, are laid on the ground, among water-worn stones, from which it is difficult to distinguish them; the young, too, are covered with mottled down that closely mimics the surroundings of the helpless little creatures.

The habits and mode of feeding are the same with this species as with the other Plovers already noticed.

\section{The Turnstone.}

Not unlike the Oyster-Catcher, but has a brown back, a black bill and dark orange-brown legs and feet. It is a coast bird and derives its name from its habit of turning over stones on the beach in search of the insects that congregate in their shelter. It is a winter visitor, departing from March to the end of April, and arriving in August or September. They very rarely stay to breed here. The Turnstone is a very cautious and wary as well as a

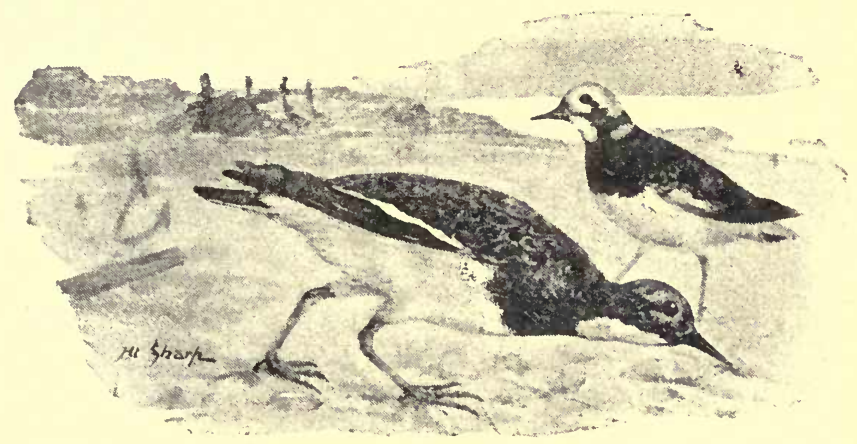

TURNSTONES.

courageous bird, boldly attacking the largest Gulls, and even terrestrial birds of prey. It is rarely seen inland.

The two sexes are very much alike in general appearance but they vary a good deal in colour according to age, they are much smaller than the Oyster-Catcher, and are easily domesticated, when their peculiar habits make them very ${ }_{i}$ nteresting inmates of the aviary. 
The Yellow Plover. See Golden Plover.

THE POCHARD. See under Ducks.

THE POOL SNIPE. See Redshank.

\section{THE PUFFIN,}

This bird is of very common occurrence in many parts of Great Britain and Ireland, and is found in lesser numbers nearly all round our coasts. It is chiefly distinguished by its peculiar beak, which is much compressed laterally and is adorned with a variety of bright colours, orange, yellow and blue, while the angles of the mouth are bright red inwardly and canary yellow on the outside. The top of the head, the back, wings, tail and a ring round the neck are black with varied metallic reflections; the under parts are white running into light grey on the vent and under tail coverts. The legs are orange, and the feet grey with an orange shading.

The solitary egg is laid under a ledge of some precipitous cliff, or in a deserted hole of a rabbit. Incubation lasts a month, and in about 6 weeks the young are fledged and able to shift for themselves. At first the bill is round and pointed like that of the Guillemot.

THE PURRE. See Dunlin (under Sandpipers).

THE PUTTOCK. See Harrier (Marsh). 


\section{THE QUAIL.}

Quails are birds of passage, arriving in April or May, and taking their departure at the end of August or the beginning of September. They are polygamous and are now much scarcer in the British Isles than they were some years ago; vast numbers of them are imported from the Continent and fattened here for the table.

If kept in an aviary one wing should be clipped, or if in a cage, this should have a canvas top, or the Quails will promptly scalp themselves by jumping up and banging their heads against the roof.

They frequent cultivated ground and live on seeds and insects. The males are very quarrelsome; in China they are trained for fighting as game-cocks and they used to be in this country not so many years ago.

The eggs are yellowish-white spotted with brown; they are not laid till June, but the young fledge rapidly, and are quite ready to accompany their parents when the latter take their departure for the south in the early autumn.

Occasionally these birds will breed in confinement, and the tiny chicks are exceedingly pretty and interesting. With a plentiful supply of ants' eggs and maggots they are not difficult to rear.

\section{THE QUEEST. See Ringdove (under Doves).}

\section{THE RAILS.}

\section{The Landrail, or Corn Crake.}

Not unlike the Water-Rail in size and appearance, but very dissimilar in its habits, for instead of frequenting moist places, it is found in the driest. In this country it is migratory, arriving in spring from no one seems to know exactly where, and taking its departure in the early autumn. It frequents meadows and cornfields and many 
of the young are destroyed by the mowing machines. Although a bird of passage and necessarily a good.flier, it will not readily take to wing, but trusts to its strong legs and feet and great running powers to escape from its enemies.

The young run about directly they are hatched, and feed on insects and small molluscs. The spots on the sides and belly are yellowish-buff, the back and wings brown, and the neck and breast bluish-grey; the chin is white.

Most people who live in the country are familiar with its harsh grating cry which it utters more frequently in the morning and evening than during the middle of the day. Albino specimens of the Landrail and the Water Rail have been met with.

If kept in confinement. it should be taken indoors about the time when it would migrate if at liberty, and be kept warm, for it is rather impatient of cold.

\section{The Water-Rail.}

Though resident in Great Britain and Ireland all the year round, the numbers of Water-rails are increased during the winter by immigrants from the north. The bird is about II inches in length, and is brown on the upper parts of the body and bluish-grey on the face, throat and breast; the sides are white, and the belly and vent buff, with black spots; the legs and toes, which are very long, are greenish-yellow, and the bill orange, darker above than on the lower mandible.

The female is very like her mate, but is somewhat lighter in colour and smaller. The tail is short and pointed, and is frequently jerked up and down as the bird walks about in search of food, which consists chiefly of small molluscs and aquatic insects and plants.

The eggs are cream coloured, marked with brown and grey spots; they vary in number from seven to ten or more. The bird can be readily tamed and will associate with poultry, coming to be fed when called, and getting very tame. 


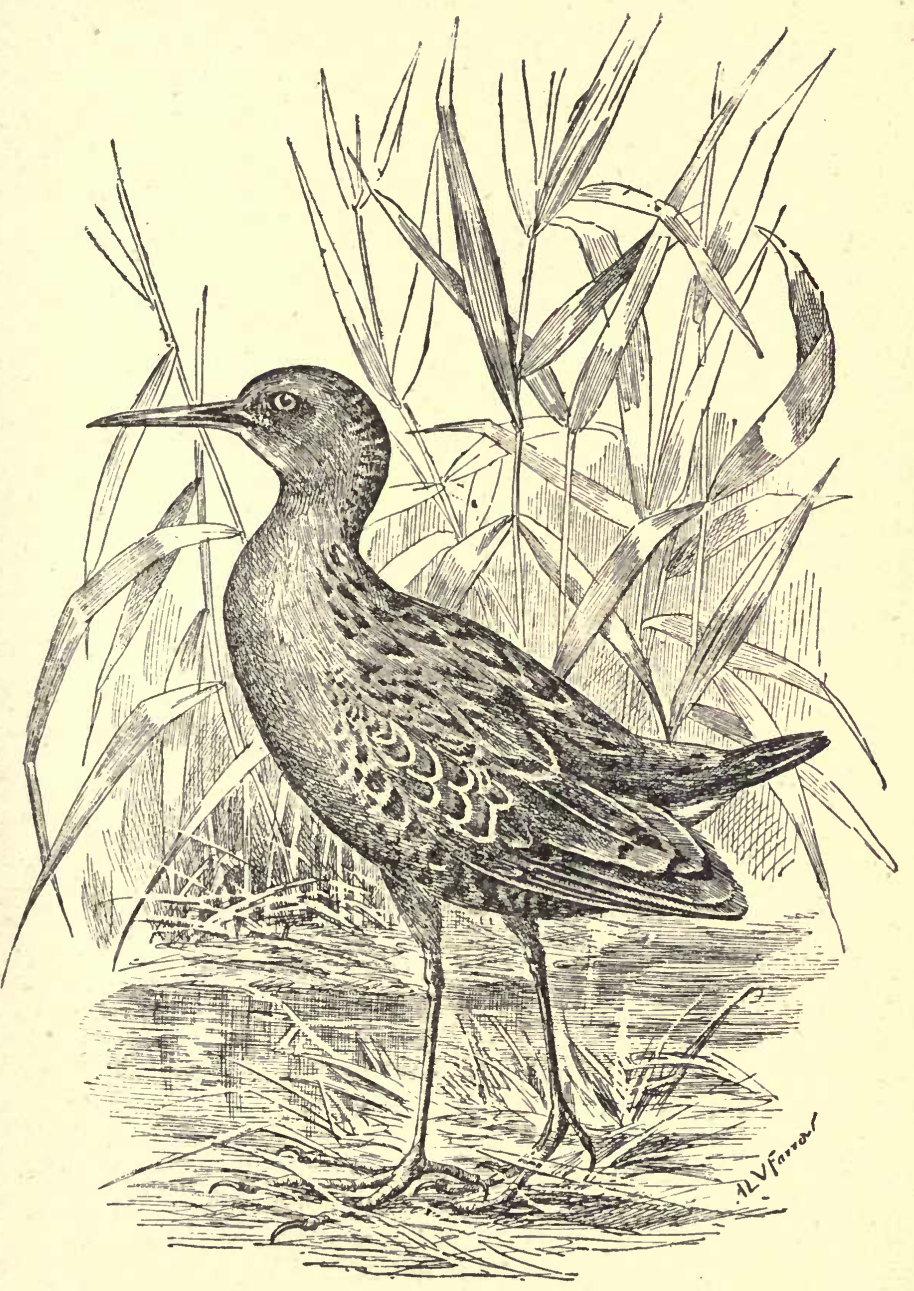

THE WATER-RAIL. 


\section{THE RAVEN.}

Unfortunately this bird is now very scarce, and with the exception of a few localities, which it would be invidious to name, has been practically exterminated in the interests (?) of game-preservers, who like to do all the killing for their own sport. It is one of the largest of our native birds, measuring about 2 feet in length, of which the tail takes up rather more than 8 inches. The general colour is deep glossy black, with metallic reflections of blue, green, and gold, which make it a very handsome creature when examined closely. It is a cunning one too, and volumes might be filled with anecdotes of its exploits in many directions. The nest, made of sticks, is placed in various situations, on a high tree, or the ledge of some inaccessible rock, or a ruined building, or, failing such points of vantage, even on the ground. The eggs, two or three in number, rarely more, are of a greenish-olive colour spotted with brown. The young are easily reared on meat, snails, worms, and insects of all kinds, and when full grown will take anything that is offered to them, but are especially fond of eggs. A pair of tame Ravens will breed in confinement and bring up four or five young ones to a brood, although in a wild state these number two, or sometimes three only.

It is a bird, however, that requires a little management, not only on account of its strength and the formidable weapon it carries on its head (its bill, that is to say), but of its cunning: for it has, in common with all the Crows, a strong passion for carrying off and hiding any small glittering object it can lift easily, such as rings, coins, teaspoons, or even a small watch, and many instances are on record where its thievish propensities have been the means of getting innocent people into trouble.

The best plan is to keep one of the wings a little clipped, but only the primaries need be so treated, and the mutilation will then be imperceptible unless the birds attempt to fly. By this means the Raven's hiding-places will be readily accessible to its master, and should from time to time be overhauled, when it will be surprising what a 
number of "unconsidered trifles" will be discovered there, things that no one ever would have imagined were possessed of any attraction for the bird: but a Raven is possessed of a strong spirit of mischief, and no doubt many of its felonious ?acts are the outcome of sheer devilry; for of course it does not hide the things with any view to a future meal, though it will bury bones and any portions of food it is unable to consume upon the spot.

If it is desired that a pair of Ravens should breed, a flat basket should be provided for their use, and may be fastened towards the upper part of their abode, or be merely left upon the ground. If they have the run of the garden, they will be able

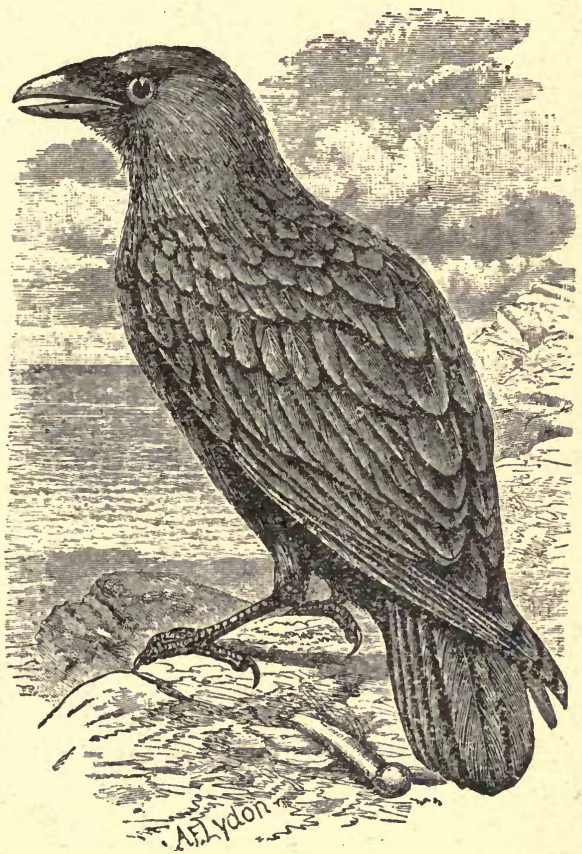

The Raven. to pick up sti cks to line it to their liking; but if, as must usually be the case where the gardener takes any pride in his work, they are confined to a.run, they may be given the disintegrated portions of a birch broom, and a little hay and some feathers; with the two last, they will line the nest they have built themselves with the former in the basket, and there, 
as they are not difficult to please in the matter of food, they will rear a succession of families, two or three in each season, for a long series of years.

The Scandinavian Raven is much larger than its British congener, and is therefore, from a utilitarian point of view in the aviary, to be preferred to the latter.

\section{THE RAZORBILL.}

This bird belongs to the Auk family and is pretty common in many parts of Britain. It is a strong flyer, and very active in swimming, in and on the water, as well as in diving. It is frequently to be seen at a considerable distance from land, e. $g$., about midway between Holyhead and Dublin. Its food consists of fish, which it secures by diving. It is migratory in its habits, breeding in the north.

The upper parts are dusky black, and the under pure white; the greater wing coverts have white tips, which form a line across the wing; there is also a white line from the brown eye to the insertion of the bill, which is black and crossed by a line of white near the muchhooked tip. The female is exactly like the male in outward appearance, and only lays one egg, in the most propitious spot she can find. They often nest with the Gulls and other sea birds.

THE RED-BACKED SHRIKE. See under Shrikes.

THE REDBREAST. See Robin.

THE RED-BREASTED FLYCATCHER. See under Flycatchers. 
THE RED-BREASTED MERGANSER. See Merganser.

THE RED-BREASTED SNIPE. See Godwit (Bartailed).

THE RED-LEGGED HORSEMAN. See Redshank.

THE RED-LEGGED PARTRIDGE. See under Partridges.

THE RED-NECKED GREBE. See under Grebes.

THE RED LINNET. See Linnet (Common).

THE REDPOLLS. See under Linnets.

THE RED.RUMPED LINNET. See Twite (under Linnets).

\section{THE REDSHANK.}

This bird is also known as the Red-legged Horseman, Sandcock, Pool Snipe, etc. It is fairly common in many parts of England and Ireland, but less numerous in Scotland. It breeds in the north, and spends the winter in more southern latitudes, where it also nests now and then, but very rarely. It is rather a handsome species, of bluish 
grey and brownish colour, thickly spotted with darker grey and brown; the long bill and legs, which last are bare for a considerable distance above the knee, are bright orange red.

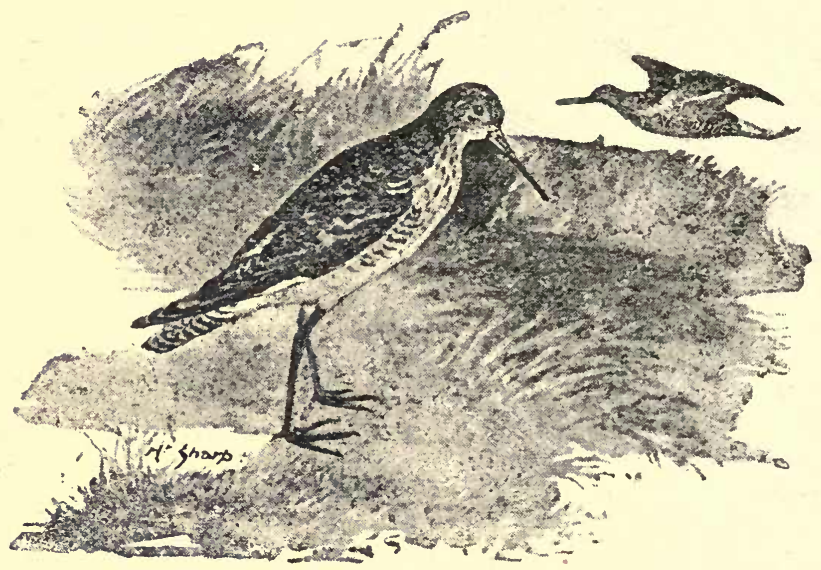

Redshanks.

The Redshank is very easily tamed and will live a considerable number of years in confinement, if suitably lodged and intelligently cared and catered for.

\section{THE REDSTART.}

This is one of the handsomest of our British Birds; it bears a considerable resemblance to the Stonechat but is of even more brilliant plumage. The bill is very dark horn-colour; the forehead, cheeks, chin, throat and upper half of the breast are jet-black; the top of the head white; the nape and back, slate colour; the rump and tail (with the exception of the central pair of feathers, which are brown), red; the wings are brown, with lighter margins; the lower half of the breast and the upper half of the abdomen are bright red, fading to grey on the under 
tail-coverts, which have a faint slate tinge; the legs and feet are brownish-slate; the iris, brown.

The female is quite different, the prevailing colour in her case being dusky ashen-grey, with a reddish shade on the rump and tail, which gives her a great resemblance to the femaleNightingale. The young are speckled with white and orange on the breast, and are two years old before they assume their full colour.

A white variety has been noticed; Morris reported one from Gloucestershire.

The Redstart is a native of, at least is found in, both $\mathrm{Eu}-$ rope (except the extreme north) and Western Asia;

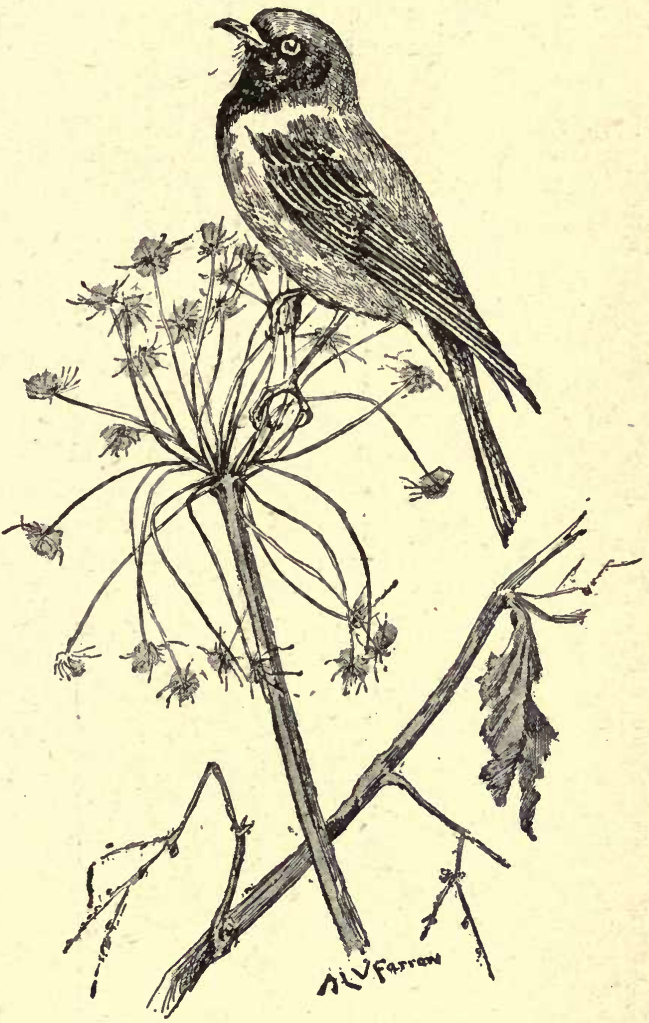

The Redstart.

it is tolerably abundant with us, preferring the vicinity of human habitations to quieter scenes. It has been noticed in several of the London parks, 
If kept in the house, the cage should be similar to that recommended for the Wheatear; but it looks better in an outdoor aviary, where a pair will occasionally breed. It must be taken into the house before the frost sets in, for it is impatient of cold, arriving here in April, to take its departure again in September, though a few may linger until the first. week in October.

When wild, the Redstart lives almost entirely on insects. Morris relates that a pair were observed to feed their young twenty-three times in an hour, usually bringing more than one caterpillar at once; but allowing that one only was carried, and taking the day as consisting of fourteen hours, the magnificent total of two thousand two hundred and fifty-four per week is arrived at. In the autumn, a few berries are partaken of. When kept in a cage, it must be fed and treated as recommended in the case of the Wheatear.

The nest consists of a few leaves and stems of grass, placed loosely together in a hole in a tree, wall, or building, or very rarely in the mouth of a disused rabbitburrow. The eggs are six or seven in number, and much resemble those of the Hedge Sparrow, but are somewhat less vividly blue.

The young can be easily brought up by hand on ants' eggs, maggots and other insects; but artificial feeding (i.e., on "prepared foods," bread and milk, and so on) is not usually a success. They leave the nest early, even before they can fly, possibly because of want of room in the crevice where they were born, or perhaps from a sense of insecurity attaching to a domicile with only one opening for ingress and exit. If they are wanted for training, therefore, they must be taken as soon as the quills of the wing and tail feathers begin to sprout, at which time they will gape more freely in order to be fed, than they would do if older.

Indigestion, from the use of unsuitable food, is at the bottom of the complaints from which the captive Redstart is liable to suffer, and if he is treated correctly he will live free from them all, and attain to the utmost term of his natural life in health, beauty and happiness, 
This bird is a natural mimic, and even in the wild state may be heard imitating the notes of other birds, so that it is not surprising that in confinement, where he has little else to do, this talent should be fully developed.

If kept in a cage or flying loose in a small conservatory, he will make a very charming pet on account of his tameness and docility.

When birds are kept in a conservatory, it should be a cool one; that is, either one that has a sunny aspect and is not artificially heated at all, or where, at most, the frost is just kept out by means of hot-water pipes during severe weather; for anything approaching a stove temperature is to be avoided, unless, perhaps, in the case of a few birds of exotic origin with which we are not at present concerned. But in any case, it is a good plan to accustom the birds to sleep in their cage, which should be wired in front only, and if a thread is fastened to the door, this can be readily closed, when the owner chooses, as soon as the bird has entered to get a mealworm, or some other dainty, placed there for the purpose. It is also a good plan to have a curtain of baize, or some other warm material, hanging over half of the front of the cage, which the bird will be found to appreciate, always sleeping behind it, and enjoying the privacy it affords.

Never, on any account, drive a bird about in order to catch it; if it must be caught, entice it into the cage, close the door noiselessly by means of the string already attached to it, and so arranged round one of the other wires as to act like a pulley. We have always found this the best plan, and use a piece of stout black thread, which the bird does not notice. When it has gone into the cage, the latter must be covered over with some dark cover, and the position of the bird having been noted, a practised hand will be able to catch it in a moment without fuss or alarm, and so transfer it, without injury to itself, to whatever cage or place it may be desired to put it into. 
THE RED.THROATED PIPIT. See under Pipits.

\section{THE REDWING.}

This is a smaller bird than either the Thrush, Blackbird, or Fieldfare, as it measures no more than 8 inches in length, of which the tail takes up $3 \frac{1}{2}$ inches. Like the Fieldfare it is a native of the north, and only visits us during the winter season. The bill is nearly an inch long, of a dark horn colour, and yellow at the base. The legs and feet are light grey with a yellowish tinge, especially on the latter. The upper surface of the body is brownisholive, and the under parts white thickly bestrewn with heart-shaped black spots; the sides, however, have a reddish hue, and the under wing coverts are orange-tawny-red, whence the bird's English name of Redwing. White, cream-coloured, and variegated specimens have been obtained at various times.

The Redwing is a migratory bird, travelling south from the far north in October, and then spreading itself over the continent of Europe as far as the shores of the Mediterranean Sea; it reaches the British Isles in large flocks, which are more than decimated before the return homeward of the survivors in March or April.

The Redwing thrives very well in a large garden aviary, and may be preserved for several years in the house in a cage of suitable dimensions, providing it is not kept in too warm a position.

It should be fed and treated exactly as recommended for the Song Thrush and Blackbird, but is even more accommodating in its appetite than the former, which is tantamount to saying that it will eat and thrive (more or less) on anything that is set before it.

Little is known about the breeding arrangements of the Redwing, but it is said to place its nest in a low bush, or even on the ground among stones, and to lay five or six bluish-green eggs spotted with brown. The nest has been occasionally met with in the north of Scotland and elsewhere. 
The diseases to which the Redwing is subject are the same as those of the Song Thrush, and are to be treated in the same way.

"Doctors differ" as much with regard to the song of the Redwing as they do in the case of the Fieldfare, Bechstein describing it as being as unmelodious as that of the latter, while Morris declares that it is "exceedingly beautiful, its high and varied notes rivalling those of the Nightingale"!

THE REED BUNTING. See under Buntings.

THE REEVE. See Ruff.

THE RICHARD'S PIPIT. See under Pipits.

THE RING BLACKBIRD. See Ring Ouzel (under Thrushes).

THE RINGDOVE. See under Doves.

THE RINGED PLOVER OR DOTTEREL. See under Plovers.

THE RING-NECKED DIVER. See Diver (Great Northern). 


\section{THE RING OUZEL. See under Thrushes.}

\section{THE ROBIN, or ROBIN-REDBREAST.}

This bird is such a familiar object in our midst, that it seems almost superfluous to take up a portion of a somewhat limited space in order to describe it: still, as in one case, at all events, that has come under the immediate notice of the writer, it was mistaken for a Goldfinch, or rather the latter bird was mis-called and believed to be a Robin, it may be as well to treat it like the other birds that occupy a place in these pages.

It is a native bird, of course, and is found in considerable numbers all over the British Isles, even in smoky suburbs, where every branch of every tree that struggles in them for existence is coated with a layer of soot, which falls so thickly on the stunted grass as positively to disguise its colour. It is essentially a friend of man, and yet no bird is shyer or more solitary during the breeding season.

The Robin is not a large bird, for it measures some $5 \frac{1}{2}$ inches in length only, $2 \frac{1}{4}$ inches of which belong to the tail. The general colour is greenish-olive, but the forehead, cheeks, throat and breast are reddish-orange. The bill and legs and feet are horn-brown, and the eye, which is very full and bright, is dark brown approaching to black.

The female is slightly smaller than her mate, is of a greyer colour on the back, and has a good deal less orange on her head and face.

The young are very unlike their parents, being dingy olive-grey in colour and spotted on the breast and wings with lighter markings of a yellowish tinge, so that they are often mistaken for young Thrushes by people who are not very conversant with birds; at the first moult, however, they assume the adult plumage, but have less red than a male of the second year, and the little round yellowish spots on the wing-coverts are not so conspicuous.

When wild the Robin is found all over Europe, except perhaps in the extreme north. With us, in Britain, he 
is stationary, but in the more northern parts of the Continent he wanders about, probably in search of food, and migrates southwards till the return of the warm weather.

Naturally of a bold and fearless disposition, the Robin very frequently avails himself of the protection that is usually extended to him by man, and will venture into the house and take up his abode there of his own free will; and if trapped or taken when full-grown he very soon becomes reconciled to captivity, providing he is supplied with suitable food and is not unnecessarily alarmed and interfered with. It is unfortunate that he should be of such unsocial habits, that he cannot have a companion of his own species, male or female, without a deadly feud springing up between them, for it is a pretty sight to see him hopping about the room in the free and easy manner he is accustomed to assume, when he honours anyone with a visit.

If kept in a cage, it does not much signify what its shape may be, providing a portion of it is shaded off from public view, for the Robin likes to retire to a quiet corner now and then, and there he will sit and sing to himself for hours, particularly in the evening.

Less stress is laid upon the size and shape of the cage, because the door of it should often be opened and the bird permitted to fly about the room, always returning to the cage to sleep and feed.

The Robin in a state of nature feeds principally on insects, and is of much service in clearing off multitudes of the gardener's worst enemies; he also eats earthworms, and makes no difficulty of disposing of one as long as himself. In the house he should be treated on the same lines, that is to say, have a diet consisting for the most part of ants' eggs (those provided by Mr. E. Romans of Llanelly, South Wales, are excellent), maggots of the flesh-fly, blackbeetles, otherwise cockroaches, and garden worms; but any of the latter that are deep red, ringed and pointed at both ends, must not be used, as they possess poisonous properties, and care must also be taken that the beetles have not been killed by means of phosphor paste, or any other deleterious substance. 
There is a popular notion abroad that the Robin will live on breadcrumbs, and so he will for a time, but on such a diet he quickly falls into a decline, and unless relieved by the addition of some animal matters in his food will die: meat, raw, may be given in moderation, and crissel or dog-biscuit will stop a gap, but must not be used too freely. In the autumn the Robin eats -

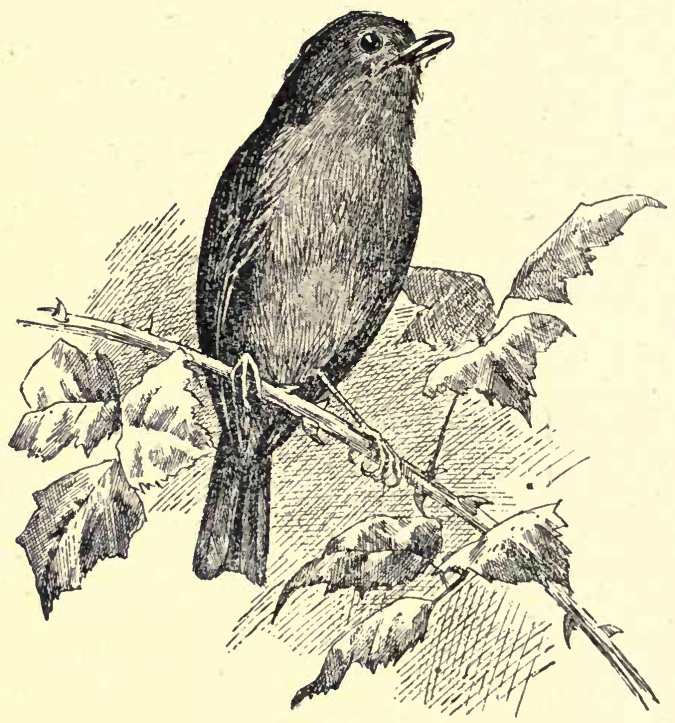

THE ROBIN.

currants, elder, ivy and other berries, and so forth; and with something similar he ought to be provided in the house, for it is good to imitate Nature as closely as possible in the dieting of cage-birds of all kinds.

$\mathrm{He}$ is extremely fond of bathing, and should have an opportunity provided for him of doing so every day, but not in his cage-rather a little pan placed for his use on the floor, and if this is put on a tray, no mess will result from his splashing about. 
The Redbreast has, generally, two broods in the year, and the nest is placed in the most varied situations; it is loosely constructed of grass and leaves, lined with hair and feathers. The eggs are from five to seven in number, of a creamy white colour, spotted with dusky-red. The young are very easily reared on ants' eggs and bread and milk, using the same precautions as are recommended in the case of the Wheatear and other small insectivorous birds. Care must, however, be taken to separate the young Robins as soon as they can feed themselves, for they are very quarrelsome, and if left together after the time when Nature bids them separate, they would be sure to fight and disfigure, if not indeed kill each other outright, the biggest and strongest remaining master or mistress of the field; but sometimes they all sink under their mutually inflicted injuries.

The tame Robin should not have any disease, and will not, if he is sensibly treated; but should he puff out his feathers and show unmistakable signs of suffering from indigestion, or liver trouble, he had better be released, for otherwise he will die, and it is always painful to witness suffering that one is unable to relieve.

It is better to bring up the young ones from the nest than to take the adults, except in the autumn; should one come into the house of his own accord, that would, of course, be the best plan of all; but in such a case, the confiding little creature should be permitted to fly away in the spring, and if so, and he remain alive, he will be certain to return to his snug retreat at the beginning of the following winter.

The really handsome plumage, the docility and extremely sweet song of the Robin, have made him such a universal favourite, that even gardeners, as a rule, have not a word to say against him, although he and his progeny certainly help themselves freely to the currants in the autumn; but, after all, the harm he may do is nothing in comparison with the benefit he confers on the horticulturist by the destruction of myriads of insect plagues. 
THE ROCK PIGEON. See under Doves.

THE ROCK PIPIT. See under Pipits.

THE ROLLER. See under Hoopoe.

\section{THE ROOK.}

This bird is rather smaller than the Carrion Crow, and may be readily distinguished from it by the fact of the skin at the base of the bill being denuded of feathers, which was long supposed to be the result of the bird's digging propensities; but as young Rooks, reared from the nest, that have never been obliged to "work for a living," also develop the same peculiarity when about two years old, the idea would appear to be untenable. The Rook is a gregarious bird, and builds in companies, as everybody knows. The young number from two to four to the nest, of which there are often two but sometimes only one in the season. Young Rooks can be reared as easily as the rest of their tribe, and, according to a correspondent of The Bazaar, "can get through more mischief in a given time than any other bird."

THE RUDDY SHELDRAKE. See Sheldrakes (under Ducks). 


\section{THE RUFF AND THE REEVE.*}

According to the Rev. F. O. Morris, "one of the most curious birds, if not the most curious, of any we have in this country." At one time it was of common occurrence, but since the draining of the fens is much less frequently met with. It is a summer visitor, arriving in April and taking its departure in September. The males precede the females, both in going and coming.

It is an extremely pugnacious bird, and if kept in an aviary, where it gets on remarkably well if fed in conformity with its natural habits, it will make war not only

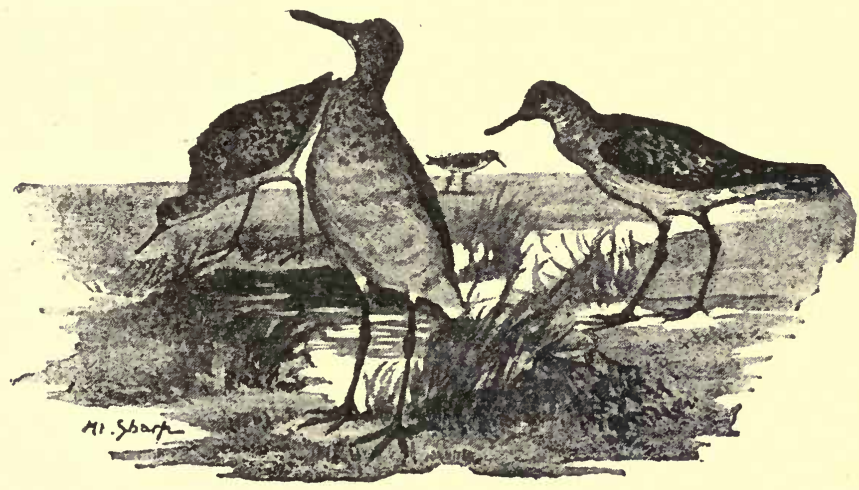

Ruffs and Reeves in Winter Plumage.

on members of its own but on those of kindred species and much damage to the combatants will be the result, for which reason it should be lodged with birds of suffcient size to be able to defend themselves successfully from its attacks.

Among its other peculiarities the Ruff is polygamous and severe battles take place at pairing time among the males. The feathers on the side of the neck are long and the creature has the power of erecting them into a kind of frill,

* The male bird is the Ruff and the female the Reeve. 
or ruff, after the manner of the Hawk-headed Parrot; it also has a bunch of erectile feathers on each side of the head, and when these all stand up the effect is remarkable indeed. The head and its long feathers are dark brown, but the ruff is much lighter in colour, or rather is dirty white minutely dotted with brown. The centre of the breast and vent is white but the sides are speckled. The rather long legs, which are bare of feathers for some distance above the knee, are greenish yellow.

The young are easily reared and used at one time to be fattened in considerable numbers for the table.

Like the Prairie and other Grouse, the Ruffs mount on any little mound to show off their attractions and challenge their rivals when they go a-courting.

\section{SABINE'S SNIPE. See Snipe (Common).}

\section{THE SANDCOCK. See Redshank.}

\section{THE SANDERLING.}

This bird is also known by the names of Curwillet and Towilly; it is very common and not possessed of any particular attractions, being of dull, not to say dingy colour

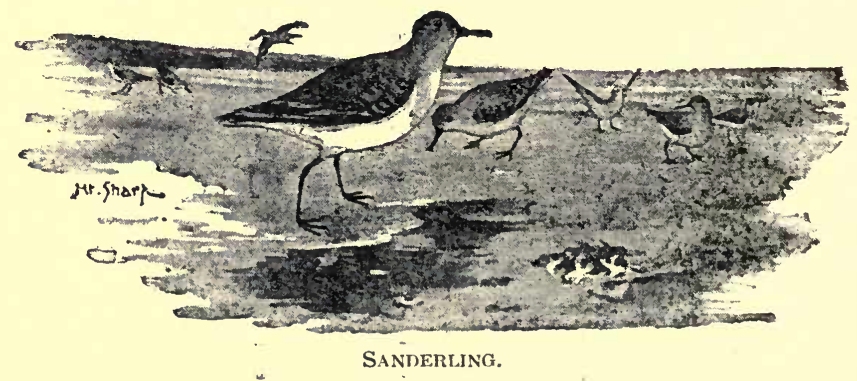


and thick-set clumsy shape. It is frequently seen in company with the Dunlin, is very active, flying and running with a very graceful action. It sometimes breeds in the north of Scotland, but as a rule retires within the Arctic Circle for that purpose. It is about 8 inches in length and may weigh a couple of ounces or a little more. It moults twice-in autumn and spring-and the summer plumage is darker than that it wears during the winter; in the latter season it is greyish white.

\section{THE SANDPIPERS.}

\section{The Common Sandpiper.}

A pretty little creature with a rather long greenish bill, and legs and feet of the same colour; it is often called the Summer Snipe and comes to us from the north in April, returning in September.

The plumage is very soft, almost silky in texture, of a greenish grey above and white on the under surface of the body slightly tinged with green and grey. It is about the size of a Snipe and lays four eggs of a creamy white speckled with brown and very large for the size. of the bird.

The food is the same as that of the other members of the family in captivity, like which it is by no means difficult to preserve in a suitably appointed place, if fed as nearly as possible on its natural diet. The young at first are thickly coated with grey yellowish down, they have a black mark on the head, and another along the centre of the back.

\section{The Dunlin, or Purre.}

This bird has a very "snipish" appearance, and not unfrequently does duty for a Snipe on the table; it is, however, one of the Sandpipers, and is very abundant throughout the British isles. It is essentially a sea-side bird, and is very seldom found at any distance inland: when so seen it has been driven in by stress of weather. 
The eggs, large for the size of the bird that produces them, are four in number, of a greenish-white colour spotted with brown, more especially at the larger end; they vary, however, a good deal in appearance. The young run about as soon as born. The general colour

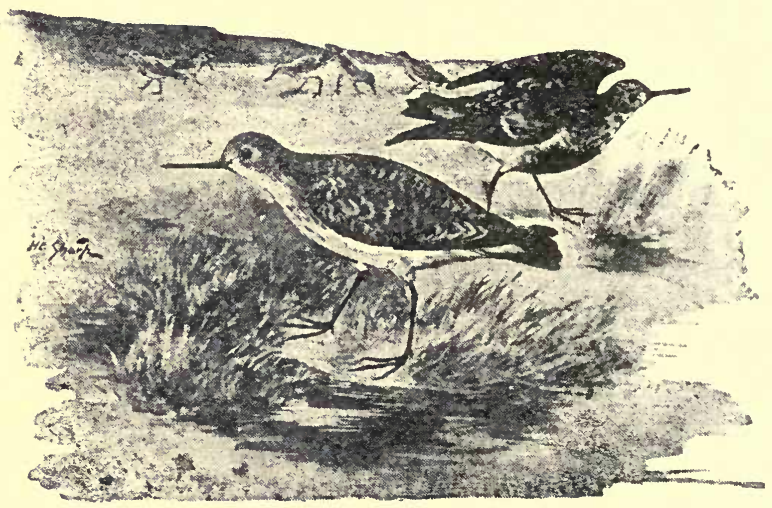

DunLin.

is brown, lighter above than below, but the breast is light grey spotted with brown, and the vent grey of a lighter shade still without spots. The legs are dark green. It is sometimes called the Plover's Page, Sea Snipe, Purre, Stint and Dunlin Sandpiper, a "confusion of epitaphs" that is decidedly misleading.

THE SCANDINAVIAN RAVEN. See Raven.

THE SCAUP. See under Ducks. 


\section{THE COMMON SCOTER.}

This is a migratory species, arriving in September from the north and returning thither in March. It flies high,

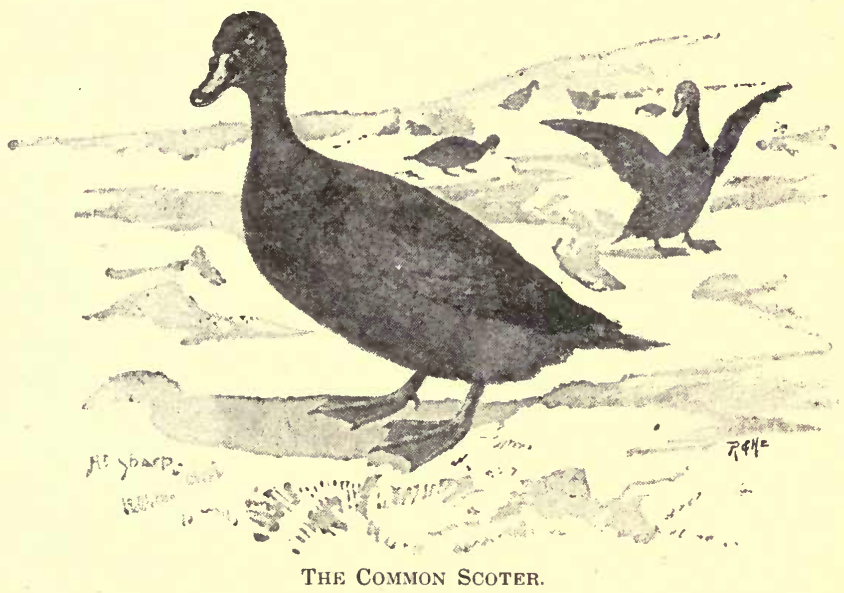

making a considerable noise with its wings. The general colour is black with blue and purple reflections; the male has a yellow knob on the bill; the female is blackish brown.

THE SEA.LARK. See Plover (Ringed).

THE SEA.MEW. See Gull (Common).

THE SEA.PIE. See Oyster-catcher (under Plovers). 
THE SEA-SNIPE. See Dunlin (under Sandpipers).

THE SEA.SWALlOW. See Tern (Common).

THE SERIN FINCH. See under Finches.

\section{THE MANX SHEARWATER.}

Though said to have been at one time common in the Isle of Man, this bird is not now frequently seen there, but is still sufficiently plentiful in the remoter Scottish islands. It is somewhat over a foot in length, and weighs a trifle over a pound. In appearance it resembles the Gulls, and is of a general dusky or brownish black colour above and white on the under parts; three ashen-grey bands crossing the region of the lower abdomen and vent. The strong bill is dark grey with a bluish tinge at the rounded tip, the front of the legs and the toes are dull orange, but the back of the legs and the webs between the toes are grey.

The young have the breast dark grey. Only one egg is laid and it is large for the size of the bird, perfectly white, and rather pointed at both ends.

THE SHELDRAKES. See under Ducks.

THE SHORE LARK. See under Larks.

THE SHOVELLER. See under Ducks. 


\section{THE SHRIEKER. See Godwit (Black-tailed).}

\section{THE SHRIKES.}

\section{The Red.Backed Shrike.}

This bird is also very commonly known as the Flusher; it is not uncommon in Britain, especially in the southern counties, but is not unknown even in the north. It is a handsome species, about 6 inches in length, of which the tail measures rather more than half. The bill is strong, black in colour, and armed with a sharp hook at the end of the upper mandible.

The forehead, or rather a narrow band on that part, the lores and a patch surrounding and projecting beyond the eyes, are jet black; the top of the head and the nape are slate-blue ; the back, reddish-chestnut-brown; the wings, greyish-brown with lighter edges to the wing-coverts and secondaries; the rump, grey; the tail, dark greyish-black at the extremity of the feathers, but the basal portion is white, which is also the colour of the vent; the throat, breast and other under parts, greyish-white; the sides, reddish; legs and feet, black.

The female is browner and greyer, and somewhat longer than her mate; and the young all resemble her until after the first moult.

The nest is built in a thick thorn bush as a rule, and is made of grass and moss bound together strongly with wool and lined with fine roots. The five or six eggs are pale greenish-white, spotted with grey and red. The male sits during the greater part of the day; the female chiefly at night. The young are fed mainly on insects, but also on the offspring of other birds, when the parents succeed in getting some.

The Shrike has a curious habit of impaling its prey on thorns, and a bush it frequents may often be seen covered with beetles, flies, grasshoppers and other insects, as well as young frogs and immature small birds transfixed in this peculiar manner. 
The young are easily reared, if their natural diet is supplied to them.

The male has a very agreeable song of his own, and is also endowed with no small imitative powers.

\section{The Great Shrike.}

The Great Shrike or Butcher-bird, also called the Grey Shrike, is met with occasionally in Britain. It is about 9 inches in length, and, as one of its names indicates, is of a bluish-grey on the upper parts of the body; wings, tail and eye-streak, black; and the remainder white; the strong beak is black, and the legs and feet dark slate.

It is easily tamed, but is dangerous with other birds, as are also the other Shrikes. It is an occasional winter visitor to this country.

\section{The Grey Shrike. See Great Shrike.}

\section{The Woodchat.}

The Woodchat is only of very casual occurrence. It bears a general likeness to the Red-backed Shrike, but has much more white about it, and a curiously notched bill; there is also a broad white stripe crossing the upper part of the wing, and a smaller spot of the same colour about the centre of it: the black eye-streak is prolonged backwards and unites with a patch of the same colour between the shoulders.

\section{THE SISKIN. See under Finches.}

\section{THE COMMON SKUA.}

This bird is also known as the Brown Gull, Teaser, Bonxie, etc. It is a fine bird more than 2 feet in length, weighing about 3 pounds and possessing a wing expanse of between 4 feet and 5 feet. 
It is one of the "sea rovers" and mostly lives by robbing other and more industrious Gulls; it is rather rare and occurs in the north only. The eggs are but two in number and are laid in June; the nest is built of heath, lichens, etc., and is placed in the most inaccessible spot the birds can discover among the cliffs.

The general colour is reddish-brown, darker on the upper than on the under surface; the breast has a greyish tinge and there is a spot of white on the wing. Legs, feet and bill dark bluish brown. See also Gulls.

THE SKYLARK. See under Larks.

THE SMEW. See under Ducks.

\section{SNIPE.}

\section{The Common Snipe.}

Like the Woodcook, the Snipe is a winter visitor to this country, where it is equally appreciated with its larger relative, as an article of food by epicures. Occasionally, too, it breeds here, and it would no doubt do so much more frequently were it not so habitually disturbed, the sight of a Snipe upon the wing, in or out of "season," having the same effect upon an average man or boy, with a gun in hand, as a crimson or red handkerchief has on the proverbial bull.

The female Snipe is larger than the male, weighing $4 \frac{1}{2}$ ounces to his 4 ounces. Albino and cinnamon or buff-coloured species have been recorded.

Like the Woodcock, a pair of Snipe will sometimes breed in a well-appointed aviary, the bulk of the diet of both species consisting of earth-worms.

A smaller kind, supposed to be a distinct species, is 
known as a Jack Snipe; it is much darker in colour, and averages $2 \frac{1}{2}$ ounces in weight, the female being a little the heavier; it is also known by the name of Judcock.

The Great or Solitary Snipe, Sabine's Snipe and the Brown Snipe are varieties, or species, that are occasionally met with, the first the most frequently, and differ but little from the ordinary type.

The Jack Snipe. See Common Snipe.

The Pool Snipe. See Redshank.

The Red.Breasted Snipe. See Godwit (Bar-Tailed).

The Sea-Snipe. See Dunlin (under Sandpipers).

The Solitary Snipe. See Common Snipe.

The Summer Snipe. See Sandpiper (Common).

THE SNOW BUNTING. See under Buntings.

THE SOLAN GOOSE. See Gannet.

THE SOLITARY SNIPE. See Snipe (Common).

THE SONG THRUSH. See under Thrushes. 


\section{THE SPARROWS.}

These form a natural group with well-defined characteristics. Two species are found in Britain, namely our household friend the Common Sparrow, and the Tree Sparrow, which bears considerable outward likeness to our familiar acquaintance of the house-tops and the streets, but also differs from it in several respects.

The food of Sparrows, when adult, consists of seeds (mostly of weeds) and insects in about equal proportions, but the young, at least while in the nest, are fed almost exclusively on the latter.

That they consume some unripe corn and garden produce is undoubted, but if the amount of good they do by devouring quantities of noxious insects and the seeds of troublesome seeds be taken into account, it will be found that the balance is not only more nearly adjusted between benefit and wrong than is often alleged against them, but that it actually inclines a long way in favour of the Sparrow.

When hand-reared from the nest one of these birds will become delightfully tame and make a charming pet, but it has a love for the comfortable, and, hiding away in corners of chairs and sofas, is sometimes sat on unawares and smothered, poor little thing!

It has been noticed that the young Sparrows fledge badly in seasons that are unproductive of insects, owing to the weather being either too dry or too cold, and many of them perish prematurely.

\section{The Common Sparrow.}

Not much space need be devoted here to the Common Sparrow, which differs considerably from the Tree Sparrow, especially as the male has a black throat and the female is so totally unlike her mate.

The nest, a slovenly affair, is built in holes of all kinds, or of hay and feathers among the boughs at the top of a tree; in the latter case it is domed.

This bird has been credited with wonderful prolificacy, but as a rule, the number of young to a nest does not 
exceed three, four being rare, while a greater number than the last is practically unknown; and yet writers have put it down at seven and even nine, and the number of broods in the season at four or five; but two is more often the case, though sometimes three.

\section{The Hedge Sparrow.}

The Hedge Sparrow, not being really a Sparrow, will be found treated separately under Hedge.

\section{The Tree Sparrow.}

This is not nearly such a common bird as its relation, and in many parts is unknown; indeed, it is not numerous anywhere. It is rather smaller than the common species, and carries more richness of colouring on its small person, which is really very handsome when critically

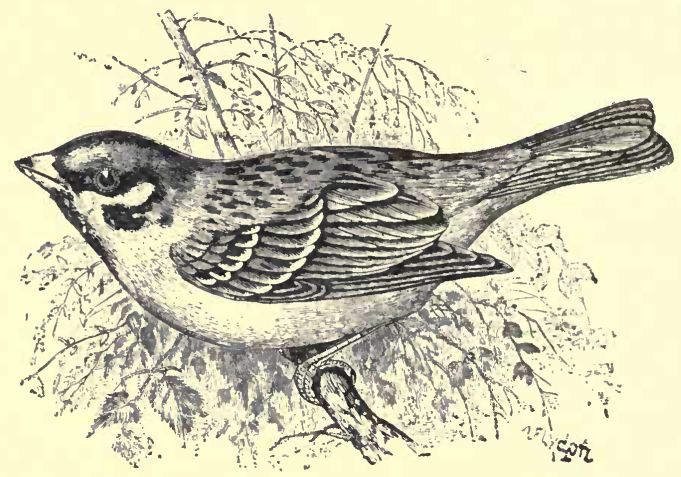

The Tree Sparrow.

examined. The top of the head is reddish-brown, the cheeks white, with a black spot; round the neck is a white ring, and the back is spotted with red and black; the lower part of the back and the rump are brownishgrey; the throat is white, and the breast pale ashen-grey; 



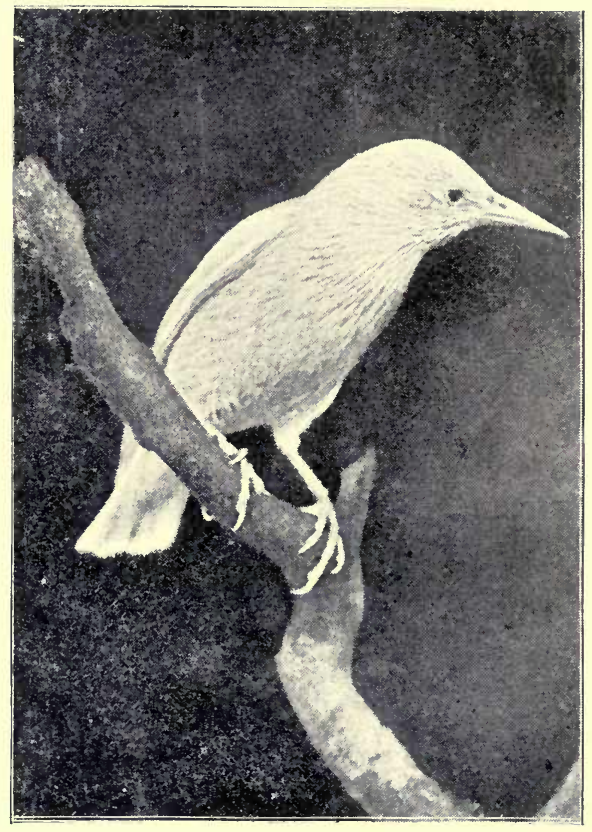

MALE ALBINO STARLING. 
the abdomen is whitish-grey, and the tail dark brown; the lesser wing-coverts are red with a rusty tinge, and the greater black with red edges and white ends forming two transverse bars across the wing.

The male and female are exactly alike.

It is a shy and solitary bird, rarely found in more than pairs in woods and copses and out-lying fields. The nest is always made in a hole in a tree, and never among the branches or in buildings of any kind.

It is not easily tamed, but will live on a mixed diet of seed and insects for several years in the house.

THE SPARROW-HAWK. See under Hawks.

THE SPOTTED FLYCATCHER. See under Flycatchers.

\section{THE SPOTTED WOODPECKERS. See underWood- peckers.}

\section{THE STANNEL HAWK. See Kestrel (under Hawks)}

\section{THE STARLING.}

Fortunately for the agriculturist, this is one of the commonest of our native birds. $\mathrm{He}$ is somewhat less in size than the Thrush and has peculiar plumage, consisting of long very pointed black feathers with metallic reflections of blue and bronze and white round spots. The female has less brilliant tints, and the young are grey, spotted with white. Albinos occasionally occur, as witness the illustration, from a photo by Mr. W. Bush, F.C.S.

In their wild state Starlings live entirely on grubs and worms, except during the fruit season, when they take a 
very moderate toll from the cherry and other trees, which should certainly not be grudged them considering the amount of good they do by the destruction of myriads of the larvæ of the daddy-long-legs, so destructive in pastures, where they burrow for several years and feed on the roots of the grass, which they kill.

In the house the Starling is a very amusing pet, learning to talk and sing in a

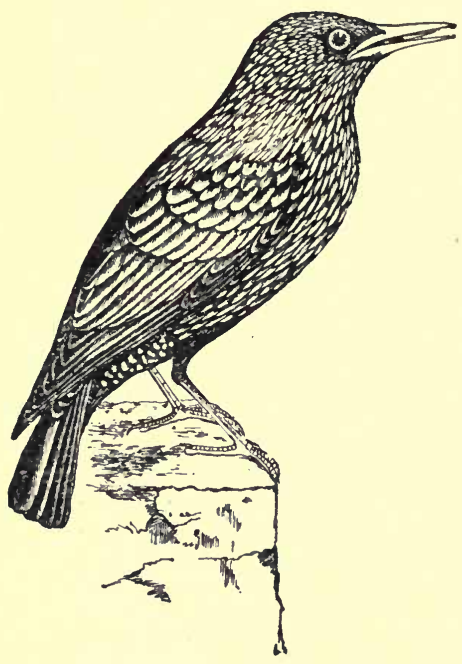

The Stariding. wonderfully accurate way. $\mathrm{He}$ is easily reared and kept on ants' eggs, maggots, and scraps of all kinds from the table. White and cinnamon varieties are not uncommon, and when found are valuable, although the price has declined somewhat of late. In a suitable place they will breed and rear their young, which, however, often turn out to be merely ordinary specimens of their kind possessing not one of the peculiar characteristics of their parents. The nest of the Starling is always placed in a hole of some kind, and the eggs, which are blue spotted with black and brown, sometimes very sparingly, are usually four or five in number. There are two broods in the season, as a rule, but sometimes three.

THE STINT. See Dunlin (under Sandpipers). 
THE STOCK DOVE. See under Doves.

\section{THE STONECHAT.}

This bird closely resembles the Whinchat in form and habit, but is more brilliantly coloured. The head, neck, chin and upper breast are jet black; the back and wings, brown with a dark centre to each feather; the rump, two of the greater wing-coverts on each side, and a round patch on the neck above the bend of the shoulder, are white; the tail is dark brown, and the breast deep orangered getting paler on the belly and almost disappearing on the vent and the under tail-coverts; the bill, legs and feet are leaden-grey.

All the directions given for preserving the Whinchat in confinement are applicable in the case of its near relative the Stonechat, which frequents the same kind of places

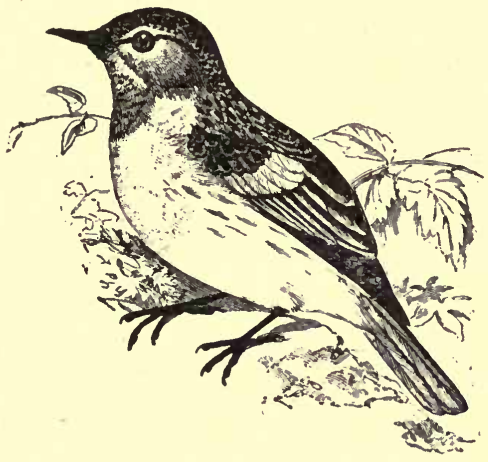

The Stonechat. as the former, and, like it, comes to us in April, to take its departure from our shores in September.

It is a very attractive-looking bird, and one that is extremely lively in its habits, but unless it has plenty of space in which to disport itself, it soon becomes dull and listless.

It has frequently been mistaken for the Whinchat, as well as for other species. 
THE STONE CURLEW. See Thick-Knee.

THE STONEGALL. See Kestrel (under Hawks).

THE SUMmer SNIPE. See Sandpiper (Common).

\section{THE SWALLOW AND THE SWIFT.}

Though both these birds are included in the "List" of birds kept at the "Zoo," they are so eminently unsuited for cage life, more especially the latter, that it is quite unnecessary to occupy space with them.

\section{THE SEA-SWALLOW. See Tern (Common).}

\section{THE SWAN.}

This is scarcely a British bird in its wild condition, but it is domesticated in many parks and other places, and occasionally a wild specimen visits us from the north during the prevalence of severe weather which drives it from its native haunts. Like the Geese, the Swans are in the main herbivorous, and should have grass and other vegetable matters provided for them as well as grain.

When the female is incubating, and when the young are small, the male Swan is apt to attack anyone approaching either the nest or the cygnets, and as he is a powerful bird becomes somewhat dangerous at such times. $\mathrm{He}$ is especially hostile to dogs and fails somewhat to discriminate between a dog and its owner.

It is unnecessary to describe the appearance of such 


$$
\text { FOR CAGES AND AVIARIES. }
$$

a well known bird; it is the type of the sub-family Cygnince, of which several other species are occasionally included in the avi-fauna of the British Isles, but without any warrant save the very rare occurrence on our shores of some wandering specimen.

THE SWIFT. See under Swallow.

THE TASSEL. See under Hawks.

THE TAWNY OWL. See under Owls.

THE TAWNY PIPIT. See under Pipits.

THE TEAL. See under Ducks.

THE TEASER. See Skua.

THE TERCEL. See under Hawks.

\section{THE TERNS.}

\section{The Arctic Tern.}

A winter visitor, occurring in considerable numbers in many places in the three Kingdoms. Morris supposes that "the name of Tern is derived from the habit the bird has of turning in the remarkable manner it does when pouncing on its prey," which consists of small fish, as well as water 
insects, worms, and anything of a like kind that comes within its reach. It is rather longer than the Common Tern and darker in colour, the long forked swallow-like tail is almost white, and the black cap extends down to the nape of the neck, where it terminates in a point. The legs and feet, as well as the bill, are of a dark orange colour.

\section{The Black Tern.}

A small bluish-black species, with a short scarcely divided tail. The top of the head and the breast are black, the cheeks and the wings and tail blue grey, the vent white, the bill dark grey, and the legs and feet reddish grey. It is a migratory species of infrequent occurrence in Britain, although at one time breeding here in considerable numbers. On the continent it is reckoned to be a delicacy and is in much request for the table! It only measures 8 or 9 inches in length, and weighs somewhat over two ounces.

\section{The Common Tern.}

This bird is also sometimes known as the Sea-Swallow. It is an extremely graceful little creature with a black head, or rather cap, and grey upper and white under parts; the long bill and the legs and feet are greyish orange.

Morris waxes so poetical in his description of the flight of these birds that we are tempted to reproduce his words: "All the varied movements of the Sea Swallow in flight are performed with that striking ease and grace which are characteristic of these birds, whether on a calm summer day when the glassy surface of the sea shimmering in the sun is broken only by the leaping of the shoals of fish over which the Terns hover, or later in the waning year when the winds their revels keep!"

The eggs are very various in appearance, and are usually three in number. Both birds share the task of incubation. Albino specimens have been obtained, and the birds have reproduced in confinement. 


\section{THE THICK-KNEE, OR STONE CURLEW.}

This is a migratory species, which is also known by the names of Great Plover and Norfolk Plover. It comes to us in March and April, and stays to breed, laying on the bare ground. The young run almost as soon as they come out of the shell, and have a curious habit of squatting on the earth with head thrown back and outstretched wings, when from their resemblance to the weather-worn. stones around them they often escape notice.

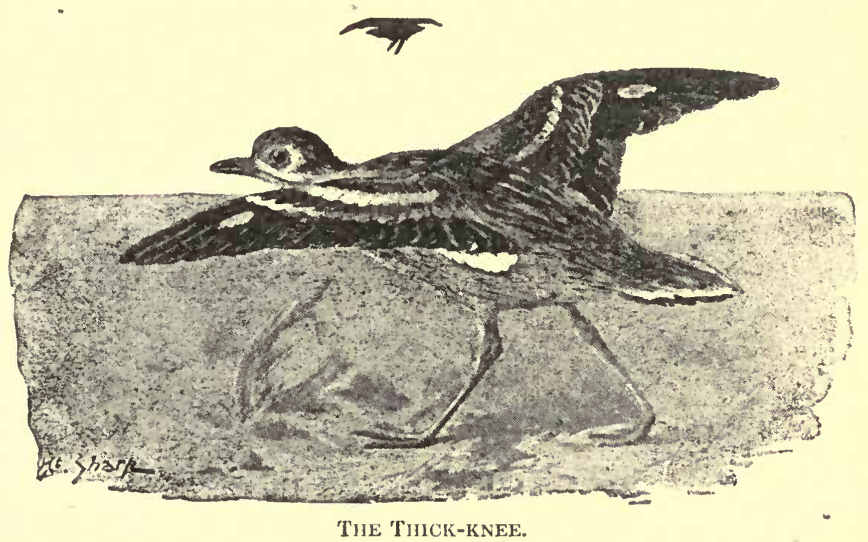

They live on beetles and other insects, snails, slugs, worms, and swallow a good deal of grit to aid digestion. They are easily domesticated, but must be protected from cold during the cold part of the year or they quickly fall into a decline and die from exhaustion.

\section{THE THRUSHES.}

In addition to the birds described hereunder, the Blackbird, Fieldfare, and Redwing belong to the Thrush family, but are for popular reasons described in this book under their own headings. 


\section{The Missel Thrush.}

This is the largest member of the Thrush family that frequents the British Isles, measuring from I I to $\mathbf{2} 2$ inches in full length, of which $3 \frac{1}{2}$ or 4 inches belong to the tail. The bill is about an inch long, of a dark brown colour, but the base of the lower mandible is yellow. All the upper surface of the body is brownish-grey, with a ruddy tint on the lower back and rump; the sides of the head and the under parts are creamy-white, with black spots of triangular shape on the breast and oval spots elsewhere, these being of a blackish-grey-brown shade.

The female is paler in all her colouring, but otherwise resembles the male.

An albino has been occasionally met with.

The Missel Thrush is found all over Europe, and is common in the British Isles, where it is resident all the year round, although on some parts of the Continent it is migratory.

In confinement, being a large bird with a good appetite and proportionate voidance, it needs a good-sized cage; but is better suited for a garden aviary, where it looks well and thrives exceedingly, than for the house. It should, however, only be lodged with birds of its own or a larger size, for among smaller ones it is apt to be somewhat spiteful.

Both in its wild state and in captivity it feeds and should be fed the same as the Song Thrush, and, contrary to what might be expected from its name, evinces no remarkable partiality for the berries of the mistletoe.

The nest is variously placed, sometimes in a bush, and sometimes on a bare horizontal bough of some tree overhanging water: grass, moss and lichens form its foundation, which is firmly cemented with mud to its support, and the inside is lined with fine grass, moss and hair. The eggs, which are four or five in number, are larger than those of the other Thrushes, and are of a greenishwhite colour speckled with brownish-red spots, especially about the larger end.

The young birds are greyer and more spotted than their elders; they are easily brought up by hand, and will 
then breed freely in confinement. A solitary female even will lay, and then perform the part of foster-mother to the orphaned young of other Thrushes, the eggs of which she will hatch as if they were her own, rearing the young successfully either in or out of doors.

The diseases to which the bird is subject are obstruction of the rump gland, which arises from insufficient opportunities

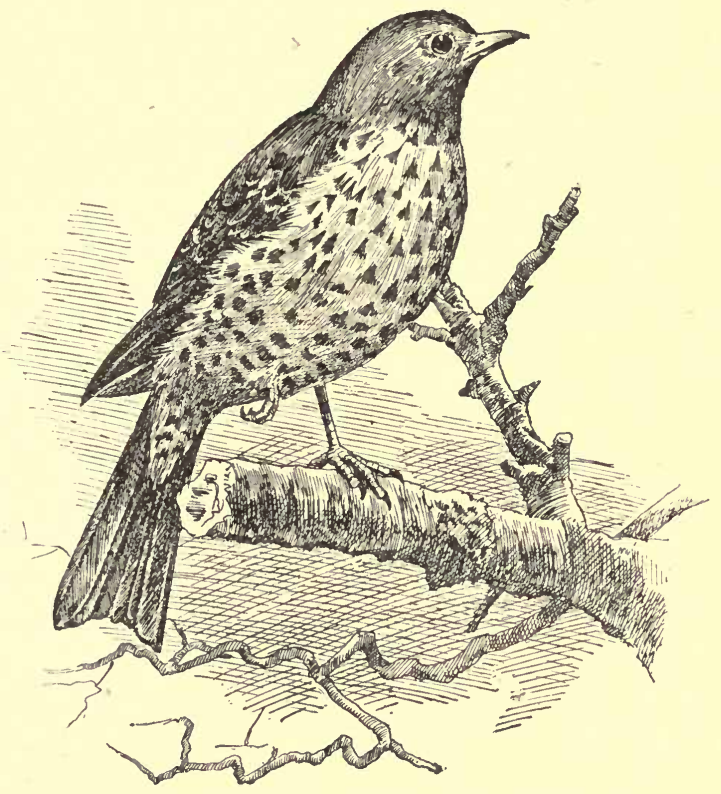

The Missel. Thrush.

for bathing; also constipation and atrophy, which are the result of injudicious treatment in the matter of diet, and consequent indigestion. A return to a more natural kind of feeding will in the latter case usually effect a cure, unless the bird is too far gone.

Morris agrees with Bechstein that the song of the 
Missel Thrush is of rather inferior quality, and the great attraction of the species in the eyes of amateurs is the facility with which it will breed in confinement and the readiness with which it will take upon itself the care of young and helpless birds belonging to the other members of its family.

\section{The Ring Ouzel.}

Unlike the other migratory Thrushes, this bird comes to us during the summer time, and breeds freely in our midst, like the Swallow, Martin and many more of the fine weather migrants; and yet, strange to say, Bechstein affirms that it arrives in Germany and England on the foggy days at the end of October or the beginning of November; Morris, more accurately, as it seems, remarking that it arrives towards the end of March and departs in October.

As there is no doubt that both authorities are referring to the same bird, the question arises, are we from this discrepancy between two famous ornithologists to conclude that the Ring Blackbird, as it is also called, has materially changed its habits in the course of half a century? By no means, but rather that even as the divine Homer has occasionally been detected napping, so the Father of Cage-bird Lore sometimes, if very rarely, nodded.

The male Ouzel varies from II to 12 inches in total length, 4 inches of which belong to the tail; the female is shorter by about an inch. The general colour of the former is black, but the feathers, especially on the lower surface of the body, are edged or fringed with grey, and a crescent-shaped shield of pure white with the points or horns directed upwards occupies the front of the breast, imparting to the wearer a characteristic appearance, that serves to identify it at once. The female is lighter in colour than the male, and has the grey edging more distinct; the white of her shield is tinged with grey. The young males resemble their mother, but the young females have scarcely any sign of the distinctive shield.

Pure white specimens of the Ring Ouzel have been occasionally met with, and others that show white on the head or on the wings are not uncommon, 


\section{FOR CAGES AND AVIARIES.}

The Ring Ouzel occurs in Northern Africa and Western Asia as well as throughout Europe, and is of wandering rather than migratory habits properly so called. It is as susceptible of domestication as the other members of the family to which it belongs, and will live from twelve to fifteen years in the house if provided with a suitable cage and properly attended to; but it is better

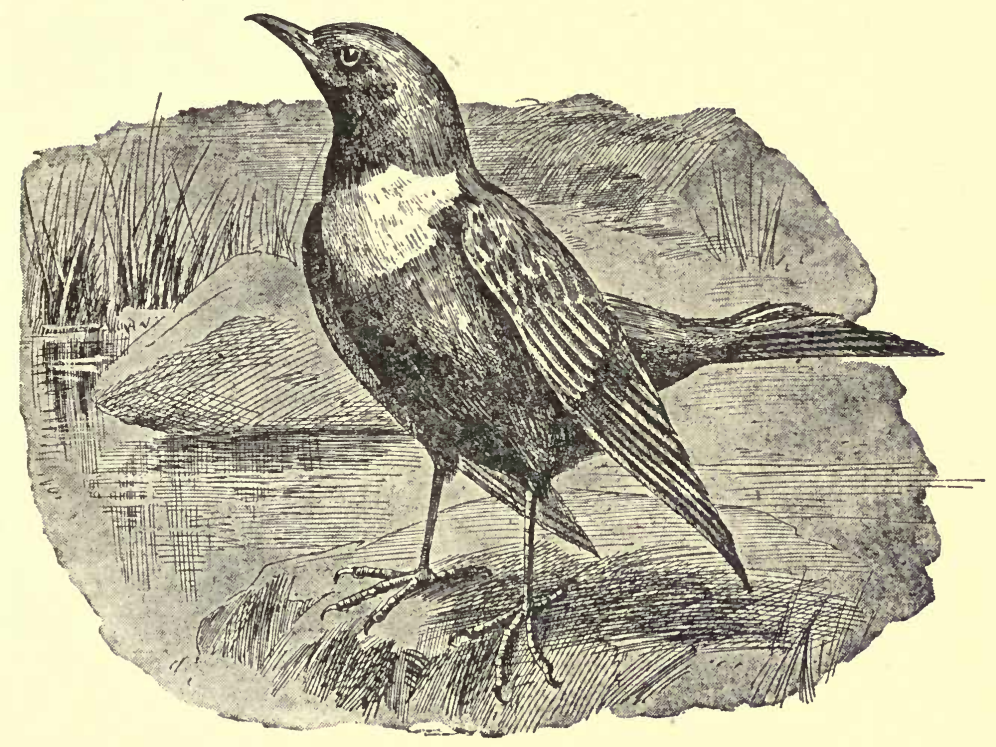

The Ring Ouzel.

suited for a garden aviary, where it is seen to the best advantage. If kept in the latter situation there should be a little rockery placed in a convenient position for it to perch on.

When wild, as well as when kept in confinement, the food is the same as that of the Song Thrush.

The nest, similar in construction to that of the Blackbird, is frequently placed upon a ledge of rock among 
heather, but also in a bush or on a tree at varying heights from the ground. The eggs are pale bluish-green speckled and streaked, particularly at the larger end, with purplishbrown, but they vary a good deal in appearance even in the same nest.

The young are readily brought up by hand if treated as recommended for those of the Song Thrush.

The Ring Ouzel is a healthy and hardy bird, that seldom ails unless as the result of injudicious treatment, when a return to a more suitable dietary will promptly effect a cure, if the case is not too far gone.

Morris writes of the song of the Ring Ouzel, that it is desultory, but sweet-a few plaintive notes uttered in a clear warbling whistle. Bechstein compares it to that of the Blackbird, and says that, although hoarser and deeper, its voice nevertheless is more harmonious and agreeable. It does not, however, appear to possess the same facility for acquiring the notes of other birds, or of imitating an artificial melody, as its sable-coated congener the Blackbird.

When shown, the Ring Ouzel should always be entered in the "Migratory Class" and not in that appropriated to the Thrushes, though we have seen it awarded a prize in the "Any Other Variety" section as well as in the Migratory, and receive a distinction in both, which was manifestly unfair or at least said little for the attention paid to his work by the judge; the only explanation being that the decision in both cases did not rest with the same person.

\section{The Song Thrush.}

This universal favourite is, most unfortunately, becoming of less frequent occurrence in many places day by day, for not only do some of our epicures imitate the French in eating him, but he is much persecuted by horticulturists in consequence of the erroneous belief that he does them a vast amount of harm, while a severe winter decimates the ranks of survivors from all other sources of danger.

Without boasting of the brilliant colouring that belongs to many tropical and to some of our indigenous species, the Song Thrush is really a very handsome 
creature, brownish-olive on the upper, and creamy-white on the lower surface of the body, where he also presents a mottled appearance in consequence of a number of heart or spearhead-shaped spots scattered irregularly on the throat and breast as well as the upper part of the abdomen.

The female may be distinguished by the decidedly greyer tinge of her plumage both on the upper and lower parts, while her spots are rounder in shape. She is somewhat smaller than her mate, who measures $8 \frac{1}{2}$ inches from the point of the bill to the extremity of the tail, which takes up $3 \frac{1}{4}$ inches of the entire length.

Albino and pied or parti-coloured Thrushes are occasionally met with, and black or melanotic specimens are tolerably frequent, and have given rise to the erroneous belief that such birds are hybrids resulting from a cross between a Thrush and a Blackbird. So prevalent is this notion that on more than one occasion a bird of this description has actually been awarded a prize in a class for hybrids at a bird show! though, it is needless to observe, no such phenomenon as cross-pairing ever takes place in a state of nature, nor has any trustworthy evidence been brought forward of Thrushes and Blackbirds mating together and producing mules even in confinement.

The Song Thrush is resident with us, and keeps pretty constantly to the spot where it was hatched: shy and solitary in its habits, even in winter, when stress of weather forces other species into unusual companionship, it is rarely seen even in pairs except during the breeding season. In the house it should be provided with a large cage, a convenient form of which is $2 \frac{1}{2}$ feet long by 15 inches wide, and 2 feet high, with the roof constructed in the Swiss cottage style, or like the letter V turned upside-down, thus $-\Lambda$, which has a better appearance than a flat top for a cage of the above dimensions. The food and water vessels may be placed nutside, but if so, the apertures through which the bird reaches their contents must be of sufficient size to prevent the feathers getting rubbed when it is eating or drinking. There are usually $t_{\text {hree perches, one each in front of the food and water }}$ 
tins, and the third above and between the other two, and they should all be of different size.

Another kind of cage is one 3 feet long by 2 feet wide, and $2 \frac{1}{2}$ feet high, and wired only in front: in either case there should be a tray that can be taken out to clean without disturbing the bird, and it is better to cover it with sawdust than with sand or mould. If this suggestion be adopted, it will be necessary to supply the indispensable grit in a tin, which need not be a very large one, hung up inside the cage.

The bath, a most important adjunct to a Thrush's cage, is best hung over the open door, and when the bird has "tubbed" it should be immediately removed, to be replaced on the following morning in the summer-time, but every third or fourth day only at other seasons.

In its wild state, the Song Thrush lives on insects, worms, snails and berries of different kinds, being particularly fond of those of the ivy and elder. It is believed to do much damage in plum and cherry orchards, as well as among currants, raspberries and strawberries; but although it cannot be denied that the bird does take toll of these, the good it does in destroying myriads of the most deadly foes of the gardener, much more than balances any harm it may do to the crops; and the horticulturist who wantonly kills a Thrush or destroys its nest is injuring himself and encouraging his own natural enemies.

The dieting of a Thrush in confinement is a very vexed question, for almost everybody who keeps one has a recipe of his own for feeding it. It is curious to notice that hemp and peas enter largely into the composition of those much vaunted "foods," and scarcely anything could have been hit upon that is more unsuitable. German paste and oatmeal porridge are two favourite substitutes in the house for the Thrush's natural diet; the former consists for the most part of coarsely-crushed peas, and the porridge sticks to the sides of the bird's mouth, causing troublesome sores (cracked lips, literally), that make the poor creature's life a burden to it.

Bread and milk would be an ideal staple food for one of these birds, if it could be guaranteed against turning 
sour, as this causes scouring, which terribly weakens the bird, and sometimes kills it outright. However, if prepared twice a day and served in a glass or porcelain vessel that can be readily cleansed and scalded, it answers very well, but must be supplemented with ants' eggs, as many as the Thrush likes to eat; garden worms, which should be placed in a shallow pan of moist earth; blackbeetles ad libitum; snails and mealworms being also allowed occasionally; fruit as in season; and lettuce or tender cabbage when these are to be had. Thrushes thus treated will do so well that they will breed even in a large cage, and the cock sings so incessantly, that neighbours have been known to complain of the noise!

As intimated, there are quite a number of special "foods" advertised for Thrushes, but their chief value consists in the ants' eggs they contain, and

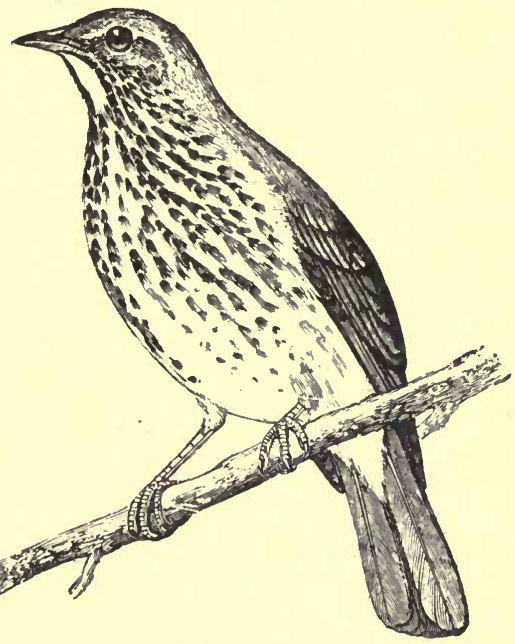

Thy Song Thrush.

as these are mixed with a good deal of "padding" in the shape of peameal and rubbish, they are expensive as well as unsatisfactory. The Thrush, however, has a very accommodating appetite, and will sometimes live for a wonderfully long time on the most unlikely and unsuitable food, hempseed for example; but a bird so dieted cannot be happy, for it is impossible, under such circumstances, that it can be healthy, and health and happiness, as a rule, are found together, 
Dog-biscuit and "crissel" are useful as articles of diet for captive Thrushes, but even the latter requires supplementing largely with insect food-in a word, feed a caged Thrush, as nearly as possible, on the lines on which it would cater for itself in a state of freedom in its native haunts, and it will do well.

The nest of the Thrush is large in proportion to the size of the bird that builds it; it is composed of stalks of grass and moss, very firmly cemented together with mud, or, where this is unobtainable, with cow-dung; but as the Thrush nearly always nests in the vicinity of water, it is but seldom that the latter material is employed.

The situation of the nest is various, but it is never found exactly on the ground, although it is occasionally met with hidden among the brambles or nettles, or even long coarse grass on a sloping bank near the root of a tree; it is, however, more frequently placed on the lower branches of the latter, or in a bush; a standard fruittree in a garden, for example, where the birds are protected, is a favourite site; and a Thrush has been known to make its nest against the side of an elm among some young growth of twigs where a branch had been lopped off quite twenty feet from the ground, while one has also been known to build among the branches of a vine in a conservatory, to which it obtained access through a broken pane of glass.

As a rule, there are two broods in the year; the first in April or May, or even in March if the weather is mild, and the second in May or June. The eggs, which are of a bluish-green colour, are sparingly speckled with large and small spots of dark blackish-brown, and are usually four or five in number, but sometimes as many as six, and occasionally as few as three, but in the last case it is probable that the bird had been previously disturbed. Incubation, performed by the female alone, lasts about fifteen days. The young are attended to by both parents, and are chiefly fed with small green caterpillars, although, failing these, other insects, snails and small white slugs, are had recourse to, as well as fruit of various kinds, The young grow rapidly, and in from a 
fortnight to three weeks, according to the state of the weather, are able to leave the nest, which they sometimes do before they can quite use their wings, and in the latter case they often perish from the combined effects of exposure and inability to follow the parent birds in their rambles, which they always try to do.

The first brood, as a rule, consists for the most part of males, and the second of females: the former are of a browner colour on the back than their sisters, but it is difficult to distinguish the sex with absolute certainty until the young birds have moulted their nest feathers. Young Thrushes are not at all difficult to bring up by hand on bread and milk, ants' eggs, and an occasional mealworm, blackbeetle, or other insect. They may be taken when the quills of the wings and tail are beginning to sprout, and in about a fortnight will be able to feed themselves. It is better to keep them in their own nest as long as possible, and if any dung is accidentally dropped into it, it must be at once removed, or the plumage will suffer, and the appearance of the young birds be more or less marred. They require to be fed every twelve or fifteen minutes, a mouthful or two at a time, from dawn to dusk, so that the task of rearing them is by no means a sinecure, if it is done as it ought to be; but if a thing is worth doing at all, it is certainly worth taking pains with, and a little extra trouble is more than repaid by the improved condition of the birds, which, when treated as advised, grow quickly and are happy and comfortable, as well as tamer and more confiding than they would have been had they been less carefully attended to.

A pair of hand-reared Thrushes will breed quite freely in an aviary, providing they have accommodation suitable to their requirements; the female sometimes building in a bush just as she would do in a wild state, but more usually placing her nest on the top of a flat box or cage, or a ledge of the covered-in portion of her abode, which doubtless in her idea is more private than the wired flight outside. An instance occurs to the writer where a hen Thrush made four nests in one season, and 
deposited no less than twenty-two eggs, every one of which was fertile; but the cock, probably missing the society of his mate, broke them all before the incubation was complete; and in several other instances a similar tragedy was enacted; so that it is necessary when the third egg has been laid to remove the gentleman, or at any rate to partition him off, in which case he tries his best by singing and calling to induce the hen to neglect her duty. The better plan is to take him away altogether, when she will sit quietly and successfully rear her brood, providing of course that she is properly attended to, as regards the quantity as well as quality of the food supplied to her.

Occasionally a solitary female in a cage will evince a disposition to become broody, and if she is provided with a nest made by a wild bird, will lay eggs in it, which must be removed, and those of another bird of the same species, of a Blackbird, or even of a Starling or Cardinal, may be substituted for them; when she will hatch them and bring up the young strangers as if they were her own.

Probably the reason why a Thrush has no more than two broods in the season is the difficulty of finding suitable food (in a dry summer many of the young die in the nest or soon after leaving it), for in an aviary they always produce three and occasionally four batches; but it is better not to allow them to exceed the natural complement, as over-egg-production has a debilitating effect on the mother, so that she moults with difficulty afterwards, and sometimes not at all.

The Thrush is a very hardy bird, and will endure a wonderful amount of privation without much apparent injury to its constitution, but it stands to reason that one correctly treated will be both handsomer and healthier, as well as more lively, than another in whose case all the laws of nature have been set at defiance.

Indigestion, resulting in convulsions or fits, and sore feet, are the principal complaints to which caged Thrushes are liable; the first can be guarded against more easily than cured, though a return to a natural diet and a pinch of bicarbonate of soda in the drinking-water will go a 
long way towards restoring the shattered health; and tender feet will not happen if sawdust instead of sand is used for the floor of the cage, and this is regularly seen to at least every second day. It is needless to remark that the perches also require attention, and should be scraped or washed as occasion may demand.

Sometimes a Thrush will catch cold from exposure to a draught, and should then be given a teaspoonful of the following mixture in two tablespoonfuls of water for drinking-any respectable chemist will make it up for a few pence: Oxymel of squills, liquor tolu, mucilage of gum acacia, and glycerine, of each twenty drops, water to one fluid ounce, mix. This will soon afford relief. Occasionally, however, a congested state of the liver will cause panting and shortness of breath, which are usually put down to an attack of "asthma," a very unusual complain among birds, although liver congestion is common; a teaspoonful of fluid magnesia (Dinneford's or Murray's) in two tablespoonfuls of water for drinking will give speedy relief.

Indigestion often gives rise to constipation, which will be relieved by the magnesia, but if not, a mealworm or blackbeetle dipped in castor-oil and then given to the bird will not fail to produce the desired effect. None of these ailments, however, need necessarily attack a caged Thrush, and if it is correctly dieted and lodged they will not, and it will be very seldom indeed that the aviarist will be obliged to have recourse to "the birds' medicine chest."

Fits may occur; these are the result of a disordered digestion, as a rule. Relief will be afforded by magnesia or oil and a return to a natural diet.

Scaly legs torment some elderly captive Thrushes and are the direct consequence of insufficient opportunities for bathing. The sufferer must be made to stand in a shallow pan of warm water by placing a dish-cover or something of the kind over it, and letting the bird remain there for a quarter of an hour or so, until the redundant scales have become softened, when they can be readily got rid off by rubbing them gently with a towel, or a piece of flannel; but unless they peel off easily, they had 
better be left till another occasion, and should on no account be forcibly removed. If the nails, or bill, grow too long they should be trimmed with a pair of sharp scissors or a penknife, taking care in either case not to go too near the quick.

If a Thrush does not moult readily, increase the allowance of insect food, and if that does not prove sufficient to get him out of his difficulty, add ten or twelve drops of Squire's syrup of hypophosphites (chemical food) to the drinking water (two tablespoonfuls), and a beneficial result will speedily follow.

A Thrush should not be kept too warm, as in a kitchen or a heated conservatory, for example; but care must be taken that he is not exposed to draughts, and if kept in an ordinary living-room the cage must be hung below the level of the gas or lamp.

With the foregoing directions duly attended to there is no reason why one of these birds should not live for twelve or fifteen or even more years in the house, although the Father of Cage-bird Lore, Bechstein, only credits him with five or six. When allowed to breed, however, he will rarely survive for more than seven or eight years.

Without exactly being a disease, the intense desire for pairing that possesses some Thrushes in the spring may give rise to serious and even to fatal complications, and the best thing to be done when the condition is discovered is to get the poor bachelor a mate, or failing that, to turn him loose in a large room and feed him more sparingly than usual, when the attack will gradually work off and the bird be himself again.

The song of the Thrush has always been much admired, and by almost universal consent he has been voted a good second to the Nightingale, which, perhaps, is an over-rating of his merits, although he is a capable vocalist all the same-the tenor, as one might say, of the feathered choir. But he requires to be listened to amid his natural surroundings in order to be properly appreciated, for his reiterated calls for "Frederick, Frederick, Frederick," are apt to become a trifle wearisome when repeated, as they 
often are, from before dawn until after dusk. He is capable of learning to repeat a tune, but has less talent in this direction than his near relation the Blackbird.

\section{The Water Thrush. See Dipper.}

\section{THE TIERCEL OR TIRCELET. See under Hawks.}

\section{THE TITS.}

\section{The Bearded Tit.}

Properly speaking, this bird is not a Tit, but should be placed midway between the Warblers and the Wrens, and by "Warblers" is meant such birds as the Chiff-chaff, the Wood and Willow Wrens, etc. It is a very pretty and interesting bird, but is, unfortunately, extinct as a native of this country, although once occurring in some parts in considerable numbers.

The Bearded Titmouse measures $6 \frac{1}{2}$ inches in length, of which the tail takes up $2 \frac{3}{4}$ inches. The bill, which is not more than four lines long, is of a yellowish-orange colour and has a number of long, black hairs, starting from its base; the lores are black and the mark is prolonged to about midway down the side of the face, where it terminates in a point, simulating a moustache, whence the trivial name "bearded."

In the female the distinctive moustache is less apparent than in the male, otherwise the sexes are much alike in outward appearance.

It frequents localities where reeds and bulrushes abound, and there it builds itself a domed nest, composed of the leaves of the plants among which it is situated, lining it with the down, or pappus, of the same.

In the house it may be kept in aviary or cage, but if in the latter, it should be as large as possible and furnished with a pot planted with sedge or other aquatic 
plants, in which these birds delight. It has been known to nest and produce eggs under such circumstances, but there is no instance on record of young ones having been reared.

The young are fed on ants' eggs and small mealworms and other insects, and may be by degrees weaned to artificial

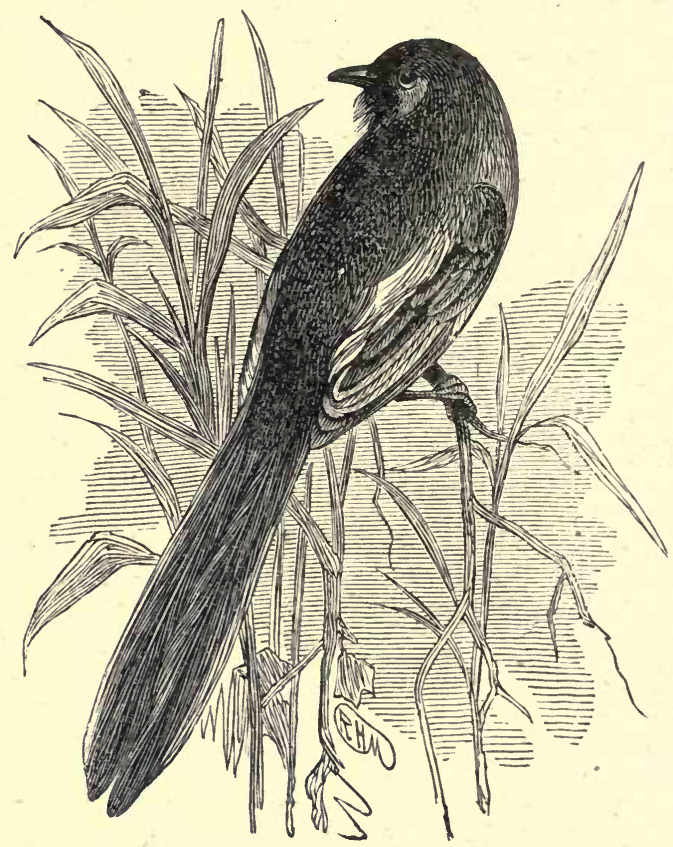

THE BEARDED TIT.

food, of which ground dog-biscuit and crissel should form the basis.

Beyond their quaint habits and pretty plumage they have nothing to recommend them for their "song" is only an insignificant twitter.

When exhibited at a show, the proper class for the Bearded 
Tit is among the smaller varieties of foreign birds for which no special place is provided, as it is quite certain that it does not now occur wild in Britain, although at no very remote period it was to be met with, even in considerable numbers, among the Lincolnshire Fens, and in other similar localities. Possibly one reason for its disappearance may be the keenness - of the pursuit directed against it by birdcatchers, although the reclamation of its favourite haunts has had no doubt something to do with its expatriation. If entered among British species, in consequence of having been actually caught in this country, it should be in one of the classes appropriated to birds of passage, for in any case it does not winter with us, but retires to warmer climates during the inclement portion of the year.

An instance of some of these birds having made nests and laid eggs in confinement has been brought under the notice of the present writer, but the young were not reared, probably owing to the want of suitable food, and, perhaps, a little to the somewhat fussy interference of the owner. Should anyone desire to try and get a pair to breed, they should have a good-sized enclosure, out of doors preferably, placed at their sole disposal, and in this should be a large pot or a small tub containing reeds or bulrushes in a living condition. Among the lower stems of these the bird will construct with the leaves their domed nest. There should be an abundance of ants' eggs at the disposal of the Tits, fresh if possible, but if not those sold by Mr. Romans of Llanelly will make a very good substitute for the recently obtained article, and will be much appreciated by the birds. Aphides, too, can readily, much too readily as a rule, be propagated in a greenhouse or a cucumber-frame, and will serve to make assurance doubly sure.

If the attempt is made out of doors, it will be well to provide a miniature pond in which the reeds can be planted, or in which, at all events, the pot containing them can be placed; this will ensure their continuing in a fresh and healthy condition, which, of course, will contribute to the success of the undertaking. 


\section{The Coal or Cole Tit.}

The Coal Tit is much smaller than its relations, as may be readily seen if a piece of suet or bacon-rind be attached to a tree or a pole in the garden, for all the Tits are directly attracted to the dainty, which they settle on in turns, the Oxeye, as becomes his superior size, taking the first bite; when he has had enough the Blue Tit appears upon the scene; to be followed by the little Coal Tit, which will then be noticed in close proximity, but afraid to come down, so long as the larger Blue Tit is hanging on to the fat; but when he goes, down comes the Coal at once, and the difference in size as well as in appearance becomes at once apparent.

\section{The Great Tit.}

This bird, which is also called Oxeye, and very often Black-cap, by the dealers, is a bold, fearless, handsome bird, at least when unsoiled by the smoke of towns, the outskirts of which he frequents in considerable numbers. Measuring nearly 6 inches in length, of which the tail accounts for $2 \frac{1}{2}$ inches, he has a conical, sharp-pointed black bill, brown eyes, and lead-coloured legs and feet. The head and throat are deep black, but the cheeks are white; the back is greenish-olive, the rump ashen-grey, and the breast and belly are yellowish-green, divided longitudinally by a black line.

The female is very like the male, but the dividing black line of the breast is shorter, and her colouring generally is duller, and this is noticeable in the young as well as in adult specimens of the species.

In their wild state the Tits feed about equally on insects and seeds and berries, taking the first chiefly in summer and the rest in autumn and winter, when insect food is more difficult to find. They all get credit for doing an immense amount of damage to trees by knocking off the buds, but really they are among Nature's most accomplished pruners, and the amount of buds they remove are as nothing compared with those that the horticulturist himself destroys when he prunes his trees. It has been 
said by some too indulgent friends of these birds, that they only pick off diseased buds, such as have insects in them, but that is scarcely so; however, notwithstanding the damage they do, it is certain that they accomplish a vast deal more good by killing myriads of destructive insects, whose eggs and pupæ they are also largely instrumental in destroying. It is asserted that trees which have been, apparently, deprived practically of all their buds by Tits, yet bear good crops of fruit in due season, often the very best in the orchard.

Tits are not suitable birds for cage or aviary; in the former they soon pine and fret themselves to death, for they have no scope there for their ceaseless activity; and in the latter, they are dangerous to their companions, even to such as are considerably larger than themselves.

However, if they must be kept, let them be fed on hemp and sunflower seeds, ants' eggs, as many mealworms

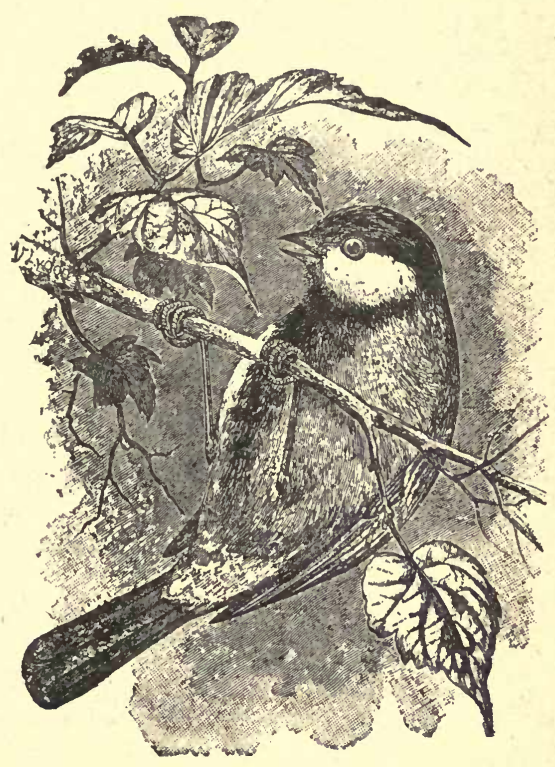

The Great Tit. and other insects as possible, and let them have a pieca of suet and a bone with a little meat on it to peck at. As these birds never roost in the open, but always in a hole or crevice of some kind, they should have a snug retreat provided for them, into which they may creep at night. 
The Blue Tit. - This bird is a miniature presentment of the Great Tit and might pass readily enough for its big brother, but it has no black on its head.

The Long-tailed Tit. See Introduction, page 8.

The Marsh Tit has the head black and the back brownish grey; while the Crested Tit is ornamented with an upstanding crest of black feathers, more than an inch long and tipped with white.

The Blue, Marsh, and Crested Tits measure each about $4 \frac{1}{2}$ inches, of which the tail accounts for $1 \frac{1}{3}$ inches.

'rHe TOWILLY. See Sanderling.

THE TREE SPARROW. See under Sparrows.

THE TUFTED DUCK. See under Ducks.

THE TURNSTONE. See under Plovers.

THE TURTLE DOVE. See under Doves.

THE TWITE. See under Linnets.

\section{THE WAGTAILS.}

These are among the prettiest and most graceful of our birds, and number five species, either indigenous or visitors to this country, where they frequent meadows and 
the borders of streams and are often to be seen in attendance upon sheep and cattle for the sake of collecting the insects the animals disturb from among their haunts in the grass.

At first sight, the Wagtails seem among the most unlikely of birds to succeed well in confinement, which simply proves that appearances are deceptive, for they get on very well indeed, even in a cage, and in a garden aviary seem to be as much at home as they are in the meadow or by the brook side, for they will breed, not only two of each species together, but individuals belonging to different varieties, and produce-hybrids or mongrels ? $\mathrm{Ah} ! \mathrm{a}$ little more experience is needed to establish that point.

In a cage they have not nested, so far as the present writer is aware, though if due attention were paid to their requirements, even in such a restricted area, there seems to be no reason why they should not do so, and that successfully.

Being of such a lively disposition, it stands to reason that the more extended the place in which they are kept the better, and in an aviary a streamlet, with a rocky background and a sandy bed, would suit them exactly: there they would live and multiply their kind in the fullest security, and of course live happily, or they would not, as they do, nest and rear their young.

A good deal of confusion exists as to the different species of Wagtails, no two writers agreeing to give them the same names, but that is not of much importance in this case, as the Pied is the only member of the Wagtail family that is to be seen here in the winter season.

\section{The Grey Wagtail.}

This is a very elegant bird, about the same size as the Pied Wagtail. Without being exactly of migratory habits, it is of a more wandering disposition than its Pied relation, and travels about in the winter-time in search of food. If it be desired to keep it in the house, it must be treated like the Pied Wagtail. 
The top of the head, nape and back are lavender-grey; throat black; eye-streak white; breast, rump and belly, yellow; wings, blackish-grey with yellowish edges to the secondary wing-feathers; the tail is black, but the inner feathers composing it are white; the bill is yellowish in colour, and the legs and feet are greyish-yellow.

It has bred mules with the Pied Wagtail, and if suitably placed, will breed freely in confinement.

\section{The Pied Wagtail.}

The Pied Wagtail is the one most commonly met with in Britain, to which country and the Scandinavian Peninsula it was believed by the late John Gould, F.R.S., to be confined.

It is 7 inches long, $3 \frac{1}{2}$ inches of which belong to the tail. The bill is dark slate-grey, almost black and

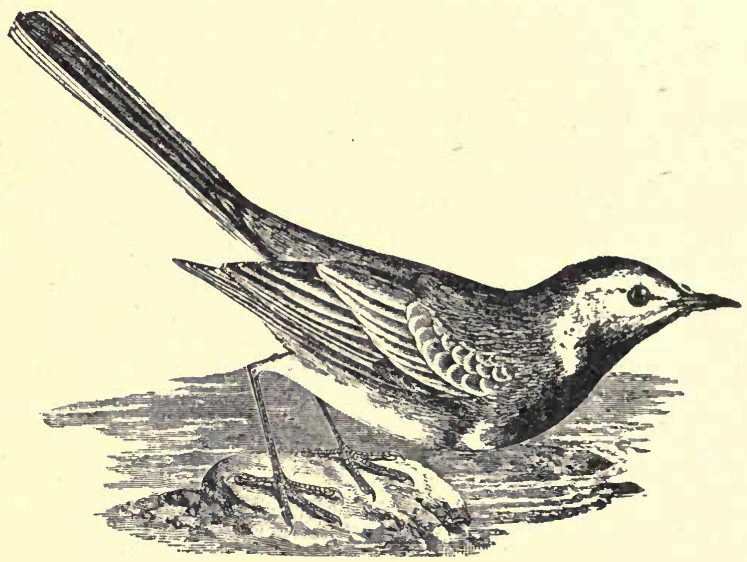

The Pied IVagtail.

very sharp at the tip. The forehead, face, a streak down the side of the neck, the lower breast and remaining under parts, as well as the edges of the wing-coverts and the secondaries, are white; and the nape, throat, and 
upper breast, jet black; the rest of the plumage is dark blackish-grey.

The female is darker and has not so much white on the face.

When wild it lives on insects and small land and water molluscs, with which it should be provided in the house, as well as with ants' eggs and insects of various kinds, including mealworms and blackbeetles. It may be accustomed to artificial food, and a little raw lean meat is now and then beneficial for a change.

When tame it is very tame, like all soft-billed birds, and makes a charming pet, living for ten or twelve years in the house.

\section{The White Wagtail.}

This is very similar to the Pied Wagtail, but is greyer than that species.

\section{The Yellow Wagtail.}

This bird is altogether lighter in colour than the Grey Wagtail. It is a summer visitor only, is found in similar situations to the other Wagtails, and should be treated like them.

THE WATER.CROW. See Dipper.

THE WATER-PIPIT. See under Pipits.

THE WATER-RAIL. See under Rails.

THE WATER-THRUSH. See Dipper. 


\section{THE WAX WING.}

This bird, often absurdly called the Bohemian Chatterer, is a winter visitant to the British Isles, and has its home within the Arctic Circle, whence it migrates south in the winter, sometimes occurring here in considerable numbers.

It is about the size of a Thrush, but being very thickly covered with soft feathers of a silky texture, looks larger. The head is ornamented with a kind of crest. The general colour is reddish-ash on the upper surface, and five or six of the secondaries are tipped with little bits of a red substance, that looks much like sealing-wax, whence the name Waxwing.

The throat, eye-streak, wings, and tail are almost black, and the two last are tipped with yellow.

There is no instance of these birds having bred here, and as a rule they are very impatient of heat. They feed on seeds, berries and insects, and soon get tame.

\section{THE WHEATEAR.}

This pretty bird, which is one of our summer visitants, is about $5^{\frac{1}{2}}$ inches in length, $1 \frac{1}{2}$ inches of which belong to the tail. The bill is very dark horn colour; the forehead, greyish-white deepening to slate-grey on the nape; a white streak surmounts the eye, which is surrounded by a black patch of irregular shape; the back is brownish-grey, shading to lighter grey at the sides; the wings are dark brownishgrey; the greater wing coverts are slightly edged with yellow; the chin, white; neck, breast, and upper part of abdomen, orange-brown; vent, white; the central pair of tail-feathers are blackish, but the rest are white with dark tips; the rump is white, and the legs and feet dark grey.

The female is reddish-grey on the back.

The young are spotted with orange on a dark ground, something after the manner of young Robin Redbreasts.

White, buff, and variegated specimens have been occasionally met with.

The Wheatear is a European species and is fairly abun- 
dant in Britain, in some localities very much so. It arrives here in March or April, and takes its departure in September. As a rule it frequents high ground, but is, nevertheless, very numerous in Holland, which is proverbially flat.

The best kind of cage for a Wheatear is one 3 feet long by 2 feet high and $1 \frac{1}{2}$ feet deep, wired only in front. If the bird is kept in a garden aviary, where it shows to great advantage on account of its lively habits and pretty plumage, it must be taken indoors at latest by the end of September, for the cold would soon kill it. With every care, it seldom lives long if kept entirely in the house.

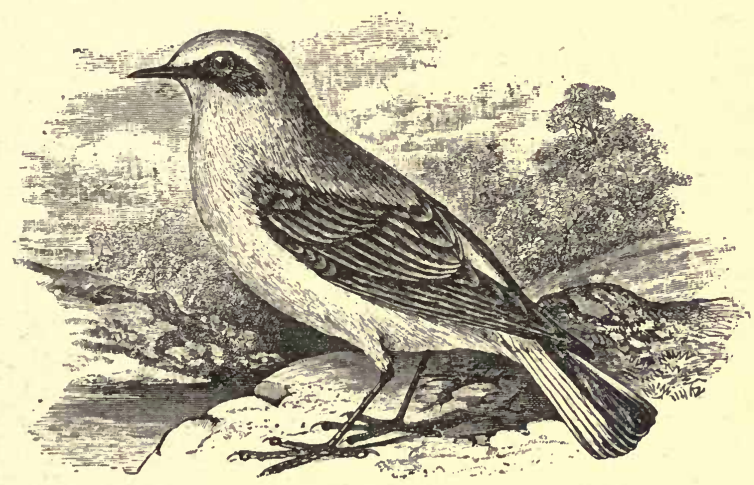

THE Wheatear.

When wild, the Wheatear subsists altogether on various kinds of insects, and as near an approach as possible to its natural diet should be provided for it, if it is to be kept in confinement. Some fanciers recommend a mixture of crushed hemp-seed (!) and breadcrumbs, to which they add a small quantity of lean raw meat cut up very small or scraped, or by way of a change a little hard-boiled egg occasionally; but ants' eggs, mealworms, blackbeetles and gentles are readily procured, and the more of them that can be supplied to the captive Wheatear, the longer it is 
likely to survive in cage or aviary. If placed in a greenhouse, one of these birds will quickly clear it of insects and prevent their subsequent invasion.

The nest is formed of stalks and blades of grass, and is lined with feathers or the hair of various animals; it is often very cleverly concealed, but is sometimes merely placed by the side of a stone, a clod of earth, or even a tuft of coarse grass. The eggs, five or six in number, and of rather elongated form, are of a pale greenish-blue colour without spots. The young can be reared on ants' eggs and maggots, with the addition of a little bread and milk; they should be taken when about half-grown.

Beauty of plumage, quaint little ways, and a pleasing song of no great volume, combine to make the Wheatear a favourite with amateurs who do not mind a little trouble in connection with their pets.

It is very fond of sitting on a stone, or a clod of earth, or even on a post or rail, and should have something similar provided for its amusement in the aviary. From these points of vantage, it makes a quick dart every now and then at some passing insect, the capture of which it rarely fails to effect, and with which it returns to its favourite perch for the purpose of quietly discussing the dainty morsel.

A pair of these birds form an extremely interesting addition to the aviary, especially during the season of love and courtship, when a great deal of amusing by-play goes on between them, and when the song of the male, which is really a very agreeable warble, is more frequently heard than at other times, and is prolonged far into the night although commenced before daylight.

Suitably provided with shelter and reasonably cared for, the Wheatear will last for several years in confinement; but on a diet of hemp-seed and breadcrumbs the days of its life are very brief indeed, and as sad as they are few.

\section{THE WHIMBREL. See under Curlews.}




\section{THE WHINCHAT.}

In general appearance the Whinchat is not unlike the Wheatear, but is smaller, only measuring $4 \frac{1}{2}$ inches, of which $I_{2} \frac{1}{2}$ inches belong to the tail. The head, back and wings are brownish-grey, with a dark spot in the centre

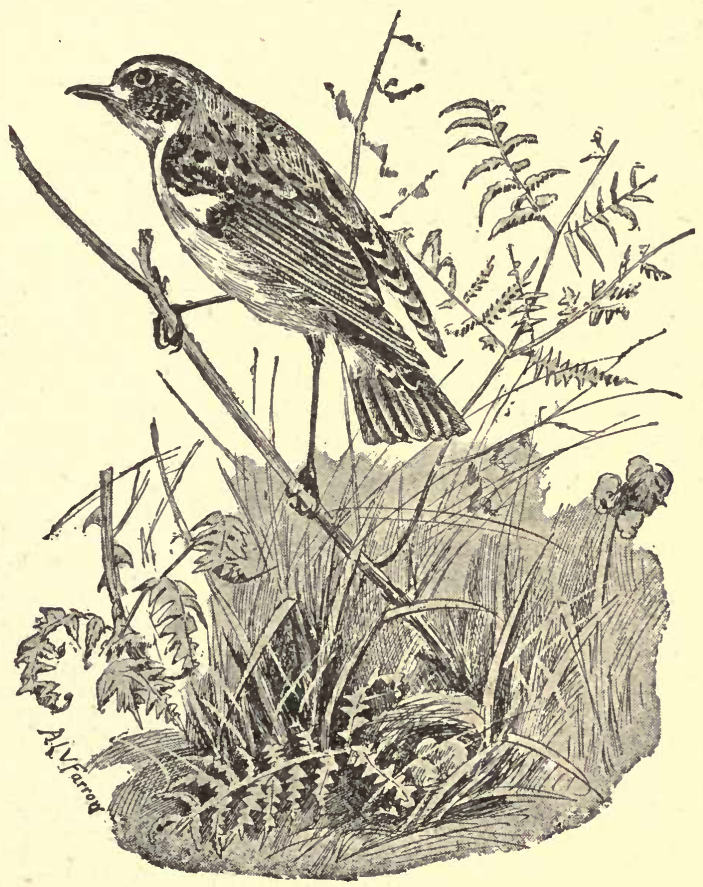

THE WHinchat.

of each feather; a long white arched band surmounts the eye; the lower parts are reddish-orange, deeper on the vent and under tail-coverts; there is a white patch on each . wing, and the tail feathers for their basal half are the same colour, the terminal half being brown. 
It is a bird of passage, and frequents heaths and commons, where it builds a compact and cleverly concealed nest of grass, lined with hair and wool, among the roots of the furze; the eggs, five or six, sometimes seven in number, are pale blue; and the young are very much spotted.

The Whinchat is fond of perching on the tops of clumps of broom and gorse, or on a thorn hedge, whence it makes constant sallies after passing insects: with these it invariably returns to the position it has just left, and trills forth its lively little song.

It is gifted with considerable powers of imitation, and in confinement will learn and render in the most accomplished manner the notes of any other birds among which it is placed.

When wild, it feeds entirely on insects, though the late Rev. F. O. Morris also gave it credit for devouring slugs! In the house, it must be treated as advised in the case of the Wheatear, otherwise its chance of survival there will be of the smallest.

The young are easily reared on ants' eggs and small insects. They should be taken just before they are ready to fly, or may be caught directly they have left the nest (which is so well concealed, that it is very difficult to find). In either case, they are to be kept, until they are able to feed themselves, in a small basket with a lid to it, and will then gape freely to be fed when it is opened. Needless to remark, that the most scrupulous attention must be paid to keeping them clean.

It is rare for a Whinchat captured when adult to survive in confinement for any length of time, but the young that have been reared from the nest will do very well in cage or aviary, and become most charmingly tame. They require plenty of space, and are very susceptible to cold: if kept out of doors they must be taken in before the advent of winter. 
THE WHITE.HEADED HARPY. See Harrier (Marsh).

THE WHITE OWL. See Barn Owl (under Owls).

\section{THE WHITETHROATS.}

\section{The Greater Whitethroat.}

This is another of the delightful warblers that come to us in the spring, stay and sing during the summer and rear a nest or two of young, to depart again in the autumn.

It is about $5^{\frac{1}{2}}$ inches in length, of which the tail measures $2 \frac{1}{2}$ or $2 \frac{3}{4}$ inches. Its general colour is ashen-grey stinged with brown, more deeply on the back than elsewhere, while the throat and belly are pure white. When singing, it has a habit of raising the feathers on the top of its head into a kind of crest, as well as of ruffling out those of the throat into a kind of frill. When singing it sits on the top of a low bush, and often darts off, ascending a few feet into the air, and singing all the time as if it had not stirred from its perch, to which it always returns. It arrives here in April and leaves us about the commencement of October.

The female is a trifle lighter in colour than her mate, but there is very little outward difference between the sexes.

In the house it should be lodged and treated like the Nightingale, but it is more delicate and requires more insect food as well as more protection from cold than the Blackcap. In its wild state it lives almost entirely on insects-flies and small caterpillars-but in the autumn, like its congeners, it will eat a little fruit, mostly small berries.

The nest has a general resemblance to that of the Blackcap, but is of much less solid construction, so flimsy indeed that the eggs can be seen through it from below, for it is often built at a height of five or six feet from the ground, though more generally only two or three.

The young have a habit of springing from the nest long 
before they are fledged, if they are discovered and looked at. They can be reared on ants' eggs and maggots, and will then live for eight or ten years.

The Whitethroat is a very interesting little creature, for it is extremely lively and full of the drollest antics, while its song is not by any means to be despised, if it does not come up to that of the Nightingale or the Blackcap.

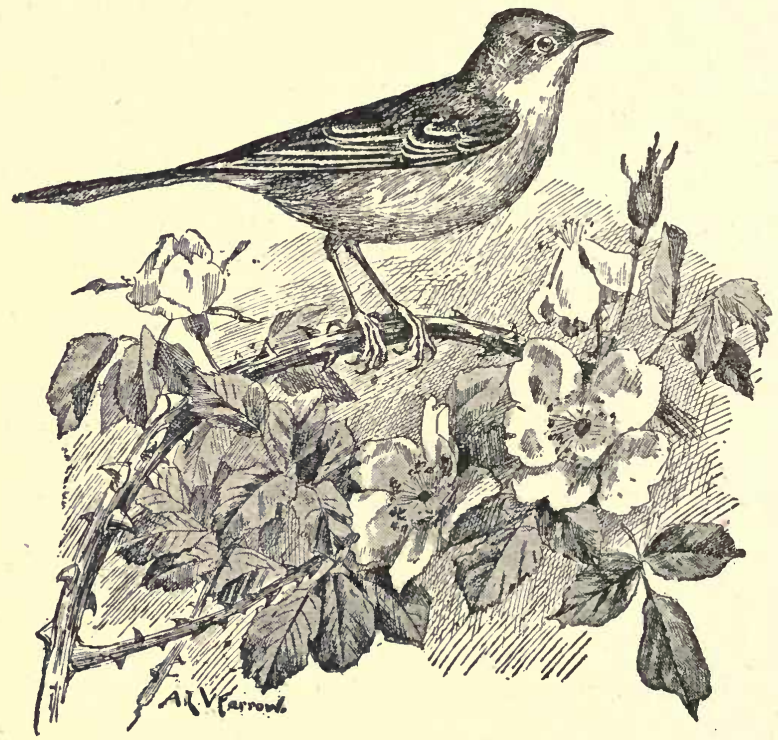

The Greater Whitethroat.

It is particularly fond of the aphides found on rose trees, and may be trained to sing at command by bribing it with a branch covered with these troublesome insects.

If the aphis has unfortunately affected a lodgment in a greenhouse, a tame Whitethroat will pretty quickly clear it of the pest; and as, unlike the Nightingale and the Blackcap, it does not peck and injure the plants, it is a very fit subject for liberating in such a situation. 
It cannot bear to hear another bird sing louder than itself, and should it do so, a regular and most amusing contest immediately ensues.

\section{The Lesser Whitethroat.}

This bird bears a general resemblance to the Greater Whitethroat, though, as its name denotes, it is a smaller bird, and especially one of much slimmer build : it measures about 5 inches in length, $2 \frac{3}{4}$ inches of which belong to the tail. The upper part of the body is grey, with a reddisholive tinge, and the under parts are similar, but of a lighter shade, not white.

The sexes are pretty much alike in outward appearance, but the female is if anything a trifle paler in colour than her mate. Like the Greater Whitethroat, it is a migratory species, arriving and departing about the same times.

It feeds on small caterpillars chiefly, and in the house must have a free supply of ants' eggs, maggots and aphides. It will also partake of fruit, and does not confine its attention to small berries, but attacks cherries and peaches and apricots, too, where they are grown out of doors. In the house it has been attempted to keep it on artificial food, but not with much success, for it seems incapable of digesting bread and milk or Crissel, or any of the prepared foods so much vaunted by dealers, the bulk of which consists of pea-meal more or less finely ground.

The nest is placed in a hedge or low bush, and is intermediate as regards solidity between that of the Blackcap and the Greater Whitethroat. The eggs are four or five in number, of a yellowish-white spotted with grey and brown. The young, like those of the Greater Whitethroat, will on being looked at jump from their nest long before they are fledged.

The Lesser Whitethroat is a lively and active little bird that has a very agreeable pretty chirping song, which it utters all day long, even when feeding, or rather when seeking for food. It does very well in a garden aviary, but must of course be taken indoors before the cold sets in. 
THE WHITE WAGTAIL. See under Wagtails.

THE WIGEON. See under Ducks.

THE WILD DUCK. See under Ducks.

THE WILLOW WREN. See under Wrens.

THE WINDHOVER. See Kestrel (under Hawks).

THE WOODCHAT. See under Shrikes.

\section{THE WOODCOCK.}

This well-known bird is a winter visitor to our shores; nevertheless numerous instances have been recorded of its having remained to breed, sometimes successfully; but being rather a conspicuous looking bird it is as a rule disturbed before the young have been fully reared and often before they have been hatched.

It varies in size in a remarkable manner, for while some Woodcocks are stated to have reached the unusual weight of 30 ounces, others have turned the scale at 5 ounces: an average weight seems to be 16 or 17 ounces, the female being rather larger and heavier than her partner.

The nest is loosely compacted of leaves, grass, etc., and is placed in woods and plantations, as a rule under the shelter of a full-foliaged tree. The eggs are four in 
number, whitish-yellow in colour, mottled with pale chestnut brown.

Needless almost to remark that the Woodcock is highly esteemed by epicures.

\section{THE WOODLARK. See under Larks.}

\section{THE WOODPECKERS.}

Properly speaking, these are not cage-birds; but as they are sometimes seen at shows it is perhaps advisable to review them briefly here. None of them are common in this country, but there are three well-known species.

If kept in a cage, they should have one of, or at least one cased with, metal, as they would readily bore through one made of wood, and speedily effect their escape from durance vile.

\section{The Greater Spotted Woodpecker.}

This bird is almost the size of a Thrush; white on the under and black on the upper surface of the body, to speak generally, but the frontlet is buff; the nape and cheeks red; a spot on each side of the neck, the saddle, and three bars across the wings, white; while the vent feathers and the tips of the inner tail feathers are pinky red. Without being exactly migratory it is of wandering habits. It breeds in April in a hole in a tree, making no nest but laying four or five white eggs on the bare wood. It is purely insectivorous in its habits, and although it certainly bores holes in trees must do a counterbalancing amount of good by the destruction of many injurious insects, their eggs and larvæ. In young birds the whole of the head is scarlet.

The young may be reared on ants' eggs, insects and a little meat. They do not readily become tame, nor will they live very long in the house. 


\section{The Green Woodpecker.}

Rather larger than the Greater Spotted, and a much handsomer bird; the prevailing colour of its plumage being green of the shade seen in Indian Parrakeets on the back,

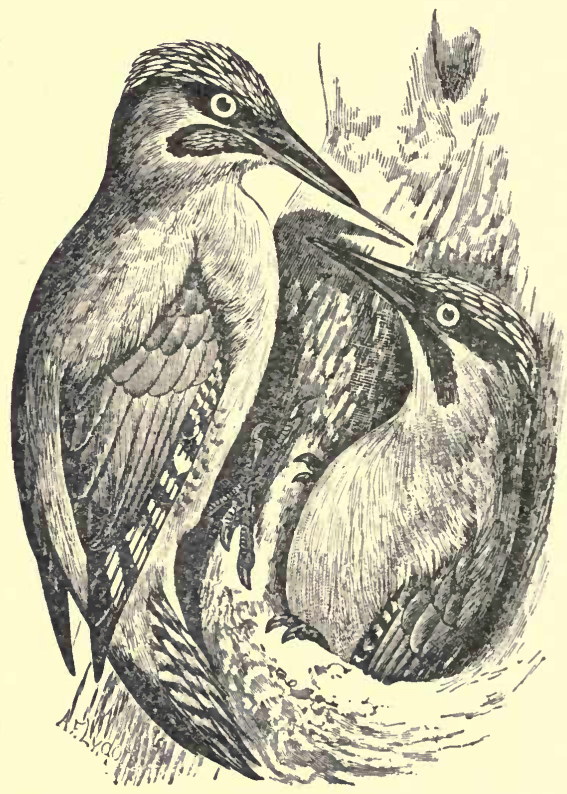

GREeN WOODPECKERS.

but greyer on the breast: it has a scarlet cap, and a red streak in the centre of the black moustache; the lores are black, and the same colour extends beyond the eye backwards to the middle of the head. The primaries are spotted with white, and the tail is traversed by yellow bars. The rump is yellow. 


\section{The Lesser Spotted Woodpecker.}

This bird, as its name implies, is smaller than the Greater Spotted, being about the size of a Lark; the red extends over the whole top of the head, forming a kind of cap, and the back is more spotted. It is even more shy and solitary than its larger relative and equally ill-adapted, if not indeed more so, for a life in captivity.

THE WOOD PIGEON, OR WOOD QUEST. See Ringdove (under Doves).

\section{THE WOOD WREN. See under Wrens.}

\section{THE WRENS.}

\section{The Common Wren.}

With the exception of the Fire-crest, the Common Wren is the smallest of our native birds, and as it resides with us all the year round and is purely insectivorous in its habits, it is quite wonderful how it manages to exist.

In length it measures $3 \frac{1}{2}$ inches, of which the tail takes $I_{\frac{1}{4}}$ inches. The upper part of the body is russet-brown with numerous streaks of a darker shade upon it. The female is lighter in colour, but the two sexes are outwardly very much alike.

When wild this small bird is found all over Europe, and in this country is very common even in the vicinity of large towns. It builds a large domed nest of moss in a great variety of situations, and snugly lines it with small feathers. Many nests are begun and abandoned before a site is finally fixed upon; and the eggs, which number from six to nine, are white, lightly spotted with reddish-brown.

In winter it comes nearer houses, sleeps under the 
eaves, and in barns and cow-houses, where it not only finds insects, but also warmth.

If it is decided to try and keep a Wren in the house, it must be accustomed to eat ants' eggs by covering them with aphides, or young spiders; but it is seldom that it can be preserved for any length of time, even with every care. As it is in the habit of always sleeping in a hole or crevice of some kind, a little box, or a cocoanut shell or husk, must be provided for it in the house, and in this it will pass not only the night, but also a considerable portion of the day.

Although apparently of a bold and fearless disposition, it is by no means easy to tame a Wren, and the only inducement for trying to do so is its wonderful song, which is very powerful for the size of the bird, continued throughout the year, and varied and well sustained.

The Golden-crested Wren. See Introduction, page 8.

\section{The Willow Wren.}

This bird is very like the Chiff-chaff, but is larger and of a brighter colour. It differs, however, in several other respects-not arriving so early, and leaving us later than the Chiff-chaff. The nest is very similar in appearance to that of its congener, and so are the eggs; indeed, were it not for the size the one bird might be looked upon as a variety of the other, but they are certainly distinct.

The song of the Willow Wren is louder and more sustained than that of the Chiff-chaff, and like the latter it has no small imitative power, but will pick up the call note, and sometimes a portion of the song, of another bird.

It is not as peacefully disposed as the Chiff-chaff, but makes its presence felt in a mixed aviary, where it will not give way to birds even considerably larger than itself.

The young are easily reared from the nest.

\section{The Wood Wren.}

This bird bears a great likeness to the Willow Wren, but the eye-streak is more distinct and the tail shorter; the 
general colour is olive-green on the upper parts, and on the under surface whitish-yellow, gradually merging to white at the vent and lower tail coverts.

It arrives in April and departs in September, frequents woods, and is rarely seen in the vicinity of human habitations. It is a tree-frequenting species, and, unlike the Chiff-chaff and the Willow Wren, does not often descend near the ground, except when nesting, which it does among a heap of leaves, so that it is very difficult to discover its habitation.

Wood Wrens are purely insectivorous, but may be preserved for several years in the house, whether hand-reared or caught when full grown, on ants' eggs, maggots and tiny scraps of raw meat, or a very little yolk of hardboiled egg. It is very impatient of cold.

\section{THE WRYNECK.}

This bird is supposed to be a connecting link between the Woodpeckers and the Tree Creepers. It is a bird of passage, and in some parts is known as the Cuckoo's Mate, from timing its arrival here a little in advance of that herald of the spring. Without being a showy, it is a handsome bird, but a difficult one to describe. Its general colour is brown, waved and spotted with several shades of the same colour; the lower breast and abdomen are white marked with little lance-shaped spots having the points directed backwards; the rump and the tail are slate, the latter crossed by three darker bands. Like the Woodpeckers it is zygodactylous, or has two toes directed forwards and two backwards. It nests in holes in trees and lays six or seven white eggs. The young can be reared on ants' eggs and flies, and will become very tame.

The present writer once had a Wryneck that was reared by hand, chiefly on flies, and which became so tame and familiar that its very fearlessness led to its untimely end; but as the story has been detailed in full in another place, it cannot be repeated here. It is, however, a further confirmation of the view that all birds can be tamed and 
kept by man, and those who deny the fact speak in ignorance or with prejudice against a most fascinating pursuit with which they are totally unacquainted: indeed, one might go further, and say that if their ignorance were enlightened they would cease to declaim as they now do.

THE YELLOW-BILLED LINNET. See Twite (under Linnets).

THE YELLOW-HAMMER. See under Buntings.

THE YELlOW PLOVER. See Plover (Golden).

THE YELLOW WAGTAIL. See under Wagtails.

THE END. 
FOR

BARGAINS in

CYCLES, JEWELLERY, BIRDS, PLANTS, GUNS, BOOKS, DOGS, DRESS, MACHINERY, ANIMALS, BRIC-Ä-BRAC, CAMERAS, INSTRUMENTS, \&C., \&C.

SEE

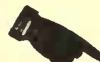

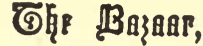

$2 d$.

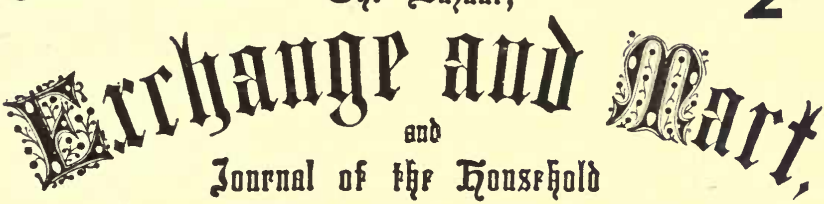

Pabfished Cuery Monday. Wednesday and Friday.

AND

ARTICLES on

DOG KEEPING, POULTRY KEEPING, SHOWS, HOME MATTERS, CURIOSITIES, STAMPS, SPORT, GAMES, FASHIONS, MECHANICS, PHOTOGRAPHY, PAINTING, GARDENING, \&c., \&c. And many Illustrations.

OF ALL NEWSAGENTS AND BOOKSTALLS. 


\section{PARROTS! PARROTS! PARROTS!}

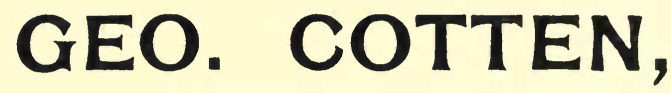

NATURALIST,

50, Rosamond Street East, Manchester.

FINE SELECTED BIRDS ALWAYS IN STOCK.

All Kinds of Specially Selected Foreign Birds Kept in Stock. GREY PARROTS, BLUE-FRONTED AMAZON PARROTS, INDIAN

PARAKEETS, COCKATOOS, LORIES, \&c., \&c.

South African GREY TALKING PARROTS a Speciality.

A viaries Stocked with every variety of Foreign Birds on Reasonable Terms.

ALL KINDS OF FANCY DOGS BOUGHT, SOLD, OR EXCHANGED.

\section{Romans' Preserved Ant Eggs \\ UNRIVALLED FOOD FOR}

INSECTIVOROUS BIRDS, GOLDFISH, \&C.

DL SOLD IN REGISTERED PACKAGES ONLY. D

"Undeniably the best thing of its kind in the market."-BAZAAR.

Tins, 3/- (equal four 1/- tins) and 1/-; Packets, 3d. and 1d, each. Stocked by most first-class Chemists, Florists, Fishing Tackle Dealers, \&c. The 3/-, 1/-, and 3d. sizes will be sent POST FREE by the SOLE PROPRIETOR, E. ROMANS, Llanelly.

1. CAUTION.-See that the name "ROMANS" appears on every Package.

AGENTS WANTED-Liberal Trade Discount.

DISEASES OF CAGE BIRDS:

Their Causes, Symptoms, and Treatment. A Handbook for everyone who keeps a Bird. By DR. W. T. G REENE, F.Z.S. In paper, price 18., by post 1s. $2 d$.

NOTES ON CAGE BIRDS.

Second Series. Being Practical Hints on the Management of British and Foreign Cage Birds, Hybrids, and Canaries. By various Fanciers. Edited

by DR. W. T. GREENE. In cloth gilt, price $6 s .$, by post $68.6 d$.

CRIES AND CALL NOTES OF WILD BIRDS.

Described at Length, and in many instances Illus'rated by Musica

Notation. In paper, price 1s., by post 18. $2 d$.

London: L. UPCOTT GILL, 170, STRAND, W.C. 


\section{THE}

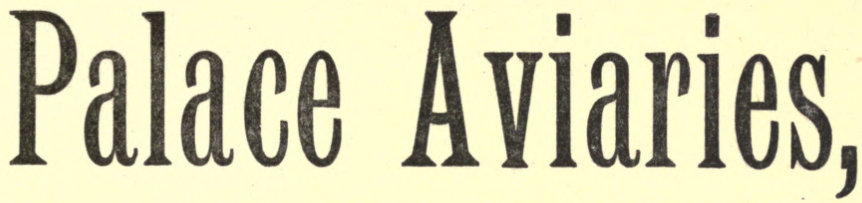

209 \& 211, Shaftesbury Avenue,

\section{LONDON, W.C.,}

Is

The fargest and Jjest Uentílated

\section{BIRD STORE IN ENGLAND.}

First Class Acclimatised Talking Grey \& Amazon Parrots always on hand. Also Tame Talking COCKATOOS and PARRAKEETS of many varieties.

FULL PARTICULARS AND PRICES WILL BE FORWARDED AT ONCE, ON APPLIOATION, TO THOSE UNABLE TO MAKE A PERSONAL VISIT.

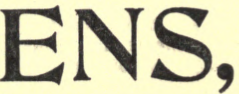

Proprietor. 


\section{CANARY BOOK.}

The Breeding, Rearing, and Management of all Varieties of Canaries and Canary Mules, and all other matters connected with this Fancy. By ROBERT L. WallaCe. Third Edition. In cloth gilt, price 58., bs post 58 . 4d. ; with COLOURED PLATES, 68. 6d., by post 68. 10d.

\section{THE GREY PARROT}

And How to Treat It. By W. T. GREenE, M.D., M.A., F.Z.S., \&c. In paper, price 18., by post 1s. 2d.

\section{THE SPEAKING PARROTS.}

The Art of Keeping and Breeding the principal Talking Parrots in Confinement. By Dr. KARL RUSS. Illustrated witli COLOURED PLA T ES and Engravings. In cloth gilt, price 58., by post 5s. $4 d$.

POPULAR PARRAKEETS.

How to Keep and Breed Them. By DR. W. T. GREenE, M.D., M.A., F.Z.S., \&c. In paper, price 18., by post 18. $2 d$.

\section{FEATHERED FRIENDS, OLD AND NEW.}

- Being the Experience of many years' Observation of the Habits of British 4. Band Foreign Cage Birds. By DR. W. T. GREENE, M.D., M.A., F.Z.S., \&c. :MIllustrated. In cloth gilt, price 5., by post $58.4 d$.

\section{FAVOURITE FOREIGN BIRDS}

For Cages and Aviaries. How to Keep them in Health. By W. T. Greene, M.D., M.A., F.Z.S., \&c. Fully Illustrated. In cloth gilt, price $28.6 \mathrm{~d}$., by post 28. $9 d$.

\section{PIGEON KEEPING FOR AMATEURS.}

A Complete ciulde to tne Amatsur Brovder of $\mathrm{D}$ mastic and Fancy Pigeons. By J. C. LYELL. Illustrated. In cloth gilt, price 28. 6d., by post 28. 9d.; in paper, price 1s., by post 18. $2 d$.

\section{FANCY PIGEONS.}

Containing full Directions for the Breeding and Manayement of Fancy Pigeons, an I Dəscriptions of every known Variety, together with all other Inform ution of Interest or Use to Pigeon Fanciers. Third Elition 18 COLOURED PLA rES and 22 other full-page Illustrations. By J. C. LYELL. In cloth gilt,

price 108. $6 d$., by post $108.10 d$.

BOOK OF THE RABBIT.

A Complete Work on Breeding and R Raring all Varieties of Fancy Rablits, giving cheir History, Variations, Uses, Points, Selection, Mating, Management, \&c., \&c. SECOND EDITION. Edited by KEMPSTER W. KNIGHT. Illustrated with Coloured and other Plates. In cloth gilt, price 10s. 61., by post 10s. 11 d.

\section{DISEASES OF RABBITS.}

Their Causes, Symptoms, and Cure. With a Chapter on The Diseases of Cavies. Reprinted from "The Book of the Rabbit" and "The Guinea Pig for Food, Fur, and Fancy." In paper, price 18., by post 18. $2 d$.

\section{RABBITS FOR PRIZES AND PROFIT.}

The Proper Management of Fancy Rabbits in Health and Disease, for Pets or the Market, and Descriptions of every known Variety, with Instructions for Breeding Good Specimens. By Charles Rayson. Illustrated. In cloth gilt, price 23. 6d., by post 28. $9 d$. Also in Sections, as follows :

General Management of Rabbits. Including Hutches, Breeding, Feeding, Diseases and their Treatment, Rabbit Courts, \&c. Fully Illustrated. In paper, price 1s., by post 18. $2 d$.

Exhibition Rabbits. Being Descriptions of all Varieties of Fancy Rabbits, their Points of Excellence, and how to obtain them. Illustrated. In paper, price 1s., by post 1s. $2 d$.

POPULAR DOG=KEEPING.

Being a Handy Guide to the General Management and Training of all Kind of Dogs for Companions and Pets. By J. MAXTEE. Illustrated. In paper, price 1s., by post 18. $2 d$. 


\section{CHAS. HARRIS,}

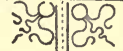

Haturalist and 3 mporter . OF .

BIRDS, BEASTS, AND REPTILES,

11, Clayton Street,

NEWCASTLE=0N-TYNE ; - Also .

294, High Street, SUNDERLAND.

Cheapest and Most Reliable Firm for

FOREIGN AND BRITISH BIRDS, PARROTS, MONKEYS, GOLD \& SILVER FISH,

HARMLESS REPTILES, \&C.

DEALERS should Apply for PRICES
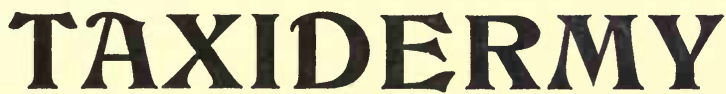

AND

\section{Natural History Appliances.}

Specimens mounted complete at following rates: Animals size of Fox, muunted under glass, 10s. 6d. ; size of Wild Rabbit, 5s.; of Stoat, 3s. Birds, also under glass, size of Heron, 8s. 6d. ; Size of Pheasant, 6s. ; of Thrush, 3s.

Collectors' requisites : Egg Cabinets, 3 drawers, 12in. by 9in., from 7s. ; 8 drawers, 19in. by 12in., 20s. ; Insect Cabinets, 3 drawers, 13in. by 8 in., from 9s. ; 8 drawers, 19in. by 12 in, $23 \mathrm{~s}$.

ALI CLASSES OF ACCESSORIES FOR COLIECTORS. WOOD-WORK AND TURNERY OF ALL CLASSES.

Natural History Ornaments, Large Variety. Lists. Shop Goods at Lowest Prices.

Highland Stags' and Rams' Heads, from 20s., up. REDUCTION ON QUANTITIES.

.. References. Iists. . .

PRICES SUBJECT TO SLIGHT RISES AND FALLS. 


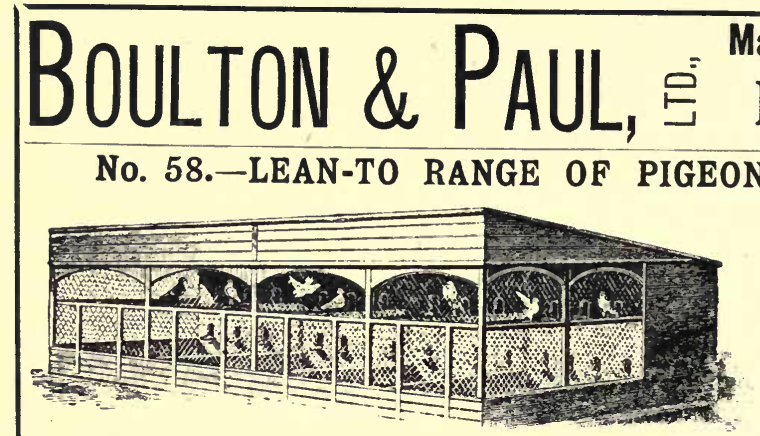
Manufacturers, NORWICH.

No. 58. - LEAN-TO RANGE OF PIGEON COTES.

10ft. long by $10 \mathrm{ft}$. wide.

Prices on Application.

No. 17. AVIARY.

For Placing Inside the Conservatory.

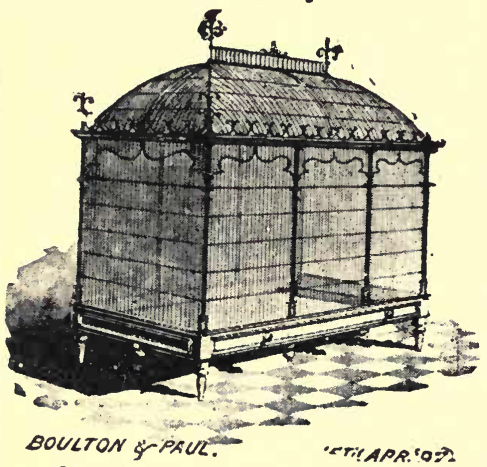

Can be made to any size. Prices and Full Particulars Free on Application.

No. 55.-PORTABLE INDEPENDENT OUTDOOR AVIARY.

笪 OUTDDOR AVIARY.

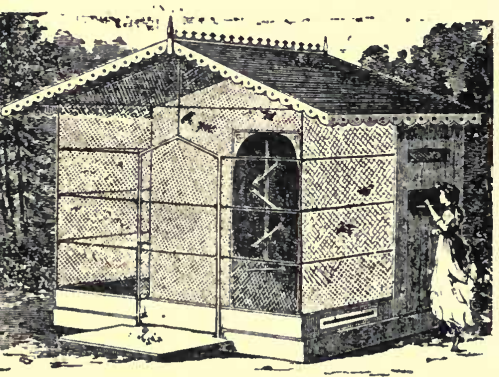

Registered Copyright

This Aviary can be taken to pieces for removal in a few minutes. It is the best constructed Outdoor A viary that is made. The wood is well seasoned, varnished, with flight of fine wire netting, galvanised, fixed to light wood framing. Cash Prices, Carrlage Paid. -4ft. by $4 \mathrm{ft}$., ift. 3 in. high at eaves, $5 \mathrm{ft}$. 9in. high to ridge, £5 $10 \mathrm{~s}$ $6 \mathrm{ft}$. by $6 \mathrm{ft}$., $5 \mathrm{ft}$. high at eaves, $7 \mathrm{ft}$. high to ridge, $£ 10$.

\section{No. 19.-OUTDOOR AVIARY. With Cosy Sleeping Compartment.}

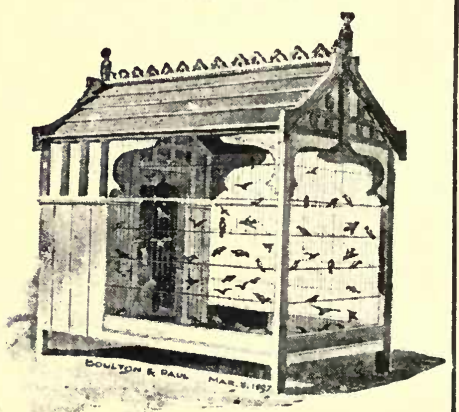

No. 53.-NEW ORNAMENTAL DOVE OR PIGEON COTE.

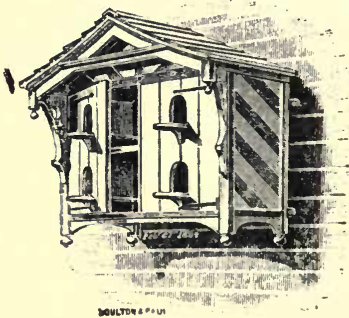

Registeate CoPyhight

For placing against a south wall. The whole of the front is mate to open. Cash Price £2 lus.

Latest Catalogue, profusely Illustrated, of Requisites for the Stable, Kennel, Park, Estate, Garden, \&c., Free on Application. 


\section{Catalogue of Practical Handbooks Published by L. Upcott Gill, 170, Strand, London, W.C.}

\section{CONTENTS.}

ART. PAGE

DESIgNing ......... 5

OLD VIOLINS .......... 12

Painting.............. 8

VIOLIN SCHOOL........ 12

AMUSEMENTS.

Amateur ENTERTainMENTS ...........

BUNKUM ENTERTAINMENTS ............

Card Conjuring...... Card Tricks.......... 4 Conjuring...........4, 11 Fortune Telling .... 6 GAMES .............

Magic Lanterns...... Patience............ Pool ................... Shadow ENTERTaINMENTS ........... Sleight of HaNd .... Solo WHIST .......... VAMPING ............. VENTRILOQUISM ...... WHIST ............ 12

\section{COILECTORS.}

AUTOGRAPH .......... Books ............... CoIns $\ldots \ldots \ldots \ldots \ldots$ Bngravings .......... Handwriting ....... Library MaNual .... Painters ............ Postage Stamps ....... Postmarks

PotTery \& Porcelain SPORTING BOoKs...... STAMPS OF EUROPE.... WAR MEDALS..........

DOGS \& HORSES. BREAKING DOGS ...... BREEDERS' RECORDS.. BRITISH DOGS ........ Colle . . . . . . . . . . Diseases of Dogs .. Diseases of Horses.. DOG-KEEPING ........ Fox Terrier ........ GREYHOUND .......... HORSE-KEEPER ...... HoRsE-KEEPING ....... ST. BERNARD.......... WHIPPET .............

\section{FARM.}

Goat.Keeping ......... PIg-Kenping.......... Poultry Farming.... SHEEP RaISING ...... Stock Records ...... Begonia Culture ....
GARDENING. PAGE

Bunb Cultue ....... 3 Cactus Culture...... Carnation Culture.. Chrysanthemum Cul-

TURE ............. CUCUMBER CULTURE .. DictionaRY ......... FERNS ............... Fruit Culture ...... Gardening in Egypt.. Grape Growing ....... GreENHOUSE MANAGEMENT ............ HaRdy PERENNials .. HOME...$\ldots \ldots \ldots$. . Mushroom Culture.. OrCHIDS .

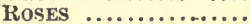
Tomato Culture .... Tomato Growing .... VegetabLe Culture..

\section{HOME.}

American Dainties .. Cold MEat CoOKerY.. Cookery............. EgG Cookery ......... DaINTIES ............ EANCY WORK.......... FISH, FLESH, \& FOWL. Home Medicine ...... MILLINERY ........... NEEDLEWORI DICTIONARY .......... SHAVING $\ldots \ldots \ldots \ldots \ldots \ldots 11$ MECHANICS.

BENT IRONWORK...... BOAT BUILDING ...... BOOKBINDING ......... Cabinet Making...... Cane Basket Work .. FIREWORK MAKING .. Fretwork.......... MARqueterie ........ MODEL YachTS......... Piano Tuning ........ Picture-Frame MakING SHEET METAL Work.. TICKET WRITING ...... TURNING Lathes...... Wire Gauges ........ Wood Carving ...... WOOD POLISHES ...... WORKSHOP MAKESHIFTS ............

NATURAI HISTORY. AQUARIA ............. BEES ................ ButTerfles......... DIRECTORY............
PAGT

DRAGONFLIES ...... 3

HAWK MOTHS ........ 7

SKETCHES ........... 8

SNAKES............. 11

TAXIDERMY $\ldots \ldots \ldots \ldots$....... 11

VIVARIUM ........... 12

PETS.

BRITISH BIRDS........

Cage Birds' Diseases

Canaries $\ldots \ldots \ldots \ldots$.

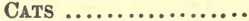

Cries and Call Notes

Feathered Friends..

Foreign BIRDS

GREY PARROTS ......

Guinea PIG .........

MICE ................

MONKEYS ............

Notes on CAGE BIRDs

ParRakeEts ..........

Pheasants ............

RabBITs ............ 10

Speaking Parrots.... 8

POULTRY \& PIGEONS.

DISEASES.............

Fancy Pigeons ......

INCUBATORS $\ldots \ldots \ldots \ldots$

LAYING Hens...........

Pigeon-KeEping ....

Poultry.Farming .....

Poultry-KeEPING ..... SPORT

ANGLING ............ 2, 6 Boat Building ....... 2 BOAT SAILING ....... 3 Cyching MaP ....... 5,10 FERRETS ............ 6 Game Preserving ... 6 SEA-FISHING ....... 2,10 SKating ............ 11 TrapPING ........... 12

WILDFOWLING ....... 12

WILD SPORTS......... 12 TOURIST.

Australia .......... Broads, THE ......... Dictionary OF Ska

TERMS ............. Friestand MERES .... INLAND WATERING

Places............. MountaineERING .... Road CHART .......... RoUTE MAP ............ SAILING Tours ......... SEA LIFE ............. 11 SEASIDE WATERING

Places............. SoLENT GuIDE ......... 10

THAMES GuIde ...... 12 
Emerican Dainties, and How to Prepare Them. By an AMerican Lady. In paper, price 18., by post $18.2 d$.

Anglex, Book of the All-Round. A Comprehensive Treatise on Angling in both Fresh and Salt Water. In Four Divisions as named below. By JOHN BICKERDY KE. With over 220 Engravings. In cloth gilt, price $58.6 d$., by post $58.10 d$. Angling for Coarse Fish. Bottom Fishing, according to the Methods in use on the Thames, Trent, Norfolk Broads, and elsewhere. Illustrated. In paper, price 18., by post $18.2 d$.

Angling for Pike. The most approved Methods of Fishing for Pike or Jack. New Edition, revised and enlarged. Profusely Illustrated. In paper, price 1s., by post 1s. $2 d$. ; cloth, 2s. (uncut), by post $28.3 d$.

Angling for Game Fish. The Various Methods of Fishing for Salmon; Moorland, Chalk-stream, and Thames Trout; Grayling and Char. Well Illustrated. In paper, price 18. 6d., by post 18. 9d.

Angling in Salt Water. Sea Fishing with Rod and Line, from the Shore, Piers, Jetties, Rocks, and from Boats; together with Some Account of Hand-Lining. Over 50 Engravings. In paper, price 18., by post, 18. 2d. ; cloth, 2s. (uncut), by post $2 s$. $3 d$.

Angler, The Modern. A Practical Handbook on all Kinds of Angling. By "OTTER." Well illustrated. New Edition. In cloth gilt, price 2s. 6d., by post $2 s .9 d$.

Aqquaria, Book of. A Practical Guide to the Construction, Arrangement, and Management of Freshwater and Marine Aquaria; containing Full Information as to the Plants, Weeds, Fish, Molluscs, Insects, \&c., How and Where to Obtain Them, and How to Keep Them in Health. By REV. GREgORY C. Bateman, A.K.C., and Reginald A. R. BennetT, B.A. Illustrated. In cloth gilt, price 5s. 6d., by post 58. $10 \mathrm{~d}$.

Aquaria, Freshwater: Their Construction, Arrangement, Stocking, and Management. By REV. G. C. BATEMAN, A.K.C. Fully Illustrated. In cloth gilt, price $3 s .6 d$., by post 3 s. $10 d$.

Aquaria, Marlne: Their Construction, Arrangement, and Management. By R. A. R. BENNETT, B.A. Fully Illustrated. In cloth gilt, price $2 s .6 d$., by post $2 s .9 d$.

Australia, Shall I Try? A Guide to the Australian Colonies for the Emigrant Settler and Pusiness Mall. With two Illustrations. By GEORGE LACON Javes. In eloth gilt, price 3s. 6d., by post 3s. $10 \mathrm{~d}$.

Autograph Collecting : A Practical Manual for Amateurs and Historical Students, containing ample information on the Selection and Arrangement of Autographs, the Detection of Forged Specimens, \&c., \&c., to which are added numerous Facsimiles for Study and Reference, and an extensive Valuation Table of Autographs worth Collecting. By HENRY T. SCOTT, M.D., L.R.C.P., \&c. In leatherette gilt, price 7s. 6 d. nett, by post $78.10 d$.

Bazaars and Fancy Fairs: Their Organization and Management. A Secretary's Vade Mecum. By JoHN MuIR. In paper, price 1s., by post 1s. 2d.

Beos and Bee-Keepling: Scientific and Practical. By F. R. Cheshire, F.I.S., F.R.M.S., Lecturer on Apiculture at South Kensington. In two vols., cloth gilt, price $168 .$, by post $16 s .6 d$.

Vol. I., Scientific. A complete Treatise on the Anatomy and Physio. logy of the Hive Bee. In cloth gilt, price 7s. 6d., by post 78. 10d.

Vol. II., Practical Management of Bees. An Exhaustive Treatise on Advanced Bee Culture. In cloth qilt, price $88.6 d$., by post $88.11 d$.

Iee-Keeping, Book of. A very practical and Complete Nanual on the Proper Management of Bees, especially written for Beginners and Amateurs who have but a few Hives. By W. B. WEBSTER, First-class Expert, B.B.K.A. Fully Illustrated. In paper, price 1s., by post 18 . 2d. ; cloth, 1s. $6 d$. , by post 1s. $8 d$.

Eegonia Culture, for Amateurs and Professionals. Containing Full Directions for the Successful Cultivation of the Begonia, under Glass and in the Open Air. By B. C. RAVENSCROFT. Ilustrated. In paper, price 18., by post 1s. $2 d$.

Bent Iron Work: A Practical Manual of Instruction for Amateurs in the Art and Craft of Making and Ornamenting Light Articles in imitation of the beautiful Medirval and Italian Wrought Iron Work. By F. J. ERSKINE. Illustrated. In paper, price 18., by post $18.2 d$.

Birds, British, for the Cage and Aylary. Illustrated. By DR. W. T. GREENE. In cloth gilt, price $3 s .6 d$., by post $3 s .9 d$.

Boat Bullding and Sailing, Practlcal. Containing Full Instructions for Designing and Building Punts, Skiffs, Canoes, Sailing Boats, \&c. Particulars of the most suitable Sailing Boats and Yachts for Amateurs, and Instructions for their Proper Handling. Fully Illustrated with Deslgns and Working Diagrains. By ADRIAN NeISON, C.E., DIXON KEMP, A.I.N.A., and G. Christopher Davies. In one vol.: cloth gilt, price 78. 6d., by post 78. 10d. 
Boat Bullding for Amateurs, Practical. Containing Full Instructions for Designing and Building Punts, Skiffs, Canoes, Sailing Boats, \&c. Fully Illustrated with Working Diagrams. By ADRIAN NEISON, C.E. Second Edition, Revised and Enlarged by Dixon KEMP, Author of "A Manual of Yacht and Boat Sailing," \&c. In cloth gilt, price 28. 6d., by post 28. 9d.

Boat Sailing for Amateurs, Practical. Containing Particulars of the most Suitable Sailing Boats and Yachts for Amateurs, and Instructions for their Proper Handling, \&c. Illustrated with numerous Diagrams. By G. Christopher Davigs. Second Edition, Revised and Enlarged, and with several New Plans of Yachts. In cloth gilt, price 58., by post 58. 4d.

Bookbinding for Amateurs : Being Descriptions of the various Tools and Appliances Required, and Minute Instructions for their Effective Use. By W. J. E. Crane. Illustrated with 156 Engravings. In cloth gilt, price 2s. 6 d., by post 2s. $9 d$.

Breeders' and Exhibitors' Record, for the Registration of Particulars con cerning Pedigree Stock of every Description. By W. K. TAunton. In 3 Parts. Part I., The Pedigree Record. Part II., The Stud Record. Part III., The Slow Record. In cloth gilt, price each Part 2s. 6d., or the set 6s., by post 6s. $6 d$.

British Dragonflies. Being an Exhaustive Treatise on our Native Odonata : Their Collection, Classification, and Preservation. By W. J. LuCAs, B.A. Very fully Illustrated, with about 40 Coloured Plates, and numerous Black. and-White Engravings. In cloth gilt, hy subscription, 218. nett. The price will be raised on publication to not less than 30s. nett.

Broads, the Land of the. By E. R. SuFfling. Illnstrated. In paper, price 1s., by post 18. $2 d$.

Bulb Culture, Popular. A Practical and Handy Guide to the Successful Cultivation of Bulbous Plants, both in the Open and under Glass. By W. D. DRURY. Fully Illustrated. In paper, price 1s., by post 1s. $2 d$.

Bunkum Entertainments: A Collection of Original Laughable Skits on Conjuring, Physiognomy, Juggliag, Performing Fleas, Waxworks, Panorama, Phrenology, Phonograph, Second Sight, Lightning Calculators, Ventriloquism, Spiritualism, \&c., to which are added Humorous Sketches, Whimsical Recitals, and Drawing-room Comedies. By ROBERT GANTIIONY Illustrated. In cloth, price $2 s .6 d$., by post $2 s .9 d$.

Butterfiles, The Book of British: A Practical Manual for Collectors and Naturalists. Splendidly Illustrated throughout with very accurate Engravings of the Caterpillars, Chrysalids, and Butterflies, both upper and under sides, from drawings by the Author or direct from Nature. By W. J. LuCas, B.A. In cloth gilt, price 3 s. $6 d$., by post 3s. 9d.

Butterfly and Moth Collecting: Where to Search, and What to Do. By G. E. Simms. Illustrated. In paper, price 18., by post 18. $2 d$.

Cabinet Making for $\mathbf{I}$ mateurs. Being clear Directions How to Construct many Useful Articles, sucl as Brackets, Sideboard, Tables, Cupboards, and other Furniture. Illustrated. In cloth gilt, price $2 s .6 d$. , by post $2 s .9 d$.

Cactus Culture for Amateurs: Being Descriptions of the various Cactuses grown in this country; with Full and Practical Instructions for their Successful Cultivation. By W. WA'rson, Assistant Curator of the Royal Botanic Gardens, Kew. Profusely Illustrated. In cloth, gilt, price 5s. nett, by post 58. 4d.

Cage Blrds, Diseases of: Their Causes, Symptoms, and Treatment. A Hand. book for everyone who keeps a Bird. By DR. W. T. GREenE, F.Z.S. In paper, vrice 18., by post $18.2 d$.

Cage Birds, Notes on. Second Series. Being Practical Hints on the Management of British and Foreign Cage Birds, Hybrids, and Canaries. $\mathrm{By}^{\prime}$ various Fanciers. Edited by DR. W. T. GREENE. In cloth gilt, price 68., by post $68.6 d$.

Canary Book. The Breeding, Rearing, and Management of all Varieties of Canaries and Canary Mules, and all other matters connected with this Fancy. By ROBERT L. WALLACE. Third Edition. In cloth gilt, price 5s., by post 58. 4d. ; with COLOURED PLATES, 68. 6d., by post 6s. $10 d$.

General Management of Canaries. Cages and Cage-making, Breeding, Managing, Mule Breeding, Diseases and their Treatment, Moulting, Pests, \&c. Illustrated. In cloth gilt, price $28.6 d$., by post $2 s .9 d$.

Exhibition Cannvies. Full Particulars of all the different Varieties, their Points of Excellence, Preparing Birds for Exhibition, Formation and Management of Canary Societies and Exhibitions. Illustrated. In cloth gilt, price $2 s .6 d$. , by post $28.9 d$. 
Cane Basket Work: A Practical Manual on Wearing Useful and Fancy Baskets By ANNIE FIRTH. Illustrated. In cloth gilt, price 18. $6 d$., by post 18.8d.

Card Conjuring : Being Tricks with Cards, and How to Perform Them. By Prof. Ellis StanYoN. Illustrated, and in Coloured Wrapper. Price 18., by post 18. $2 d$.

Card Tricks, Book of, for Drawing-room and Stage Entertainments by Amateurs; with an: xposure of Tricks as practised by Card Sharpers and Swindlers. Numerous Illustrations. By PROF. R. KUNARD. In illustrated wrapper, price $2 s .6 d$., by post $2 s .9 d$.

Carnation Culture, for Amateurs. The Culture of Carnations and Picotees of all Classes in the Open Ground and in Pots. By B. C. RAVENSCROFT. Mllustrated. In paper, price 18., by post 18. $2 d$.

Cats, Domestic or Fancy : A Practical Treatise on their Antiquity, Domesti. cation, Varieties, Breeding, Management, Diseases and Remedies, Exhibition and Judging. By JoHN JENNiNGS. Illustrated. In cloth gilt, price $28.6 d$., by post 28. 9d.

Chrysanthemum Culture, for Amateurs and Professionals. Containing Full Directions for the Successful Cultivation of the Chrysanthemum for Exhibition and the Market. By B. C. Ravenscroft. New Edition. Illustrated. In paper, price 1s., by post 1s. $2 d$.

Chrysanthemum, The Show, and Its Cultixation. By C. Scotr, of the Sheffield Chrysanthemum Society. In paper, price $6 d$., by post $7 d$.

Coins, a Gulde to English Pattern, in Gold, Silver, Copper, and Pewter, from Edward I. to Victoria, with their Value. By the REv. G. F. CrowTHER, M.A. Illustrated. In silver cloth, with gilt facsimiles of Coins, price 58., by post 58. 3d.

Colns of Great Britain and Ireland, a Guide to the, in Gold, Silver, and Copper, from the Earliest Period to the Present Time, with their Value. By the late Colonel W. STEwart Thorburn. Third Edition. Revised and Enlarged, by H. A. GRUEBER, F.S.A. IHustrated. In cloth gilt, price 108. $6 d$. nett, by post 10 s. $10 d$.

Cold Meat Cookery. A Handy Guide to making really tasty and much appreciated Dishes from Cold Meat. By MRs. J. E. Davidson. In paper, price 18., by post 1s. $2 d$.

Colle, The. Its History, Points, and Breeding. By HUGH DalzikL, Illus. trated with Coloured Frontispiece and Plates. In paper, price 18., by post 18. $2 d$. ; cloth gilt, 28 ., by post $283 d$.

Collie Stud Book. Edited by Hugh Darziel. In cloth gilt, price 38. 6 d. each, by post 38 . 9 d. each.

Vol. I., containing Pedigrees of 1308 of the best-known Dogs, traced to their most remote known ancestors; Show Record to Feb., 1890, \&c.

Vol. II. Pedigrees of 795 Dogs, Show Record, \&c.

Vol. III. Pedigrees of 786 Dogs, Show Record, \&c.

Conjuring, Book of Modern. A Practical Guide to Drawing-room and Stage Magic for Amateurs. By Professor R. KunaRD. Illustrated. In illustrated wrapper, price 28 . 6d., by post $2 s .9 d$.

Conjuring for Amateurs. A Practical Handbook on How to Perform a Number of Amusing Tricks. By PROF. Ellis STANYON. In paper, price 1s., by post $18.2 d$.

Cookery, The Encyclopadia of Practical. A complete Dictionary of all pertaining to the Art of Cookery and Table Service. Edited by THEo. Francis Garretr, assisted by eminent Chefs de Cuisine and Confectioners. Profusely Illustrated with Coloured Plates and Engravings by Harold FurNess, Geo. CRUIKSHANK, W. MUNN ANDREW, and others. In 2 vols., demy 4to., half morocco, cushion edges, price $£ 33$ s.; carriage free, $£ 35 s$.

Cookery for Amateurs; or, French Dishes for English Homes of all Classes. Includes Simple Cookery, Middle-class Cookery, Superior Cookery, Cookery for Invalids, and Breakfast and Luncheon Cookery. By MaDAMx VALÉRIE. Second Edition. In paper, price 1s., by post 18. $2 d$.

Cucumber Culture for Amateurs. Including also Melons, Vegetable Marrows, and Gourds. Illustrated. By W.J. MAX. In paper, price 18., by post 18. $2 d$. 
Cyclist's Route Map of England and Wales. Shows clearly all the Main, and most of the Cross, Roads, Railroads, and the Distances between the Chlef Towns, as well as the Mileage from London. In addition to this, Routes of Thirty of the Most Interesting Tours are printed in red. Fourth Edition, thoroughly revised. The map is printed on specially prepared vellum paper, and is the fullest, handiest, and best up-to-date tourist's map in the market. In cloth, price 18., by post 18. $2 d$.

Dainties, English and Foreign, and How to Prepare Them. By MRS. DAvidson. In paper, price 18 , by post $18.2 d$.

Designing, Harmonic and Keyboard. Explaining a System whereby an endless Variety of Most Beautiful Designs suited to numberless Manufactures may be obtained by Unskilled Persons from any Printed Music. Illustrated by Numerous Explanatory Diagrams and Illustrative Examples. By C. H. WILKINSON. Demy 4to, cloth gilt, price $£ 33 s$. nett, by post £3 $3 s .8 d$.

Dogs, Breaking and Training: Being Concise Directions for the proper education of Dogs, both for the Field and for Companions. Second Edition. By "PAThFinder." With Chapters by HUGH Dalziel. Illustrated. In cloth gilt, price 68. 6d., by post 6s. 10d.

Dogs, British, Anclent and Modern: Their Varieties, History, and Characteristics. By HUGH DALZIEL, assisted by Eminent Fanciers. Beautifully Illustrated with COLOURED PLATES and full-page Engravings of Dogs of the Day, with numerous smaller illustrations in the text. This is the fullest work on the various breeds of dogs kept in Kngland. In three volumes, demy $8 v 0$, cloth gilt, price $10 \mathrm{~s}$. 6d. each, by post 118. each.

Vol. I. Dogs Used in Field Sports.

Vol. III. Practical Kennel Management: A Complete Treatise on all Matters relating to the Proper Management of Dogs whether kept for the Show Bench, for the Field, or for Companions.

Vol. II. is out of print, but Vols. I. and III. can still be had as above.

Dogs, Diseases of: Their Causes, Symptoms, and Treatment; Modes of Administering Medicines; Treatment in cases of Poisoning, \&c. For the use of Amateurs. By Hugh DaLziel. Fourth Edition. Fntirely Re-written and brought up to Date. In paper, price 1s., by post 18. 2d. ; in cloth gilt, 28., by post $2 s .3 d$.

Dog-Keeping, Popular: Being a Handy Guide to the General Management and Training of all Kinds of Dogs for Companions and Pets. By J. MAXTEe. Illustrated. In paper, price 18., by post 18. $2 d$.

Egీ Cookery. How to Cook Eggs, One Hundred and Fifty Different Ways, English and Foreign. In paper, price 18., by post 18. $2 d$.

Engrayings and their Yalue. Containing a Dictionary of all the Greatest Engravers and their Works. By J. H. Slater. New Fdition, Revised and brought up to date, with latest Prices at Auction. In cloth gilt, price 158. nett, by post, $158.5 d$.

Entertainments, Amateur, for Charitable and other Objects: How to Organise and Work them with Profit and Success. By ROBERT Ganthony. In paper. price 1s., by post 18. $2 d$.

Fancy Work Series, Artistic. A Series of Illustrated Manuals on Artistic and Popular Fancy Work of various kinds. Each number is complete in itself, and issued at the uniform price of $6 \mathrm{~d}$., by post $7 \mathrm{~d}$. Now ready-(1) Macramé LaCe (Second Edition); (2) Patchwork ; (3) Tatting ; (4) Crewel WORK ; (5) APPLIQUE ; (6) FANCY NETTING.

Feathered Friends, Old and Newx. Being the Experience of many years' Observation of the Habits of British and Foreign Cage Birds. By DR. W. T. GREENE. Illustrated. In cloth qilt, price 58., by post $58.4 d$.

Ferns, The Book of Cholce: for the Garden, Conservatory, and Stove. Describing the best and most striking Ferns and Selaginellas, and giving explicit directions for their Cultivation, the formation of Rockeries, the arrangement of Ferneries, \&c. By GEORGE SCHNEIDER. With numerous Coloured Plates and other Illustrations. In 3 vols., large post 4 to. Cloth gilt, price $£ 338$. nett, by post $£ 358$.

Ferns, Choice British. Descriptive of the most beautiful Variations from the common forms, and their Culture. By C. T. DRUERY, F.I.S. Very accurate PLATES, and other Illustrations. In cloth gilt, price 2s. 6 ., by post 2s. $9 d$. 
Ferrets and Ferreting. Containing Instructions for the Breeding, Manage. ment, and Working of Ferrets. Second Edition, Re-written and greatly Inlarged. Illustrated. In paper, price $6 d$., by post $7 d$.

Fentility of Eggs Certificate. These are Forms of Gnarantee given by the Sellers to the Buyers of Eggs for Hatching, undertaking to refund value of any unfertile eggs, or to replace them with good ones. Very valuable to sellers of eggs, as they induce purchases. In books, with counterfoils. price $6 d$., by post $7 d$.

Firework Making for Amateurs. A complete, accurate, and easily. understood work on Making Simple and High-class Fireworks. By DR. W. H. BROWNE, M.A. In coloured wrapper, price $2 s 6 d$., by post $2 s$. $9 d$.

Fisherman, The Practical. Dealing with the Natural History, the Legendary Lore, the Capture of British Fresh-Water Fish, and Tackle and Tackle-making. By J. H. KEENE. In cloth gilt, price $7 \mathrm{s.} 6 \mathrm{~d}$., by post $7 \mathrm{~s} .10 \mathrm{~d}$.

Fish, Flesh, and Fowl. When in Season, How to Select, Cook, and Serve. By MaRY BarRetT Brown. In paper, price 1s., by post 1s. $3 d$.

Eoreign Birds, Fayourite, for Cages and Aviaries. How to Keep them in Heaith. By W. T. GREENE, M.A., M.D., F.Z.S., \&c. Fully Illustrated. In cloth gilt, price $2 s .6 d$., by post $2 s$. $9 d$.

Fortune Telling by Cards. Describing and Illustrating the Methods usually followed by Persons Professing to Tell Fortunes by Cards. [In the press.

Fox Terrier, The. Its History, Points, Breeding, Rearing, Preparing for Exhibition, and Coursing. By HUGII DALZIEL. Illustrated with Coloured Frontispiece and Plates. In paper, price 1s., by post 1s. $2 d$.; cloth, 28 ., by post $2 s .3 d$.

Fox Terrier Stud Book. Edited by Hugh DalzIEL. In cloth gilt, price $38.6 \mathrm{~d}$. each, by post 38. 9d. each.

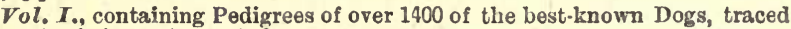
to their most remote known ancestors.

Vol. II. Pedigrees of 1544 Dogs, Show Record, \&c.

Vol. IIT. Pedigrees of $1214 \mathrm{Dogs}$, Show Record, \&c.

Vol. IV. Pedigrees of 1168 Dogs, Show Record, \&c.

Vol. $\boldsymbol{V}$. Pedigrees of 1662 Dogs, Sllow Record, \&c.

Fretwork and Marquetry. A Practical Manual of Instructions in the Art of Fret-cutting and Marquetry Work. By D. DENNING. Profusely Illustrated. In cloth gilt, price $28.6 d$., by post $2 s .9 d$.

Friesland Meres, $\mathbf{A}$ Cruise on tho. By ERNEST R. Suffling. Illustrated. In paper, price 18., by post 18 . $2 d$.

Eruit Culture for Amateurs. By S. T. WRIGHT. With Chapters on Insect and other Fruit Pests by W. D. DRURY. Second Edition. Illustrated. In cloth gilt, price 3 s. 6 d., by post $38.9 d$.

Game Preserying, Practical. Containing the fullest Directions for Rearing and Preserving both Winged and Ground Game, and Destroying Vermin; with other Information of Value to the Game Preserver. By W. Carnegiz. Illustrated. In cloth gilt, demy $8 v 0$, price 21s., by pnst $218.5 d$.

Games, the Book of a Hundred. By MARY WHITE. These Games are for Adults, and will be found extremely serviceable for Parlour Entertainment. They are Clearly Explained, are Ingenious, Clever, Amusing, and exceedingly Novel. In stiff boards, price $2 s$. $6 d$. by post $2 s .9 d$.

Gardening, Dictionary of. A Practical Encyclopædia of Horticulture, for Amateurs and Professionals. Illustrated with 2440 Engravings. Edited by G. Nicholson, Curator of the Royal Botanic Gardens, Kew ; assisted by Prof. Trail, M.D., Rev. P. W. Myles, B.A., F.I.S.. W. Watson. J. Garrett, and other Specialists. In 4 vols., large post 4 to. Cloth gilt, price $£ 3$, by post $£ 328$.

Gardening in Egypt. A Handbook of Gardening for Lower Egypt. With a Calendar of Work for the different Months of the Year. By WALTER DRAPER. In cloth gilt, price 3s. $6 d$., by post $3 s$. $9 d$.

Gardening, Home. A Manual for the Amateur, Containing Instructions for the Laying Out, Stocking, Cultivation, and Management of Small GardensFlower, Fruit, and Vegetable. By W. D. DRURY, F.R.H.S. Illustrated. In paper, price 1s., by post 18 . $2 d$.

Goat, Book of the. Containing Full Particulars of the Varinus Breeds of Goats, and their Profitable Management. With many Plates. By H. STEPHeN HOLMES PEGLER. Third Edition, with Engravings and Coloured Frontispiece. In cloth gilt, price $4 s .6 d$., by post $4 s .10 d$.

Goat-Keeping for A mateurs : Being the Practical Management of Goats for Milking Purposes. Abridged from "The Book of the Goat." Illustrated. In paper, price 1s., by post 1s. $2 d$. 
Grape Growing for A mateurs. A Thoroughly Practical Book on Successful Vine Culture. By E. Moly neUx. Illustrated. In paper, price 1s., by post 18. $2 d$.

Greenhouse Management for Amateurs. The Best Greenhouses and Frames, and How to Build and Heat them, Illustrated Descriptions of the most suitable Plants, with general and Spectal Cultural Directions, and all necessary information for the Guidance of the Amateur. By W. J. MAY. Second Edition Revised and Enlarged. Magnificently Illustrated. In cloth gilt, price 58 ., by post $5 s .4 d$.

Creyhound, The: Its History, Points, Breeding, Rearing, Training, and Running. By Hugh Dalziet. With Coloured Frontispiece. In cloth gilt, demy 8vo., price 2s. $6 d$., by post $28.9 d$.

Guinea Pig, The, for Food, Fur, and Fancy. Its Varieties and its Management. By C. Cumberland, F.Z.S. Illustrated. In paper, price 1s., by post 1s. 2d. In cloth gilt, with coloured frontispiece, price $2 s .6 d$., by post $2 s .9 d$.

Hand witing, Character Indicated by. With Illustrations in Support of the Theories advanced, taken from Autograph Letters, of Statesmen, Lawyers, Soldiers, Ecclesiastics, Authors, Poets, Musicians, Actors, and other persons. Second Edition. By R. Baughan. In cloth gilt, price 2s. 6d., by post 2s. 9d.

Iardy Perennials and Old-fashioned Garden Flowers. Descriptions, alphabetically arranged, of the most desirable Plants for Borders, Rockeries, and Shrubberies, including Foliage as well as Flowering Plants. By J. WooD. Profusely Illustrated. In cloth gilt, price $3 s .6 d$., by post $38.9 d$.

Hayk Moths, Book of British. A Popular and Practical Manual for all Iepiclopterists. Copiously. illustrated in black and white from the Author's own exquisite Drawings from Nature. By W. J. LuCaS, B.A. In cloth gilt, price 38. 6d., by post 3s. $9 d$.

Home Medicine and Surgery: A Dictionary of Diseases and Accidents, and their proper Home Treatment. For Family Use. By W. J. Mackenzie, M.D. Illustrated. In cloth gilt, price $2 s .6 d$., by post $2 s, 9 d$.

Horse-Keeper, The Practical. By George Fleming, C.B., LL.D., F.R.C.V.S.. late Principal Veterinary Surgeon to the British Army, and Ex-President of the Royal College of Veterinary Surgeons. In cloth gilt, price 3. $6 d$., by post 3s. 10d.

Horse-Keeping for Amateurs. A Practical Manual on the Management of Horses, for the guidance of those who keep one or two for their personal use. By FoX RUSSELL. In paper, price 18., by post $1 s$. $2 d$. ; cloth gilt 28 ., by post $28.3 d$.

Horses, Diseases of: Their Causes, Symptoms, and Treatment. For the use of Amateurs. By HUGH DALZIEL. In paper, price 1s., by post $1 s .2 d$.; eloth gilt 28., by post $28.3 d$.

Incubators and their Management. By J. H. SuTcliffe. New Edition, Revised and Enlarged. Illustrated. In paper, price 18., by post $18.2 d$.

Inland Watering Places. A Description of the Spas of Great Britain and Ireland, their Mineral Waters, and their Medicinal Value, and the attractions which they offer to Invalids and other Visitors. Profusely illustrated. A Companion Volume to "Seaside Watering Places." In cloth gilt, price 2s. $6 d$., by post 28. $10 d$

Jack All Alone. Being a Collection of Descriptive Yachting Reminiscences. By FRANK COWPER, B.A., Author of "Sailing Tours." Illustrated. In cloth gilt, price 3 s. $6 d$., by post 3s. $10 d$.

Journalism, Practical: How to Enter Thereon and Succeed. A book for all who think of "writing for the Press." By JoHN DAwson. In cloth gilt, price $2 s .6 d$., by post $28.9 d$.

Laying Hens, How to Keep and to Rear Chickens in Large or Small Numbers, in Absolute Confinement, with Perfect Success. By MAJOR G. F. MORANT. In paper, price $6 d$., by post $7 d$.

Llbrary Manual, The. A Guide to the Formation of a Iibrary, and the Values of Rare and Standard Books. By J. H. SLATER, Barrister-at-1.aw. Third Edition. Revised and Greatly Enlarged. In cloth gilt, price 7s. 6d. nett, by post 78. $10 d$.

Magic Lanterns, Modern. A Guide to the Management of the Optical Lantern, for the Use of Entertainers, Lecturers, Photograpers, Teachers, and others. By R. ChILD BAYLEY. In paper, price 1s., by post 1s. $2 d$.

Mice, Fancy: Their Varieties, Management, and Breeding. Third Edition, with additional matter and Illustrations. In coloured wrapper representing different varieties, price $18 .$, by post $1 s .2 d$. 
Millinery, Handbook of. A Practical Manual of Instruction for Ladies. Illustrated. By MME. Roske, Court Milliner, Principal of the School of Millinery. In paper, price 18., by post 18. 2d.

Model Yachts and Boats: Their Designing, Making, and Sailing. Illustrated with 118 Designs and Working Diagrams. By J. DU V. GRosvmor. In leatherette, price 58. , by post 58 . $3 d$.

Monkeys, Pet, and How to Manage Them. Illustrated. By ARTHuR PatrerSON. In cloth gilt, price 2s. $6 d$., by post $2 s$. $9 d$.

Mountaineering, Welsh. A Complete and Handy Guide to all the Best Roads and Bye-Paths by which the Tourist should Ascend the Welsh Mountains. By A. W. PERRY. With numerous Maps. In cloth gilt, price $2 s .6 d$., by post $2 s .9 d$.

Mushroom Culture for Amateurs. With Full Directions for Successful Growth in Houses, Sheds, Cellars, and Pots, on Shelves, and Out of Doors. By W. J. MAY. Illustrated. In paper, price 1s., by post 18. 2d.

Natural History sketches among the Carnivora-Wild and Domesticated; with Observations on their Habits and Mental Faculties. By ARTHuR NICOLS, F.G.S., F.R.G.S. Illustrated. In cloth gilt, price $2 s .6 d$., by post $2 s .9 d$.

Naturalist's Directory, The, for 1899 (Fifth year of issue). Invaluable to all Students and Collectors. In paper, price 1s., by post $18.3 \mathrm{~d}$.

Needlework, Dictionary of. An Encyclopædia of Artistic, Plain, and Fancy Needlework; Plain, practical, complete, and magnificently Illustrated. By S. F. A. CAulfeild and B. C. SAward. In demy 4 to, $528 p p$, 829 Illustra. tions, extra cloth gilt, plain edges, cushioned bevelled boards, price 21s. nett, by post 21s.9d.; with COLOURED PLATES, elegant satin brocade cloth binding, and coloured edges, 31s. 6d. nett, by post 328 .

Orchids: Their Culture and Management, with Descriptions of all the Kinds in General Cultivation. Illustrated by Coloured Plates and Engravings. By W. WATsoN, Assistant-Curator, Royal Botanic Gardens, Kew ; Assisted by W. BEan, Foreman, Royal Gardens, Kew. Second Edition, Revised and with Extra Plates. In cloth gilt and gilt edges, price £1 1s. nett, by post £1 1s. $6 d$.

Painters and Thelr Works. A Work of the Greatest Value to Collectors and such as are interested in the Art, as it gives, besides Biographical Sketches of all the Artists of Repute (not now living) from the 13th Century to the present date, the Market Value of the Princlpal Works Painted by Them, with Full Descriptions of Same. In 3 vols., cloth gilt, price 378. $6 d$. nett, by post 38s. $3 d$.

Painting, Decoratixe. A practical Handbook on Painting and Etching upon Textiles, Pottery, Porcelain, Paper, Vellum, Leather, Glass, Wood, Stone, Metals, and Plaster. for the Decoration of our Homes. By B. C. SAWARD. In cloth gilt, price 3s. 6d., by post 3s. $9 d$.

Parcel Post Dispatch Book (registered). An invaluable book for all who send parcels by post. Provides Address Labels, Certiflcate of Posting, and Record of Parcels Dispatched. By the use of this book parcels are insured against loss or damage to the extent of £2. Authorised by the Post Office. Price 18., by post 18. 2d., for 100 parcels; larger sizes if required.

Parrakeets, Popular. How to Keep and Breed Them. By DR. W. T. GREENE, M.D., M.A., F.Z.S., \&c. In paper, price 18., by post, 1s. $2 d$.

Parrot, The Grey, and How to Treat it. By W. T. Greene, M.D., M.A., F.Z.S., \&c. In paper, price 1s., by post $18.2 d$.

Paxrots, the Speaking. The Art of Keeping and Breeding the principal Talking Parrots in Conflnement. By DR. KARL Russ. Illustrated with COLOURED PLATES and Engravings. In cloth gitt, price 5s., by post 5 s. $4 d$.

Patlence, Games of, for one or more Players. How to Play 142 different Games of Patience. By M. Whitmore Jones. Illustrated. Series I., 39 games; Series II., 34 games; Series III., 33 games; Series IV., 37 games. Each, in paper, 18., by post 18. 2d. The four bound together in cloth gilt, price $58 .$, by post $58.4 d$.

Pedigree Record, The. Being Part I. of "The Breeders and Exhibitors Record," for the Registration of Particulars concerning Pedigrees of Stock of every Description. By W. K. TAunTon. In cloth gilt, price 2s. 6d., by post 2s. $9 d$.

Perspective, The Essentials of. With numerous Illustrations drawn by the Author. By L. W. Miller, Principal of the School of Industrial Art of the Pennsylvania Museum, Philadelphia. Price 68. 6d., by post 6s. $10 d$. 
Pheasant-Keeping for Amateurs. A Practical Handbook on the Breed. ing, Rearing, and General Management of Fancy Pheasants in Confinement. By GEO. HORNe. Fully Illustrated. In cloth gilt, price 3 s. $6 d$., by post 3s. $9 d$.

Photographic Printing Processes, Popular. A Practical Guide to Printing with Gelatino-Chloride, Artigue, Platinotype, Carbon, Bromide, Collodio-Chloride, Bichromated Gum, and other Sensitised Papers. By H. MACLEAN, F.R.P.S. Illustrated. In cloth gilt, price 2s. $6 d$., by post $28.10 d$.

Photography (Modern) for Amateurs. New and Revised Edition. By J. EATON FEARN. In paper, price 18., by post $18.2 d$.

Pianofortes, Tuning and Repairing. The Amateur's Guide to the Practical Management of a Piano without the intervention of a Professional. By Charles Babbington. In paper, price $6 d$., by post $6 \frac{1}{2} d$.

Ploture-Frame Making for Amateurs. Being Practical Instructions in the Making of various kinds of Frames for Paintings, Drawings, Photographs, and Engravings. By the REv. J. LukIN. Illustrated. In paper, price 18., by post $182 d$.

Pig, Book of the. The Selection, Breeding, Feeding, and Manazement of the Pig; the Treatment of its Diseases; the Curing and Preserving of Hams, Bacon, and other Pork Foods; and other information appertaining to Pork Farming. By Professor JAMES LONG. Fully Illustrated with Portraits of Prize Pigs, Plans of Model Piggeries, \&c. In cloth gilt, price 108. 6d., by post 108. 11d.

Pig-Keeplng, Practical: A Manual for Amateurs, based on personal Experience in Breeding, Feeding, and Fattening; also in Buying and Selling Pigs at Market Prices. By $\boldsymbol{K}$. D. GaRratr. In paper, price 18., by post 18. $2 d$.

Plgeons, Fancy. Containing full Directions for the Breeding and Manage. ment of Fancy Pigeons, and Descriptions of every known Variety, together with all other information of interest or use to Pigeon Fanciers. Third Edition. 18 COLOURED PLATES, and 22 other full-page Illustrations. By J. C. LY ELL. In cloth gilt, price 108. 6d., by post 10s. $10 d$.

Pigeon-Keeping for Amateurs. A Complete Guide to the Amateur Breeder of Domestic and Fancy Pigeons. By J. C. LYELL. Illustrated. In cloth gilt, price 2s. 6d., by post 2s. 9d.; in paper, price 1s., by post 1s. $2 d$.

Polishes and Stains for Wood: A Complete Guide to Polishing Wood. work, with Directions for Staining, and Full Information for Making the Stains, Polishes, \&c., in the simplest and most satisfactory manner. By David Denning. In paper, 18., by post 18. $2 d$.

Pool, Games of. Describing Various English and American Pool Games, and giving the Rules in full. Illustrated In paper, price 18., by post 1s. $2 d$.

Postage Stamps, and their Collection. A Practical Handbook for Collectors of Postal Stamps, Envelopes, Wrappers, and Cards. By OLIVER FIRTH, Member of the Philatelic Societies of London, Leeds, and Bradford. Profusely Illustrated. In cloth gilt, price $38,6 d$., by post 38. $10 d$.

Postage Stamps of Europe, The Adhesive: A Practical Guide to their Collection, Identitication, and Classitication. Especially designed for the use of those commencing the Study. By W. A. S. WESTOBY. Beautifully Illustrated. In paper Parts, 18. each, by post 18. 2d. Vol. I., cloth gilt, price 78. 6d., by post 88 .

Postmarks, History of British. With 350 Illustrations and a. List of Numbers used in Obliterations. By J. H. DANIELs. In cloth gilt, price $2 s_{.} 6 d_{\text {. }}$, by post $28.9 d$.

Pottery and Porcelain, English. A Guide for Collectors. Handsomely Illustrated with Engravings of Specimen Pieces and the Marks used by the different Makers. New Edition, Revised and Enlarged. By the REv. E. A. DOWNMAN. In cloth gilt, price 58 ., by post $58.3 d$.

Poultry-Farming, Profitable. Describing in Detail the Methods that Give the Best Results, and pointing out the Mistakes to be Avoided. By J. H. SUTCLIFFE. Illustrated. In paper, price 18., by post $18.2 d$.

Poultry-Keeping, Popular. A Practical and Complete Guide to Breeding and Keeping Poultry for Eggs or for the Table. By F. A. MACKenzie. Illus. trated. In paper, price 1s., by post 18. $2 d$. 
Poultry for Prizes and Profit. Contains: Breeding Poultry for Prizes, Exhibition Poultry and Management of the Poultry Yard. Handsomely Illus. trated. Second Edition. By PROF. JAMES LONG. In cloth gilt, price $28.6 d .$, by post 2s. 10d.

Rabbit, Book of The. A Complete Work on Breeding and Rearing all Varieties of Fancy Rabbits, giving their History, Variations, Uses, Points, Selection, Mating, Management, \&c., \&c. SECOND EDITION. Edited by KEMPSTRR W. KNIGHT. Illustrated with Coloured and other Plates. In cloth gilt, price 10s. $6 d$., by post 10s. $11 d$.

Rabbits, Diseases of: Their Causes, Symptoms, and Cure. With a Chapter on THE DISEASES OF CAviEs. Reprinted from "The Book of the Rabbit" and "The Guinea Pig for Food, Fur, and Fancy." In paper, price 1s., by post 18. $2 d$.

Rabbits for Prizes and Profit. The Proper Management of Fancy Rabbits in Health and Disease, for Pets or the Market, and Descriptions of every known Variety, with Instructions for Breeding Good Specimens. By CHARLES RAYSON. Illustrated. In cloth gilt, price 2s. 6d., by post $2 s .9 d$. Also in Sections, as follows:

General Management of Rabhits. Including Hutches, Breeding, Feeding, Diseascs and their Treatment, Rabbit Courts, \&c. Fully Illustrated. In paper, price 1s., by post 1s. $2 d$.

Exhibition Rabbits. Being descriptions of all Varieties of Fancy Rabbits, their Points of Excellence, and how to obtain them. Illustrated. In paper, price 1s., by post $1 s .2 d$

Road Charts (Registered). For Arny Men, Volunteers, Cyclists, and other Road Users. By S. W. H. Dixon and A. B. H. Clerke. No. 1.-London to Brighton. Price $2 d$., by post $2 \frac{1}{2} d$.

Roses for Amateurs. A Practical Guide to the Selection and Cultivation of the best iroses. Illustrated. By the REv. J. HONYWOOD D'OMBrain, Hon. Sec. Nat. Rose Soc. In paper, price 18., by post 1s. $2 d$.

Gaillng Guide to the Solent and Poole Harbour, with Practical Hint: as to hiving and Cooking on, and Working a Small Yacht. By LIEUT.-Co.L. T. G. CUTHELL. Illustrated with Coloured Charts. In cloth gilt, price 28. 6d., by post 2s. \&d.

Salling Tours. The Yachtman's Guide to the Cruising Waters of the English and Adjacent Coasts. With Descriptions of every Creek, Harbour, and Roadstead on the Course. With numerous Charts printed in Colours, showing Deep water, Shoals, and Sands exposed at low water, with sounding. By FrANK COWPER, B.A. In Crown 8vo., cloth gilt.

Vol. I., the Coasts of Essex and Suffolk, from the Thames to Aldborough. Six Charts. Price 5 s., by post 58 . $3 d$.

Vol. II. The South Coast, from the Thames to the Scilly Islands, twenty. five Charts. Price 7s. 6d., by post 7s. $10 d$.

Vol. III. The Coast of Brittany, from L'Abervrach to St. Nazaire, and an Account of the Loire. Twelve Charts. Price 7s. 6d., by post 7s. $10 d$.

Vol. IV. The West Coast, from Land's End to Mull of Galloway, in. cluding the East Coast of Ireland. Thirty Charts. Price 108. $6 d$., by post 108. $10 d$.

$V o$ l. $V$. The Coasts of Scotland and the N. F. of England down te Ald. borough. Forty Charts. Price 10s. 6d., by post 10s. 10d.

5t. Bernard, The. Its History, Points, Breeding, and Rearing. By HuaH DALziel. Illustrated with Coloured Frontispiece and Plates. In cloth gilt, price $2 s .6 d$., by post $2 s$. $9 d$.

5t. Bernard Stud Book. Edited by Hugh Dalziel. In cloth gilt, price 3s. 6 d. each, hu post $38.9 d$. each.

Vol. I. Pedigrees of 1278 of the best known Dogs traced to their most remote known ancestors, Show Record, \&c.

Vol. Ir. Pedigrees of 564 Dogs, Show Record, \&c.

Sea-Fishing for Amateurs.. Practical Instructions to Visitors at Seaside Places for Catching Sea-Fish from Pier-heads, Sbore, or Boats, principally by means of Hand Lines, with a very useful List of Fishing Stations, the Fish to be caught there, and the Best Seasons. By FRANK HUDSON. Illustrated. In paper, price 1s., by post $18.2 d$.

Sea-Fishing on the English Coast. The Art of Making and Using Sea. Tackle, with a full account of the methods in vogue during each month of the year, and a Detailed Guide for Sea-Fishermen to all the most Popular Water. ing Places on the English Coast. By F. G. AfLaL.o. Illustrated. In cloth ailt, price 2s. $6 d$., by post $2 s$. $9 d$. 
Bea-Life, Realities of. Describing the Duties, Prospects, and Pleasures of a Young Sallor in the Mercantile Marine. By H. E. ACRAMAN CoATE. With a Preface by J. R. DIGGLE, M.A., M.L.S.B. In cloth gilt, price $3 s_{\text {. }} 6 \mathrm{~d}$., by post 3s. 10d.

Seaside Watering Places. A Description of the Holiday Resorts on the Coasts of England and Wales, the Channel Islands, and the Isle of Man, giving full particulars of them and their attractions, and all information likely to assist persons in selecting places in which to spend their Holiday according to their individual tastes. Illustrated. 'Twenty-second Year of Issue. In cloth gilt, price $2 s$. $6 d$., by post $2 s$. $10 d$.

Sea Terms, a Dictionary of. For the use of Yachtsmen, Amateur Boat. men, and Beginners. By A. ANSTED. Fully Illustrated. In cloth gilt, price 7s. 6 d. nctt, by post $7 s$. $11 d$.

Shadow Entertainments, and How to Work them: being Something about Shadows, and the way to make them Protitable and Funny. By A. Patrer. son. Illustrated. In paper, price 1s., by post 1s. $2 d$.

Shaye, An Easy : The Mysteries, Secrets, and Whole Art of, laid bare. Edited by JOSEPH MORToN. Price 1s., by post 1s. $2 d$.

Sheep Raising and Shepherding. A Ilaudbook of Sheep Harming. 1y W. J. MALDEN, Principal of the Agricultural College, Vekfield. Illustrater. Cloth yilt, price 3s. 6d, by post 3s. 9d.

Sheet Metal, Working in: Being Practical Instructions for Making and Mending Small Articles in Tin, Copper. Iron, Zinc, and Brass. By the Rev. T. T'NIN, B.A. Illustrated. Third Edition. In paper, price 18., by post 18. 1d.

Shorthand, Exercises in, for Daily IIalf Hours, on a Newly-devised and Simple Method, free from the Labour of Learning. Illustrated. Being Part II. of "Lessons in Shorthand on Gurney's System (Improved)." By R. F. MILlER. In paper, price $9 d$., by post $10 d$.

Show Record. The. Being Part III. of "The Breeders' and Exhibitors' Recorl," for the Registration of Particulars concerning the Exhibition of Pedigree stock of every Description. By W. K. TAUnTon, In cloth gilt, price 2s. $6 d$., by post $28.9 d$.

Skating Cards : An Easy Method of Learning Figure Skating, as the Cards can be used on the Ice. In cloth case, price 28 . $6 d$. ., by post 2s. 9d.; leather. price 3s. 6d., by post 3s. 9d. A cheap form is issued printed on paper and made up as a small book, price 18., by post 1s. Id.

Sleight of Hand. A Practical Manual of Legerdemain for Amateurs and Others. New Filition, Reviser and Enlarged Profusely Illustrated. By E. SACHS. In cloth gilt, price $68.6 d$., by post $6 s .10 d$.

Snakes, Marsuplals, and Birds. A Charming Book of Anecdotes, Adven. tures, and Znological Notes. A capital Book for Boys. By ARTIUU Nicols, F.G.S., F.R.G.S., \&c. Illustrated. In cloth gilt, price 38. 6d., by post 3s. $10 d$.

Eolo Whist. A Practical Manual both for Beginners and Advanced Students, with Amended Exhaustive Code of Laws. By C. J. MELrose. In cloth gilt, price 3 s. $6 d$., by post $38.10 d$.

Sporting Books, Illustrated. A Descriptive Survey of a Collection of Finglish Illustrated Works of a Sporting and Racy Character, with an Appendix of Prints relating to Sports of the Field. The whole valued by reference to Average Auction Prices. By J. H. Slater, Author of "Library Manual," "Fngravings and Their Value," \&c. In cloth gilt, price 7s. $6 d$. nett, by post $78.10 d$.

Stud Record. The. Being Part II. of "The Breeders' and Exhibitors" Record," for the Registration of Particulars concerning Pedigree Stock of every Description. By W. K. 'TAUNTON. In cloth gilt, price 2s. 6d., by post 2s. 9d.

Taxidermy, Practical. A Manual of Instruction to the Amateur in Collecting, Preserving. and Setting-up Natural History Specimens of all kinds. With Wxamples and Working Diagrams. By MNNTAGU BROWNE, F.Z.S., Curator of Leicester Museum, Second Edition. In cloth gilt, price 78. 6d., by post 7s. 10d. 
Thames Guide Book. From Lechlade to Richmond. For Boating Men, Anglers, Picnic Parties, and all Pleasure-seekers on the River. Arranged on an entirely new plan. Second Edition, profusely Illustrated. In cloth, price 18. $6 d$., by post 18. $9 d$; in paper, price 18., by post 18. $2 d$.

Tomato and Fruit Growing as an Industry for Women. Lectures given at the Forestry Exhibition, Earl's Court, during July and August, 1893. By Grace Harriman, Practical Fruit Grower and County Council Lecturer. In paper, price 18., by post 18. 1 d.

Tomato Culture for Amateurs. A Practical and very Complete Manual on the subject. By B. C. RAVENSCROFT. Illustrated. In paper, price 1s., by post 1s.1d.

Trapping, Practical: Being some Papers on Traps and Trapping for Vermin, with a Chapter on General Bird Trapping and Snaring. By W. CARNEGIE. In paper, price 18., by post $18.2 d$.

Turning Lathes. A Manual for Technical Schools and Apprentices. A Guide to Turning, Screw-cutting, Metal-spinning, \&c. Edited by JAMES LukIN, B.A. Third Edition. With 194 Illustrations. In cloth gilt, price 38., by post $3 d$. $3 s$.

Xamp, How to. A Practical Guide to the Accompaniment of Songs by the Unskilled Musician. With Examples. In paper, price $9 d$., by post $10 d$.

Yegetable Culture for Amateurs. Containing Concise Directions for the Cultivation of Vegetables in small Gardens so as to insure Good Crops. With Lists of the Best Varieties of each. Sort. By W. J. MAY Illustrated. In paper, price 18., by post $18.2 d$.

Yentriloquism, Practical. A thoroughly reliable Guide to the Art of Voice Throwing and Vocal Mimicry, Vocal Instrumentation, Ventriloquial Figures, Entertaining, \&c. By ROBERT GANTHONY. Numerous Illustrations. In cloth gilt, price $28.6 d$., by post $2 s .9 d$.

Ylolins (Old) and their Makers: Including some References to those of Modern Times. By James M. Fleming. Illustrated with Facsimiles of 'Tickets, Sound-Holes, \&c. In oloth gilt, price 68. 6 d. nett, by post $68.10 d$.

Yiolin School, Practical, for Home Students. Instructions and Exercises in Violin Playing, for the use of Amateurs, Self-learners, Teachers, and others. With a Supplement on "Easy Legato Studies for the Violin." By J. M. Flemina. Demy 4to, cloth gilt, price 98. 6d., by post 108. $2 d$. Without Supplement, price 78. $6 d$., by post 88 .

Yixarium, The. Being a Full Description of the most Interesting Snakes, Lizards, and other Reptiles, and How to Keep Them Satisfactorily in Con. finement. By REv. G. C. BateMan. Beautifully Illustrated. In cloth gilt, price $78.6 d$. nett, by post 88 .

War Medals and Decorations. A Manual for Collectors. with some account of Civil Rewards for Valour. By D. HASTINGs IRWIN. Revised and Enlarged Edition. Beautifully Illustrated. In cloth gilt, price 128. $6 d$. nett, by post 12s. 10d.

Whippet and Race-Dog, The: How to Breed, Rear, Train, Race, and Exhibit the Whippet, the Management of Raee Meetings, and Original Plans of Courses. By FReEman Lloyd. In cloth gilt, price 38. 6d., by post 38. $10 d$.

Whist, Scientific: Its Whys and Wherefores. Wherein all Arbitrary Dicta of Authority are eliminated, the Keader being taken step by step through the Reasoning Operations upon which the Rules of Play are based. By C.J. MELROSE. With Illustrative Hands printed in Colour. In cloth gilt, price 68., by post $68.6 d$.

wild Birds, Cries and Call Notes of, Described at Length, and in many instances Illustrated by Musical Notation. In paper, price 18., by post 18. $2 d$

Wildfowling, Practical: A l3ook on Wildfowl and Wildfowl Shooting. By HY. SHARP. The result of 25 years experience Wildfowl Shooting under all sorts of conditions of locality as well as circumstances. Profusely Illus. trated. Demy 8vo, cloth gilt, price 12s. 6d. nett, by post $12 s .10 d$.

YIld Sports in Ireland. Being Picturesque and Entertaining Descriptions of several visits paid to Ireland, with Practical Hints likely to be of service to the Angler, Wildfowler, and Yaclitsman. By JOHN BICK RRDYKE, Author of "The Book of the All-Round Angler," \&c. Beautifully Illustrated from Photographs taken by the Author. In cloth gilt, price 68., by post 68. 4d. 
Window Ticket Writing. Containing full Instructions on the Method of Mixing and Using the Various Inks, \&c., required, Hints on Stencilling as applied to Ticket Writing, together with Lessons on Glass Writing, Japanning on Tin, \&c. Especially written for the use of Learners and Shop Assistants. By WM. C. ScotT. In paper, price 18., by post 18. $2 d$.

Wire and Sheet Gauges of the World. Compared and Compiled by C. A. B. PFeILschmidt, of Sheffield. In paper, price 18., by post 18. $1 d$.

Wood Carying for Amateurs. Full Instructions for producing all the different varieties of Carvings. SECOND EDITION. Edited by D. DENNING. In paper, price 1s., by post $18.2 d$.

Workshop Makeshifts. Being a Collection of Practical Hints and Suggestions for the use of Amateur Workers in Wood and Metal. By H. J. S. CassalL. Fully Illustrated. In cloth gilt, price $28.6 \mathrm{~d}$., by post $2 s .9 d$.

\section{FICTION LIBRARY.}

Decameron of a Hypnotist. Tales of Dread. By E. Suffurva, Author of "The Story Hunter," \&c. With Illustrations. In paper, price is, by post 18. $3 d$.

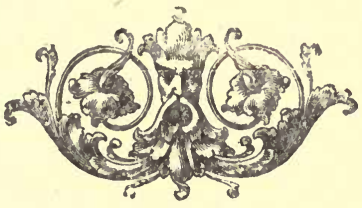

IN PREPARATION.

\section{THE 1899 EDITION OF}

\section{Seaside Watering Places (23rd YEAR OF PUBLICATION).}

A Description of over 250 Holiday Resorts on the Costs of England and Wales, the Isle of Wight, the Channel Islands, and the Isle of Man, including the gayest and most quiet. places, giving full particulars of them and their attractions, and all other information likely to assist persons in selecting places in which to spend their Holidays according to their individual tastes; with Business Directory of Tradesmen, so that Visitors can send orders in advance of their arrival.

Corrections, Directory Announcements, and Advertisements should now be sent in.

PROSPECTUSES FREE ON APPIICATION.

London: L. Upcott Gill, 170, Strand, W.C. 


\section{NICHOLSON'S}
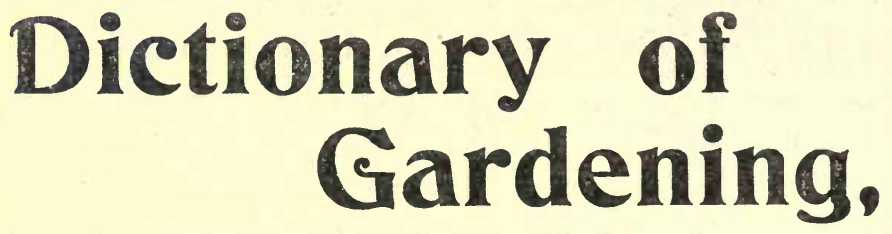

Is in preparation, bringing this great work on the Art and Practice of Horticulture right up to date. This is the finest work on Gardening at present existing, and the Supplement -which is magnificently illustrated-will make it the newest.

It is expected that the first portion will be ready at an early date.

\section{THE SEA SERVICES.}

A Guide to the Royal Navy and Mercantile Marine, INCLUDING

PILOT, COASTGUARD, LIFEBOAT, LIGHTSHIP; WATER POLICE, AND CUSTOMS SERVICE.

\section{By A. COWIE.}

\section{Life Studies in Palmistry.}

The hands of notable persons read according to the practice of Modern Palmistry.

ILLUSTRATED.

By INĀ OXENFORD.

LONDON :

L. UPCOTT GILL, 170, STRAND, W.C. 


\section{PUBLISHED BY E. and F. N. SPON, Ltd.}

Foolscap 8vo, leather cloth, 2s. 6 d.

Quick and Easy Methods of Calculating. A Simple Explanation of the Theory and Use of the Slide-Rule, Logarithms, \&c., with numerous Examples worked out. By R. G. Blaine, Assoc. Mem. Inst. C.E., Author of "Hydraulic Machinery," \&c.

Twelfth Edition, 64mo roan, gilt edges, 1s. Waistcoat pockict size.

Spons" Tables and Memoranda for Engineers. By J. T. Hurst, C.E. (Late Surveyor War Department), \&c. Author" of "Hurst's Tredgold's Carpentry," "Architectural Surveyor's Hand Book," \&c. Also in celluloid case, $1 \mathrm{~s}$. $6 \mathrm{~d}$.

64 mo roan, gilt edges, $1 \mathrm{~s}$. Waistcoat pocket size.

Electrical Tables and Memoranda. By Silvanus P. Thompson, D.Sc., B.A., F.R.S., \&c., and Eustace Thomas.

With Illustrations, erown 8vo, eloth, 7s. $6 \mathrm{~d}$.

Magnets and Electric Currents. An Elementary Treatise for the Use of Electrical Artisans and Science Teachers. By Professor J. A. Fleming, D.Sc., F.R.S.

\section{Fourth Edition, demy 8ro, cloth, 6s.}

Spons' Mechanics' Own Book. A Manual for Handicraftsmen and Amateurs. Containing 700 pages, and 1420 Illustrations. Also in handsome French Morocco binding, 7s. 6d.

Royal 8vo, cloth, 12s. 6d.

Art of Coppersmithing. A practical Treatise for working Sheet Copper into all forms. By JoHn FuLLer, Sen. Numerous engravings illustrating every branch of the art.

\section{Fourth Edition, 4to, cloth, 18s.}

The Mechanician. A Treatise on the Construction and Manipulation of Tools, for the Use and Instruction of young Engineers and Scientific Amateurs. Comprising the Arts of Blacksmithing and Forging; the Construction and Manufacture of Hand Tools, and the various Methods of Using and Grinding them; the Construction of Machine Tools, and how to work them; Turning and Screw-Cutting; the various details of setting-out work, de. By Cameron KnIGHT, Engineer. 96 4to plates, containing 1147 illustrations, and 397 pages of letterpress.

Fourth Edition, 8vo, cloth, 4s. 6d.

Bicycle Repairing. A Manual compiled from Articles in the "Iron Age," by S. D. V. BURR. 208 pages, with over 200 illustrations.

\section{Crown 8vo, eloth, 3s. net.}

On the Springing and Adjusting of Watches: Being a Description of the Balance Spring and the Compensation Balance, with Directions for Applying the Spring and Adjusting for Isochronism and 'Temperature. By F. J. BritTen, Author of "The Watch and Clock Maker's Handbook," \&c.

CATAlOgue POST FREE ON APPLICATION.

\section{LONDON : E. \& F. N. SPON LTD., 125, STRAND,}

AND OF ALL BOOKSELLERS. 

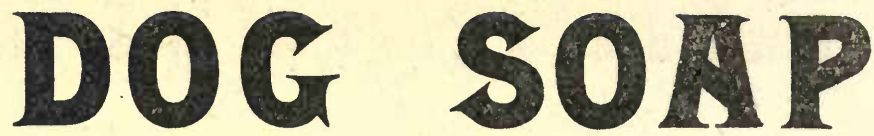

MADE BY

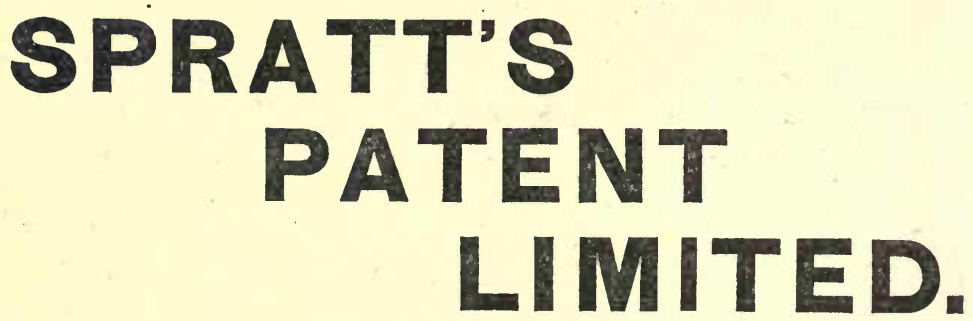

\section{A NON-POISONOUS PREPARATION.}

Invaluable for Preparing the Coat for Exhibition. SOLD IN TABLETS.

\section{DOG MEDICINES.}

Alterative Cooling Powders Aperient Tasteless Biscuits Chronic Skin Disease Cure Congh Pills Chemical Food Chorea Pills (St. Vitus' Dance)

Diarrhœa Mixture

Distemper Powders

Distemper Pills

Disinfectant for Kennels

Ear Canker Lotion

Eczema Lotion

Eye Lotion

Hair Stimulant
Jaundice or "Yellows" Pills

Locurium Oil (Patent) for Anima Use

Locurium Oil (Patent) for Human Use (including Govern. ment Stamp)

Mange Lotion

Purging Pills

Rheumatic and Sprain Liniment Rheumatic and Chest Founder Pills Tonic Condition Pills

Vegetable Puppy Vermifuge Worm Powders Worm Pills

YOUR TRADESMAN OR STORES WILL SUPPLY YOU. Spratt's Patent Limited, Bermondsey, London, S.E. PAMPHLET ON CANINE DISEASES, POST FREE. 



\section{RETURN CIRCULATION DEPARTMENT}

TO $\Rightarrow 202$ Main Library

\begin{tabular}{l|l|l}
\hline $\begin{array}{c}\text { LOAN PERIOD 1 } \\
\text { HOME USE }\end{array}$ & 2 & 3 \\
\hline 4 & 5 & 6 \\
\hline
\end{tabular}

ALL BOOKS MAY BE RECALLED AFTER 7 DAYS

1-month loans may be renewed by calling $\$ 42-3405$

1-year loans may be recharged by bringing the books to the Circulation Desk

Renewals and recharges may be made 4 days prior to due date

\section{DUE AS STAMPED BELOW}

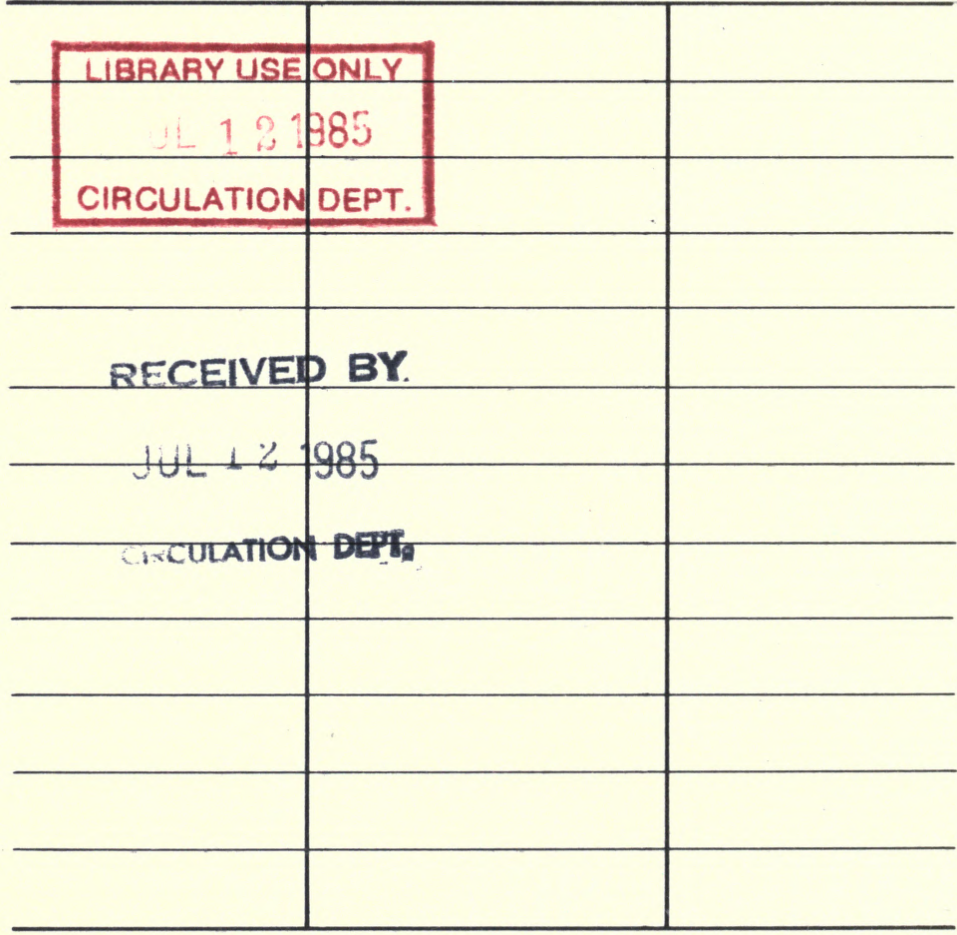

UNIVERSITY OF CALIFORNIA, BERKELEY

FORM NO. DD6, 60m, 1/83 BERKELEY, CA 94720 

aig

(7) P.

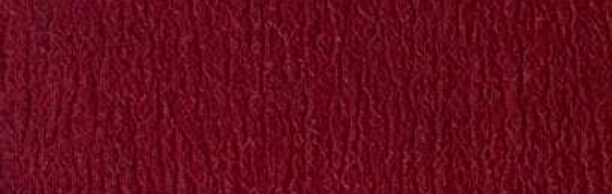

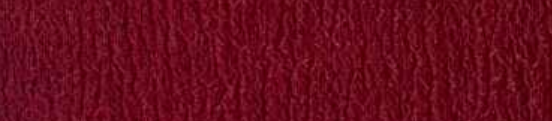

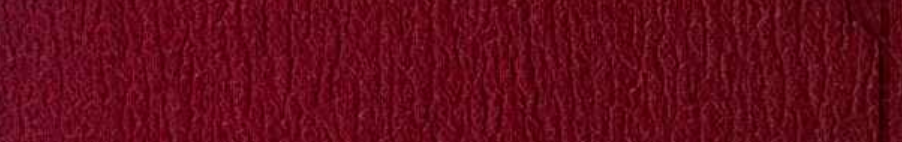
15 to

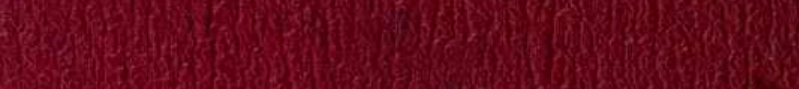
3. 3.t. 3. 